\title{
Short- and long-term cardiometabolic consequences of infant growth: size matters
}

Citation for published version (APA):

Touwslager, R. N. (2014). Short- and long-term cardiometabolic consequences of infant growth: size matters. [Doctoral Thesis, Maastricht University]. Maastricht University.

https://doi.org/10.26481/dis.20140627rt

Document status and date:

Published: 01/01/2014

DOI:

10.26481/dis.20140627rt

Document Version:

Publisher's PDF, also known as Version of record

\section{Please check the document version of this publication:}

- A submitted manuscript is the version of the article upon submission and before peer-review. There can be important differences between the submitted version and the official published version of record.

People interested in the research are advised to contact the author for the final version of the publication, or visit the DOI to the publisher's website.

- The final author version and the galley proof are versions of the publication after peer review.

- The final published version features the final layout of the paper including the volume, issue and page numbers.

Link to publication

\footnotetext{
General rights rights.

- You may freely distribute the URL identifying the publication in the public portal. please follow below link for the End User Agreement:

www.umlib.nl/taverne-license

Take down policy

If you believe that this document breaches copyright please contact us at:

repository@maastrichtuniversity.nl

providing details and we will investigate your claim.
}

Copyright and moral rights for the publications made accessible in the public portal are retained by the authors and/or other copyright owners and it is a condition of accessing publications that users recognise and abide by the legal requirements associated with these

- Users may download and print one copy of any publication from the public portal for the purpose of private study or research.

- You may not further distribute the material or use it for any profit-making activity or commercial gain

If the publication is distributed under the terms of Article $25 \mathrm{fa}$ of the Dutch Copyright Act, indicated by the "Taverne" license above, 
Short- and long-term cardiometabolic consequences of infant growth: size matters 
${ }^{\odot}$ R.N.H. Touwslager, Maastricht, The Netherlands, 2014

Cover design: thanks to Jelte Post. Photo: Colourbox.com.

Layout: Tiny Wouters

Printed by: Gildeprint Drukkerijen

ISBN / EAN: 978-94-6108-689-1

The research presented in this thesis was funded by a Kootstra Fellowship from Maastricht University and a Profileringsfonds grant from Maastricht University Medical Center.

The printing of this thesis was kindly supported by: Stichting Bevordering Kindergeneeskunde, Stichting Hartsvrienden Rescar, Perimed A.B., De Nassau, Abbott and Friso Nederland B.V. (Hero Baby). 


\title{
Short- and long-term cardiometabolic consequences of infant growth: size matters
}

\author{
PROEFSCHRIFT \\ Ter verkrijging van de graad van doctor aan de Universiteit Maastricht, \\ op gezag van de Rector Magnificus, prof. dr. L.L.G. Soete \\ volgens het besluit van het College van Decanen, \\ in het openbaar te verdedigen \\ op vrijdag 27 juni 2014 om 12.00 uur
}

door

Robbert Nicolaas Hendrik Touwslager 


\section{Promotores:}

Prof. dr. L.J. Zimmermann

Prof. dr. C.D.A. Stehouwer

\section{Co-promotores:}

Dr. A.L.M. Mulder

Dr. M. Gielen

\section{Beoordelingscommissie:}

Prof. dr. M.E. Spaanderman (voorzitter)

Prof. dr. J.B. van Goudoever (VU Medisch Centrum en Academisch Medisch Centrum, Amsterdam)

Prof. dr. P.W. de Leeuw

Prof. dr. M.H. Prins

Prof. dr. E. Thiery (Universiteit Gent) 


\section{Contents}

$\begin{array}{lll}\text { Chapter } 1 & \text { Introduction and outline of the thesis } & 7\end{array}$

$\begin{array}{lll}\text { Chapter } 2 \text { Methods } & 21\end{array}$

Part I Birth weight, postnatal growth and their association to later health 35

Chapter 3 Genetic, maternal and placental factors in the association between 37

birth weight and physical fitness: a longitudinal twin study

PLoS One 2013 Oct 23;8(10):e76423

Chapter 4 Longitudinal growth during the first years of life: what is normal?

Hormone Research 2008;70:273-277

Chapter 5 Determinants of infant growth in four age windows: a twin study

The Journal of Pediatrics 2011;158:566-572

Chapter 6 Changes in genetic and environmental effects on growth during infancy

The American Journal of Clinical Nutrition 2011;94:1568-74

Chapter 7 Genetic and environmental factors in associations between infant growth and adult cardiometabolic risk profile in twins The American Journal of Clinical Nutrition 2013;98:994-1001

Part II A clinical study into birth weight, postnatal growth, body composition and their association with endothelial function

Chapter 8 Endothelial vasodilatation in newborns is related to body size and maternal hypertension

The Journal of Hypertension 2012;30:124-131

Chapter 9 Influence of growth during infancy on endothelium-dependent vasodilatation at the age of 6 months Hypertension 2012;60:1294-1300

Chapter 10 Growth and endothelial function in the first 2 years of life:

a longitudinal study

Submitted

Chapter 11 General discussion 
Samenvatting

Dankwoord

Curriculum Vitae

185

List of publications 
Chapter 1

Introduction

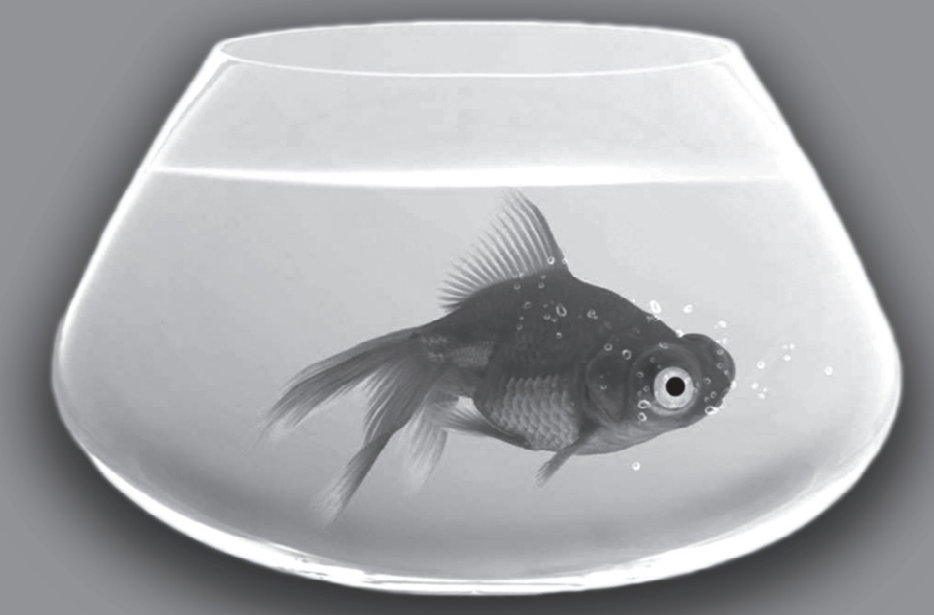


Chapter 1 


\section{Introduction}

\section{The fetal origins hypothesis}

This thesis was initially inspired by the so called 'fetal origins hypothesis' ${ }^{1}$. This hypothesis was put forward to the broader public by Professor David Barker from the University of Southampton in the late 1980s and early 1990s with a series of studies identifying a relationship between birth size and cardiovascular disease later in life, or risk factors for cardiovascular disease ${ }^{2-4}$. These studies were performed after he and his coworkers observed a geographical association between the rates of neonatal death and later death from coronary heart disease in 1366 different areas of England and Wales ${ }^{5}$. As these parallels did not seem to be explained by differences in social conditions, diet or smoking, and because neonatal mortality was strongly associated with low birth weight at the time the data were collected, it was hypothesized that the association reflected an effect of low birth weight and therefore originated in utero. Barker's observations were replicated all over the world, in men and women, for a wide variety of clinical cardiovascular end points ever since ${ }^{6-8}$.

There are several mechanisms aiming to explain the fetal origins hypothesis biologically. There are, however, two overarching and related concepts that apply to all mechanisms: developmental plasticity and the developmental mismatch. The first concept constitutes that an organism is able to adapt to its environment (to be plastic) $)^{9}$. Usually, these 'predictive adaptive responses' occur during critical time windows, after which they are irreversible. When organisms are subject to developmental plasticity in utero, this can be termed 'fetal programming'. A discrepancy (mismatch, the second concept) between an anticipated environment (based on in utero conditions) and the actual (postnatal) environment may give rise to disease ${ }^{10}$. One can think of this metaphorically as a Polar bear being born on a tropical island. A striking real-life example is the water flea Daphnia. When mothers are exposed to predators, their offspring are born with defensive 'helmets' ${ }^{11}$. If the postnatal environment however does not contain predators, the 'helmet-fleas' have reduced competitive success relative to 'non-helmet-fleas'. Focused on this thesis, it has been suggested that a poor fetal environment (meaning a bad nutrient and oxygen supply) prepares the fetus for an environment in which nutrients will be scarce. This has been termed a 'thrifty phenotype' since the fetus has to be thrifty in utero to survive until birth ${ }^{12}$. When this fetus, however, is born into our current industrialized society with abundant nutrient availability it is a clear disadvantage to, for example, store as much nutrients as possible as fat. As a result fetal programming becomes a disadvantage on the long term. It should however be noted that, from an evolutionary point of view, attaining the reproductive age is more important than health at an older age. Many organs and systems have been proposed to be involved in intrauterine programming of cardiovascular disease. These include the stress responses (hypothalamus-pituitary-adrenal axis) ${ }^{13}$, a congenital nephron deficit ${ }^{14}$, appetite 
hormones ${ }^{15}$ and, of importance for this thesis, the endothelium ${ }^{16-18}$. An extensive review on possible mechanisms is provided by McMillen and Robinson ${ }^{19}$.

Regardless of the systems or organs involved in programming, there is the important issue of 'nature versus nurture' or 'genes versus environment'. In the association between birth weight and later cardiovascular disease, there may be a predominant role for environmental factors, such as the fetal oxygen and nutrient supply. As an alternative to an exclusive effect of intrauterine environment, it was proposed that there is one (insulin-resistant) genotype that could be responsible for both low birth weight and later cardiovascular disease $\mathrm{e}^{20}$. Insulin is an important intrauterine growth factor and insulin resistance is a major risk factor for cardiovascular disease, but other genotypes may also be involved. For example, by use of twins as a study population, it has been shown that common genetic factors are likely to exist for birth weight and hypertension, and that this association may be mediated by sympathetic activity ${ }^{21,22}$. While one can be sure that, in reality, all diseases are the result of both genetic and environmental factors (and/ or the interaction between the two $)^{23}$, it is important to study which of the two is of primary importance. This can be stated from an academic point of view, as well as in terms of possible interventions. In current clinical practice, it is not possible to intervene in a (future) patient's genotype, but it is possible to intervene in one's environment. In case of birth weight this could be the intrauterine or maternal environment, and a concrete possible intervention could be to alter maternal diet.

\section{The developmental origins of health and disease}

The concept of fetal origins of adult disease described above has been extended to also involve postnatal life $e^{24,25}$. The concept that early life factors in the broad sense impact on later health is termed 'developmental origins of health and disease' or $\mathrm{DOHaD}$. The 'popularity' of DOHaD is illustrated by the initiation of a scientific journal, especially designed for this concept ${ }^{26}$ and by 2708 PubMed hits on 'developmental origins' (search dated October 2013).

Many organs and regulatory systems continue to develop in postnatal life and hence the infant is still very plastic and able to make long-lasting adaptations in response to the environment. A well-known example of postnatal plasticity is the beneficial effect of breast feeding on childhood atopic dermatitis ${ }^{27}$ and asthma ${ }^{28}$, and many different risk factors for cardiovascular disease, such as cholesterol levels, risk for type 2 diabetes, hypertension, endothelial function and possibly obesity, far after the children were weaned ${ }^{29-32}$. However, due to ethical randomization problems strong causal evidence for a beneficial effect of breast-feeding is scarce. No more than two randomized controlled trials were performed and only one has shown favorable cardiovascular effects in individuals born preterm ${ }^{33}$. The mechanism behind the (likely) beneficial effects of breast-feeding has been proposed to be slower growth in infancy in a paper by Singhal and Lucas ${ }^{34}$. Their 'accelerated growth hypothesis' states that not 
low birth weight per se, but the subsequent accelerated growth has long-term detrimental effects. Because low birth weight and accelerated growth are highly correlated $^{35,36}$, this hypothesis was in line with the existing evidence that linked low birth weight to adult disease. Many studies have shown that accelerated postnatal growth indeed has detrimental long-term effects. Accelerated infant growth has been associated with later cardiovascular risk factors, including reduced insulin sensitivity, an adverse lipid profile, hypertension and obesity ${ }^{37-41}$.

As stated earlier, programming occurs in a critical period and with regard to postnatal growth there have been attempts to identify such a period. Even within infancy, it has been shown that certain growth periods are more critical than others. In the bestknown study on this topic, growth from 0-3 months proved to be of pivotal importance for later cardiovascular risk profile ${ }^{38}$. Moreover, the search for a critical growth period goes beyond infancy, as childhood growth may also have important effects on later cardiovascular health ${ }^{42}$. On this topic there is a lack of studies investigating both infant and childhood growth in relation to later disease. However, when both growth periods were analyzed simultaneously, it was shown that infant growth was more important than childhood growth, at least when clustered metabolic risk in adolescence is concerned $^{43}$. Furthermore, it is likely that any possible critical growth window would not be the same for all organ systems and hence not for all cardiovascular risk factors. Finally, analogously to the earlier statement on possible shared genes explaining both low birth weight and later cardiovascular disease, one may also wonder whether there are shared genes involved in both postnatal growth and adult cardiovascular risk profile, or whether there is a more important role for environmental factors. When the associations prove to be mainly under environmental control, interventions in for example infant nutrition to target growth may be more successful in the primary prevention of cardiovascular disease than when genetic factors a of main importance.

\section{Infant growth}

While one would expect a tangible and general process like postnatal growth to be thoroughly studied, there is limited detailed information regarding factors affecting it. However, it is known that, among other factors, birth weight, sex, parity, gestational age, breast-feeding, maternal smoking during pregnancy, parental heights and socioeconomic status are important ${ }^{44,45}$. As was described above infant growth is a potential therapeutic target for the very early primary prevention of cardiovascular disease. If one is interested in modifying early growth, a detailed description with regard to the factors determining it is important.

Another way to look at growth is to wonder what is normal. Is 'accelerated' growth relative to the population equivalent to accelerated growth on an individual level? Also, low birth weight babies may remain small their entire life, but is this normal? Finally, and returning to genetic importance, it may be most feasible to perform interventions in growth when growth is not under (main) control of genetic factors, 
since these cannot be changed by currently available therapeutic options. The identification of growth windows under environmental control may therefore facilitate more effective preventive interventions to slow down growth.

\section{Twins}

To obtain information on genetic and environmental importance in growth, but also in the relationships between birth weight, postnatal growth and later cardiovascular disease, we analyzed twin data. Nowadays twins constitute $3-4 \%$ of all births, according to data from the United States. In the Netherlands, this number was $3.33 \%$ in $2007^{46}$. Over the last 30 years, there has been an approximate $100 \%$ increase in the occurrence of twins in the United States ${ }^{47}$. This rise was paralleled to a lesser extent in other industrialized countries ${ }^{48}$ and was also clearly observed in the Belgian data of the East Flanders Prospective Twin Survey (EFPTS). In 1985108 twins were born in East Flanders, while this number had risen to 263 in 2009 (Dr. C. Derom, unpublished data). There are two main reasons for this recent increase in twinning rates: older age of the mothers and assisted reproductive techniques ${ }^{49}$. Indeed, in the EFPTS in 1985 only 22 twins were born after assisted reproductive techniques, while this number was 115 in 2009 (Dr. C. Derom, unpublished data).

Twins can originate in two different ways: the first (resulting in dizygotic -DZ- or fraternal twins) is by the fertilization of two eggs (ova) by two different sperm cells, the second (resulting in monozygotic -Mz- or identical twins) is by splitting of one fertilized egg (ovum). In the first case, two ova ovulate in the same ovulatory cycle. Alternatively, two zygotes are transferred to the uterus as part of assisted reproductive techniques. In fact, the above referenced increase in twinning rates can be attributed almost entirely to DZ twins, as $94 \%$ of the twins born after assisted reproductive techniques in the EFPTS was DZ. DZ twins always have two chorionic membranes and two placentas, which can be separate, connected by membranes, or fused. On average, these twins share $50 \%$ of their genetic information and, hence, are just as alike as any pair of brothers and sisters. MZ twins occur after a split of one zygote and therefore it is commonly thought that the individuals are always $100 \%$ identical, in terms of genetic material. However, it has been shown that this is not necessarily the case $^{50}$. However, the possible discordances that are described in $M Z$ twins do not seem to be influencing the validity of the assumption that $M Z$ twins as a group share all their genetic information to a great extent. The exact intrauterine features of this type of twins depend on the moment of splitting of the zygote, the mechanism behind which is unknown. If the zygote splits in the first 3 days after fertilization, it is still early enough in the implantation process for each zygote to form its own chorionic membrane (and placenta) and amniotic sac, yielding dichorionic-diamniotic twins. This group forms about one third of all $\mathrm{MZ}$ twins ${ }^{51,52}$. If the zygote splits between about day 4 and about day 8 , the twins will share one chorionic membrane (and one placenta), but will still have their own amniotic sac, so these twins are monochorionic-diamniotic. 
This group comprises about two third of all $M Z$ twins. The last type of twins are monochorionic-monoamniotic twins (about $2 \%$ of all $\mathrm{MZ}$ twins), which occur when splitting takes place between day 8 and $12^{53}$. When, in a rare case, splitting of the zygote takes place after about day 12-13, conjoined or Siamese twins are the result. The many statistical approaches that can be used in the analysis of twin data are explained in detail in chapter 2 .

\section{Need for prospective data}

Many of the studies on the developmental origins of health and disease referenced above have been of observational nature, and most of these studies were performed retrospectively. This type of study is inexpensive, relatively easy to perform and able to use existing databases for contemporary research questions. However, prospective observational studies are less prone to bias, such as recall bias or missing data bias. In recall bias a condition or disease influences the way the participants report past events and in missing data bias data are selectively missing ${ }^{54}$. Three prospective studies are featured in the present thesis. Two studies will be described in more detail, since they are featured in multiple chapters. With regard to the third study, a growth study in more than 1000 children from the south of Limburg, more can be read in chapter 4 .

\section{The East Flanders Prospective Twin Survey}

The EFPTS (Figure 1.1) is a population-based prospective study that has included all live-born twins in the Belgian province of East Flanders since $1964^{51}$ and has some worldwide distinctive features. For example, basic perinatal data are collected prospectively, chorionicity and zygosity are determined at birth and the EFPTS is based on a very homogenous Caucasian population. Especially the determination of chorionicity is a valuable asset of the EFPTS. For research purposes, and especially in research involving birth weight, information on chorionicity is important. Monochorionic twins are smaller at birth and their intrauterine environment is generally considered to be less optimal than that of dichorionic twins ${ }^{55}$.

Two different samples were used in the present thesis. First, a sample was collected during the Leuven Longitudinal Twin Study (LLTS). The LLTS recruited participants from the EFPTS to study them from $10-18$ years of age ${ }^{56,57}$. Growth was monitored in detail, and in this thesis data on several measures of physical fitness and muscle strength were used, since these are important determinants of cardiovascular risk in adulthood. Second, there is the so-called 'Barker subset', in which data were originally collected to test the 'fetal origins hypothesis' ${ }^{58,59}$. In this sample in adulthood, at an average age of 25 years, a little over 400 twin pairs were subjected to several cardiometabolic tests, including blood pressure measurements, measures of glucose tolerance and analysis of lipid profile. Of importance for this thesis, besides prenatal and perinatal data, additional information was obtained on postnatal growth by collecting the growth data recorded by the child welfare centers. This study provided an excellent opportunity to 
study the associations between birth weight and later cardiometabolic risk, and it was used in the present thesis to perform detailed analyses on infant growth and its association with adult health.

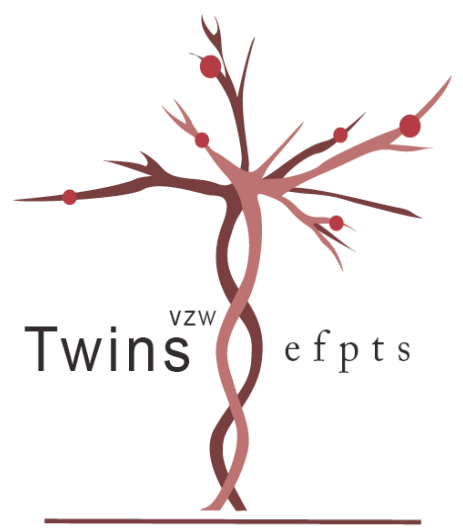

Figure 1.1 The EFPTS logo.

\section{Prospective study in Maastricht University Medical Center (MUMC)}

The MUMC study aimed to identify critical windows of infant growth and, secondly, aimed to integrate analyses on birth weight, body composition and postnatal growth to assess their relative importance. The primary outcome variable was endotheliumdependent vasodilatation, which is a precursor of atherosclerosis in adults. An elaborate technical description of these measurements is provided in chapter 2 . From January 2006 to May 2010, healthy term newborns (gestational age 37-42 weeks) that were born at MUMC, The Netherlands, and remained at the hospital for at least 3 days were eligible to participate in the study. Exclusion criteria were perinatal hypoxia, acidosis, infection, abnormal genotype and abnormal phenotype (as evaluated by a neonatologist). Transient asymptomatic hypoglycemia, phototherapy and prophylactic treatment with antibiotics without signs of infection were not considered exclusion criteria. The parents of a total of 104 newborns gave informed consent for their children to participate in our study. The average birth weight was 3187 grams, which corresponds to a standard deviation score of -0.35 . The average gestational age was 39 weeks and one day. 44 were boys, which was $42 \%$ of the total sample. Data were collected on many anthropometric features, such as weight, height and head circumference. Furthermore, several maternal characteristics were recorded, such as the occurrence of gestational hypertension, gestational diabetes and smoking. Finally, social and familial data were recorded, including parental education levels and the family history of cardiovascular disease. The newborns underwent their first measurements in the first week of life, after which they returned for follow-up visits at 
the respective ages of 6, 12 and 24 months. A good follow-up percentage of $85 \%$ at the age of 24 months was achieved (Figure 1.2).

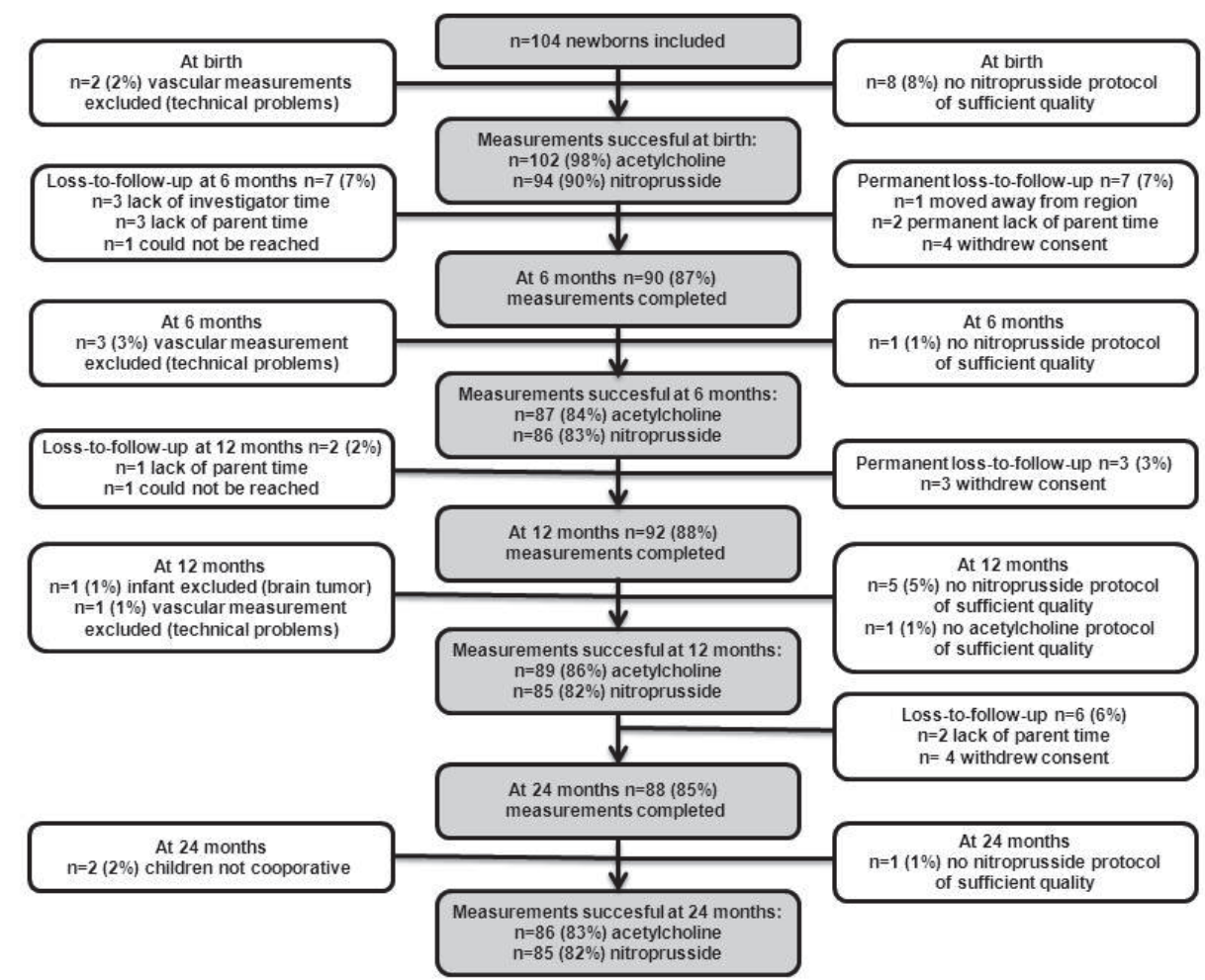

Figure 1.2 Participant flow MUMC study. 


\section{Aims and outline}

The studies presented in this thesis were performed to address three aims.

The first aim was to assess the relative importance of genetic and environmental factors in the associations between early life factors and later health. In chapter 3, a twin sample was studied to investigate this in the relationship between birth weight and adolescent physical fitness. Moreover, the importance of placental factors was analyzed. In chapter 7, a different twin sample was used: the predicting variable was infant growth and the outcome variables were a variety of cardiometabolic risk factors in adulthood (including for example blood pressure and insulin resistance).

The second aim of the present thesis was to obtain more detailed knowledge on normal infant growth, the factors affecting it, and the degree to which infant growth is influenced by genetic factors. Chapter 4 aimed to answer the question what can be considered normal growth during the first 2 years of life, using a sample of infants from the south of The Netherlands. The factors that influence infant growth were identified in chapter 5 . The degree to which different windows of infant growth are under the influence of genetic factors (the extent to which growth is heritable) was quantified in chapter 6 .

The final aim of this thesis was to study the association between infant growth, body composition and endothelial function, a precursor of atherosclerosis, in the first 2 years of life. Hereto, at Maastricht University Medical Center, a little over one hundred newborns were included in a clinical study and followed prospectively. The results of this study are detailed in chapters 8, 9 and 10.

Chapter 1 provides the necessary background information on the developmental origins of health and disease and on our study samples, while chapter 2 discusses the statistical approaches in the analysis of twin data, the measurement of endothelial function and the determination of body composition in detail. The results are finally put into perspective in chapter 11 , where also recommendations are made for future research. 


\section{References}

1. Barker DJ. Fetal origins of coronary heart disease. BMJ. 1995;311:171-174

2. Barker DJ, Winter PD, Osmond C, Margetts B, Simmonds SJ. Weight in infancy and death from ischaemic heart disease. Lancet. 1989;2:577-580

3. Barker DJ, Martyn CN, Osmond C, Hales CN, Fall CH. Growth in utero and serum cholesterol concentrations in adult life. BMJ. 1993;307:1524-1527

4. Barker DJ, Osmond C, Simmonds SJ, Wield GA. The relation of small head circumference and thinness at birth to death from cardiovascular disease in adult life. BMJ. 1993;306:422-426

5. Barker DJ. The origins of the developmental origins theory. Journal of internal medicine. 2007;261: 412-417

6. Leon DA, Lithell HO, Vagero D, Koupilova I, Mohsen R, Berglund L, Lithell UB, McKeigue PM. Reduced fetal growth rate and increased risk of death from ischaemic heart disease: Cohort study of 15000 swedish men and women born 1915-29. BMJ. 1998;317:241-245

7. Stein CE, Fall CH, Kumaran K, Osmond C, Cox V, Barker DJ. Fetal growth and coronary heart disease in south india. Lancet. 1996;348:1269-1273

8. Rich-Edwards JW, Stampfer MJ, Manson JE, Rosner B, Hankinson SE, Colditz GA, Willett WC, Hennekens $\mathrm{CH}$. Birth weight and risk of cardiovascular disease in a cohort of women followed up since 1976. BMJ. 1997;315:396-400

9. Bateson P, Barker D, Clutton-Brock T, Deb D, D'Udine B, Foley RA, Gluckman P, Godfrey K, Kirkwood T, Lahr MM, McNamara J, Metcalfe NB, Monaghan P, Spencer HG, Sultan SE. Developmental plasticity and human health. Nature. 2004;430:419-421

10. Gluckman PD, Hanson MA. Living with the past: Evolution, development, and patterns of disease. Science. 2004;305:1733-1736

11. Agrawal AA, Laforsch C, Tollrian R. Transgenerational induction of defences in animals and plants. Nature. 1999;401:60-63

12. Hales CN, Barker DJ. Type 2 (non-insulin-dependent) diabetes mellitus: The thrifty phenotype hypothesis. Diabetologia. 1992;35:595-601

13. Phillips DI. Programming of the stress response: A fundamental mechanism underlying the long-term effects of the fetal environment? J Intern Med. 2007;261:453-460

14. Zandi-Nejad K, Luyckx VA, Brenner BM. Adult hypertension and kidney disease: The role of fetal programming. Hypertension. 2006;47:502-508

15. Phillips DI, Fall CH, Cooper C, Norman RJ, Robinson JS, Owens PC. Size at birth and plasma leptin concentrations in adult life. Int J Obes Relat Metab Disord. 1999;23:1025-1029

16. Goodfellow J, Bellamy MF, Gorman ST, Brownlee M, Ramsey MW, Lewis MJ, Davies DP, Henderson AH. Endothelial function is impaired in fit young adults of low birth weight. Cardiovasc Res. 1998;40: 600-606

17. Leeson CP, Kattenhorn M, Morley R, Lucas A, Deanfield JE. Impact of low birth weight and cardiovascular risk factors on endothelial function in early adult life. Circulation. 2001;103:1264-1268

18. Martin H, Hu J, Gennser G, Norman M. Impaired endothelial function and increased carotid stiffness in 9-year-old children with low birthweight. Circulation. 2000;102:2739-2744

19. McMillen IC, Robinson JS. Developmental origins of the metabolic syndrome: Prediction, plasticity, and programming. Physiol Rev. 2005;85:571-633

20. Hattersley AT, Tooke JE. The fetal insulin hypothesis: An alternative explanation of the association of low birthweight with diabetes and vascular disease. Lancet. 1999;353:1789-1792

21. RG I, Stehouwer CD, Boomsma DI. Evidence for genetic factors explaining the birth weight-blood pressure relation. Analysis in twins. Hypertension. 2000;36:1008-1012

22. RG I, Stehouwer CD, de Geus EJ, van Weissenbruch MM, Delemarre-van de Waal HA, Boomsma DI. Low birth weight is associated with increased sympathetic activity: Dependence on genetic factors. Circulation. 2003;108:566-571

23. Rothman KJ, Greenland S, Lash TL. Modern epidemiology. Lippincott Williams \& Wilkins; 2008:13-15.

24. Lucas A, Fewtrell MS, Cole TJ. Fetal origins of adult disease-the hypothesis revisited. BMJ. 1999;319:245-249 
25. Gluckman PD, Hanson MA, Cooper C, Thornburg KL. Effect of in utero and early-life conditions on adult health and disease. N Engl J Med. 2008;359:61-73

26. Krishnaveni GV, Veena SR, Wills AK, Hill JC, Karat SC, Fall CH. Adiposity, insulin resistance and cardiovascular risk factors in 9-10-year-old indian children: Relationships with birth size and postnatal growth. J Dev Orig Health Dis. 2010;1:403-411

27. Gdalevich M, Mimouni D, David M, Mimouni M. Breast-feeding and the onset of atopic dermatitis in childhood: A systematic review and meta-analysis of prospective studies. J Am Acad Dermatol. 2001;45:520-527

28. Gdalevich M, Mimouni D, Mimouni M. Breast-feeding and the risk of bronchial asthma in childhood: A systematic review with meta-analysis of prospective studies. J Pediatr. 2001;139: 261-266

29. Owen CG, Whincup PH, Cook DG. Breast-feeding and cardiovascular risk factors and outcomes in later life: Evidence from epidemiological studies. Proc Nutr Soc. 2011;70:478-484

30. Jarvisalo MJ, Hutri-Kahonen N, Juonala M, Mikkila V, Rasanen L, Lehtimaki T, Viikari J, Raitakari OT. Breast feeding in infancy and arterial endothelial function later in life. The cardiovascular risk in young finns study. Eur J Clin Nutr. 2009;63:640-645

31. Khan F, Green FC, Forsyth JS, Greene SA, Newton DJ, Belch JJ. The beneficial effects of breastfeeding on microvascular function in 11- to 14-year-old children. Vasc Med. 2009;14:137-142

32. Beyerlein A, von Kries R. Breastfeeding and body composition in children: Will there ever be conclusive empirical evidence for a protective effect against overweight? Am J Clin Nutr. 2011;94:1772S-1775S

33. Fewtrell MS. Breast-feeding and later risk of cvd and obesity: Evidence from randomised trials. Proc Nutr Soc. 2011;70:472-477

34. Singhal A, Lucas A. Early origins of cardiovascular disease: Is there a unifying hypothesis? Lancet. 2004;363:1642-1645

35. Hokken-Koelega AC, De Ridder MA, Lemmen RJ, Den Hartog H, De Muinck Keizer-Schrama SM, Drop SL. Children born small for gestational age: Do they catch up? Pediatr Res. 1995;38:267-271

36. Karlberg J, Albertsson-Wikland K. Growth in full-term small-for-gestational-age infants: From birth to final height. Pediatr Res. 1995;38:733-739

37. Adair LS, Martorell R, Stein AD, Hallal PC, Sachdev HS, Prabhakaran D, Wills AK, Norris SA, Dahly DL, Lee NR, Victora CG. Size at birth, weight gain in infancy and childhood, and adult blood pressure in 5 low- and middle-income-country cohorts: When does weight gain matter? Am J Clin Nutr. 2009;89:1383-1392

38. Leunissen RW, Kerkhof GF, Stijnen T, Hokken-Koelega A. Timing and tempo of first-year rapid growth in relation to cardiovascular and metabolic risk profile in early adulthood. JAMA. 2009;301:2234-2242

39. Singhal A, Cole TJ, Fewtrell M, Kennedy K, Stephenson T, Elias-Jones A, Lucas A. Promotion of faster weight gain in infants born small for gestational age: Is there an adverse effect on later blood pressure? Circulation. 2007;115:213-220

40. Ong KK, Loos RJ. Rapid infancy weight gain and subsequent obesity: Systematic reviews and hopeful suggestions. Acta Paediatr. 2006;95:904-908

41. Soto N, Bazaes RA, Pena V, Salazar T, Avila A, Iniguez G, Ong KK, Dunger DB, Mericq MV. Insulin sensitivity and secretion are related to catch-up growth in small-for-gestational-age infants at age 1 year: Results from a prospective cohort. J Clin Endocrinol Metab. 2003;88:3645-3650

42. Barker DJ, Osmond C, Forsen TJ, Kajantie E, Eriksson JG. Trajectories of growth among children who have coronary events as adults. N Engl J Med. 2005;353:1802-1809

43. Ekelund U, Ong KK, Linne Y, Neovius M, Brage S, Dunger DB, Wareham NJ, Rossner S. Association of weight gain in infancy and early childhood with metabolic risk in young adults. J Clin Endocrinol Metab. 2007;92:98-103

44. Hindmarsh PC, Geary MP, Rodeck CH, Kingdom JC, Cole TJ. Factors predicting ante- and postnatal growth. Pediatr Res. 2008;63:99-102

45. Ong KK, Preece MA, Emmett PM, Ahmed ML, Dunger DB. Size at birth and early childhood growth in relation to maternal smoking, parity and infant breast-feeding: Longitudinal birth cohort study and analysis. Pediatr Res. 2002;52:863-867

46. Web page: Http://www.Cbs.Nl/en-gb/menu/themas/bevolking/publicaties/artikelen/archief/2008/ 2008-2643-wm.Htm?Languageswitch=on (statistics netherlands). Last accessed: October 2013

47. Chauhan SP, Scardo JA, Hayes E, Abuhamad AZ, Berghella V. Twins: Prevalence, problems, and preterm births. Am J Obstet Gynecol. 2010;203:305-315 
48. Imaizumi Y. Trends of twinning rates in ten countries, 1972-1996. Acta Genet Med Gemellol (Roma). 1997;46:209-218

49. Ananth CV, Chauhan SP. Epidemiology of twinning in developed countries. Semin Perinatol. 2012;36: 156-161

50. Gringras P, Chen W. Mechanisms for differences in monozygous twins. Early Hum Dev. 2001;64: 105-117

51. Derom CA, Vlietinck RF, Thiery EW, Leroy FO, Fryns JP, Derom RM. The east flanders prospective twin survey (efpts). Twin Res Hum Genet. 2006;9:733-738

52. Morley R, Dwyer T, Carlin JB. Studies of twins: Can they shed light on the fetal origins of adult disease hypothesis? Twin Res. 2003;6:520-525

53. Chitnis S, Derom C, Vlietinck R, Derom R, Monteiro J, Gregersen PK. X chromosome-inactivation patterns confirm the late timing of monoamniotic-mz twinning. Am J Hum Genet. 1999;65:570-571

54. Rothman KJ, Greenland S, Lash TL. Modern epidemiology. Lippincott Williams \& Wilkins; 2008:95-97.

55. Gielen M, Lindsey PJ, Derom C, Smeets HJ, Souren NY, Paulussen AD, Derom R, Nijhuis JG. Modeling genetic and environmental factors to increase heritability and ease the identification of candidate genes for birth weight: A twin study. Behav Genet. 2008;38:44-54

56. Geithner CA, Thomis MA, Vanden Eynde B, Maes HH, Loos RJ, Peeters M, Claessens AL, Vlietinck R, Malina RM, Beunen GP. Growth in peak aerobic power during adolescence. Med Sci Sports Exerc. 2004;36:1616-1624

57. Maes HH, Beunen GP, Vlietinck RF, Neale MC, Thomis M, Vanden Eynde B, Lysens R, Simons J, Derom C, Derom R. Inheritance of physical fitness in 10-yr-old twins and their parents. Med Sci Sports Exerc. 1996;28:1479-1491

58. Loos RJ, Fagard R, Beunen G, Derom C, Vlietinck R. Birth weight and blood pressure in young adults: A prospective twin study. Circulation. 2001;104:1633-1638

59. Loos RJ, Beunen G, Fagard R, Derom C, Vlietinck R. Birth weight and body composition in young women: A prospective twin study. Am J Clin Nutr. 2002;75:676-682 


\section{Chapter 2}

Methods

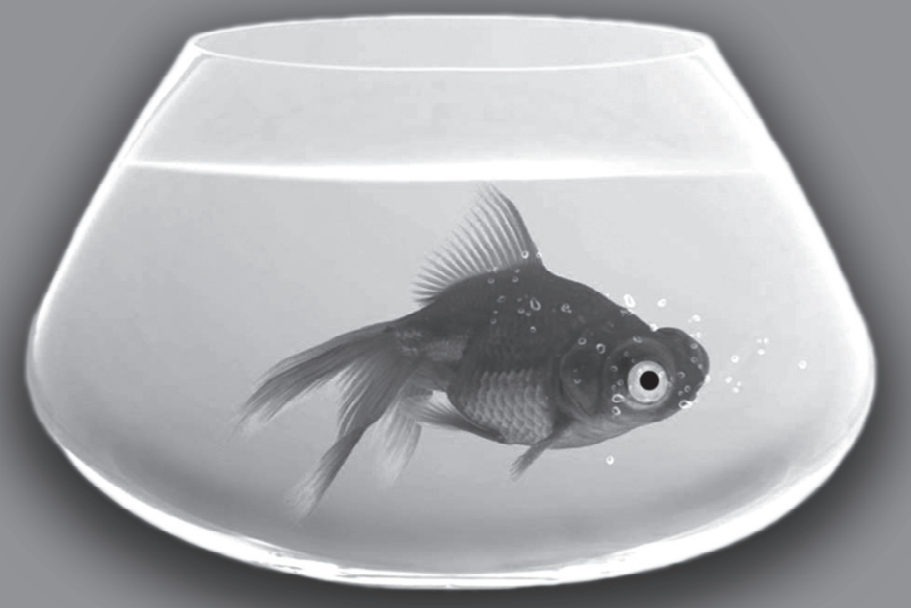


Chapter 2 


\section{Methods}

The specific methods applied in the different chapters are introduced within those chapters. However, three key topics (statistical analysis in twins, measurement of endothelial function and measurement of body composition) warrant a more elaborate explanation, which is provided in this chapter.

\section{Statistical approaches in twin data}

Twins provide an exciting natural experiment and have been used for over 100 years to study the genetic and environmental contributions to health and disease ${ }^{1,2}$, particularly in the field of mental health. Although it may not be $100 \%$ accurate ${ }^{3}$, the applied model in the classical twin study is as follows. Since monozygotic (MZ) or identical twins share the exact same genetic information, any differences between the members of the pair must have arisen from differences in the environment. Dizygotic (DZ) or fraternal twins are, on average, $50 \%$ identical with respect to their genetic constitution. While this makes them equally comparable as any pair of siblings, they have the extra advantage of growing up in the same time period as their co-twin and, in most studies, in the same families and environment. As we can assume that $M Z$ and DZ twin members share their common environment to the same extent, more resemblance for a certain trait within $\mathrm{MZ}$ twins, compared to $\mathrm{DZ}$ twins, is an argument for genetic importance in the development of the trait. A classical twin study aims to give an estimate of the heritability of a trait, in other words, what percentage of the total observed phenotypic variation can be attributed to genetic variation. A simple way to calculate heritability is by use of the formula developed by Douglas Scott Falconer: heritability $(\%)=2^{*}(\mathrm{MZ}$ correlation - DZ correlation). In this case 'correlation' refers to the correlation between twin 1 and twin 2 within a twin pair. However, this formula does not accommodate sex differences and other covariates. Nowadays, detailed variance decomposition methods are applied which use variance instead of correlation, and which use maximum likelihood estimation and pre-defined variance-covariance matrices. In the classical twin study in chapter 6 , for example, the statistical program $\mathrm{Mx}$ was used ${ }^{4}$. The observed variance can be decomposed into 3 components: additive genetic ( $A$, additive effects of genes on multiple loci), common environmental ( $C$, environmental effects shared by twins reared in the same family), and unique environmental ( $E$, environmental effects unique to the individual). Next, in nested models it can be further examined whether the $A$ and/ or $C$ component can be left out of the model without significant worsening of the model fit. In other words: it can be examined whether an $\mathrm{AE}, \mathrm{CE}$ or $\mathrm{E}$ model is equal to the full (ACE) model. If this is the case, the smaller model is the most parsimonious model and is therefore considered superior. By definition, the E component is always in the model, because all traits are under the influence of unique environmental factors. 
Examining the heritability of traits is not the only way twins can be analyzed. First, as the simplest approach, twins can be treated as 'individuals' in analyses to study the relationship between a predictor variable and an outcome variable of interest. In this way, no specific use is made out of the fact that the individuals are member of twin pairs. However, data obtained in the two members of a twin pair are still correlated. This poses a problem, as parametric statistical techniques such as linear regression analysis assume that the data belonging to different individuals are independent. Therefore, the appropriate technique to study relationships between for example birth weight and adult physical fitness is multilevel regression analysis ${ }^{5}$. One can think of this statistical technique as a linear regression analysis that incorporates the fact that twins are clustered in pairs. In this thesis this method was applied in chapters 3, 5 and 7.

Second, a possible relationship between for example birth weight and adult physical fitness can be examined in more detail to answer the research question: 'Is the association based on shared (maternal) factors or on individual factors (for example the fetal supply line)?' This can be done by performing analyses within the twin pairs, hence taking advantage of the fact that the individuals are members of twin pairs ${ }^{6}$. For birth weight, separate within-twin-pair (using the individual twin's birth weight deviation from the pair mean as a determinant) and between-pair regression coefficients (using the average birth weight of the pair as a determinant) can be analyzed simultaneously. If the within-twin-pair regression coefficient is equal to zero but the observed crude association can be found in the between-twin-pairs regression coefficient, factors that distinguish the individual twin from his or her co-twin have no effect, and hence shared (maternal) factors are most likely involved. If the betweenpair regression coefficient is equal to zero, but the within-pair regression coefficient is similar to the crude regression coefficient, factors that distinguish the pair from other pairs are unimportant, so this result favors individual factors such as the fetal supply line. Of course, also some intermediate results can occur, with more nuanced interpretations ${ }^{6}$. This analysis was performed in chapter 3.

A third approach, also aiming to analyze the relative importance of shared and individual factors, again uses the association within the pairs. In this type of analysis, the data obtained for twin 2 are subtracted from the data obtained in twin 1, yielding a difference score for both the predictor and the outcome variable. Now every twin pair has only one value and linear regression can be applied, since these observations are independent of each other. If an observed association holds within the twins, the importance of individual factors is supported ${ }^{7}$. A similar possibility to analyze twins aims to find an answer to the question: 'is an observed association based on genetic or on environmental factors?' It involves breaking up the analysis described above into $\mathrm{MZ}$ and $\mathrm{DZ}$ analyses. If an observed association using the twins as 'individuals' holds within the $M Z$ pairs, there are environmental influences on the association. This is true since a possible association in $\mathrm{MZ}$ pairs is independent of genetic factors (since these are equal within the $\mathrm{MZ}$ pairs) and independent of shared environmental and parental factors (since the pairs experienced the same environment and have the same 
parents). In DZ twins, the associations insensitive to common environmental factors will hold, but these results can still be confounded by genetic factors. The analyses described in this paragraph were applied in chapter 7. The types of analyses described above are summarized in Table 2.1.

Table 2.1 Summary of statistical approaches for twin data when studying the developmental origins of health and disease.

\begin{tabular}{|c|c|c|}
\hline Research question & Method & Sample \\
\hline What is the heritability of trait $A$ ? & Structural equation modeling & MZ vs. DZ twins \\
\hline Association between $A$ and $B$ ? & Multilevel linear regression on individual data & All twins \\
\hline $\begin{array}{l}\text { Association between birth weight } \\
\text { and B based on shared or individual } \\
\text { factors? }\end{array}$ & $\begin{array}{l}\text { Linear regression on intra-pair and between-pairs } \\
\text { birth weight data (multilevel regression in case of } \\
\text { longitudinal data) }\end{array}$ & All twins \\
\hline $\begin{array}{l}\text { Association between } A \text { and } B \text { based } \\
\text { on genetic factors? }\end{array}$ & $\begin{array}{l}\text { Linear regression on intra-pair predictor and } \\
\text { outcome data (multilevel regression in case of } \\
\text { longitudinal data) }\end{array}$ & MZ vs. DZ twins \\
\hline
\end{tabular}

\section{Endothelial function}

The vascular endothelium is the inner layer of blood vessels. It has a barrier function and is involved in many different processes, such as leukocyte adhesion. The endothelium also produces nitric oxide (NO), which has important vasodilatory properties and is also involved in clotting by inhibiting platelet function ${ }^{8,9}$. In fact, NO is such an important molecule, that the Nobel Prize for medicine was awarded for its discovery in 1998. Physiologically, the endothelium is stimulated to produce NO mainly under the influence of shear stress. Shear stress occurs when more blood is needed in an organ or in tissue than can be transported through the supplying blood vessel, and hence the endothelium makes sure that the capacity increases. Shear stress initiates an intra-cellular cascade in which NO is formed out of L-arginine, under the influence of endothelial nitric oxide synthase $(\mathrm{eNOS})^{10}$. NO diffuses into the vascular smooth muscle cells and stimulates the transformation of guanosine triphosphate (GTP) into cyclic guanosine monophosphate (cGMP), thereby causing a relaxation of the smooth muscle cell and hence vasodilatation of the blood vessel. As such, the endothelium is of vital importance for the regulation of blood pressure, but also for vascular health in general. Endothelial dysfunction is thought to occur very early in the process of atherosclerosis, is an important feature of hypertension and may even precede the development of hypertension ${ }^{11-13}$. Similarly, the presence of coronary endothelial dysfunction in adults predicts long-term atherosclerotic disease progression and cardiovascular events ${ }^{14,15}$. 
Endothelial function can be measured in different ways and in different parts of the vascular tree. The most central level to measure endothelial function is the level of the coronary arteries. The measurement closest to a gold standard when one is interested in cardiac events is the vasodilatory response of the coronary arteries to exogenously administered acetylcholine ${ }^{14,16}$, an endothelium-dependent vasodilator, which initiates the same eNOS pathway as is biologically induced by shear stress (Figure 2.1). Importantly, other substances including prostanoids and endothelium-derived hyperpolarization factor are also produced to contribute to vasodilatation in response to acetylcholine ${ }^{17}$. Of course, this diagnostic method cannot be used in clinical practice. An intermediate level to measure endothelial function is the level of the conduit arteries, which is also the main site of atherosclerosis. Measurement of endothelial function in the brachial artery (a conduit artery) is considered a good measure of systemic endothelial function. Flow-mediated dilatation (FMD) of the brachial artery is a widely used test to measure endothelial function. After occlusion of this artery, the sudden increase in blood flow after release of the cuff causes increased shear stress and thereby endothelium-mediated vasodilatation. This vasodilatation can be quantified by ultrasonography ${ }^{18}$. Endothelial function at the smallest level of the vascular tree, the microvasculature, has also been implicated in the development of hypertension, but also diabetes, at least in adult obesity ${ }^{19}$. The microvasculature is easily accessible at the level of the skin and -partly- therefore acceptable for use in all age groups, including newborns ${ }^{20}$. We have therefore chosen to apply this technique in our clinical study.

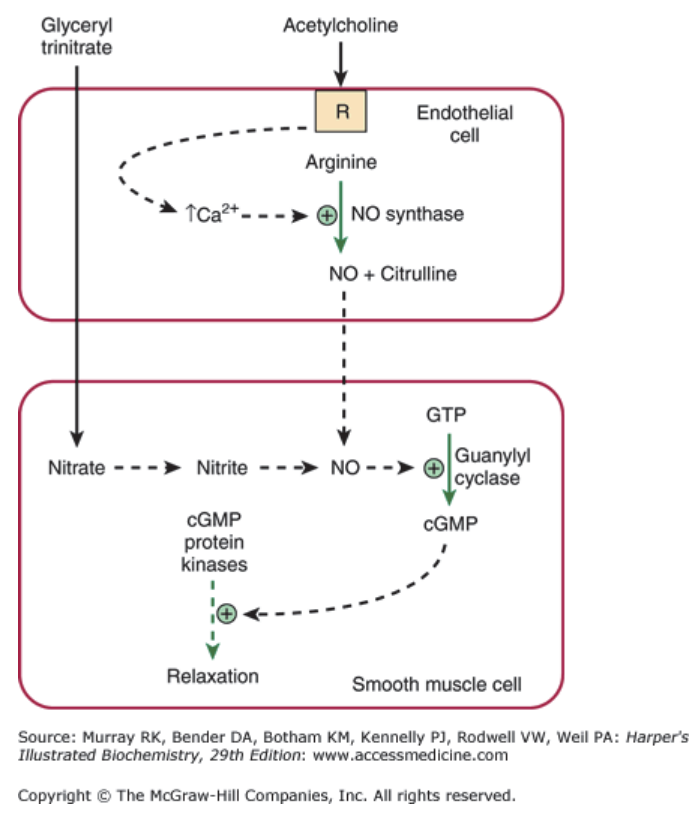

Figure 2.1 The smooth muscle cell relaxation pathway: role of acetylcholine and nitric oxide. 
As our main outcome variable, we aimed to quantify the maximum perfusion of the skin blood vessels in response to acetylcholine. To assure the obtained measurements would actually reflect function of the endothelium, instead of a response to the applied technique or vasodilatation due to other mechanisms, we also obtained the maximum perfusion in response to nitroprusside. Nitroprusside is a direct NO donor and therefore its effect does not rely on endothelial function ${ }^{21}$. We used single-point laser-Doppler flowmetry (Periflux system, Perimed A.B., Sweden), to sample the velocity and quantity of passing blood cells (expressed in perfusion units) in a small area of the skin vasculature of the dorsal side of the forearm. To induce vasodilatation, we administered acetylcholine through the skin by use of iontophoresis. Iontophoresis uses a small voltage difference, in our case between the upper and the lower arm, to create a current (Figures 2.2). This current moves the acetylcholine (and nitroprusside), in ionic form, through the skin to reach an approximate one square millimeter beneath the skin. Because the drug delivery electrode was integrated in the laser-Doppler probe, the effect of the acetylcholine could be measured directly, locally, and without any systemic effects. This technique was well tolerated by the participants, and the administration went unnoted most of the times.
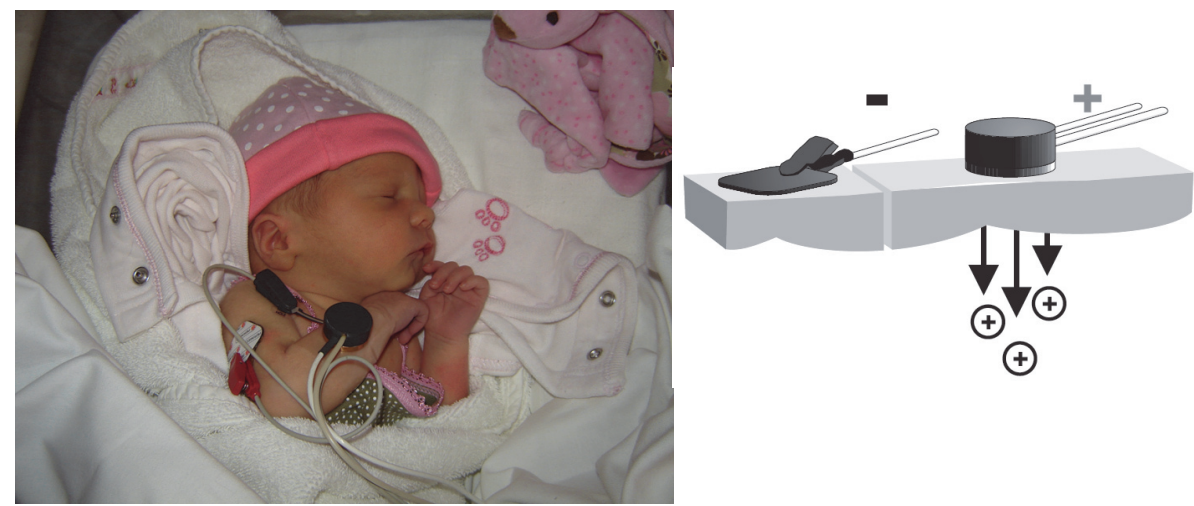

Figures 2.2 Experimental setting and detail of the site of iontophoresis.

We created cumulative dose-response curves to reach a maximum plateau of perfusion in every participant. To obtain these maxima, for acetylcholine ( $1 \%$ solution, Miochol, Novartis Pharma) 7 successive doses were administered with a 60 second interval, and for nitroprusside ( $0.1 \%$ solution, sodium nitroprusside) 9 doses with a 90 second interval were used. Administration required 20 seconds of iontophoresis using a $0.10 \mathrm{~mA}$ anodal current (acetylcholine) or a $0.20 \mathrm{~mA}$ cathodal current (nitroprusside). 


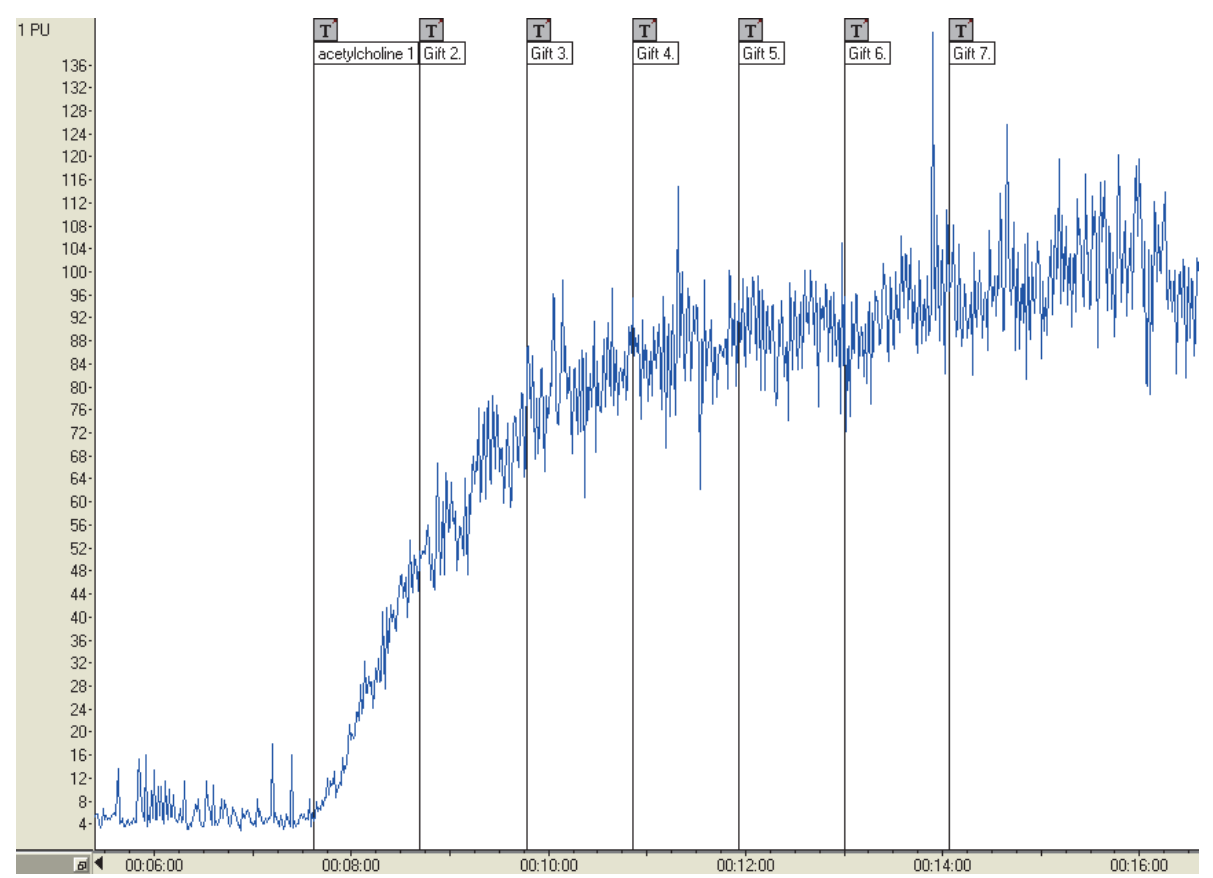

Figure 2.3 Dose-response curve for acetylcholine. On the y-axis perfusion is depicted in perfusion units (PU), time is on the x-axis (minutes). At each vertical line, one dose of acetylcholine was administered.

\section{Body composition}

In adults, obesity is associated with risk for, and death from, cardiovascular disease 22,23 and is currently combated as one of the major health issues in the Western world. It is not clear whether obesity is an independent risk factor for cardiovascular disease or that its importance can be fully attributed to its association with several physiological and metabolic changes, which in turn increase the risk for cardiovascular disease. These conditions include type 2 diabetes mellitus ${ }^{24}$, hypertension ${ }^{25}$ and dyslipidemia ${ }^{26}$. These 3 conditions have been shown to relate to obesity, already in childhood ${ }^{27}$. Importantly for our clinical study and this thesis, obesity also relates to endothelial function $^{28-30}$, and to endothelium-independent vascular function ${ }^{31}$ in children. One study even showed associations between both endothelium-dependent and endothelium-independent vasodilatation, measured with the laser-Doppler technique, in healthy non-obese children ${ }^{32}$.

In adults, obesity is defined as a body mass index (BMI, weight in kilograms divided by squared height in meters) $>30$. In children, the generally accepted age at which BMI measures start to be used, is 2 years of age. Before the age of 2 years, it is common practice to work with weight-for-length reference values. The age of 2 coincides with 
the end point of our clinical study, and for continuity reasons, we have used weightfor-length measures throughout the study. Importantly, BMI and weight-for-length measures both aim to quantify fat, but do not directly measure fat. Although BMI correlates well with directly measured fat percentage ${ }^{33}$ in older children, it is a surrogate measure, as is weight-for-length.

We aimed to measure body fat directly using the deuterium dilution method, because of its acceptability in all age groups ${ }^{34}$. We have attempted to perform these measurements at the respective ages of 0,6 and 12 months, but these data were unreliable: extensive spilling was recorded, or the parents did not comply with the instructions in a considerable percentage of measurements. At the age of 2 years, spilling was reduced to a minimum and parents were able to plan urine collection better, so we only used body composition data at the age of two years.

For our calculations of body fat percentage, we applied the two-compartment model, which assumes that the human body consists of fat mass (FM) and fat-free mass (FFM), the latter containing all body water. As the percentage of FFM that consists of water is known (this 'hydration constant' is for example $73 \%$ in adults, but higher in children ${ }^{35}$ ), FFM can be estimated if the total amount of water in the body (TBW) is known. An assumption for use of the hydration constant is that the children have a normal hydration of the FFM, which seems reasonable in our healthy term study population. The deuterium dilution method consists of the measurement of deuterium oxide in (blood, saliva or) urine, before and after the ingestion of a known amount of deuterium oxide. Deuterium or 'heavy hydrogen' is a stable hydrogen isotope, which, contrary to hydrogen, carries a neutron in its nucleus (hydrogen: ${ }^{1} \mathrm{H}$, deuterium: ${ }^{2} \mathrm{H}$ ). Deuterium oxide or deuterium-labeled water ('heavy water') is therefore chemically written as ${ }^{2} \mathrm{H}_{2} \mathrm{O}$. We applied an adapted version of the Maastricht protocol ${ }^{36}$, where the children ingested $25 \mathrm{ml}$ of a $5 \%$ deuterium oxide solution (saturation of the original deuterium oxide: $99.9 \%$ atom excess) under supervision of the researchers, after a baseline urine sample was collected at home first. Absorbent cotton wool rolls were placed in the children's diapers by their parents to collect the urine samples. A baseline urine sample was collected to measure background isotope level, as this is known to differ over time and between individuals, most likely because of differences and changes in the drinking (tap) water, which contains a low percentage of deuterium oxide. This percentage increases geographically towards the Equator (due to selective evaporation: the 'lightest' water evaporates relatively easier), and is lowest in people consuming water from melted snow ${ }^{36}$. In Maastricht, tap water contains 147.42 parts per million (PPM) deuterium oxide (L. Wouters, unpublished data). At least six hours after ingestion of the deuterium, to allow for full equilibration with the body water, the final urine sample was collected at home by the parents and the exact time between ingestion of the deuterium oxide and collection of the sample was recorded. The parents sent these samples back to the hospital in glass containers (to prevent evaporation) by mail and the samples were stored at $-20^{\circ} \mathrm{C}$ until analysis. 
The deuterium oxide solution tastes exactly like tap water en was ingested by the children in pure form or after mixing with the child's own drink. After drinking the deuterium oxide container and the bottle the child drank from were rinsed with tap water. This was also given to the children to ensure complete ingestion of the deuterium oxide. On average the children ingested about 1.17 grams of pure deuterium oxide, reaching an on average additional enrichment of body water with deuterium oxide of about 125 PPM (mean baseline enrichment was about 150 PPM). During drinking, the children were closely watched for spilling, because this may lead to an overestimation of TBW. The obtained samples (baseline and enriched) were analyzed using isotope ratio mass spectrometry (Optima, Micromass United Kingdom). Dilution space was calculated using the difference in deuterium oxide concentration in the two samples. Dilution space can be converted into TBW by dividing it by 1.04 , assuming a $4 \%$ exchange of the deuterium oxide with the non-water compartment in the body. TBW consists of water for $77 \%$ in 2-year-old boys and for $78 \%$ in 2-year old girls $^{35}$, so dividing TBW by 0.77 or 0.78 yields FFM in kilograms for boys and girls, respectively. Written as a formula, we calculated TBW as follows ('before' and 'after' refer to drinking of the deuterium oxide):

$$
\operatorname{TBW}(\mathrm{I})=\frac{18 *{ }^{2} \mathrm{H}_{2} \mathrm{O} \text { dose } *\left(0.999-\frac{{ }^{2} \mathrm{H}[\mathrm{PPM}] \text { after }}{1.000 .000}\right) * 1.000}{20 * 1.04 *\left({ }^{2} \mathrm{H}[\mathrm{PPM}] \text { after }-{ }^{2} \mathrm{H}[\mathrm{PPM}] \text { before }\right)}
$$

In this formula, 18 is the weight (g) of 1 mole $\mathrm{H}_{2} \mathrm{O} .{ }^{2} \mathrm{H}_{2} \mathrm{O}$ dose is the weight (g) of the deuterium oxide ingested. 0.999 refers to the percentage of pure deuterium oxide in the original solution, before dilution to about $5 \%$ for ingestion. Since concentrations are measured in parts per million (PPM), 1.000.000 is incorporated in the formula to convert this. 20 is the weight (g) of 1 mole ${ }^{2} \mathrm{H}_{2} \mathrm{O}$.

Subsequently, FFM was calculated as follows:

$$
\text { FFM }_{\text {boys }}(\mathrm{kg})=\frac{T B W}{0.77} \text { and FFM girls }(\mathrm{kg})=\frac{T B W}{0.78}
$$

As the two-compartment model assumes that the body consists of FM and FFM, the percentage of body fat, which we used as a potential confounder in our analyses, was calculated by the following formula:

$$
\% f a t=\frac{\text { weight }-F F M}{\text { weight }} * 100
$$




\section{References}

1. Barker DJ. Fetal origins of coronary heart disease. BMJ. 1995;311:171-174

2. Barker DJ, Winter PD, Osmond C, Margetts B, Simmonds SJ. Weight in infancy and death from ischaemic heart disease. Lancet. 1989;2:577-580

3. Barker DJ, Martyn CN, Osmond C, Hales CN, Fall CH. Growth in utero and serum cholesterol concentrations in adult life. BMJ. 1993;307:1524-1527

4. Barker DJ, Osmond C, Simmonds SJ, Wield GA. The relation of small head circumference and thinness at birth to death from cardiovascular disease in adult life. BMJ. 1993;306:422-426

5. Barker DJ. The origins of the developmental origins theory. J Intern Med. 2007;261: 412-417

6. Leon DA, Lithell HO, Vagero D, Koupilova I, Mohsen R, Berglund L, Lithell UB, McKeigue PM. Reduced fetal growth rate and increased risk of death from ischaemic heart disease: Cohort study of 15000 swedish men and women born 1915-29. BMJ. 1998;317:241-245

7. Stein $\mathrm{CE}$, Fall $\mathrm{CH}$, Kumaran $\mathrm{K}$, Osmond C, Cox V, Barker DJ. Fetal growth and coronary heart disease in south india. Lancet. 1996;348:1269-1273

8. Rich-Edwards JW, Stampfer MJ, Manson JE, Rosner B, Hankinson SE, Colditz GA, Willett WC, Hennekens $\mathrm{CH}$. Birth weight and risk of cardiovascular disease in a cohort of women followed up since 1976. BMJ. 1997;315:396-400

9. Bateson P, Barker D, Clutton-Brock T, Deb D, D'Udine B, Foley RA, Gluckman P, Godfrey K, Kirkwood T, Lahr MM, McNamara J, Metcalfe NB, Monaghan P, Spencer HG, Sultan SE. Developmental plasticity and human health. Nature. 2004;430:419-421

10. Gluckman PD, Hanson MA. Living with the past: Evolution, development, and patterns of disease. Science. 2004;305:1733-1736

11. Agrawal AA, Laforsch C, Tollrian R. Transgenerational induction of defences in animals and plants. Nature. 1999;401:60-63

12. Hales CN, Barker DJ. Type 2 (non-insulin-dependent) diabetes mellitus: The thrifty phenotype hypothesis. Diabetologia. 1992;35:595-601

13. Phillips DI. Programming of the stress response: A fundamental mechanism underlying the long-term effects of the fetal environment? J Intern Med. 2007;261:453-460

14. Zandi-Nejad K, Luyckx VA, Brenner BM. Adult hypertension and kidney disease: The role of fetal programming. Hypertension. 2006;47:502-508

15. Phillips DI, Fall CH, Cooper C, Norman RJ, Robinson JS, Owens PC. Size at birth and plasma leptin concentrations in adult life. Int J Obes Relat Metab Disord. 1999;23:1025-1029

16. Goodfellow J, Bellamy MF, Gorman ST, Brownlee M, Ramsey MW, Lewis MJ, Davies DP, Henderson AH. Endothelial function is impaired in fit young adults of low birth weight. Cardiovasc Res. 1998;40: 600-606

17. Leeson CP, Kattenhorn M, Morley R, Lucas A, Deanfield JE. Impact of low birth weight and cardiovascular risk factors on endothelial function in early adult life. Circulation. 2001;103:1264-1268

18. Martin H, Hu J, Gennser G, Norman M. Impaired endothelial function and increased carotid stiffness in 9-year-old children with low birthweight. Circulation. 2000;102:2739-2744

19. McMillen IC, Robinson JS. Developmental origins of the metabolic syndrome: Prediction, plasticity, and programming. Physiol Rev. 2005;85:571-633

20. Hattersley AT, Tooke JE. The fetal insulin hypothesis: An alternative explanation of the association of low birthweight with diabetes and vascular disease. Lancet. 1999;353:1789-1792

21. RG I, Stehouwer CD, Boomsma DI. Evidence for genetic factors explaining the birth weight-blood pressure relation. Analysis in twins. Hypertension. 2000;36:1008-1012

22. RG I, Stehouwer CD, de Geus EJ, van Weissenbruch MM, Delemarre-van de Waal HA, Boomsma DI. Low birth weight is associated with increased sympathetic activity: Dependence on genetic factors. Circulation. 2003;108:566-571

23. Rothman KJ, Greenland S, Lash TL. Modern epidemiology. Lippincott Williams \& Wilkins; 2008:13-15.

24. Lucas A, Fewtrell MS, Cole TJ. Fetal origins of adult disease-the hypothesis revisited. BMJ. 1999;319:245-249

25. Gluckman PD, Hanson MA, Cooper C, Thornburg KL. Effect of in utero and early-life conditions on adult health and disease. N Engl J Med. 2008;359:61-73 
26. Krishnaveni GV, Veena SR, Wills AK, Hill JC, Karat SC, Fall CH. Adiposity, insulin resistance and cardiovascular risk factors in 9-10-year-old indian children: Relationships with birth size and postnatal growth. J Dev Orig Health Dis. 2010;1:403-411

27. Gdalevich M, Mimouni D, David M, Mimouni M. Breast-feeding and the onset of atopic dermatitis in childhood: A systematic review and meta-analysis of prospective studies. J Am Acad Dermatol. 2001; 45:520-527

28. Gdalevich M, Mimouni D, Mimouni M. Breast-feeding and the risk of bronchial asthma in childhood: A systematic review with meta-analysis of prospective studies. J Pediatr. 2001;139: 261-266

29. Owen CG, Whincup PH, Cook DG. Breast-feeding and cardiovascular risk factors and outcomes in later life: Evidence from epidemiological studies. Proc Nutr Soc. 2011;70:478-484

30. Jarvisalo MJ, Hutri-Kahonen N, Juonala M, Mikkila V, Rasanen L, Lehtimaki T, Viikari J, Raitakari OT. Breast feeding in infancy and arterial endothelial function later in life. The cardiovascular risk in young finns study. Eur J Clin Nutr. 2009;63:640-645

31. Khan F, Green FC, Forsyth JS, Greene SA, Newton DJ, Belch JJ. The beneficial effects of breastfeeding on microvascular function in 11- to 14-year-old children. Vasc Med. 2009;14:137-142

32. Beyerlein A, von Kries R. Breastfeeding and body composition in children: Will there ever be conclusive empirical evidence for a protective effect against overweight? Am J Clin Nutr. 2011;94:1772S-1775S

33. Fewtrell MS. Breast-feeding and later risk of cvd and obesity: Evidence from randomised trials. Proc Nutr Soc. 2011;70:472-477

34. Singhal A, Lucas A. Early origins of cardiovascular disease: Is there a unifying hypothesis? Lancet. 2004;363:1642-1645

35. Hokken-Koelega AC, De Ridder MA, Lemmen RJ, Den Hartog H, De Muinck Keizer-Schrama SM, Drop SL. Children born small for gestational age: Do they catch up? Pediatr Res. 1995;38:267-271

36. Karlberg J, Albertsson-Wikland K. Growth in full-term small-for-gestational-age infants: From birth to final height. Pediatr Res. 1995;38:733-739

37. Adair LS, Martorell R, Stein AD, Hallal PC, Sachdev HS, Prabhakaran D, Wills AK, Norris SA, Dahly DL, Lee NR, Victora CG. Size at birth, weight gain in infancy and childhood, and adult blood pressure in 5 low- and middle-income-country cohorts: When does weight gain matter? Am J Clin Nutr. 2009;89:1383-1392

38. Leunissen RW, Kerkhof GF, Stijnen T, Hokken-Koelega A. Timing and tempo of first-year rapid growth in relation to cardiovascular and metabolic risk profile in early adulthood. JAMA. 2009;301:2234-2242

39. Singhal A, Cole TJ, Fewtrell M, Kennedy K, Stephenson T, Elias-Jones A, Lucas A. Promotion of faster weight gain in infants born small for gestational age: Is there an adverse effect on later blood pressure? Circulation. 2007;115:213-220

40. Ong KK, Loos RJ. Rapid infancy weight gain and subsequent obesity: Systematic reviews and hopeful suggestions. Acta Paediatr. 2006;95:904-908

41. Soto N, Bazaes RA, Pena V, Salazar T, Avila A, Iniguez G, Ong KK, Dunger DB, Mericq MV. Insulin sensitivity and secretion are related to catch-up growth in small-for-gestational-age infants at age 1 year: Results from a prospective cohort. J Clin Endocrinol Metab. 2003;88:3645-3650

42. Barker DJ, Osmond C, Forsen TJ, Kajantie E, Eriksson JG. Trajectories of growth among children who have coronary events as adults. N Engl J Med. 2005;353:1802-1809

43. Ekelund U, Ong KK, Linne $Y$, Neovius M, Brage S, Dunger DB, Wareham NJ, Rossner S. Association of weight gain in infancy and early childhood with metabolic risk in young adults. J Clin Endocrinol Metab. 2007;92:98-103

44. Hindmarsh PC, Geary MP, Rodeck CH, Kingdom JC, Cole TJ. Factors predicting ante- and postnatal growth. Pediatr Res. 2008;63:99-102

45. Ong KK, Preece MA, Emmett PM, Ahmed ML, Dunger DB. Size at birth and early childhood growth in relation to maternal smoking, parity and infant breast-feeding: Longitudinal birth cohort study and analysis. Pediatr Res. 2002;52:863-867

46. Web page: Http://www.Cbs.Nl/en-gb/menu/themas/bevolking/publicaties/artikelen/archief/2008/ 2008-2643-wm.Htm?Languageswitch=on (statistics netherlands).Last accessed: October 2013

47. Chauhan SP, Scardo JA, Hayes E, Abuhamad AZ, Berghella V. Twins: Prevalence, problems, and preterm births. Am J Obstet Gynecol. 2010;203:305-315

48. Imaizumi Y. Trends of twinning rates in ten countries, 1972-1996. Acta Genet Med Gemellol (Roma). 1997;46:209-218 
49. Ananth CV, Chauhan SP. Epidemiology of twinning in developed countries. Semin Perinatol. 2012;36: 156-161

50. Gringras P, Chen W. Mechanisms for differences in monozygous twins. Early Hum Dev. 2001;64: 105-117

51. Derom CA, Vlietinck RF, Thiery EW, Leroy FO, Fryns JP, Derom RM. The east flanders prospective twin survey (efpts). Twin Res Hum Genet. 2006;9:733-738

52. Morley R, Dwyer T, Carlin JB. Studies of twins: Can they shed light on the fetal origins of adult disease hypothesis? Twin Res. 2003;6:520-525

53. Chitnis S, Derom C, Vlietinck R, Derom R, Monteiro J, Gregersen PK. X chromosome-inactivation patterns confirm the late timing of monoamniotic-mz twinning. Am J Hum Genet. 1999;65:570-571

54. Rothman KJ, Greenland S, Lash TL. Modern epidemiology. Lippincott Williams \& Wilkins; 2008:95-97.

55. Gielen M, Lindsey PJ, Derom C, Smeets HJ, Souren NY, Paulussen AD, Derom R, Nijhuis JG. Modeling genetic and environmental factors to increase heritability and ease the identification of candidate genes for birth weight: A twin study. Behav Genet. 2008;38:44-54

56. Geithner CA, Thomis MA, Vanden Eynde B, Maes HH, Loos RJ, Peeters M, Claessens AL, Vlietinck R, Malina RM, Beunen GP. Growth in peak aerobic power during adolescence. Med Sci Sports Exerc. 2004;36:1616-1624

57. Maes HH, Beunen GP, Vlietinck RF, Neale MC, Thomis M, Vanden Eynde B, Lysens R, Simons J, Derom C, Derom R. Inheritance of physical fitness in 10-yr-old twins and their parents. Med Sci Sports Exerc. 1996;28:1479-1491

58. Loos RJ, Fagard R, Beunen G, Derom C, Vlietinck R. Birth weight and blood pressure in young adults: A prospective twin study. Circulation. 2001;104:1633-1638

59. Loos RJ, Beunen G, Fagard R, Derom C, Vlietinck R. Birth weight and body composition in young women: A prospective twin study. Am J Clin Nutr. 2002;75:676-682 
Birth weight, postnatal growth and their association to later health

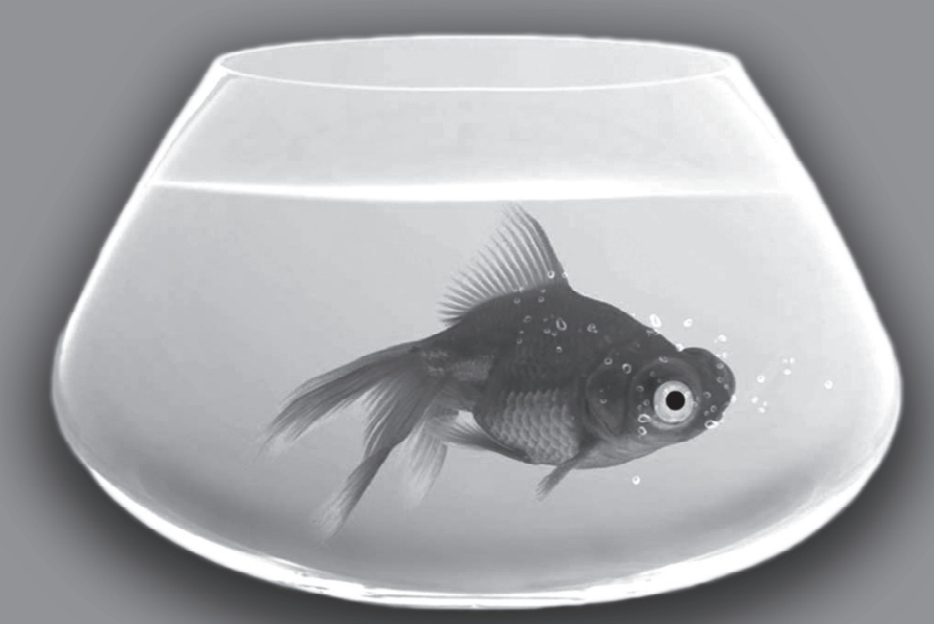




\section{Chapter 3}

Genetic, maternal and placental factors in the association between birth weight and physical fitness:

a longitudinal twin study

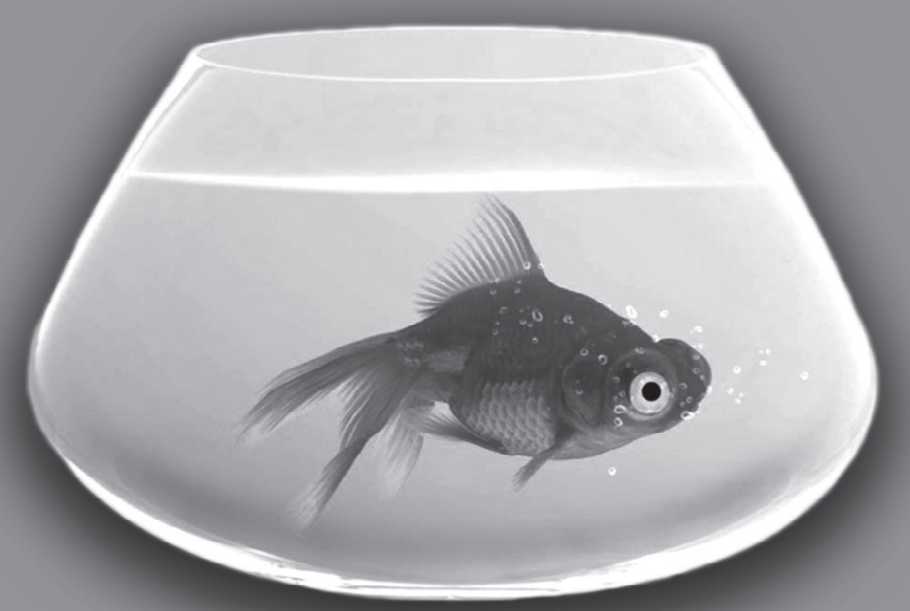

RNH Touwslager

M Gielen FES Tan

ALM Mulder WJM Gerver

L Zimmermann

AJHM Houben MP Zeegers

C Derom

R Vlietinck

HH Maes

CDA Stehouwer

M Thomis 


\section{Abstract}

\section{Background}

Adult cardiorespiratory fitness and muscle strength are related to all-cause and cardiovascular mortality. Both are possibly related to birth weight, but it is unclear what the importance is of genetic, maternal and placental factors in these associations.

\section{Design}

Peak oxygen uptake and measures of strength, flexibility and balance were obtained yearly during adolescence (10-18 years) in 114 twin pairs in the Leuven Longitudinal Twin Study. Their birth weights had been collected prospectively within the East Flanders Prospective Twin Survey.

\section{Results}

We identified linear associations between birth weight and adolescent vertical jump $(b=1.96 \mathrm{~cm}$ per $\mathrm{kg}$ birth weight, $\mathrm{P}=0.02)$, arm pull $(\mathrm{b}=1.85 \mathrm{~kg}$ per $\mathrm{kg}$ birth weight $\mathrm{P}=0.03)$ and flamingo balance $(\mathrm{b}=-1.82$ attempts to stand one minute per kg birth weight, $\mathrm{P}=0.03$ ). Maximum oxygen uptake appeared to have a $\mathrm{U}$-shaped association with birth weight (the smallest and largest children had the lowest uptake, $P=0.01$ ), but this association was no longer significant after adjustment for parental BMI. Using the individual twin's deviation from his own twin pair's average birth weight, we found positive associations between birth weight and adolescent vertical jump $(b=3.49$, $\mathrm{P}=0.0007)$ and arm pull $(\mathrm{b}=3.44, \mathrm{P}=0.02) . \Delta$ scores were calculated within the twin pairs as first born twin minus second born twin. $\Delta$ birth weight was associated with $\Delta$ vertical jump within $\mathrm{MZ}$ twin pairs only $(b=2.63, \mathrm{P}=0.009)$, which indicates importance of placental factors.

\section{Conclusions}

We found evidence for an association between adolescent physical performance (strength, balance and possibly peak oxygen uptake) and birth weight. The associations with vertical jump and arm pull were likely based on individual, more specifically placental (in the case of vertical jump) factors. Our results should be viewed as hypothesis-generating and need confirmation, but potentially support preventive strategies to optimize birth weight, for example via placental function, to target later fitness and health. 


\section{Introduction}

Adult cardiorespiratory fitness is related to all-cause mortality and, more specifically, to cardiovascular mortality ${ }^{1,2}$. Likewise, in adolescence and in young adults suboptimal cardiorespiratory fitness has been linked to unfavorable cardiovascular outcomes ${ }^{3-5}$. In addition, there is considerable interest in the developmental origins of cardiovascular fitness, which is mainly focused on the association with birth weight ${ }^{6-8}$.

A number of studies suggest a positive association between birth weight and later cardiorespiratory fitness, which indicates that low birth weight babies may be programmed to have impaired cardiorespiratory fitness in adulthood ${ }^{6-8}$. In general, the fetus is thought to be plastic, adjusting itself to intrauterine circumstances in anticipation of its future, extrauterine environment ${ }^{9}$. A mismatch between intrauterine and extrauterine environment may give rise to disease. This may be the case when a growth-restricted fetus is born into the present Western society, where nutrients are abundantly available. Thus, the positive association between birth weight and adult cardiorespiratory fitness is in accordance with observations that low birth weight is related to cardiovascular disease and its risk factors later in life $\mathrm{e}^{10-12}$. However, several studies failed to show an association between birth weight and cardiorespiratory fitness later in life $\mathrm{e}^{13-15}$. These inconsistencies are possibly caused by methodological issues, such as the variety of measurement tools used to quantify cardiorespiratory fitness and by the different sets of potential confounders used in the analyses. Another possible explanation for these inconsistent findings is confounding by genetic factors. So far, the role of genetic factors in these associations has remained unclear.

To address the latter issue and to further explore the developmental origins of cardiorespiratory fitness, twin studies may be a useful tool, as they provide the possibility to unravel genetic and environmental (both fetoplacental and maternal) influences on the possible associations. We define maternal factors as all non-genetic maternal influences on both members of a twin pair, such as body mass index (BMI) and smoking. In dizygotic (DZ) twins, maternal factors are identical, but genetic factors are not, while in monozygotic (MZ) twins, both maternal and genetic factors are identical. In contrast to the maternal environment, the fetoplacental environment can be different for both members of a twin pair. A previous study used a twin sample to disentangle genetic and environmental factors in the association between birth weight and adult hand grip strength (a marker of muscle strength, which is also related to cardiovascular disease [16]) and found evidence for importance of genetic factors ${ }^{17}$.

In the Leuven Longitudinal Twin Study (LLTS) we used a twin sample from the East Flanders Prospective Twin Survey (EFPTS), in which we measured cardiorespiratory fitness, as well as muscle strength, flexibility and balance, up to eight times during adolescence (10-18 years). We studied the associations between these variables and birth weight. Additionally, the importance of individual and shared factors was disentangled. Finally, we analyzed to what extent genetic, maternal or fetoplacental factors were involved. 


\section{Subjects and methods}

\section{Participants}

In a longitudinal study carried out from 1985-1999 (Leuven Longitudinal Twin Study) 114 twin pairs and their parents were recruited from the East Flanders Prospective Twin Survey (EFPTS), which is a population-based register of all twins born in the Belgian province of East Flanders since $1964^{18}$. All families with twins reaching the age of 10 years had been contacted by letter and had been further informed by telephone calls or home visits. The response rate was approximately $40 \%$. The twins were first invited around the age of 10 years, and followed yearly to the age of 16 years, with one additional measurement at 18 years of age. At each visit anthropometric measurements were taken, motor performance was assessed by the Leuven Motor Test Battery and a maximum exercise test on a treadmill measured cardiorespiratory fitness (detailed description in the next section). The parents were assessed once, at the first visit.

\section{Ethics statement}

Both parents and twins gave written informed consent/ assent. Ethical approval was given by the Medical Ethics Committee of the Fund for Medical Research and of the former Institute of Physical Education and Physiotherapy, KU Leuven.

\section{Variables}

\section{Physical fitness}

Our primary outcome measure was peak oxygen uptake $\left(\mathrm{VO}_{2}\right.$ peak, measured in $\mathrm{ml} / \mathrm{min} / \mathrm{kg}$ ) as obtained by a maximal exercise test on a treadmill (ELG2, Woodway, Waukesha, United States), according to the Bruce protocol ${ }^{19}$. Details of the test have been described previously ${ }^{20}$. Only results obtained at a heart rate $>180$ beats per minute were used in the analyses.

In addition, the test battery included measures of static strength (arm pull, in kilograms), explosive strength (vertical jump, in centimeters), muscle endurance/ functional strength (bent arm hang, in seconds), muscle endurance/ trunk strength (leg lifts, $\mathrm{n}$ in 20 seconds), running speed and agility (10 time 5 meters shuttle run test, in seconds), speed of limb movement (plate tapping test, $\mathrm{n}$ in 20 seconds), flexibility (sitand-reach test, centimeter) and balance (flamingo balance test, $\mathrm{n}$ attempts to stand on one leg for one minute). Details of these tests have been described previously ${ }^{21,22}$.

\section{Anthropometry}

Body mass was measured to the nearest $0.1 \mathrm{~kg}$ using a balance scale (SECA 709, Hamburg, Germany) with subjects in underwear. Standing height was measured on 
bare feet using a Harpenden stadiometer (Holtain Instruments, Crymych, United Kingdom) to the nearest millimeter.

\section{Perinatal characteristics}

Birth weight, gestational age, sex, zygosity and chorionicity were collected prospectively. Zygosity was determined using sequential analysis based on sex, fetal membranes, blood groups, placental alkaline phosphatase and DNA marker analysis. Zygosity and chorionicity were analyzed as three groups: dizygotic (always dichorionic), monozygotic-dichorionic (MZDC) and monozygotic-monochorionic (MZMC) twins.

\section{Potential confounders}

As potential confounders we recorded smoking, physical activity and parental BMI. As a measure of physical activity, the average number of hours the children participated in sport activities expressed per week during the last year was recorded. At each visit smoking status was recorded and analyzed in three groups: current smoker, former smoker or never smoker. Parental weight and height were collected using the same methods as used in the twins during the first visit, and (parental) BMI was calculated as (weight in kilograms/ height in meters ${ }^{2}$ ).

\section{Statistical analysis}

\section{Descriptive analysis}

In the descriptive analyses, for continuous variables differences between MZ and DZ twins were calculated by use of the t-test (normally distributed variables) or the Wilcoxon rank sum test (non-normally distributed variables), when appropriate. The $\chi^{2}$ test was used to compare frequencies between $\mathrm{MZ}$ and $\mathrm{DZ}$ twins.

\section{Twins as individuals}

We used multivariable multilevel regression analysis to study the association between birth weight and the outcome variables. Failure to take the correlated nature of the data into account would lead to biased estimates and incorrect standard errors and $P$ values. Therefore, a three level random intercept model was used, taking into account the fact that the measurements were taken longitudinally in the same individuals (level 2), which were in turn clustered in twin pairs (level 3, highest level). The variancecovariance structure of DZ, MZDC and MZMC twins was allowed to differ. Three models were constructed: 1) basic model, adjusted only for sex, age (as time point) and gestational age, 2) as model 1, but adjusted also for child-specific factors: zygositychorionicity, smoking, physical activity, height and weight at the time of assessment, and 3) as model 2, but with additional inclusion of parental factors: maternal and paternal BMI. Since $\mathrm{VO}_{2}$ peak was already calculated relative to weight, weight was not 
included in $\mathrm{VO}_{2}$ peak models 2 and 3 . The data used in figure 1 were calculated using the 'least squared means' function.

\section{Individual versus shared factors}

To evaluate the importance of individual (for example placental function) and shared factors (for example maternal characteristics) in the relationship between birth weight and the outcome parameters, separate within-twin-pair (using the individual twin's birth weight deviation from the pair mean as a determinant) and between-pair regression coefficients (using the average birth weight of the pair as a determinant) were calculated.

\section{Twins as pairs}

To unravel genetic, maternal and placental influences on the associations, the samesex twins were studied as pairs using a two level random intercept model, which takes the longitudinal measurements within the same individuals into account. We analyzed the association between intra-pair difference in birth weight and intra-pair difference in physical fitness for $\mathrm{MZ}$ and $\mathrm{DZ}$ twins separately. Since $\mathrm{MZ}$ twins share approximately $100 \%$ of their genes, genetic factors cannot be responsible for any differences observed within the pair and any association between birth weight and adult fitness observed within $\mathrm{MZ}$ pairs hence indicates environmental influences on the association. Since maternal factors are identical, but fetoplacental factors are never identical, these environmental influences can be pinpointed to fetoplacental factors. DZ twins share on average $50 \%$ of their genes and therefore intra-pair analysis in DZ twins is still partly confounded by genetic effects. The difference scores were calculated as first-born twin minus second-born twin (this yields the same results as subtracting the fastest from the slowest growing twin) $)^{23}$. In the within-pair analyses, the difference in smoking status was not included in the model, because this categorical variable would yield too many possible difference scores for our moderate sample size. In the within-pair analyses, shared variables were not included in the models.

The analyses were performed in SAS 9.2 using SAS Enterprise Guide 4 (SAS institute, Cary, NC, USA). A $P$-value $<0.05$ was considered statistically significant.

\section{Results}

A total of 114 twin pairs were analyzed (Table 3.1). As expected, MZ twins were lighter than DZ twins at birth, but they were also of shorter gestational age. The MZ twins were slightly older and taller when the first measurement was performed and they smoked less at the last measurement. MZ twins performed slightly better on the sitand-reach test and on the shuttle run at the age of 10.5 years. Approximately two 
thirds of the $M Z$ twins were monochorionic $(M C)$, while the percentage of boys and girls in the $\mathrm{MZ}$ and $\mathrm{DZ}$ groups was approximately equal.

Table $3.1 \quad$ Twin characteristics at the start of the study.

\begin{tabular}{|c|c|c|c|c|}
\hline & \multicolumn{3}{|c|}{$M Z(n=94)$} & \multirow[t]{2}{*}{$D Z(n=134)$} \\
\hline & $\mathrm{n}$ & & $\mathrm{n}$ & \\
\hline \multicolumn{5}{|l|}{ General characteristics } \\
\hline Age (years) & 92 & $10.5[10.3,10.6]$ & 126 & $10.4[10.1,10.5]^{* *}$ \\
\hline Birth weight (grams) & 94 & $2401 \pm 509$ & 134 & $2631 \pm 465^{* *}$ \\
\hline Gestational age (weeks) & 92 & $37.0[34.0,38.0]$ & 124 & $38.0[37.0,39.0]^{* *}$ \\
\hline Monochorionic (n, \%) & 94 & $66(70.2)$ & 134 & $0(0)$ \\
\hline Male (n, \%) & 94 & $46(48.9)$ & 134 & $66(49.3)$ \\
\hline \multicolumn{5}{|l|}{ Confounders } \\
\hline Smoking-never $(\mathrm{n}, \%)^{*}$ & 77 & $61(79.2)$ & 107 & $67(62.6)^{* *}$ \\
\hline Smoking-former $(\mathrm{n}, \%)^{*}$ & 77 & $6(7.8)$ & 107 & $7(6.5)$ \\
\hline Smoking-current $(n, \%)^{*}$ & 77 & $10(13.0)$ & 107 & $33(30.8)$ \\
\hline Physical activty (hours per week) & 80 & $1.3[0.0 .3 .0]$ & 105 & $1.0[0.0 .2 .0]$ \\
\hline Height (m) & 94 & $1.42[1.35,1.45]$ & 134 & $1.39[1.36,1.43]^{* *}$ \\
\hline Weight (kg) & 94 & $32.0[28.0,34.4]$ & 134 & $31.0[28.1,34.6]$ \\
\hline Maternal BMI & 94 & $22.8[21.4,25.7]$ & 126 & $24.2[22.3,26.4]$ \\
\hline Paternal BMI & 88 & $25.0[23.4,27.3]$ & 112 & $25.0[23.1,26.1]$ \\
\hline \multicolumn{5}{|l|}{ Fitness parameters } \\
\hline V02 peak ( $\mathrm{ml} / \mathrm{min} / \mathrm{kg}$, only heart rate $>180$ beats $/ \mathrm{min})$ & 72 & $48.9 \pm 11.4$ & 87 & $48.7 \pm 10.5$ \\
\hline Vertical jump (cm) & 94 & $28.8 \pm 4.7$ & 132 & $28.2 \pm 4.2$ \\
\hline Arm pull (kg) & 94 & $25.7 \pm 4.3$ & 132 & $24.7 \pm 4.7$ \\
\hline Standing long jump (cm) & 94 & $157[145,168]$ & 132 & $155[142,165]$ \\
\hline Situps ( $\mathrm{n}$ in $20 \mathrm{~s}$ ) & 94 & $13[10,14]$ & 132 & $13[10,14]$ \\
\hline Flamingo balance ( $\mathrm{n}$ attempts to stand 1 minute) & 94 & $16.6 \pm 5.5$ & 132 & $17.1 \pm 6.5$ \\
\hline Plate tapping test ( $\mathrm{n}$ in $20 \mathrm{~s}$ ) & 94 & $63.9 \pm 6.2$ & 132 & $62.0 \pm 8.2$ \\
\hline Sit and reach test $(\mathrm{cm})$ & 94 & $22[18,26]$ & 132 & $21[15,25]^{* *}$ \\
\hline Lef lifts ( $n$ in $20 \mathrm{~s}$ ) & 94 & $15[13,16]$ & 132 & $15[12,16]$ \\
\hline Bent arm hang (s) & 92 & $10.5[5.9,16.0]$ & 132 & $8.6[4.2,16.1]$ \\
\hline Shuttle run (s) & 94 & $23.1[22.0,24.5]$ & 132 & $22.5[21.8,24.0]^{* *}$ \\
\hline
\end{tabular}

* For description purposes, smoking was analyzed for the final measuring moment instead of at the start of the study. Results are given as mean $\pm \mathrm{SD}$, median [interquartile range] or as $\mathrm{n}(\%) . \mathrm{MZ}$ : monozygotic, $\mathrm{DZ}$ : dizygotic, ** Comparison $\mathrm{MZ}$ and $\mathrm{DZ}$ twins $<0.05$ (t-test)

\section{Twins as individuals}

Table 3.2 shows the regression coefficients obtained from our three different models in which the twins were regarded as individuals. Peak oxygen uptake showed a negative association with birth weight in models 1 and $2: b=-2.53 \mathrm{ml} / \mathrm{min} / \mathrm{kg}$ per $\mathrm{kg}$ 
birth weight $(P=0.04)$ and $b=-2.74(P=0.04)$, respectively. Peak oxygen uptake was not related to birth weight in the fully adjusted model (model 3 ). To further explore the unanticipated negative associations in models 1 and 2, we extended the analysis to study birth weight quartiles. The highest birth weight quarter was used as the reference category. We identified significant differences between the birth weight quartiles in models 1 and 2, and a similar, though non-significant, data structure in model 3 (Figure 3.1). The data in Figure 3.1 represent the expected peak oxygen uptake for a hypothetical average participant of the study in a specific quartile. The corresponding values for model 2 were: smallest quarter $48.2 \mathrm{ml} / \mathrm{min} / \mathrm{kg}(P=0.36$ from largest quarter), second quarter $50.1 \mathrm{ml} / \mathrm{min} / \mathrm{kg}(P=0.01)$, third quarter $50.2 \mathrm{ml} / \mathrm{min} / \mathrm{kg}$ $(P=0.004)$ and the largest quarter: $46.8 \mathrm{ml} / \mathrm{min} / \mathrm{kg}$, overall $P=0.01$. For model 3 , the corresponding values were: smallest quarter $49.0 \mathrm{ml} / \mathrm{min} / \mathrm{kg}(P=0.52$ from largest quarter), second quarter $50.5 \mathrm{ml} / \mathrm{min} / \mathrm{kg}(P=0.06)$, third quarter $50.3 \mathrm{ml} / \mathrm{min} / \mathrm{kg}$ $(P=0.07)$ and the largest quarter: $47.8 \mathrm{ml} / \mathrm{min} / \mathrm{kg}$, overall $P=0.16$. There were no other non-linear associations identified in models 2 or 3.

Table 3.2 Regression coefficients for birth weight in the individual analysis

\begin{tabular}{|c|c|c|c|c|c|c|c|c|c|}
\hline & \multicolumn{9}{|c|}{ Birth weight (kg) } \\
\hline & \multicolumn{3}{|c|}{ Model 1} & \multicolumn{3}{|c|}{ Model 2} & \multicolumn{3}{|c|}{ Model 3} \\
\hline & $\mathrm{n}$ & $b$ & $P$ & $\mathrm{n}$ & $b$ & $P$ & $\mathrm{n}$ & $b$ & $P$ \\
\hline pV02 Peak (ml/min/kg) & 108 & -2.53 & 0.04 & 100 & -2.74 & 0.04 & 85 & -2.01 & 0.16 \\
\hline Vertical jump (cm) & 108 & 1.25 & 0.11 & 100 & 1.38 & 0.09 & 85 & 1.96 & 0.02 \\
\hline Arm pull (kg) & 108 & 3.44 & 0.0002 & 100 & 1.35 & 0.10 & 85 & 1.85 & 0.03 \\
\hline Standing long jump (cm) & 108 & -0.26 & 0.92 & 100 & -1.93 & 0.47 & 85 & -0.76 & 0.79 \\
\hline Situps ( $\mathrm{n}$ in $20 \mathrm{~s}$ ) & 108 & 0.25 & 0.64 & 100 & 0.60 & 0.28 & 85 & 0.76 & 0.23 \\
\hline Flamingo balance ( $\mathrm{n}$ attempts to stand 1 minute) & 108 & -0.71 & 0.35 & 100 & -1.36 & 0.08 & 85 & -1.82 & 0.03 \\
\hline Plate tapping test ( $\mathrm{n}$ in $20 \mathrm{~s}$ ) & 108 & 1.55 & 0.16 & 100 & 0.76 & 0.50 & 85 & 1.59 & 0.18 \\
\hline Sit and reach test $(\mathrm{cm})$ & 108 & 0.17 & 0.87 & 100 & -0.96 & 0.37 & 85 & -0.59 & 0.59 \\
\hline Lef lifts ( $\mathrm{n}$ in $20 \mathrm{~s}$ ) & 108 & -0.74 & 0.04 & 100 & -0.60 & 0.10 & 85 & -0.24 & 0.55 \\
\hline Bent arm hang (s) & 108 & -0.21 & 0.91 & 100 & 1.83 & 0.38 & 85 & 4.39 & 0.052 \\
\hline Shuttle run (s) & 108 & 0.12 & 0.54 & 100 & 0.03 & 0.89 & 85 & -0.17 & 0.45 \\
\hline
\end{tabular}

Results were obtained by use of a three-level random intercept, random slope (for time) model, Model 1: birth weight, gestational age, time point and sex. Model 2: model $1+$ zygosity-chorionicity, smoking, physical activity, height and weight (the latter not included in the V02 peak models). Model 3: model $2+$ parental BMI

In the fully adjusted models using birth weight as a continuous variable adolescent vertical jump ( $b=1.96 \mathrm{~cm}$ per kg birth weight, $P=0.02)$, arm pull $(b=1.85 P=0.03)$ and flamingo balance $(b=-1.82, P=0.03)$ were related to birth weight. In all three cases, higher birth weight was associated with better performance, since performance on the flamingo balance is better when fewer attempts are needed to complete the test (Table 3.2).

When the twin pair's average birth weight was used as the independent variable in the fully adjusted model, no associations were identified (Table 3.3). On the other hand, using the individual twin's deviation from his own twin pair's average birth weight, we 
found positive associations between birth weight and adolescent vertical jump $(b=3.49, P=0.0007)$ and between birth weight and adolescent arm pull $(b=3.44$, $P=0.02$ ).

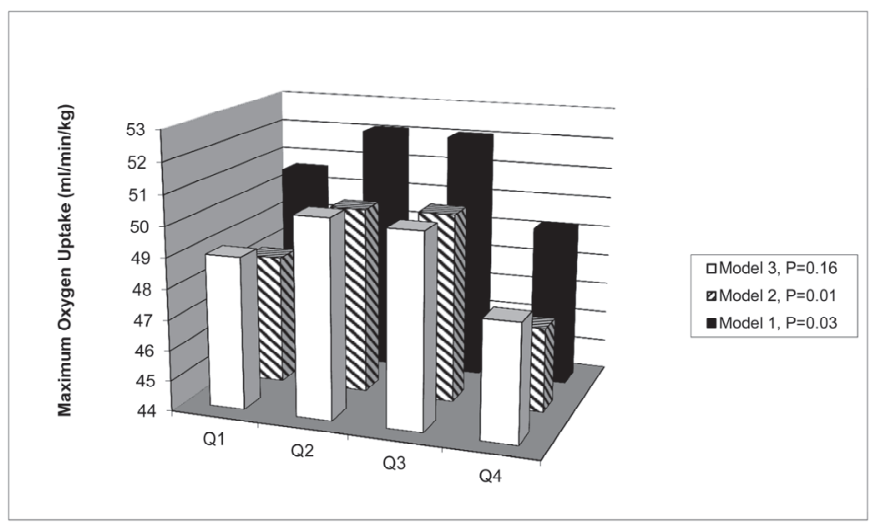

Figure 3.1 Average maximum oxygen uptake in birth weight quarters. Q1-Q4: Birth weight quarter 1-4 (Q1 = lowest quarter).

\section{Twins as pairs}

When $M Z$ and $D Z$ twins were analyzed separately, no associations were found within DZ twins. Several associations were observed in MZ twins in the basic model: birth weight was positively related to vertical jump, arm pull, standing long jump, and plate tapping, while it was inversely related to flamingo balance and shuttle run (Table 3.4). One association remained significant in the fully adjusted model: $\Delta$ birth weight was associated with $\Delta$ vertical jump, in $\mathrm{MZ}$ twins only $(\mathrm{b}=2.63, P=0.009)$.

\section{Discussion}

In the present prospective, longitudinal, twin study we found that the lowest and highest birth weight groups had the lowest peak oxygen uptake in adolescence (i.e. a U-shaped association). However, after adjustment for parental BMI the effect size was attenuated and the association was no longer significant. We hypothesized a lesser performance by children small at birth, but apparently also high birth weight children are at risk. It is not clear what the exact mechanistic meaning of adjustment for parental BMI is. We speculate that parental BMI may be a surrogate for a sedentary lifestyle, poor nutritional habits, genetic predisposition for obesity, low educational level, or a combination of the above. It is most likely also related to birth weight, given 
the confounding characteristics. Given the similar data structure in models 2 and 3 and the accompanying loss of 15 twin pairs, model 3 was potentially influenced by a statistical power problem.

From the other variables studied not only static (arm pull) and explosive (vertical jump) strength were associated with birth weight, but also a more complex measure as balance appeared to be associated with birth weight. In all cases, low birth weight was associated with a lesser performance in adolescence, thereby supporting developmental programming by low birth weight. Importantly, muscle strength, at least as measured by grip strength, is inversely related to cardiovascular and all-cause mortality ${ }^{24,25}$. With regard to the strength variables our results are in accordance with the literature ${ }^{26,27}$. Furthermore, there is prior evidence that balance is positively related to birth weight in elderly men ${ }^{28}$.

Furthermore, our study shows that the association between birth weight and static and explosive strength is most likely due to individual (genetic or fetoplacental) factors, as the association was observed using the twin's individual deviation of the pair's mean birth weight. This means that having a lower birth weight than one's cotwin results in lower adult strength than one's co-twin and hence this cannot be the result of a shared factor. This result is contrary to the only other study in this field, which concluded that genetic factors were most likely to be important in the association between birth weight and, in this case, adult hand grip strength ${ }^{17}$. In this study, however, a different outcome variable was studied at a different age (25 years). In the case of vertical jump, we were more specifically able to show a likely importance of fetoplacental factors, as can be inferred from the fact that we observed the association within $\mathrm{MZ}$ twin pairs, who have identical genetic and maternal characteristics. Hence, genetic and maternal factors cannot cause the association and fetoplacental factors are the only remaining explanation. Placental factors are known to play a role in the developmental origins of health and disease as the placenta is the primary organ to regulate oxygen and nutrients to the developing fetus ${ }^{29}$. This means that fetal adaptations (plasticity) are partly made based on placental function. For example, placental inefficiency was shown to relate to childhood blood pressure ${ }^{30}$. Altogether, our data are supportive of preventive strategies during pregnancy, such as prevention of maternal smoking and promotion of healthy maternal diet and body composition to optimize placental function. In addition, our data are supportive of 'environmental' hypotheses regarding developmental programming, such as the thrifty phenotype hypothesis, and do not support the fetal insulin hypothesis, which assumes a common genotype for both birth weight and adult cardiovascular disease ${ }^{31,32}$.

As a limitation, extrapolation of birth weight studies from twins to singletons should be done with caution. Twins have lower birth weights and shorter gestational ages than singletons, and their prenatal environment is different from that of singletons ${ }^{33}$. Second, our study represents a simplification of reality, because we treat MZ twins as $100 \%$ genetically identical in our analyses. We know that post-zygotic copy number variations (CNV's) and single nucleotide polymorphisms (SNP's) are highly concordant 
in $\mathrm{MZ}$ twins ${ }^{34}$. However, we did not take epigenetic drift, which constitutes that $\mathrm{MZ}$ twins have increasing intra-pair differences in epigenetic profiles with age, into account. These differences are detectable at birth, and increase with age, although their crude magnitude is small and highly variable, depending on the genetic region $^{34-37}$. It seems reasonable to expect a small amount of epigenetic differences within our young MZ twins, which we did not measure. Third, we present a study of a moderate sample size, which increased the risk for a type 1 error. Although the outcome variables were selected by factor analysis and therefore represent different entities within the concept of physical fitness, the risk for a type 1 error is still present ${ }^{38}$. Since our results would not withstand multiple testing adjustment, they should be viewed as hypothesis-generating and therefore need confirmation in other studies.

As important advantages, we present a study in which we repeatedly measured the same broad spectrum of outcome parameters in the same individuals. This yields increased precision in the measurements and provides a rather complete overview of different fitness, strength and performance parameters. Birth weight was thereby collected prospectively.

In summary, we found evidence for an association between adolescent physical performance (strength, balance and possibly peak oxygen uptake) and birth weight. The associations with vertical jump and arm pull were most likely based on individual, more specifically placental (in the case of vertical jump), factors. Our results should be viewed as hypothesis-generating, but potentially support early preventive strategies to optimize birth weight to target later physical performance and probably cardiovascular health. This might be possible by prevention of smoking and by promotion of healthy diets for pregnant women to improve placental function. These possible developmental strategies should be applied together with attempts to improve cardiorespiratory fitness through life style changes in adult patients at risk. With regard to cardiorespiratory fitness, more research is needed, especially on the exact meaning of adjusting these types of data for parental BMI. 


\section{References}

1. Blair SN, Kohl HW, 3rd, Barlow CE, Paffenbarger RS, Jr., Gibbons LW, et al. Changes in physical fitness and all-cause mortality. A prospective study of healthy and unhealthy men. JAMA. 1995;273: 1093-1098

2. Sandvik L, Erikssen J, Thaulow E, Erikssen G, Mundal R, et al. Physical fitness as a predictor of mortality among healthy, middle-aged Norwegian men. N Engl J Med. 1993;328:533-537.

3. Carnethon MR, Gidding SS, Nehgme R, Sidney S, Jacobs DR, Jr., et al. Cardiorespiratory fitness in young adulthood and the development of cardiovascular disease risk factors. JAMA. 2003;290:3092-3100

4. Ferreira I, Twisk JW, Van Mechelen W, Kemper HC, Stehouwer CD. Current and adolescent levels of cardiopulmonary fitness are related to large artery properties at age 36: the Amsterdam Growth and Health Longitudinal Study. Eur J Clin Invest. 2002;32:723-731

5. Ekelund U, Anderssen SA, Froberg K, Sardinha LB, Andersen LB, et al. Independent associations of physical activity and cardiorespiratory fitness with metabolic risk factors in children: the European youth heart study. Diabetologia. 2007;50:1832-1840

6. Ridgway $\mathrm{CL}$, Ong KK, Tammelin T, Sharp SJ, Ekelund U, et al. Birth size, infant weight gain, and motor development influence adult physical performance. Med Sci Sports Exerc. 2009;41:1212-1221

7. Boreham CA, Murray L, Dedman D, Davey Smith G, Savage JM, et al. Birthweight and aerobic fitness in adolescents: the Northern Ireland Young Hearts Project. Public Health. 2001;115:373-379

8. Lawlor DA, Cooper AR, Bain C, Davey Smith G, Irwin A, et al. Associations of birth size and duration of breast feeding with cardiorespiratory fitness in childhood: findings from the Avon Longitudinal Study of Parents and Children (ALSPAC). Eur J Epidemiol. 2008;23:411-422

9. Gluckman PD, Hanson MA, Bateson P, Beedle AS, Law CM, et al. Towards a new developmental synthesis: adaptive developmental plasticity and human disease. Lancet. 2009;373:1654-1657

10. Barker DJ, Winter PD, Osmond C, Margetts B, Simmonds SJ. Weight in infancy and death from ischaemic heart disease. Lancet. 1989;2:577-580

11. Grunnet L, Vielwerth S, Vaag A, Poulsen P. Birth weight is nongenetically associated with glucose intolerance in elderly twins, independent of adult obesity. J Intern Med. 2007;262:96-103

12. Poulter NR, Chang CL, MacGregor AJ, Snieder H, Spector TD. Association between birth weight and adult blood pressure in twins: historical cohort study. BMJ. 1999;319:1330-1333

13. Laaksonen DE, Lakka HM, Lynch J, Lakka TA, Niskanen L, et al. Cardiorespiratory fitness and vigorous leisure-time physical activity modify the association of small size at birth with the metabolic syndrome. Diabetes Care. 2003;26:2156-2164

14. Ortega FB, Labayen I, Ruiz JR, Martin-Matillas M, Vicente-Rodriguez G, et al. Are muscular and cardiovascular fitness partially programmed at birth? Role of body composition. J Pediatr/ 2009;154: 61-66 e61

15. Salonen MK, Kajantie E, Osmond C, Forsen T, Yliharsila H, et al. Developmental origins of physical fitness: the Helsinki Birth Cohort Study. PLoS One 2011;6:e22302.

16. Gale CR, Martyn CN, Cooper C, Sayer AA. Grip strength, body composition, and mortality. Int J Epidemiol. 2007;36:228-235

17. Ridgway CL, Sharp SJ, Derom C, Beunen G, Fagard R, et al. The contribution of prenatal environment and genetic factors to the association between birth weight and adult grip strength. PLoS One. 2011;6: e17955

18. Derom C, Thiery E, Peeters H, Vlietinck R, Defoort P, et al. The East Flanders Prospective Twin Survey (EFPTS): An Actual Perception. Twin Res Hum Genet. 2013;16:58-63

19. Bruce RA, Blackmon JR, Jones JW, Strait G. Exercising Testing in Adult Normal Subjects and Cardiac Patients. Pediatrics. 1963;32:Suppl 742-756

20. Geithner CA, Thomis MA, Vanden Eynde B, Maes HH, Loos RJ, et al. Growth in peak aerobic power during adolescence. Med Sci Sports Exerc. 2004;36:1616-1624

21. Simons J, Beunen GP, Renson R, Claessens ALM, Vanreusel B, et al. Growth and Fitness of Flemish Girls: The Leuven Growth Study. HKP Sport Science Monograph Series, 1990; Vol 3,(Eds). Champaign, IL: Human Kinetics. pp. 1-173

22. Adam C, Klissouras V, Ravasollo M. Eurofit: Handbook for the Eurofit Tests of Physical Fitness: Rome: Council of Europe. Committee for the Development of Sport, 1988. 
23. Carlin JB, Gurrin LC, Sterne JA, Morley R, Dwyer T. Regression models for twin studies: a critical review. Int J Epidemiol. 2005;34:1089-1099

24. Ortega FB, Silventoinen K, Tynelius P, Rasmussen F. Muscular strength in male adolescents and premature death: cohort study of one million participants. BMJ. 2012;345: e7279

25. Sasaki H, Kasagi F, Yamada M, Fujita S. Grip strength predicts cause-specific mortality in middle-aged and elderly persons. Am J Med. 2007;120:337-342

26. Inskip HM, Godfrey KM, Martin HJ, Simmonds SJ, Cooper C, et al. Size at birth and its relation to muscle strength in young adult women. J Intern Med. 2007;262:368-374

27. Yliharsila H, Kajantie E, Osmond C, Forsen T, Barker DJ, et al. Birth size, adult body composition and muscle strength in later life. Int J Obes (Lond). 2007;31:1392-1399

28. Martin HJ, Syddall HE, Dennison EM, Cooper C, Sayer AA. Physical performance and physical activity in older people: are developmental influences important? Gerontology. 2009;55:186-193

29. Thornburg KL, O'Tierney PF, Louey S. Review: The placenta is a programming agent for cardiovascular disease. Placenta. 2010;31 Suppl:S54-59

30. Wen X, Triche EW, Hogan JW, Shenassa ED, Buka SL. Association between placental morphology and childhood systolic blood pressure. Hypertension. 2011;57:48-55

31. Hales CN, Barker DJ. The thrifty phenotype hypothesis. Br Med Bull. 2001;60:5-20

32. Hattersley AT, Tooke JE. The fetal insulin hypothesis: an alternative explanation of the association of low birthweight with diabetes and vascular disease. Lancet. 1999;353:1789-1792

33. Loos RJ, Derom C, Derom R, Vlietinck R. Determinants of birthweight and intrauterine growth in liveborn twins. Paediatr Perinat Epidemiol. 2005;19 Suppl 1:15-22

34. Scheet $P$, Ehli EA, Xiao $X$, van Beijsterveldt CE, Abdellaoui $A$, et al. Twins, tissue, and time: an assessment of SNPs and CNVs. Twin Res Hum Genet. 2012;15:737-745

35. Loke YJ, Novakovic B, Ollikainen M, Wallace EM, Umstad MP, et al. The Peri/postnatal Epigenetic Twins Study (PETS). Twin Res Hum Genet. 2013;16:13-20

36. Fraga MF, Ballestar E, Paz MF, Ropero S, Setien F, et al. Epigenetic differences arise during the lifetime of monozygotic twins. Proc Natl Acad Sci USA. 2005;102:10604-10609

37. Talens RP, Christensen K, Putter H, Willemsen G, Christiansen L, et al. Epigenetic variation during the adult lifespan: cross-sectional and longitudinal data on monozygotic twin pairs. Aging Cell. 2012;11:694-703

38. Simons J, Beunen G, Ostyn M. Constuction d'une batterie de test d'aptitude motrice pour garc, ons de 12 a' 19 ans, par la me'thode de l'analyse factorielle (Use of factor analysis to build up a physical fitness test battery for boys aged 12 to 19 years). Kinanthropologie. 1969;1:323-362 


\title{
Chapter 4
}

Longitudinal growth during the first years of life: What is normal?

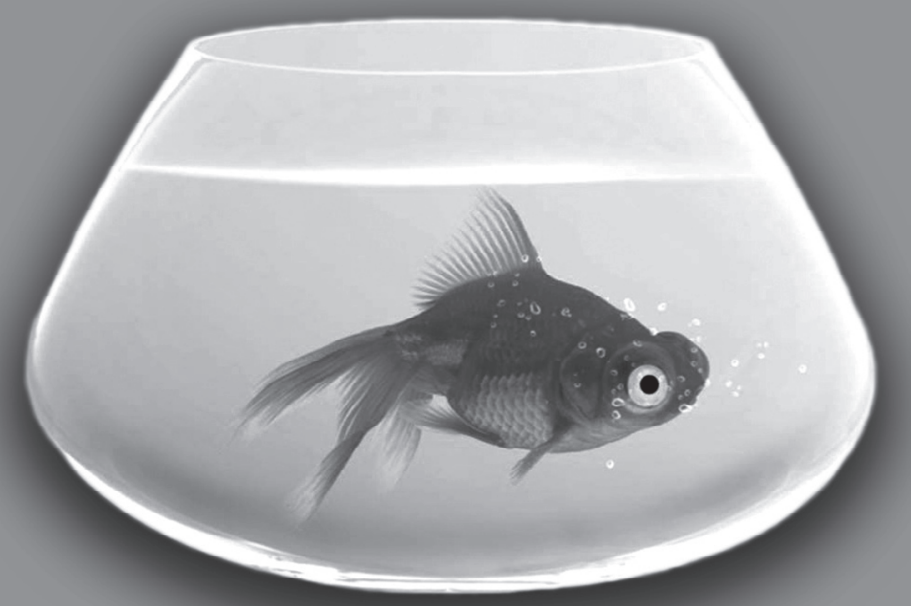

\author{
RNH Touwslager \\ WJM Gerver \\ ALM Mulder \\ AGJM Gerver Jansen \\ $\mathrm{R}$ de Bruin
}

Hormone Research 2008;70:273-277 


\section{Abstract}

The anthropometric data of a longitudinal growth study on healthy infants, followed from birth until the age of 4 years and performed during 1995-1999 in The Netherlands, were used to analyze the general growth patterns in terms of height, weight and head circumference, based on z-scores, during the first 4 years of life. The well-known phenomenon where each infant or child tends to decelerate or accelerate its growth velocity depending on its starting position on the reference curve is obvious in this study too. This phenomenon, known as the regression to the mean, is a strong phenomenon especially during the first year. Regression to the mean is calculated for the different age groups as factor. With the given $\alpha$, it is possible to estimate the individual expectation of growth. 


\section{Introduction}

In 1989, Barker et al. ${ }^{1}$ demonstrated a positive correlation between intrauterine growth retardation and cardiovascular disease in adulthood. Since then, many studies have focused on the biological cause for this relationship and, in larger perspective, on the developmental origins of health and disease ${ }^{2-4}$. Recent studies suggest that, next to intrauterine growth restriction, accelerated postnatal weight gain also increases the risk of obtaining cardiovascular disease as an adult ${ }^{5}$. This accelerated weight gain is frequently seen in intrauterine retarded infants and therefore may play an essential role in the explanation of Barker's theory. Singhal and Lucas ${ }^{6}$ suggest terming this concept the 'accelerated growth hypothesis'. But what does accelerated growth mean? It is a statistical certainty that the individual growth pattern tends to shift to the population mean over time, which is known as the 'regression to the mean' ${ }^{7}$. From this phenomenon it follows that individual growth parameters, expressed as z-scores, tend to zero. However, it must be realized that the more extreme a z-score is, the stronger its 'correction' will be in an absolute sense although relatively it remains the same. Therefore, neonates born small for gestational age (SGA) will change their z-score significantly but it is important to know whether a SGA infant simply shows the expected regression to the mean or shows an increased or decreased growth pattern as compared to the expected one.

The aim of the present study is to analyze the general growth patterns in terms of height, weight and head circumference, based on z-scores, during the first 4 years of life. For that reason the anthropometric data of a longitudinal growth study on healthy infants followed from birth until the age of 4 years and performed during 1995-1999 in The Netherlands were used ${ }^{8}$.

\section{Methods}

\section{Study population}

From 1995 till 1999 a semi-longitudinal growth study was performed in the south of The Netherlands. The study population consisted of 1,234 full-term infants, 678 boys (55\%) and 556 girls (45\%). The infants were measured at the infant and child health centers from birth until 4 years of age with a monthly interval in the first half-year, every 2 months during the next half year and twice a year thereafter. The individuals included were non-hospitalized children whose parents were both of Caucasian origin and whose health and living circumstances were such that neither in the past nor during the study had growth retardation been expected. 


\section{Measurements}

Length was measured using the Harpenden infanto- and stadiometer. Until the age of 2 years, length was measured in the supine position, thereafter as standing height. Weight was measured using an electronic scale accurate to $1 \mathrm{~g}$ and giving automatically the mean of several measurements within 1 min after start of weighing and head circumference was measured with a non-stretchable tape around the most protruding points of occiput and forehead. All measurements were either supervised or recorded by one trained person (A.G.J.).

\section{Data analysis}

Since not all individuals were measured exactly on specified age points in time, for each individual the available data were interpolated to the exact ages of $0,0.75,1.75$, 2.75 and 3.75 using linear regression. These points were chosen because of their highest density of data. Linear interpolation was performed only when at least two measurements were available in a period of 0.25 year around the age of 0.75 and 0.5 years about the ages of $1.75,2.75$ and 3.75 . For the calculation of age 0 , the two measurements had to be between corrected age -0.06 and 8 weeks after birth. The age -0.06 or 37 weeks' gestation is used as lower border to exclude premature birth. Birth weight or height was not taken as a solitary measurement because it seems more accurate to take the interpolated data of several measurements perinatally ${ }^{9}$. The values were corrected for gestational age if the gestational age was different from the expected 40 weeks.

Of each measurement the standard deviation score (SDS), $z(t)$, is calculated as

$z(t)=((x(t)-\mu(t)) / \sigma(t)$,

where $x(t)$ denotes the individual's body measurement score at age $t, \mu(t)$ denotes the population mean at age $t$, and $\sigma(t)$ the corresponding standard deviation (SD).

For each individual the $z\left(t_{i}\right)$ and $z\left(t_{j}\right), i<j$, are plotted against each other. A linear regression is applied through the total of pairs of measurements according to the formula $z_{j}=\alpha_{i j} z_{i}$, where $\alpha_{i j}$ indicates the slope of the linear regression. The value of $\alpha_{i j}$ represents the regression to the mean between the age $t_{i}$ and $t_{j}$. The $95 \%$ confidence interval $(\mathrm{Cl})$ was calculated on the basis of expected and realized values and equals $\pm 2 \sqrt{1}-\alpha^{2}$.

\section{Results}

Table 4.1 gives a list of the number of measurements taken at each visit. Of all infants, 17 were only measured once, 9 infants twice, etc. At the end, only those infants were used who were measured at least 8 times in the case of infants and 5 times in the case 
of children older than 1 year. In total we used 1,279 children. Of these, 45 were excluded because they missed reasonable consecutive measurements. At the end the data of 1,234 children were taken into account.

Table 4.1 Number of infants who were included for the calculation of the longitudinal growth during the first years of life.

\begin{tabular}{lcc}
\hline Visits & Infants & Children $>1$ year \\
\hline 1 & 17 & 101 \\
2 & 9 & 147 \\
3 & 3 & 172 \\
4 & 14 & 132 \\
5 & 19 & 169 \\
6 & 43 & 263 \\
7 & 119 & \\
8 & 267 & \\
9 & 464 & \\
10 & 116 & 984 \\
Total & 1,071 & \\
\hline
\end{tabular}

Table 4.2 shows the mean $(\mu)$ and SD $(\sigma)$ for supine length or height, weight, and head circumference of the interpolated data for boys and girls at the 5 different ages.

Table 4.2 Mean $(\mu)$ and SD $(\sigma)$ of the interpolated data for boys and girls at 5 ages are presented for supine length or height, weight, and head circumference $(\mathrm{cm})$ and age (years).

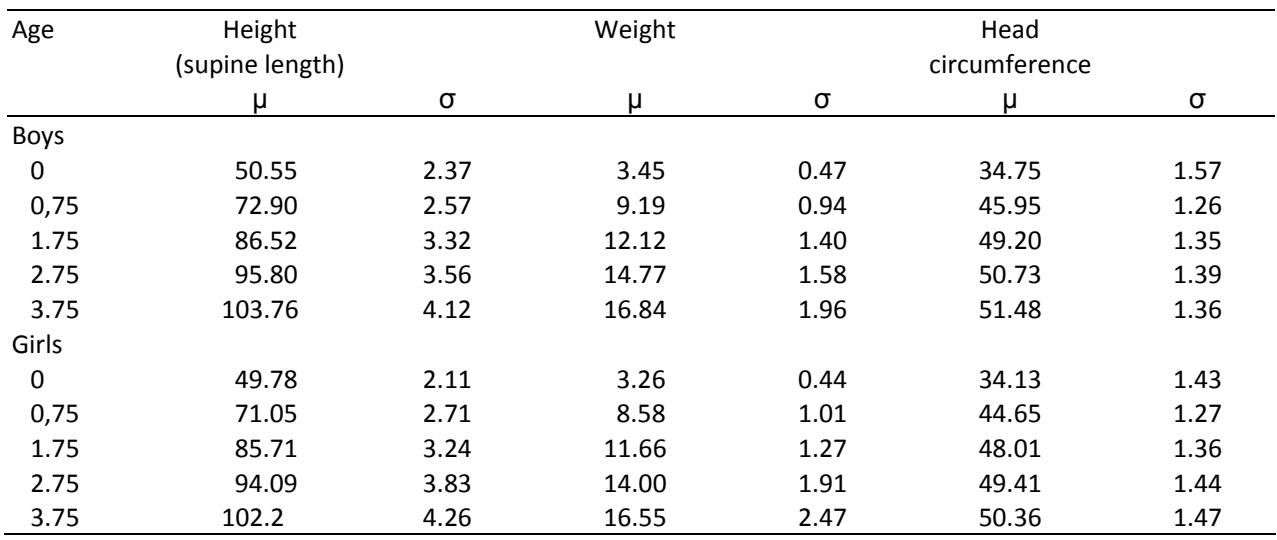

In Tables 4.3-4.5 the regression factors for the different measurements are given for boys and girls separately. Out of these factors it is possible to estimate height, weight and/or head circumference for any time interval. For example, if someone wants to estimate the weight of a male infant at age 1.75 years with known weight at birth, the SD of his birth weight must be multiplied with factor 0.34 to get the expected SD of his 
weight at 1.75 years of age. Out of the expected SD at age 1.75 , weight in $\mathrm{kg}$ can be calculated from the reference values at that age given in Table 4.1 .

Table 4.3 Regression factors for supine length/height (boys top, girls bottom) for various end ages defining the age span in years ( $x$-axis) and the initial age points in years ( $y$-axis).

\begin{tabular}{|c|c|c|c|c|}
\hline \multirow[t]{2}{*}{ Initial ages } & \multicolumn{4}{|c|}{ Age span (defined by end age) } \\
\hline & 0.75 & 1.75 & 2.75 & 3.75 \\
\hline \multirow[t]{2}{*}{0.00} & 0.41 & 0.37 & 0.29 & 0.39 \\
\hline & 0.41 & 0.32 & 0.41 & 0.32 \\
\hline \multirow[t]{2}{*}{0.75} & & 0.80 & 0.72 & 0.71 \\
\hline & & 0.78 & 0.78 & 0.67 \\
\hline \multirow[t]{2}{*}{1.75} & & & 0.88 & 0.90 \\
\hline & & & 0.75 & 0.85 \\
\hline \multirow[t]{2}{*}{2.75} & & & & 0.97 \\
\hline & & & & 0.96 \\
\hline
\end{tabular}

Table 4.4 Regression factors for weight (boys top, girls bottom) for various end ages defining the age span in years ( $x$-axis) and the initial age points in years ( $y$-axis).

\begin{tabular}{|c|c|c|c|c|}
\hline \multirow[t]{2}{*}{ Initial ages } & \multicolumn{4}{|c|}{ Age span (defined by end age) } \\
\hline & 0.75 & 1.75 & 2.75 & 3.75 \\
\hline \multirow[t]{2}{*}{0.00} & 0.34 & 0.34 & 0.25 & 0.33 \\
\hline & 0.34 & 0.35 & 0.40 & 0.38 \\
\hline \multirow[t]{2}{*}{0.75} & & 0.69 & 0.68 & 0.70 \\
\hline & & 0.77 & 0.55 & 0.50 \\
\hline \multirow[t]{2}{*}{1.75} & & & 0.80 & 0.65 \\
\hline & & & 0.84 & 0.84 \\
\hline \multirow[t]{2}{*}{2.75} & & & & 0.96 \\
\hline & & & & 0.95 \\
\hline
\end{tabular}

Table 4.5 Regression factors for head circumference (boys top, girls bottom) for various end ages defining the age span in years ( $x$-axis) and the initial age points in years ( $y$-axis).

\begin{tabular}{lcccc}
\hline Initial ages & \multicolumn{3}{c}{ Age span (defined by end age) } \\
& 0.75 & 1.75 & 2.75 & 3.75 \\
\hline 0.00 & 0.29 & 0.43 & 0.28 & 0.29 \\
& 0.26 & 0.24 & 0.33 & 0.21 \\
0.75 & & 0.85 & 0.84 & 0.84 \\
& & 0.83 & 0.86 & 0.83 \\
1.75 & & 0.94 & 0.93 \\
& & & 0.97 & 0.86 \\
2.75 & & & 0.96 \\
& & & & 0.97 \\
\hline
\end{tabular}

In Table 4.6, the 95\% Cls for the different measurements, length (L), weight (W) and head circumference $(H C)$, are given for various end ages defining the age span in years $(x$-axis) and the initial age points in years ( $y$-axis). 
Table 4.6 95\% Cls for the different measurements: length (L), weight $(\mathrm{W})$ and head circumference $(\mathrm{HC})$ for various end ages defining the age span in years ( $x$-axis) and the initial age points in years ( $y$ axis).

\begin{tabular}{|c|c|c|c|c|}
\hline \multirow[t]{2}{*}{ Initial ages } & \multicolumn{4}{|c|}{ Age span (defined by end age) } \\
\hline & 0.75 & 1.75 & 2.75 & 3.75 \\
\hline \multirow[t]{3}{*}{0.00} & $1.83(\mathrm{~L})$ & & & \\
\hline & $1.88(W)$ & & & \\
\hline & $1.92(\mathrm{HC})$ & & & \\
\hline \multirow[t]{3}{*}{0.75} & & $1.09(\mathrm{~L})$ & & \\
\hline & & $1.25\left(W^{\prime}\right.$ & & \\
\hline & & $0.88(\mathrm{HC})$ & & \\
\hline \multirow[t]{3}{*}{1.75} & & & $1.08(\mathrm{~L})$ & \\
\hline & & & $1.05(W)$ & \\
\hline & & & $0.89(\mathrm{HC})$ & \\
\hline \multirow[t]{3}{*}{2.75} & & & & $0.28(\mathrm{~L})$ \\
\hline & & & & $0.65(W)$ \\
\hline & & & & $0.28(\mathrm{HC})$ \\
\hline
\end{tabular}

Figure 4.1 shows the differences between the expected z-values (using $\alpha$ ) and the measured z-values for weight at 0.75 years versus birth weight according to the method described above. In figure 2 an example is depicted of the predicted outcome of an infant, born with a weight of -1.88 SD.

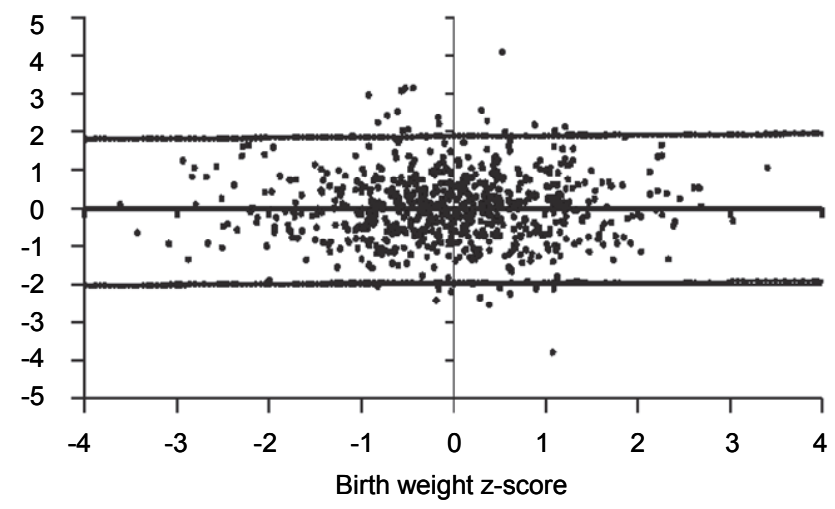

Figure 4.1 Differences between the expected z-values and the measured z-values for weight between respectively 0 and 0.75 year.

\section{Discussion}

The Dutch longitudinal growth study on healthy infants, followed from birth until the age of 4 years, offered the possibility to investigate the variation in individual growth pattern during the first 4 years of age. This growth pattern shows a well-known 
phenomenon where each infant or child tends to decelerate or accelerate its growth velocity depending on its starting position on the reference curve. It is known as the regression to the mean. This regression to the mean, expressed as $\alpha$, is also obvious in this study and clearly very strong during the first year of life as visible in Tables 4.3-4.5. For infants the $\alpha$ of supine length is only 0.41 , of weight 0.34 and in the case of head circumference $\alpha$ is about 0.27 . It means that any infant during his first year of life can be expected to increase or decrease his z-score for any measurement at birth with $\alpha$ times his birth-z-score for that measurement. During the following years the $\alpha$ for the different measurements increases to nearly 1 . A value 1 for $\alpha$ means that there is no longer any regression to the mean and hence the child follows 'his percentile'. The situation where $\alpha$ is almost 1 can be observed beyond the first year of life and is maintained till early puberty when its value lowers drastically again.

Not only the value of $\alpha$ must be considered, but also its estimated $\mathrm{Cl}$. During the first year the $\mathrm{Cl}$ of $\alpha$ is as great as 1.83 SD for height, 1.88 SD for weight and 1.92 SD for head circumference. It means that during infancy the regression factor is small but the $\mathrm{Cl}$ large, as opposed to the situation beyond infancy where, for example, at 4 years of age the regression factor is large but the $\mathrm{Cl}$ small with values of 0.28 for height, 0.65 for weight and 0.28 for head circumference.

This information about $\alpha$ and its $\mathrm{Cl}$ provides us the expectation of the future development of any healthy individual child. Comparing the predicted outcome with the actual z-score gives an answer to the question if a child is growing too fast or too slow. Especially in SGA infants this question is of importance with regard to their risk on metabolic syndrome. Considering Figure 4.1 , where the difference between the predicted value of weight at age 0.75 years or 9 months and the actual measured value is plotted against the z-score at birth, it is clear that there are 10 infants whose pair of $\mathrm{z}$-score was below the lower limit of the $\mathrm{Cl}$ meaning a change of their weight to a lower z-score than could be expected. The same is true in the opposite direction for 18 infants who changed their weight to a higher level. This is remarkable because the reference study concerns a group of healthy children. None of the infants born SGA defined as birth weight below -1.88 SDS showed a growth pattern not fitting in the regression to the mean of the reference group. This can be said too about the other parameters and of all four intervals, meaning that being SGA seems to have no impact on natural growth rates of height, weight and head circumference in the first years after birth. The accelerated growth in our SGA children seems to be no more than the regression to the mean.

In Figure 4.2 the predicted outcome of an SGA infant born with a weight of -1.88 SD is illustrated. The outcome is estimated based on the regression factors at four different ages together with the $\mathrm{Cl}$. Four intervals are depicted: (1) given the $\mathrm{z}$-score at $\mathrm{t}=0$ $(z=0.5),(2)$ given the $z$-score at $t=0.75,(3)$ given the $z$-score at $t=1.75$, and ( 4 ) given the $\mathrm{z}$-score at $\mathrm{t}=\mathbf{2 . 7 5}$. It is clear that during the first 9 months there is an upward change from -1.88 to -0.64 SD with a $\mathrm{Cl}$ of -1.58 to +0.30 SD. It means that a SGA infant is 
allowed to change its weight from -1.88 to +0.30 SD or an upward shift of 1.58 SD without being outside the expected change.

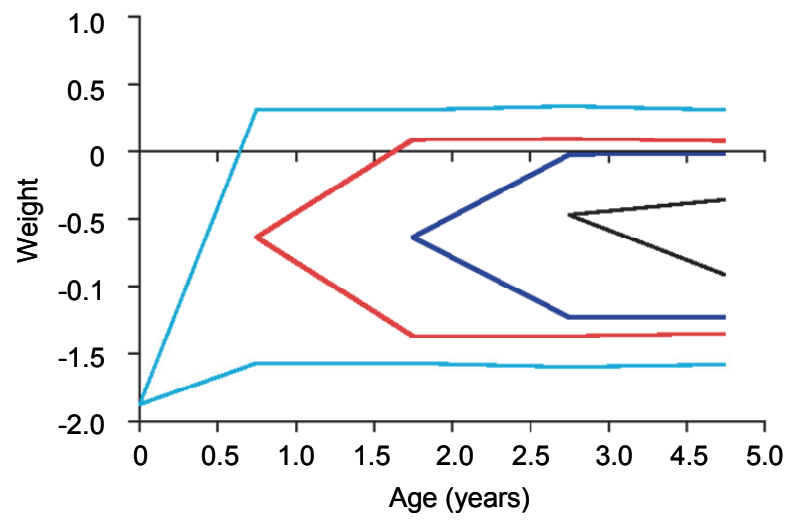

Figure 4.2 $\mathrm{Cl}$ of conditional expectations for weight $-1.88 \mathrm{SD}$ at birth.

As a consequence of the finding that SGA and LGA infants show the same catch-up or catch-down growth as all other infants, although more extensively in case of a lower or higher starting point, one must pay attention not only to an abnormal birth weight but especially to an abnormal postnatal growth pattern. Clearly, most SGA infants show a catch-up growth that cannot be considered as being abnormal or unexpected while there are a lot of infants with a normal birth weight but with an unexpected postnatal increase of weight or length. It therefore makes sense to investigate the relationship between the evidence of the metabolic syndrome and the increase of weight or height outside the limits of expectation for all infants irrespective of their birth weight. 


\section{References}

1. Barker DJ, Winter PD, Osmond C, Margetts B, Simmonds SJ: Weight in infancy and death from ischaemic heart disease. Lancet. 1989;2:577-580

2. Martyn CN, Barker DJ, Osmond C: Mothers' pelvic size, fetal growth, and death from stroke and coronary heart disease in men in the UK. Lancet. 1996;348:1264-1268

3. Leon DA, Lithell HO, Vagero D, Koupilova I, Mohsen R, Berglund L, Lithell UB, Mc Keigue PM: Reduced fetal growth rate and increased risk of death from ischaemic heart disease: cohort study of 15,000 Swedish men and women born 1915-1929. BMJ. 1998;317:241-245

4. Eriksson JG, Forsen T, Tuomilehto J, Osmond C, Barker DJ: Early growth and coronary heart disease in later life: longitudinal study. BMJ. 2001;322:949-953

5. Ravelli AC, van der Meulen JH, Michels RP, Osmond C, Barker DJ, Hales CN, Bleker OP: Glucose tolerance in adults after prenatal exposure to famine. Lancet. 1998;351:173-177

6. Singhal A, Lucas A: Early origins of cardiovascular disease: is there a unifying hypothesis? Lancet. 2004; 363:1642-1645

7. Barnett AG, van der Pols JC, Dobson AJ: Regression to the mean: what it is and how to deal with it. Int J Epidemiol. 2005;34:215-220

8. Gerver WJM, Bruin RD: Paediatric Morphometrics: A Reference Manual, ed 2. Maastricht, University Press Maastricht, 2001

9. Rosen O, Cohen A: Analysis of growth curves via mixtures. Statist Med. 2003;22:3641-3654 


\section{Chapter 5}

\section{Determinants of infant growth in four age windows: a twin study}

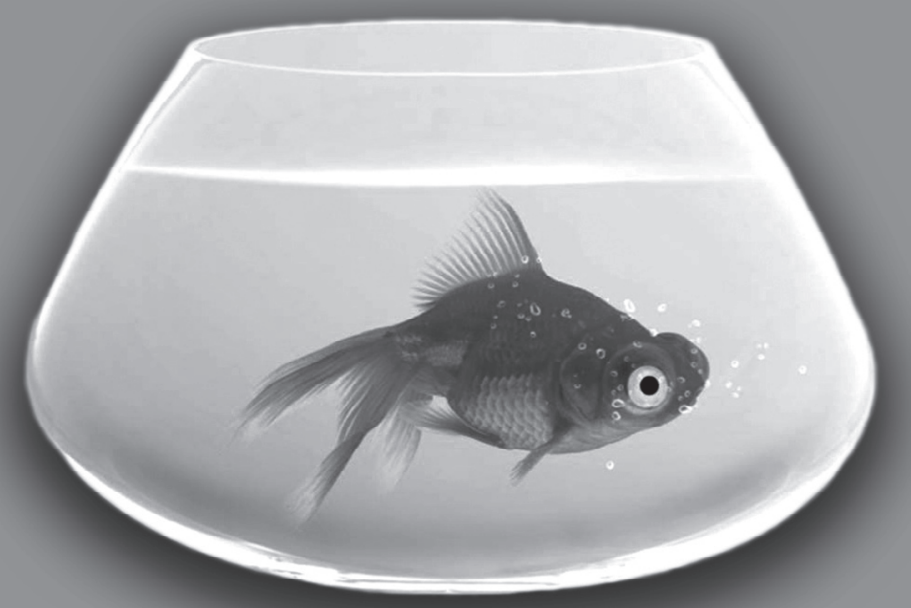

RNH Touwslager M Gielen C Derom ALM Mulder WJM Gerver LJ Zimmermann AJHM Houben CDA Stehouwer R Vlietinck RJF Loos MP Zeegers

The Journal of Pediatrics 2011;158:566-572 


\section{Abstract}

\section{Objective}

To identify determinants of growth during infancy.

\section{Study design}

The sample included 424 twin pairs from the East Flanders Prospective Twin Survey. Multilevel regression analysis was performed and intra-pair growth correlations were calculated. The main outcome measure was growth, measured in $\mathrm{g} / \mathrm{kg} / \mathrm{d}$ (0-1 month) or in change in weight z-score (0-6, 6-12 and 12-24 months).

\section{Results}

Growth during infancy was associated with birth weight and gestational age. One $\mathrm{z}$-score increase in birth weight resulted in $-1.77 \mathrm{~g} / \mathrm{kg} / \mathrm{d}$ less growth from 0 to 1 month $(P<0.0001)$. The effect size decreased with age until $-0.02(P=0.70) z$-scores less growth from 12 to 24 months. Corresponding numbers for one z-score increase in gestational age decreased from $0.78(P=0.001)$ to $0.06(P=0.40)$. From 12 to 24 months, paternal height had a significant positive effect. The difference in growth similarity within the twin pair between monozygotic and dizygotic twins increased from non-significant from 0 to 1 month $(P=0.49)$ to a monozygotic:dizygotic ratio approximating 2:1 from 12 to 24 months $(P=0.002)$.

\section{Conclusion}

From 0 to 1 month, environmental factors are most important for growth, whereas genetic factors become more important over time. This is a first step in identifying age windows for future counseling and interventions on the effects of accelerated growth. 


\section{Introduction}

There is an inverse association between birth weight and risk of disease later in lifeespecially cardiovascular disease and related traits ${ }^{1,2}$. Newborns who are small for gestational age more frequently have accelerated growth relative to their normal birth weight counterparts ${ }^{3}$. The "accelerated growth hypothesis" proposes that this explains the relationship between low birth weight and cardiovascular disease ${ }^{4}$. Accelerated growth -in varying age windows from the first 2 weeks to the first 2 years of life-was linked to endothelial dysfunction ${ }^{5}$, increased blood pressure ${ }^{6}$, obesity ${ }^{7}$, and insulin resistance ${ }^{8}$.

Considering the potential long-term negative effects of early accelerated growth, it would be of importance to know its determinants. Several studies have focused on factors influencing postnatal anthropometry in the first 2 years of life. Positive (growth-promoting) effects were found for birth weight, ${ }^{9}$ gestational age ${ }^{9}$, parental heights $^{9}$, nulliparity ${ }^{10}$, gestational diabetes ${ }^{11}$, and socioeconomic status ${ }^{9}$. Negative (growth-demoting) effects were reported for preeclampsia 12 and breast feeding ${ }^{10,13}$. Positive and negative effects for maternal smoking on growth have been described ${ }^{10,14-16}$. In the light of the effects of accelerated growth, the studies investigating determinants of infant growth mentioned above are hard to interpret. First, accelerated growth, as early as the first 2 weeks of life, has long-term effects5; none of the studies investigating determinants of infant growth has specifically looked at growth in an age window smaller than 0 to 3 months. A recent article has studied different growth windows and, again, concluded that early growth ( $<3$ months) was more clearly associated with adult cardiovascular risk profile than "later" growth (3-12 months). ${ }^{17}$ When studying infant growth, an early age window should be included. Second, to ensure that effects of certain determinants remain important when confounders are considered, possible determinants should be studied together with confounders in a multivariable analysis. In addition, birth weight should be included as a determinant in the analysis to prevent confounding effects. From the studies mentioned earlier, two adjusted their analysis for birth weight ${ }^{9,11}$.

It may be expected that in certain age windows external (environmental) factors have more influence on growth than in other, more genetically dominated age windows. For example, nutrition can be expected to have more impact on growth when growth is mainly under environmental control than it would have on genetically controlled growth. Distinguishing between environmental and genetic control of growth in a specific age window could therefore identify age windows in which an opportunity exists to provide counseling on the negative effects of accelerated growth or to study (nutritional) interventions. The twin approach permits the identification of the relative contributions of genes and environment to growth at different age windows. With progression of gestation, intrauterine growth is increasingly determined by environmental factors ${ }^{18}$, for example, because of nutritional limitations. We therefore 
expect the abundance of nutrients available after birth to cause the infant to grow ever more toward his or her genetic potential.

\section{Methods}

The study sample consisted of live-born twin pairs selected from the East Flanders Prospective Twin Survey, Belgium. The survey started in 1964, recording all multiple births in the Belgian Province of East Flanders until the present day. The East Flanders Prospective Twin Survey is a population based survey that is conducted in a homogenous white population. Details of the selection process of the subset used have been described previously.19 Between February 1997 and April 2000, a total of 424 young adult twin pairs (804 individuals, mean age 25 years) born between 1964 and 1982 participated in a prenatal programming study, in which weights in the first 2 years of life were collected. Informed consent was obtained, and ethical approval was given by the Ethics Committee of the Faculty of Medicine of the Katholieke Universiteit Leuven. At birth, weight, gestational age, sex, parity, zygosity, and chorionicity were collected prospectively. Zygosity was determined by use of sequential analysis on the basis of sex, fetal membranes, blood groups, placental alkaline phosphatase, and DNA marker analysis. Parity was analyzed dichotomously (nulliparous/multiparous). Zygosity and chorionicity were analyzed in three groups: dizygotic (always dichorionic), monozygotic-dichorionic (MZDC) and monozygotic-monochorionic (MZMC) twins.

When the twins were at adult age, as part of the prenatal programming study, the parents of the twins filled out questionnaires. Maternal smoking during pregnancy (yes/no), the occurrence of hypertension during pregnancy (yes [including preeclampsia]/no), gestational diabetes (yes/no/unknown), parental height, parental education, and breast feeding (in weeks) were collected retrospectively in this way. Gestational diabetes was defined as the occurrence of sugar in the urine. Educational level was divided into four groups according to the Belgian education system20: no education or primary school, lower secondary education, higher secondary education, and tertiary education. When the educational level of both parents was available, the highest level was used in the analysis.

\section{Growth}

From the total of 804 individuals, 522 had growth data available. Growth data were obtained by collecting growth charts from the infant and child welfare centers ("Kind en Gezin" [Child and Family]). These health care centers offer periodic medical examination (including weight recording) and can be visited more often if desired or necessary.

Growth data were based on body weight, and growth was calculated for four age windows: from birth to 1 month, from birth to 6 months, from 6 to 12 months, and 
from 12 to 24 months. In the first age window, birth weight and one measurement obtained between 2 and 6 weeks, as close as possible to 4 weeks, were used. Growth was calculated as grams increase in weight, per kilogram weight (using average weight), per day using the exponential formula as described by Patel et al. ${ }^{21}$ Growth was expressed per day, uncorrected for gestational age, to study all individuals at the same postnatal age, regardless of gestational age.

For the remaining three age windows, changes in body weight z-score (standard deviation score) were used, on the basis of postnatal ages corrected for gestational age. Birth weight z-scores were constructed by use of singleton reference data per week of gestation from the Study Center for Perinatal Epidemiology in Brussels (personal written communication, June 24, 2009) ${ }^{22}$. Singleton reference data were used, because Belgian twin reference data were not available. Postnatal z-scores were calculated by use of the singleton Flemish growth curves $2004^{23}$. Individuals were included in the analysis if they had two measurements available in the age windows 0.4-0.6, 0.75-1.25 and/or 1.5-2.5 years, corresponding to 4.8-7.2, 9-15, and 18-30 months. Linear interpolation was used to construct values at exactly 6,12 , and 24 months of age.

\section{Statistical analysis}

The twins were considered as individuals and as members of pairs. Before all analyses, the appropriate assumptions were checked. Differences between monozygotic and dizygotic twins were analyzed by use of a $t$ test for continuous variables and a $\chi^{2}$ test for categorical variables. When data were not normally distributed, the Wilcoxon ranksum test was used instead of the $t$ test.

First, the twins were analyzed as individuals in a multilevel regression analysis to account for relatedness between twin members by adding a random effect to the model. The variance-covariance structure for growth was allowed to differ among the three zygosity-chorionicity groups. The following potential determinants were investigated: birth weight, sex, gestational age, zygosity-chorionicity group, parity, smoking, hypertension during pregnancy, gestational diabetes, breast feeding, parental height, and parental educational level. Univariable and multivariable standardized regression coefficients for the four different age windows were computed. Standardized regression coefficients were calculated to allow direct comparison of the results between variables entered in the model, even though they were originally measured on different scales (e.g., grams, weeks, and centimeters). Significant confounders were identified from the full multivariable model. Significant determinants were subsequently analyzed for possible interactions. On the basis of the multivariable models, expected mean growth scores were calculated.

For birth weight, separate within-twin-pair (using the individual twin's birth weight deviation from the pair mean as a determinant) and between-pair regression coefficients (using the average birth weight of the pair as a determinant) were also 
calculated. To evaluate the importance of individual and shared factors in the relationship between birth weight and growth, these regression coefficients were compared with the crude regression coefficients for birth weight (using just the individual's birth weight as a determinant ${ }^{24}$. Differences between the separate coefficients were calculated with the likelihood ratio (LR) test. This more-detailed assessment of birth weight was performed in the complete twin pairs, using the unstandardized variables in a multivariable model. Second, the twins were studied as pairs. Only pairs of whom both individuals had data available were analyzed. Pearson correlation coefficients for intra-pair growth were computed for each age window, with and without adjustment for confounders. Adjustment for confounders was realized by adding the determinants of growth in that specific window to the correlation analysis as partial determinants. The correlation coefficients were computed for the three zygosity-chorionicity groups separately. Differences in correlation coefficients between zygosity-chorionicity groups were tested using Fisher's r-to-z transformation ${ }^{25}$. Because monozygotic twins are genetically identical and dizygotic twins share on average $50 \%$ of their genes, higher intra-pair correlations for weight change in monozygotic twins compared with that in dizygotic twins are indicative of genetic influence.

All $P$ values are two-sided and were considered statistically significant if they were $<0.05$. All analyses were performed with SAS 9.2 and SAS Enterprise Guide 4 (SAS Institute, Cary, North Carolina).

\section{Results}

The most important baseline characteristics of the study sample are in Table 5.1 (an expanded version is available at www. jpeds.com; Table 5.2).

\section{Multilevel regression analysis}

Compared with the results of the univariable analyses, correction for confounding in multivariable analyses did not yield substantially different results. From 0 to 1 month and 6 to 12 months, the analyses were corrected for birth weight and gestational age. From 0 to 6 months, significant confounders were birth weight, gestational age and sex. From 12 to 24 months, the analysis was corrected for sex, zygosity-chorionicity group, paternal height, and gestational diabetes. In this age window, birth weight and gestational age were no longer significant confounders. Exceptions to the comparability of univariable and multivariable analyses were gestational age from 0 to 1 month and zygosity-chorionicity group from 12 to 24 months (Table 5.3; available at www.jpeds.com). No consistent interactions were found. 


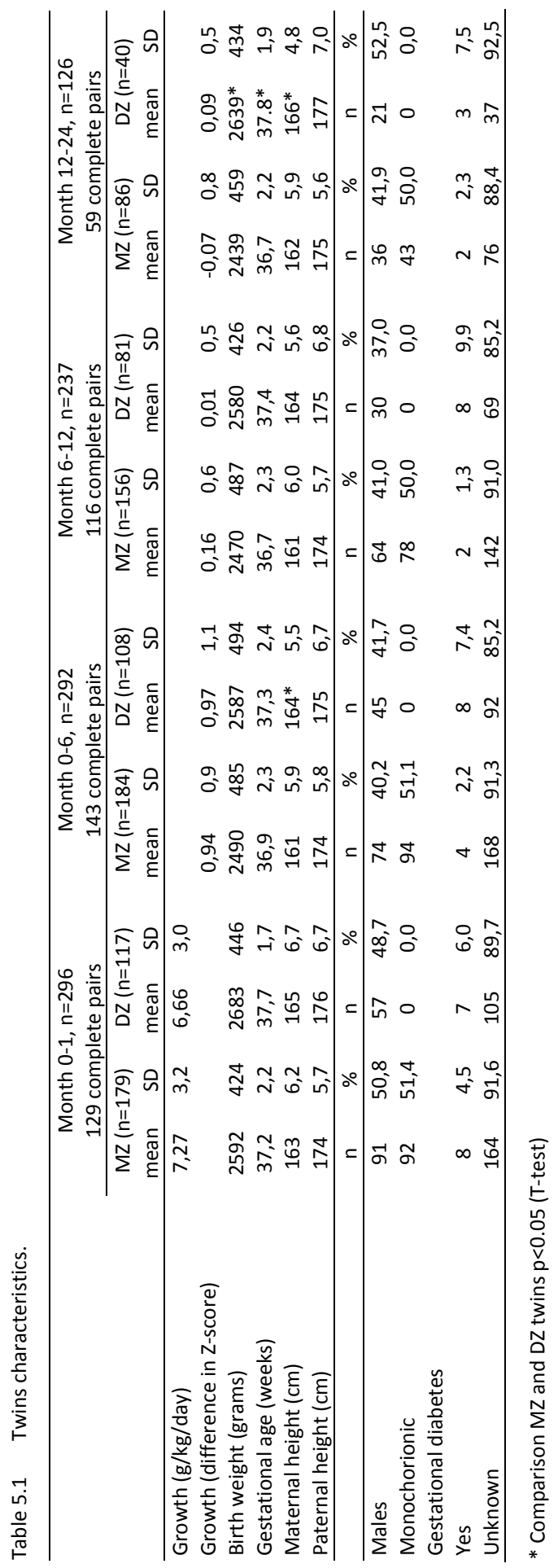


Table 5.2 Multivariable standardized regression coefficients for growth.

\begin{tabular}{|c|c|c|c|c|c|c|c|c|}
\hline & \multicolumn{2}{|c|}{ Month 0-1 } & \multicolumn{2}{|c|}{ Month 0-6 } & \multicolumn{2}{|c|}{ Month 6-12 } & \multicolumn{2}{|c|}{ Month 12-24 } \\
\hline & $\beta^{* *}$ & $\mathrm{P}$ & $\beta^{* * *}$ & $\mathrm{P}$ & $\beta^{* *}$ & $\mathrm{P}$ & $\beta^{* * * *}$ & $\mathrm{P}$ \\
\hline Birth weight & $-1,77$ & $<0.0001$ & $-0,52$ & $<0.0001$ & $-0,14$ & 0,0001 & $-0,02$ & 0,70 \\
\hline Gestational age & 0,78 & 0,001 & 0,52 & $<0.0001$ & 0,22 & $<0.0001$ & 0,06 & 0,40 \\
\hline Male sex & 0,65 & 0,06 & $-0,49$ & $<0.0001$ & 0,11 & 0,16 & 0,26 & 0,03 \\
\hline \multicolumn{9}{|c|}{ Zygosity-chorionicity* } \\
\hline $\mathrm{DZ}$ & $-0,61$ & 0,41 & 0,03 & 0,97 & $-0,17$ & 0,12 & 0,32 & 0,04 \\
\hline MZDC & $-0,24$ & & 0,00 & & 0,03 & & 0,52 & \\
\hline MZMC & ref & & ref & & ref & & ref & \\
\hline Maternal height & 0,00 & 0,99 & 0,06 & 0,39 & 0,01 & 0,76 & $-0,11$ & 0,17 \\
\hline Paternal height & $-0,30$ & 0,15 & 0,06 & 0,37 & $-0,03$ & 0,54 & 0,18 & 0,004 \\
\hline \multicolumn{9}{|c|}{ Gestational diabetes } \\
\hline Yes & $-0,16$ & 0,86 & $-0,03$ & 0,15 & $-0,14$ & 0,65 & 0,94 & 0,004 \\
\hline Unknown & $-0,51$ & & 0,53 & & 0,10 & & 0,03 & \\
\hline No & ref & & ref & & ref & & ref & \\
\hline
\end{tabular}

MZ: monozygotic; DZ: dizygotic; ${ }^{* *}$ Adjusted for birth weight and gestational age; *** Adjusted for birth weight, gestational age and sex; $* * * *$ Adjusted for sex, zygosity-chorionicity group, paternal height and gestational diabetes.

There were no differences between within-twin-pair and between-pair regression coefficients for birth weight in the first three age windows (LR tests, $P>0.08$ ). However, from 12 to 24 months the within-twin-pair coefficient was -0.26 z-scores $/ k g(P=0.04)$, and the between-twin-pair coefficient was $0.40 \mathrm{z}$-scores/kg $(P=0.01)$ (LR test $P=0.002)$. The corresponding crude analysis with birth weight yielded a regression coefficient of 0.02 z-scores/kg ( $P=0.83)$.

Multivariable regression analysis in the four age windows showed that the standardized regression coefficient for birth weight decreased from -1.77 (with $\mathrm{g} / \mathrm{kg} / \mathrm{d}$ ) from 0 to 1 month to -0.02 from 12 to 24 months (Tables 5.3 and 5.4). Gestational age had a growth-promoting effect: the standardized regression coefficient decreased from 0.78 (with $\mathrm{g} / \mathrm{kg} / \mathrm{d}$ ) from 0 to 1 month to 0.06 from 12 to 24 months. In males, growth was less pronounced from 0 to 6 months but more pronounced from 12 to 24 months. In the other two age windows, there was no sex difference. From 12 to 24 months paternal height was positively related to growth. Also in the second year, the zygosity-chorionicity group was a significant determinant, with MZMC twins growing more slowly than the MZDC and dizygotic twins.

Infants born to mothers with gestational diabetes showed faster growth than control subjects from 12 to 24 months.

Figure 5.1 expresses the results from Tables 5.3 and 5.4 in a graphical way, with expected growth. The mean expected growth for a certain age window is depicted by the value at " 0, , in which " 0 " represents the actual mean values of birth weight, gestational age, and paternal height in the four age windows. As an example, expected growth from 0 to 1 month for an infant with a birth weight $1000 \mathrm{~g}$ below average was $10.98 \mathrm{~g} / \mathrm{kg} / \mathrm{d}$, which was $4.08 \mathrm{~g} / \mathrm{kg} / \mathrm{d}$ above the expected growth from an infant with an average birth weight $(6.91 \mathrm{~g} / \mathrm{kg} / \mathrm{d}$ value at " 0 ") (Figure $5.1 \mathrm{~A})$. 


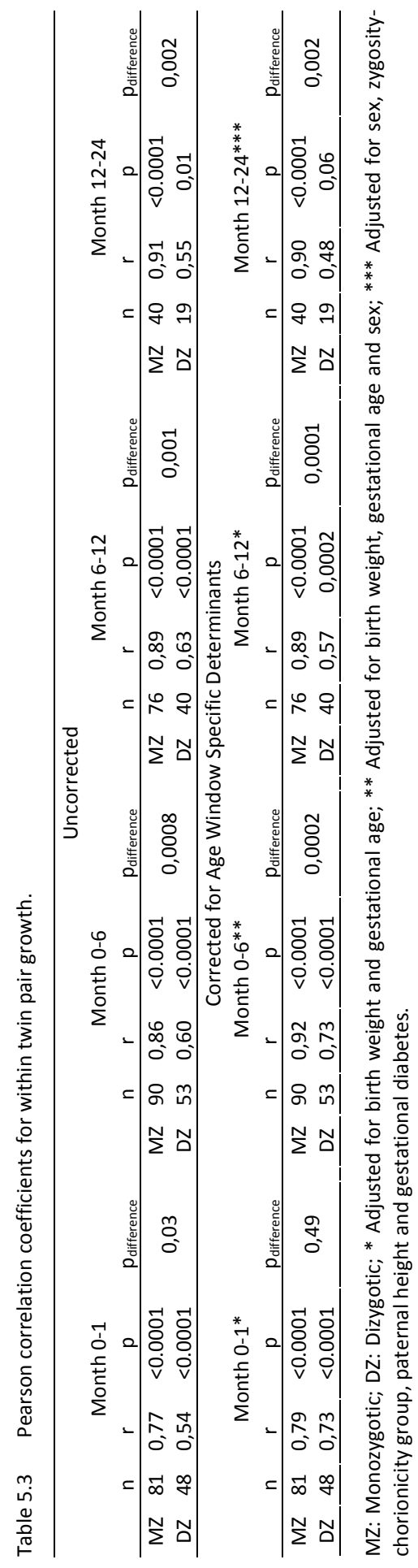



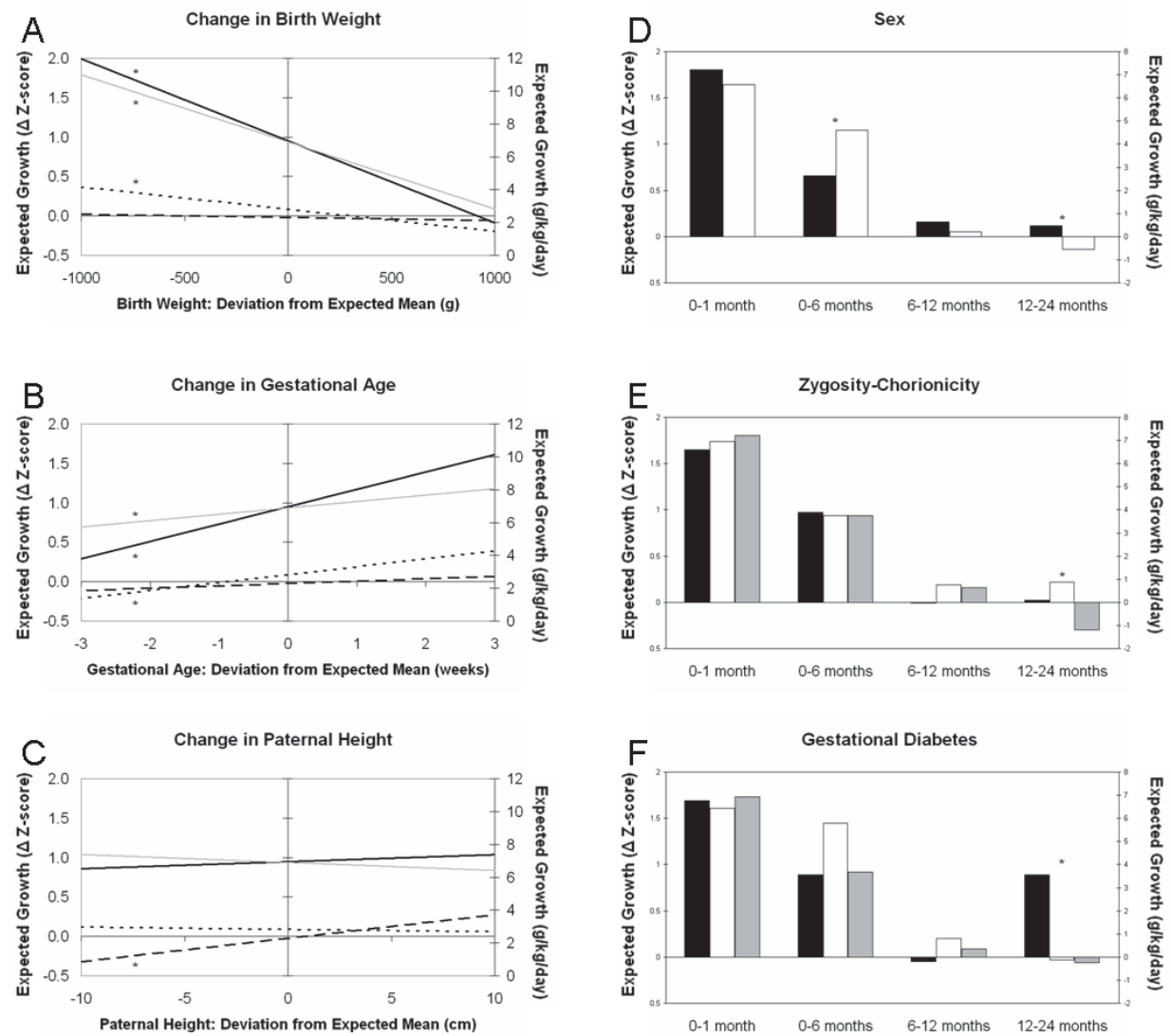

Figure 5.1 Expected growth by varying determinants in different age windows.

Subfigures A, B and C: - 0-1 month; - - - 0-6 months; - - 6-12 months; - 12-24 months. Subfigure D: $\square$ Male; $\square$ Female. Subfigure E: $\square$ Dizygotic; $\square$ Monozygotic-Dichorionic;

Monozygotic-Monochorionic. Subfigure F: $\square$ Yes; $\square$ Unknown; $\square$ No. All figures: ${ }^{*} P<0.05$ for the effect of the determinant

\section{Correlations}

MZMC and MZDC twins did not differ significantly in correlation scores, except from 12 to 24 months (MZMC 0.96, MZDC 0.83, $P_{\text {difference }}=0.02$ ). Because MZMC and MZDC twins hardly differed in correlation coefficients, correlation coefficients for monozygotic twins are presented in Table 5.5. The differences between monozygotic and dizygotic twins in uncorrected correlation coefficients for intra-pair growth were similar to those in corrected analyses, except for the age window from 0 to 1 month. In this window, the difference between monozygotic and dizygotic twins in intra-pair growth correlation disappeared in the corrected analysis. All three subsequent age windows $(0-6,6-12$, and $12-24$ months) showed significant differences in correlations 
between monozygotic and dizygotic twins. The correlations within monozygotic pairs gradually increased (from 0.79 from $0-1$ month to 0.90 from month 12-24), and intrapair dizygotic correlations gradually decreased (from 0.73 from month 0-1 to 0.48 from month 12-24). From 12 to 24 months, the monozygotic:dizygotic correlation ratio approximated 2:1. Restriction of the analysis to same-sex twins (not shown) did not yield significantly different results compared with the analysis including mixed-sex pairs.

\section{Discussion}

Although, in the first year of life, the two main determinants of growth were birth weight and gestational age, the effect of these two factors gradually decreased over time and disappeared in the second year of life, when other factors emerged. One of these determinants was paternal height, which we consider to be a proxy of a genetic contribution. The increasing importance of genetic factors over time was confirmed in our correlation analysis, which showed an increasing difference in intra-pair correlations for growth between monozygotic and dizygotic twins. The monozygotic:dizygotic ratio approximated 2:1 from 12 to 24 months, which is indicative of important genetic influence.

It is important to study early postnatal growth because it may play a role in the development of cardiovascular and metabolic disease. Its effect is related to the concept of plasticity, which refers to the ability of organisms to adapt their phenotype to the environment to be prepared for their anticipated future environment ${ }^{26}$. A mismatch between these adaptations in the organism and its actual circumstances later in life may give rise to disease. It has been suggested that developmental plasticity is affected, at least in part, by epigenetic changes that are established in early life $^{27}$. Post-weaning diet in mice caused permanent epigenetic changes in growthrelated genes, 28 and this may be a mechanism by which accelerated growth (influenced by diet) leads to disease later in life.

In our study, birth weight had a growth-demoting effect in the age window from 0 to 6 months. This is contrary to the effect that was found in an earlier study using crosssectional weight at 6 months as outcome variable ${ }^{9}$. It follows that a larger birth weight will yield a larger weight at 6 months $^{9}$, but it will decrease growth from 0 to 6 months, as shown in our study. This example illustrates the advantage of our study design in exploring the "accelerated growth hypothesis". Furthermore, although weight change from 0 to 1 and 0 to 6 months incorporated birth weight, birth weight remained a significant determinant in our models, indicating its large influence on growth. In the first year, the effect of birth weight was probably caused by shared (maternal) factors, as well as individual factors because we were not able to show differences between within-twin-pair and between-pair regression coefficients. From 12 to 24 months, the results indicated that the relationship between birth weight and growth is mostly 
determined by shared (maternal) factors, while individual factors also are important. It should be noted, however, that these two effects equal out in the individual child, resulting in a non-significant effect of individual birth weight.

Chorionicity is known to influence birth weight.18 Surprisingly, it appears that this influence on birth weight does not make chorionicity a determinant of growth from 0 to 1 month. Also in the age windows from 0 to 6 and 6 to 12 months, no significant influence of chorionicity on weight was found, which is in concordance with a previous twin study conducted in childhood ${ }^{29}$. However, from 12 to 24 months a significant effect of chorionicity was found: MZMC twins grew more slowly than MZDC twins. This effect pattern was different from the (non-significant) patterns observed in the earlier age windows. Further research is needed to explore the effect of chorionicity on growth after 1 year of age.

From 0 to 6 months, females grew faster; from 12 to 24 months males grew faster. In the other age windows there was no significant effect of sex. In our study, twins who experienced gestational diabetes grew faster than control subjects, but only in the time period from 12 to 24 months. This is in concordance with data from a previous study in which, before the age of 1 year, no signs of obesity in infants of mothers with gestational diabetes or insulin-treated preexistent diabetes were found. After this age they became up to $30 \%$ heavier than expected for their height at the age of 8 years ${ }^{30}$.

Breast feeding has a growth-demoting effect on growth, and the beneficial effect of breast feeding on long-term risk of obesity might partly be attributed to the slowing of early postnatal growth. ${ }^{31}$ We were not able to show a significant influence of breast feeding in our study.

Our results should be interpreted with caution. First, twins do not show the same growth patterns as singletons. Twins are born at a shorter gestational age and have a lower birth weight as compared with singletons ${ }^{32}$, which was also true in our study. Postnatally, twins are subject to accelerated growth, especially in the first 3 months of life $^{33}$. The twins in our study experienced strongly accelerated growth in the first 6 months of life, on average above the generally accepted cutoff point of +0.67 change in z-score ${ }^{7}$, and remained at about the same average z-score from 6 months onward. Second, although low birth weight and accelerated growth predispose to cardiovascular disease, twins do not show increased rates of cardiovascular disease ${ }^{34}$. In a recent study, however, weight gain in twins was found to be associated with sum of skin folds, fasting insulin levels, and blood pressure in childhood ${ }^{35}$. This finding suggests a similar response to accelerated growth in twins as compared with singletons ${ }^{6-8}$.

In the intra-pair growth correlation analysis, an increasing role for genetic factors over time was found, which is in line with previous cross-sectional data ${ }^{36}$. The opposite pattern is found in the prenatal period. Environmental factors become more important with progression of gestation, and, hence, heritability of birth weight decreases with advancing gestational age $\mathrm{e}^{18}$. Combining the results of the prenatal and postnatal 
period indicates a prenatal decrease and a postnatal increase of heritability of growth, suggesting a U-shaped heritability of growth around birth.

The correlation analysis showed no difference in intra-pair growth between monozygotic and dizygotic twins in the first month of life, indicating an important role for environmental factors. In practice, it may be easier to intervene in an age window in which environmental factors are dominant, compared with genetically dominated age windows. The identification of an environmentally dominated age window-from 0 to 1 month-may be a first step in identifying age windows that give the opportunity for counseling or for studying possible (nutritional) interventions on the long-term effects of accelerated growth. However, it is important to note that weight gain has clear advantages on resistance to infection and survival in the short term and on final height and cognitive development in the long term ${ }^{37}$. Therefore future research should focus on the balance between the benefits and harms of accelerated growth and look for "optimal" growth. 


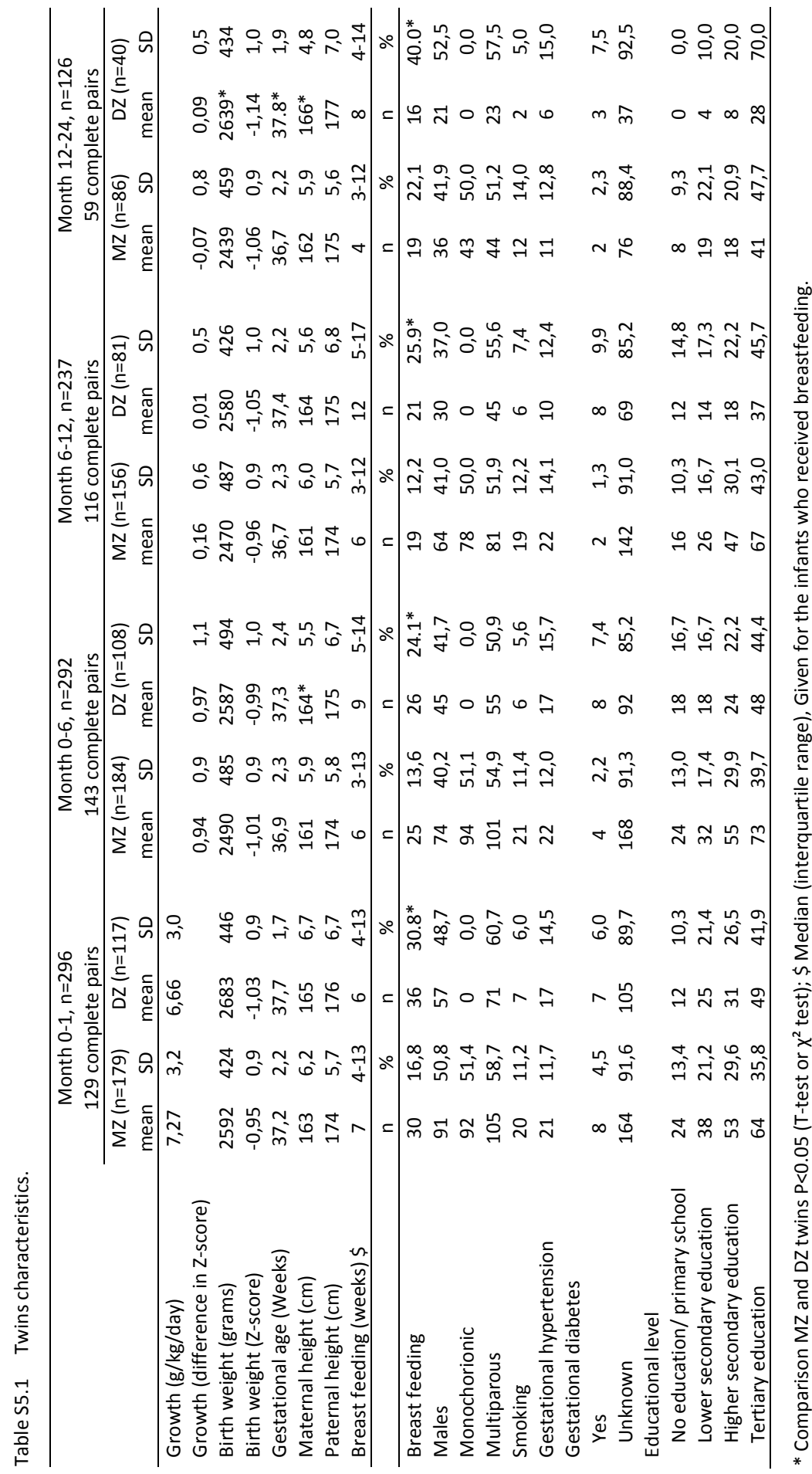




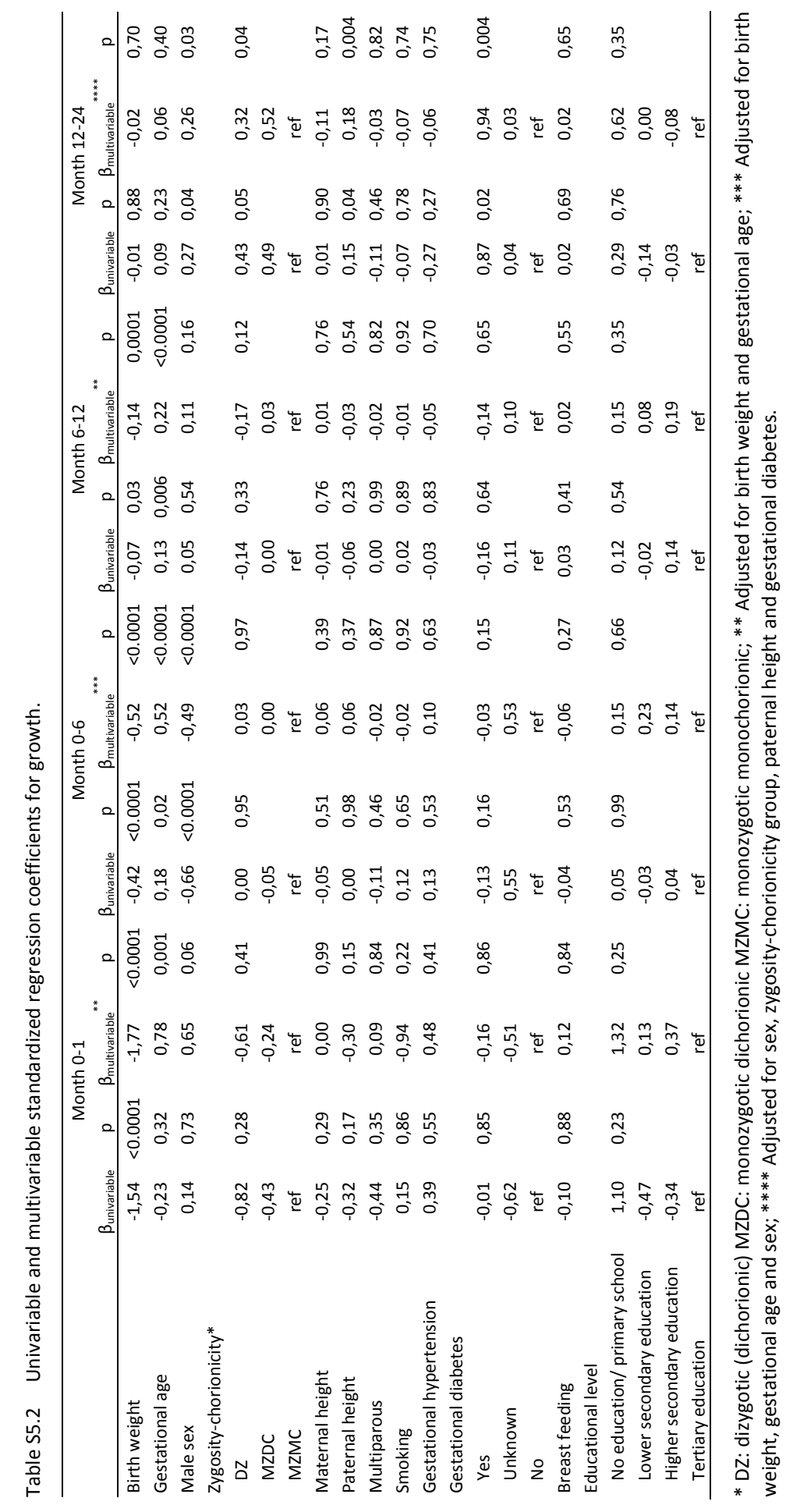




\section{References}

1. Barker DJ, Winter PD, Osmond C, Margetts B, Simmonds SJ. Weight in infancy and death from ischaemic heart disease. Lancet. 1989;2:577-580

2. Newsome CA, Shiell AW, Fall CH, Phillips DI, Shier R, Law CM. Is birth weight related to later glucose and insulin metabolism? -A systematic review. Diabet Med. 2003;20:339-348

3. Hokken-Koelega AC, De Ridder MA, Lemmen RJ, Den Hartog H, De Muinck Keizer-Schrama SM, Drop SL. Children born small for gestational age: do they catch up? Pediatr Res. 1995;38:267-271

4. Singhal A, Lucas A. Early origins of cardiovascular disease: is there a unifying hypothesis? Lancet. 2004;363:1642-1645

5. Singhal A, Cole TJ, Fewtrell M, Deanfield J, Lucas A. Is slower early growth beneficial for long-term cardiovascular health? Circulation. 2004;109:1108-1113

6. Singhal A, Cole TJ, Fewtrell M, Kennedy K, Stephenson T, Elias-Jones A, et al. Promotion of faster weight gain in infants born small for gestational age: is there an adverse effect on later blood pressure? Circulation. 2007;115:213-220

7. Ong KK, Loos RJ. Rapid infancy weight gain and subsequent obesity: systematic reviews and hopeful suggestions. Acta Paediatr. 2006;95:904-908

8. Mericq V, Ong KK, Bazaes R, Pena V, Avila A, Salazar T, et al. Longitudinal changes in insulin sensitivity and secretion from birth to age three years in small- and appropriate-for-gestational-age children. Diabetologia. 2005;48:2609-2614

9. Hindmarsh PC, Geary MP, Rodeck CH, Kingdom JC, Cole TJ. Factors predicting ante- and postnatal growth. Pediatr Res. 2008;63:99-102

10. Ong KK, Preece MA, Emmett PM, Ahmed ML, Dunger DB. Size at birth and early childhood growth in relation to maternal smoking, parity and infant breast-feeding: longitudinal birth cohort study and analysis. Pediatr Res. 2002;52:863-867

11. Vohr BR, McGarvey ST. Growth patterns of large-for-gestational-age and appropriate-for-gestationalage infants of gestational diabetic mothers and control mothers at age 1 year. Diabetes Care. 1997;20:1066-1072

12. Silveira RC, Procianoy RS, Koch MS, Benjamin AC, Schlindwein CF. Growth and neurodevelopment outcome of very low birth weight infants delivered by preeclamptic mothers. Acta Paediatr. 2007;96:1738-1742

13. Rzehak P, Sausenthaler S, Koletzko S, Bauer CP, Schaaf B, von Berg A, et al. Period-specific growth, overweight and modification by breastfeeding in the GINI and LISA birth cohorts up to age 6 years. Eur J Epidemiol. 2009;24:449-467

14. Vielwerth SE, Jensen RB, Larsen T, Greisen G. The impact of maternal smoking on fetal and infant growth. Early Hum Dev. 2007;83:491-495

15. Fenercioglu AK, Tamer I, Karatekin G, Nuhoglu A. Impaired postnatal growth of infants prenatally exposed to cigarette smoking. Tohoku J Exp Med. 2009;218:221-228

16. Conter V, Cortinovis I, Rogari P, Riva L. Weight growth in infants born to mothers who smoked during pregnancy. BMJ. 1995;310:768-771

17. Leunissen RW, Kerkhof GF, Stijnen T, Hokken-Koelega A. Timing and tempo of first-year rapid growth in relation to cardiovascular and metabolic risk profile in early adulthood. JAMA. 2009;301:2234-2242

18. Gielen M, Lindsey PJ, Derom C, Smeets HJ, Souren NY, Paulussen AD, et al. Modeling genetic and environmental factors to increase heritability and ease the identification of candidate genes for birth weight: a twin study. Behav Genet. 2008;38:44-54

19. Loos RJ, Beunen G, Fagard R, Derom C, Vlietinck R. The influence of zygosity and chorion type on fat distribution in young adult twins consequences for twin studies. Twin Res. 2001;4:356-364

20. Flemish Department of Education [Homepage on the Internet]. Available from: http://www.ond.vlaanderen.be/english. In. 21. Patel AL, Engstrom JL, Meier PP, Jegier BJ, Kimura RE. Calculating postnatal growth velocity in very low birth weight (VLBW) premature infants. J Perinatol. 2009;29:618-622

22. Cammu H, Martens G, Landuyt J, de Koen K, Defoort P. Perinatale Activiteiten in Vlaanderen 2006. SPE, Brussel 2007 
23. Roelants $M$, Hauspie $R$, Hoppenbrouwers $K$. References for growth and pubertal development from birth to 21 years in Flanders, Belgium. Ann Hum Biol. 2009;1-15

24. Carlin JB, Gurrin LC, Sterne JA, Morley R, Dwyer T. Regression models for twin studies: a critical review. Int J Epidemiol. 2005;34:1089-1099

25. VassarStats [Homepage on the Internet]. Available from: http://faculty. vassar.edu/lowry/rdiff.html.

26. West-Eberhard MJ. Developmental Plasticity and Evolution. Oxford University Press, New York 2003

27. Gluckman PD, Hanson MA, Buklijas T, Low FM, Beedle AS. Epigenetic mechanisms that underpin metabolic and cardiovascular diseases. Nat Rev Endocrinol. 2009;5:401-408

28. Waterland RA, Lin JR, Smith CA, Jirtle RL. Post-weaning diet affects genomic imprinting at the insulinlike growth factor 2 (Igf2) locus. Hum Mol Genet. 2006;15:705-716

29. Hur YM, Shin JS. Effects of chorion type on genetic and environmental influences on height, weight, and body mass index in South Korean young twins. Twin Res Hum Genet. 2008;11:63-69

30. Silverman BL, Rizzo T, Green OC, Cho NH, Winter RJ, Ogata ES, et al. Long-term prospective evaluation of offspring of diabetic mothers. Diabetes. 1991;40(Suppl. 2):121-5

31. Singhal A. Does breastfeeding protect from growth acceleration and later obesity? Nestle Nutr Workshop Ser Pediatr Program. 2007;60:15-25. discussion -9

32. Loos RJ, Derom C, Derom R, Vlietinck R. Determinants of birthweight and intrauterine growth in liveborn twins. Paediatr Perinat Epidemiol. 2005;19(Suppl. 1):15-22

33. Wilson RS. Twin growth: initial deficit, recovery, and trends in concordance from birth to nine years. Ann Hum Biol. 1979;6:205-220

34. Christensen K, Wienke A, Skytthe A, Holm NV, Vaupel JW, Yashin Al. Cardiovascular mortality in twins and the fetal origins hypothesis. Twin Res. 2001;4:344-349

35. Beardsall K, Ong KK, Murphy N, Ahmed ML, Zhao JH, Peeters MW, et al. Heritability of childhood weight gain from birth and risk markers for adult metabolic disease in prepubertal twins. J Clin Endocrinol Metab. 2009;94:3708-3713

36. Wilson RS. Concordance in physical growth for monozygotic and dizygotic twins. Ann Hum Biol. 1976;3:1-10

37. Ong KK. Catch-up growth in small for gestational age babies: good or bad? Curr Opin Endocrinol Diabetes Obes. 2007;14:30-34 
Chapter 5 


\section{Chapter 6}

Changes in genetic and environmental effects on growth during infancy

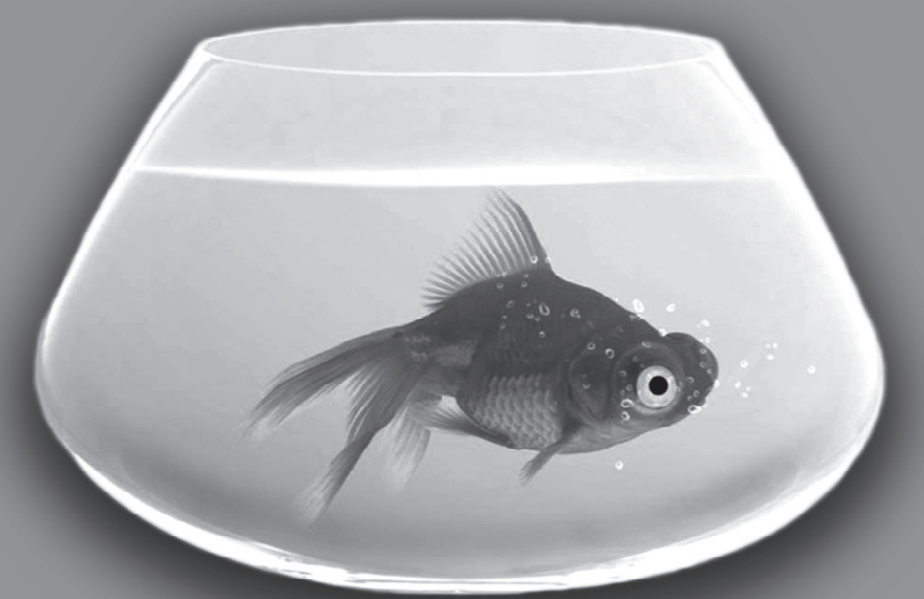
RNH Touwslager
M Gielen
ALM Mulder
WJM Gerver
L Zimmermann
T Fowler
AJHM Houben
CDA Stehouwer
C Derom
R Vlietinck
RJF Loos
MP Zeegers

The American Journal of Clinical Nutrition 2011;94:1568-74 


\section{Abstract}

\section{Background}

Accelerated infant growth is a possible explanation for the relation between birth weight and adult diseases.

\section{Objective}

The aim of this study was to estimate the heritability of infant growth and to examine whether the genetic contribution changes with increasing or decreasing birth weight and gestational age.

\section{Design}

Growth (change in weight z-score) was analyzed in 522 infants from the East Flanders Prospective Twin Survey for age windows of $0-1,1-6,6-12$, and 12-24 mo. Structural equation modeling was performed to estimate the relative importance of additive genetic, shared environmental, and unique environmental sources of variance.

\section{Results}

We showed no genetic contribution to growth in the 0-1-mo growth period. However, at later ages, the heritability of growth was high at $94 \%(95 \% \mathrm{Cl}: 90 \%, 96 \%)$ from 1 to $6 \mathrm{mo}, 85 \%(95 \% \mathrm{Cl}: 80 \%, 89 \%)$ from 6 to $12 \mathrm{mo}$, and $86 \%(95 \% \mathrm{Cl}: 77 \%, 91 \%)$ in the 12-24-mo growth period. Nevertheless, in the last age window, a model without genetic factors was also statistically plausible. From 0 to $1 \mathrm{mo}$, the genetic contribution to growth was low in the average birth weight range but higher at both extremes of birth weight. The genetic contribution from 0 to 1 mo increased with increasing gestational age from $36 \mathrm{wk}$ of gestation onward.

\section{Conclusion}

This study shows that genetic factors are not important in early infant growth (0--1 mo), whereas heritability is high after 1 mo. Because many (nutritional) interventions are aimed at influencing early postnatal growth, to target long-term health, these interventions may be most successful if implemented in the first month of postnatal growth. 


\section{Introduction}

Birth weight is inversely associated with risk of many diseases in adulthood, including hypertension ${ }^{1}$, type 2 diabetes $^{2}$, and ischemic heart disease ${ }^{3}$. One of the proposed mechanisms that could explain these associations is accelerated postnatal growth ${ }^{4}$, which is more common in small-for-gestational-age infants ${ }^{5}$. Although many negative long-term effects of accelerated postnatal growth have been shown, there is debate about the relative importance of growth in infancy compared with growth in childhood $^{6,7}$. Accelerated growth in these 2 age windows has been linked to unfavorable cardiovascular risk profiles in childhood and adulthood and to cardiovascular events in adulthood ${ }^{8-14}$. Multiple studies implied that there may be a very early neonatal critical growth window ${ }^{15-17}$. Because of the above results, it is important to understand the regulation of infant growth, especially to inform future counseling approaches and, possibly, (nutritional) interventions in infant growth.

Cross-sectional heritability studies of postnatal anthropometric measures in infancy and childhood showed increasing heritability estimates with age $\mathrm{e}^{18,19}$. However, crosssectional studies that compare heritability estimates of anthropometric measures for different age groups do not provide an optimal description of the actual growth process that has long-term negative effects. Two studies ${ }^{20,21}$, both of which were preceded by earlier works ${ }^{22,23}$, analyzed infant growth velocity by using genetically sensitive designs and longitudinal data. In the Fels Longitudinal Study, heritability estimates of 0.66 (0-6 mo), 0.55 (0-12 mo), and 0.82 (0-24 mo) were shown for weight change by using pedigree data ${ }^{20}$. A twin study that was based on a population from Amsterdam, Netherlands, showed heritability estimates of weight velocity at the age of 1 y of 0.57 (girls) and 0.63 (boys) ${ }^{21}$. However, to our knowledge, there is no reported study of the potentially important early neonatal age windows.

The advantage of the twin approach is the possibility of estimating the relative importance of genetic and environmental factors in infant growth in terms of heritability. A crude analysis of heritability, however, may not give a true picture of the underlying etiology if heritability depends on certain environmental factors. For example, we expect light babies to be more vulnerable to the influence of the environment (such as nutrition) than heavy babies. The lowest perinatal mortality in twins occurs in infants born between 37 and 38 wk of gestation ${ }^{24,25}$, and therefore, this gestational age can be considered as an optimal start for postnatal growth. Thus, we expected infants born around this gestational age to be minimally dependent on the environment. An understanding of the effects of birth weight and gestational age on the regulation of infant growth by genetic and environmental effects may assist in tailoring research, counseling, and possibly interventions in infant growth to specific subgroups in which attaining a health benefit is more likely.

In the current study we estimated the heritability of infant growth and examined whether the genetic contribution varied with birth weight and gestational age by using a twin sample from the East Flanders Prospective Twin Survey (EFPTS). 


\section{Subjects and methods}

The study sample consisted of live-born twin pairs of white ethnic background selected from the EFPTS, Belgium. The EFPTS started in 1964 and records all multiple births in the Belgian Province of East Flanders and is a population-based survey. Details of the selection process of the subset used in this study were described previously ${ }^{26}$. The sample consisted of 424 young adult twin pairs (804 individuals; mean age: 25 y) who were born between 1964 and 1982 and participated in a prenatal programming study in which weights in the first 2 y of life were collected. Informed consent was obtained, and ethical approval was given by the Ethics Committee of the Faculty of Medicine of the Katholieke Universiteit Leuven.

At birth, weight, gestational age, sex, zygosity, and chorionicity were collected prospectively. Zygosity was determined by using sequential analysis on the basis of sex, fetal membranes, blood groups, placental alkaline phosphatase, and DNA-marker analysis.

When the twins were at adult age (February 1997 to April 2000), as part of the prenatal programming study, the parents of the twins filled out questionnaires to provide information on gestational diabetes and paternal height. Gestational diabetes was defined as the occurrence of sugar in the urine.

\section{Growth in infancy}

Of all 804 individuals, 522 subjects had data on growth available, which was collected by means of growth charts from infant- and child-welfare centers [Kind en Gezin (Child and Family)]. These centers offer medical examinations throughout infancy, including weight recording. Parents and infants voluntarily visited after regular invitations.

Growth was defined as the change in body weight z-score and was calculated for 4 age windows as follows: from birth to $1 \mathrm{mo}(0-1 \mathrm{mo})$, from 1 to $6 \mathrm{mo}(1-6)$, from 6 to 12 mo (6-12), and from 12 to 24 mo (12-24). The availability of growth data differed for the 4 age windows, which resulted in different subsamples in each age window. Birth weight z-scores were constructed by using sex-specific Flemish singleton reference data per week of gestation from the Study Center for Perinatal Epidemiology in Brussels (personal written communication, G Martens, June 2009) ${ }^{27}$. Postnatal z-scores were based on postnatal ages corrected for gestational age. Postnatal z-scores were calculated by using the 2004 sex-specific singleton Flemish growth curves ${ }^{28}$. Singleton reference data were used because these represent normal growth in the Belgian population. Individuals were included in the analysis if they had 2 measurements available in the age windows $0.04-0.12,0.4-0.6,0.75-1.25$, and 1.5-2.5 y, which corresponded to 2-6 wk and 4.8-7.2, 9-15, and 18-30 mo. Linear interpolation was used to construct values at exactly 4 wk and 6, 12, and 24 mo of age. All participants who were analyzed had complete data for all other variables used in the analyses. 


\section{Statistical analysis}

In a previous study in the EFPTS prenatal programming study sample, the following determinants of postnatal growth were identified: birth weight and gestational age (0-1 mo and 6-12 mo); sex, birth weight, and gestational age (0-6 mo); and chorionicity, sex, gestational diabetes, and paternal height (12-24 mo ${ }^{29}$.

Therefore, the structural equation modeling analyses in this study were adjusted for these determinants by using determinants from 0 to 6 mo for our analyses from 1 to 6 mo. Structural equation modeling was performed to quantify the genetic and environmental contributions to the observed phenotypic variance (of growth). To estimate genetic and environmental components of the phenotypic variance, the variance was decomposed in additive genetic ( $A$, additive effects of genes on multiple loci), common environmental $(C$, environmental effects shared by twins reared in the same family), and unique environmental ( $E$, environmental effects unique to the individual) effects. This is the classic ACE model. Thus, heritability $\left(a^{2}\right)$ was defined as the proportion of observed variance, which is explained by genetic factors ( $a^{2}=$ variance due to $A$ /total variance). These models assume that monozygotic and dizygotic twins share a common environment to the same extent and assume no interaction between genes or between genes and environment. A non-additive or dominant genetic contribution model was not considered in the current study because the within-pair Pearson correlation coefficient in monozygotic pairs was not more than twice that of dizygotic pairs in a previous study in this study sample ${ }^{29}$.

In the descriptive statistics, group differences between monozygotic and dizygotic twins were analyzed by using a t test for independent samples for continuous variables and a chi-square test for categorical variables. These analyses were performed with SAS version 9.2 software with the SAS Enterprise Guide 4 software package (SAS Institute).

With regard to structural equation modeling, the appropriate assumptions were checked first and shown to be satisfactory; there were no significant differences in means or SDs of growth between individuals categorized as twin 1 (first born member of the pair) and individuals categorized as twin 2 or between monozygotic and dizygotic twins of same sex. There were also no significant differences in means or SDs of growth between opposite-sex twins and same-sex twins. Growth correlations in opposite-sex twins and dizygotic same-sex twins were similar.

Alternative univariate nested models ( $A C E, C E, A E$, and $E$ models) were fitted to the raw data. A maximum-likelihood approach with accompanying Akaike's information criterion (AIC) was used ${ }^{30}$. The model with the lowest AIC reflected the most parsimonious model. The differences between the models were statistically tested by hierarchical chi-square tests on the basis of the -2 log likelihood. When the results of these hierarchical tests are interpreted, the best model is the model that uses the least parameters, while not being inferior to the model it is nested in. For example, if the $A E$ model is not significantly worse than the ACE model, the AE model is preferred. Absolute values of the fit statistics (AIC and -2 log likelihood) do not provide 
information on the goodness of the fit. To test whether genetic and environmental factors influenced the trait to the same degree in men and women, the unstandardized path coefficients were tested for equality in men and women (quantitative differences). To assess whether it was likely that different sets of genes were involved in the determination of growth in men and women, these qualitative differences were also analyzed in a sex-limitation model. Finally, the possibility of heritability changing with increasing or decreasing birth weight or gestational age was studied by using a gene-environment interaction script ${ }^{31}$. In these analyses the interaction between a moderator variable ( $M$ : birth weight or gestational age in this study) and one of the variance components $(A, C$, or $E)$ was studied. These interactions are referred to as $T$, $\mathrm{U}$, and $\mathrm{V}$. T represents the $\mathrm{M} \times \mathrm{A}$ interaction, $\mathrm{U}$ represents the $\mathrm{M} \times \mathrm{C}$ interaction, and $\mathrm{V}$ represents the $M \times E$ interaction. $M$ was included in the means model to adjust for gene-environment correlation. We performed the interaction analyses on the full (ACE) model to address the possibility that $A, C$, or $E$ is not important for a specific age window as a whole but is important under specific circumstances, such a low or high birth weight.

Structural equation modeling was performed with $M x$ software ${ }^{32}$. Scripts for the $M x$ analyses were modified from the GenomEUtwin Mx script library ${ }^{33}$. The analyses were performed in all 4 age windows separately. All $P$ values were 2 -sided and were considered statistically significant if they were $<0.05$.

\section{Results}

Baseline characteristics of the study sample are given in Table 6.1. For weight change in the 0-1-mo growth period, there was no evidence of a genetic component, whereas common environmental sources accounted for $77 \%$ (95\% Cl: $68 \%, 84 \%)$ of the variance in the best-fitting (CE) model (Table 6.2). For the 1-6-and 6-12-mo growth periods, a model with only additive genetic [94\% (95\% Cl: 90\%, 96\%) from 1 to 6 mo and $85 \%$ (95\% Cl: 80\%, 89\%) from 6 to $12 \mathrm{mo}$ ] and unique environmental [6\% (95\% Cl: $4 \%, 10 \%)$ from 1 to 6 mo and $15 \%$ (95\% Cl: 11\%, 20\%) from 6 to $12 \mathrm{mo}$ ] sources of variance (AE) was the best fitting model. For the 12-24-mo growth period, the CE and AE models were equally suitable. Heritability (in the AE model) was similar to the previous age window at $86 \%$ (95\% Cl: $77 \%, 91 \%)$, whereas in the CE model, $83 \%$ (95\% Cl: $74 \%, 89 \%)$ of the variance was explained by common environmental factors. All best-fitting models are shown in Table 6.2.

Sex-limitation models did not reveal any qualitative sex differences. For the 12-24-mo growth period, a significant quantitative sex difference was detected, with the genetic contribution being more important in women. More specifically, estimates of variance components for the full ACE model in men were $3 \%(95 \% \mathrm{Cl}: 0 \%, 62 \%)$ for additive genetic factors, $86 \%(95 \% \mathrm{Cl}: 27 \%, 95 \%)$ for common environmental factors, and $10 \%$ (95\% Cl: $5 \%, 23 \%)$ for unique environmental factors. 


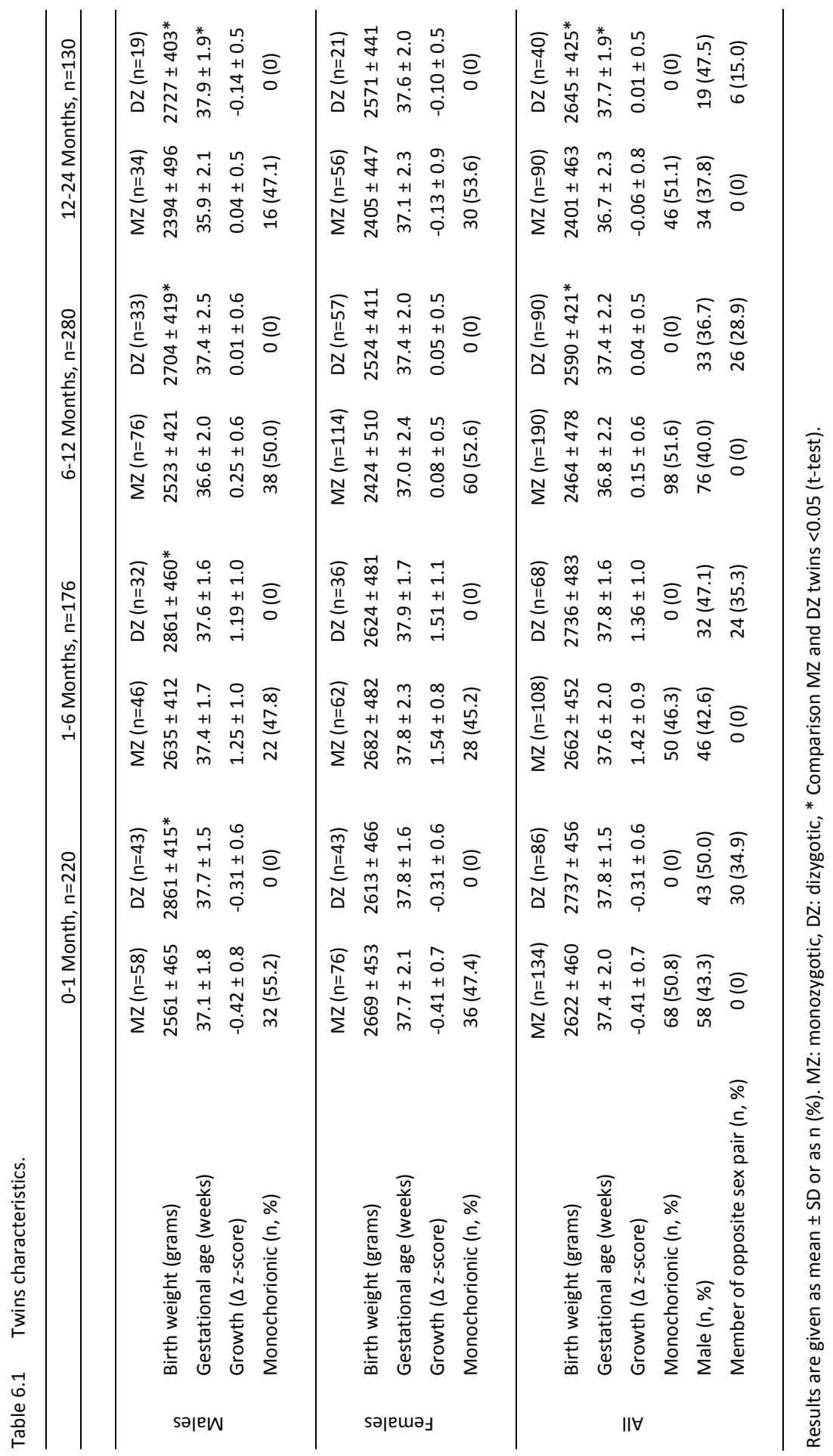




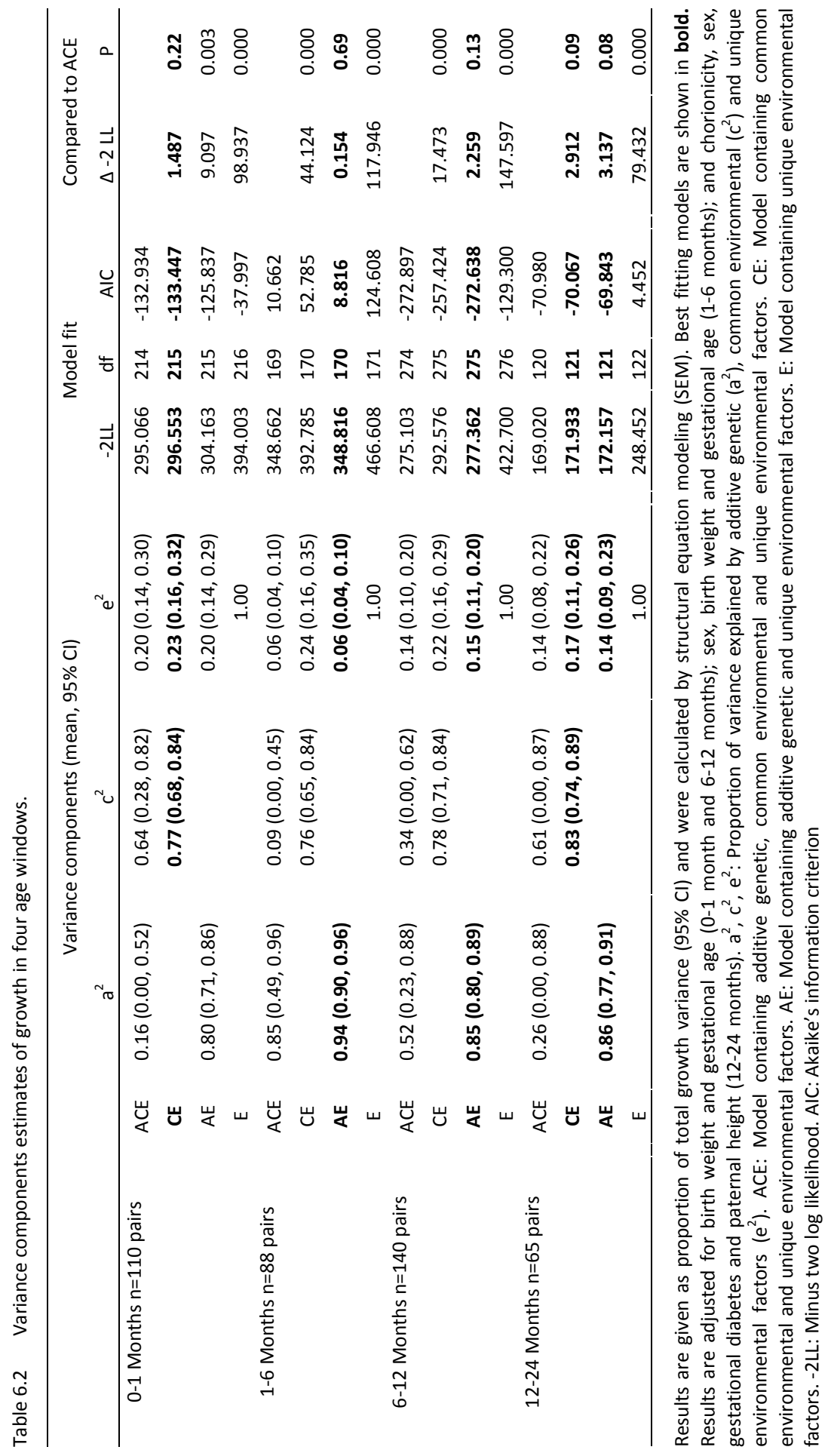


Corresponding numbers for women were $45 \%(95 \% \mathrm{Cl}: 0 \%, 91 \%), 40 \%(95 \% \mathrm{Cl}: 0 \%$, $84 \%)$, and $15 \%(95 \% \mathrm{Cl}: 8 \%, 27 \%)$, respectively (P-difference $=0.005)$.

Complete results from the gene-environment interaction analyses are available (see Table 6.1 under "Supplemental data" in the online issue). Accompanying variances of the best-fitting models from supplemental Table 6.1 (see Table 6.1 under "Supplemental data" in the online issue), which showed a significant interaction, are presented in Figure 6.1. On the $y$ axes in Figure 6.1, the observed growth variation (variance) is depicted, whereas on the $x$ axis, the different values for the moderator are shown. For a specific birth weight or gestational age (moderator; $x$ value), summed values of the $A, C$, and $E$ variances represent the total observed growth variance. For example, from 0 to $1 \mathrm{mo}$, for a birth weight of $1.75 \mathrm{~kg}$, the total variance of growth was $\sim 5.5$ (summed values of $A, C$, and $E$ ). Of this 5.5 , a little more than 3 was explained by $A$, and hence, the genetic variance was relatively large in postnatal growth at a birth weight of $1.75 \mathrm{~kg}$. Similarly, from 0 to $1 \mathrm{mo}$, the genetic contribution to growth (growth variance because of A) was low around the average value of birth weight in our sample $(\sim 2.6 \mathrm{~kg})$ but was also larger at the high end of the spectrum. Because growth variance that was due to $C$ and growth variance that was due to $E$ showed no interaction with birth weight in the age window from 0 to $1 \mathrm{mo}$, these lines were horizontal. For the 1-6-mo growth period, no interactions were identified with birth weight (see Table 6.1 under "Supplemental data" in the online issue). For the 6-12-mo growth period, the contribution of unique environmental factors to growth decreased slightly with increasing birth weight (Figure 6.1). For the 12-24-mo growth period, no interactions were identified with birth weight (see Table 6.1 under "Supplemental data" in the online issue). With respect to gestational age, the unique and common environmental contributions declined with advancing gestational age for the 0-1-mo growth period (the common environment showed a steep decrease), whereas the additive genetic contribution showed a minimum of $\sim 36 \mathrm{wk}$ of gestation. For the 1-6-mo growth period, common environmental factors explained the minimal variance at a gestational age slightly larger than $37 \mathrm{wk}$, but this contribution increased sharply for shorter and longer gestation. No interactions were identified with gestational age from 6 to 12 and 12 to 24 mo (see Table 6.1 under "Supplemental data" in the online issue).

\section{Discussion}

This study showed that genetic factors were not important in early infant growth (0-1 mo), whereas heritability was high after $1 \mathrm{mo}$. This difference was reflected in the structural equation modeling analyses, which showed no additive genetic contribution in the best-fitting model in the growth period from 0 to 1 mo and high heritability thereafter. For the 12-24-mo growth period, both the AE and CE models fitted the data. Although the AE model showed a heritability of $86 \%$, the CE model resulted in a 
heritability of $0 \%$. This discrepancy was most likely due to low statistical power in the age window from 12 to 24 mo. Nevertheless, the intra-pair correlation for growth in this sample was 0.90 in monozygotic twins and 0.48 in dizygotic twins in this age window $^{29}$, which suggests a substantial genetic component and favors the AE model, in which case the heritability would be $86 \%$.
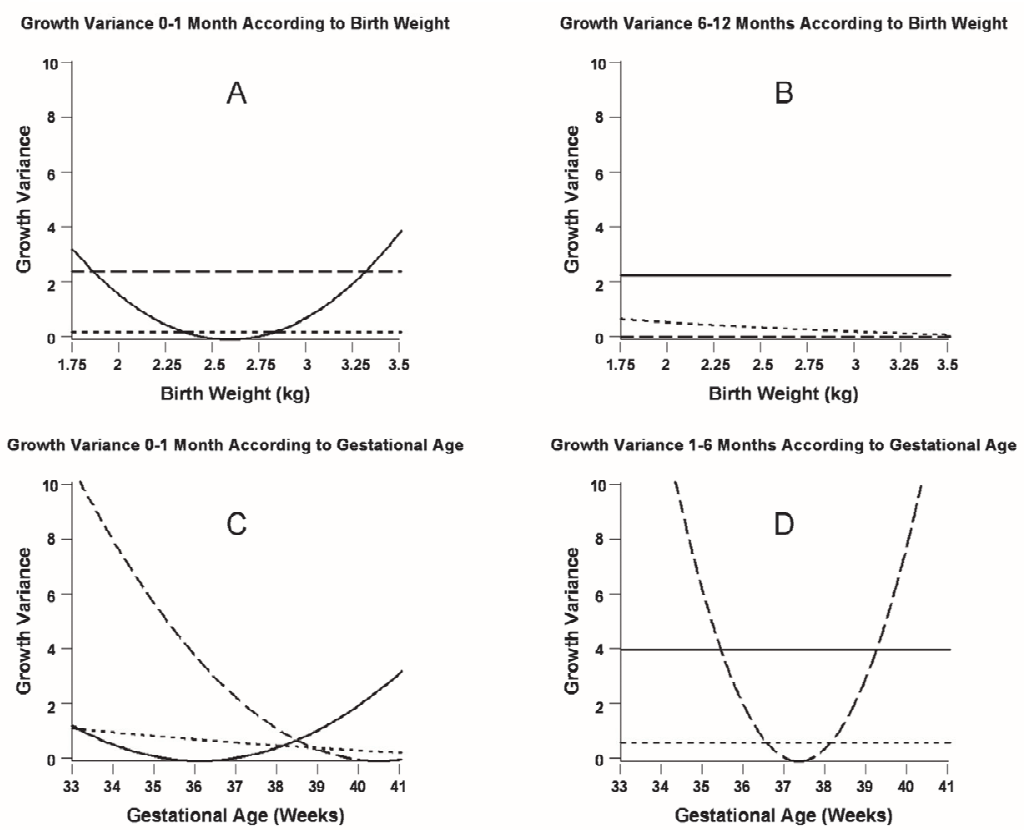

Figure 6.1 Birth weight and gestational age as moderators of growth. Results are given as growth variance and were calculated by using structural equation modeling. - , additive genetic variance $(A)$; - - - , common environmental variance $(C) ;---$, unique environmental variance (E).

These results suggested that, after 1 mo, growth was mainly determined by genetic factors, which is in accordance with earlier studies ${ }^{18-21}$. Our heritability estimates could not be compared directly to any study because, to our knowledge, our study is the first study to examine a change in weight in consecutive age windows including in an early age window (0-1 mo). However, the Fels Longitudinal Study reported a heritability of $66 \%{ }^{20}$ for growth from 0 to 6 mo. Given our results, we speculated that this estimate was a weighted average of 2 age windows of low (0-1 mo) and high (1-6 mo) heritability.

We used postnatal ages adjusted for gestational age to calculate z-scores at the age of 1 mo. In infants with gestational age, $36 \mathrm{wk}$, this may have resulted in negative adjusted ages. 
Because a z-score for a negative age was calculated by using birth weight reference values (because references for negative ages do not exist), this may have been a suboptimal method, and this may have contributed to the unexpected growth pattern from 0 to $1 \mathrm{mo}$, during which period the average z-score decreased (Table 6.1). To avoid this problem, growth can be expressed in grams per kilogram per day, as suggested by Patel et al. ${ }^{34}$. Therefore, we performed an extra analysis with this method of expressing growth and also showed that $\mathrm{AE}$ was the best model from 0 to $1 \mathrm{mo}$, with even lower estimates of $A$ in the ACE model [0\% (95\% Cl: $0 \%, 30 \%)$ ].

To our knowledge, our study is the first study to examine the importance of genetic factors under different circumstances (varying gestational age and birth weight) in early postnatal growth. We speculated that heavier babies were born after more optimal intrauterine conditions, and hence, we expected their postnatal growth to show less dependence on the environment (such as nutrition). We showed that the genetic contribution from 0 to 1 mo was, on average, low but may have been of importance at the birth weight extremes. This may have also indicated that a larger birth weight does not render the infant's growth independent of the environment. As regards gestational age, the optimal gestational age of 37-38 wk of gestation was expected to result in less dependence on the environment. This pattern was clearly shown from 1 to 6 mo but not from 0 to 1 mo when the relative importance of genetic factors only increased from $36 \mathrm{wk}$ of gestation onwards. The interaction analyses may have been underpowered because of our moderate sample size, and therefore, these results should be interpreted and extrapolated with caution.

There is an increased interest in early postnatal growth because it has been linked to adverse cardiometabolic outcomes later in life. Variations in growth may lead to lasting epigenetic differences ${ }^{35,36}$ and/or to a reprogramming of hormonal axes that regulate food intake and metabolism, for example via leptin ${ }^{37}$.

Therefore, the modification of postnatal growth is a potential target for the prevention of adult cardiometabolic disease. Nutritional changes have their effect through the environment and may, therefore, be more successful in age windows in which the environment is of importance; according to our study, this age window would be 0-1 mo. Two recent studies underlined the importance of early postnatal growth compared with later growth with respect to obesity and cardiometabolic risk profiles $^{38,39}$.

Given the results of the varying genetic contribution with increasing or decreasing birth weight and gestational age, interventions aimed at influencing growth from 0 to 1 mo to target long-term health might be most successful in infants of average (twin) birth weight and in infants of low gestational age.

One of the strengths of this study was the assessment of growth over time in 4 consecutive age windows and the inclusion of correction methods for factors that are known to influence growth in this sample. However, the extrapolation of growth studies from twins to singletons should be done with caution. Twins do not show the same growth patterns as singletons, and it is debated whether they show the same 
relations between birth weight and cardiometabolic risk factors ${ }^{40,41}$. Furthermore, twins do not have the same average birth weight and gestational age as singletons, and their prenatal environment is different from that of singletons. Even within a pair of monochorionic twins, the prenatal environment may differ. Although we presented a sample size of several hundreds, it is likely that some of our analyses were underpowered; especially in the age window from 12 to $24 \mathrm{mo}$, in which the least data were available. This was also illustrated by our wide Cls, the sometimes small statistical differences between different models, and because we did not detect a (biologically plausible) $C$ in all windows (Table 6.2). Our limited power should be kept in mind when our results are interpreted. Finally, our data represented growth in weight, and therefore, this study could not clarify whether our models would also be appropriate for growth in length or growth in BMI.

In conclusion, this study provides evidence that genetic factors are not important for postnatal growth before 1 mo of age but are very important after 1 mo of age. Because many (nutritional) interventions are aimed at influencing early postnatal growth, to target long-term health, these interventions may be most successful if implemented shortly after birth. 
Table S6.1: Model fits for birth weight and gestational age as moderators of growth

\begin{tabular}{|c|c|c|c|c|c|c|c|}
\hline & & Model & $-2 \mathrm{LL}$ & $\mathrm{AIC}$ & $\mathrm{df}$ & $\mathrm{P}$ & Comparison \\
\hline \multirow{27}{*}{ 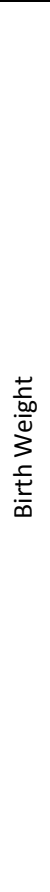 } & 0-1 Month ( $n=110$ Pairs) & & & & & & \\
\hline & 1. full & ACE TUV M & 1266.92 & 842.92 & 212 & & \\
\hline & 2. $U=0$ & ACE TV M & 1267.30 & 841.30 & 213 & 0.54 & 2 vs 1 \\
\hline & 3. $\mathrm{U}=0 \mathrm{~T}=0$ & ACE V M & 1303.85 & 875.85 & 214 & $<0.0001$ & 3 vs 2 \\
\hline & 4. $U=0 \mathrm{~V}=0$ & ACE T M & 1267.30 & 839.30 & 214 & 0.94 & 4 vs 2 \\
\hline & 5. $U=0 \mathrm{~V}=0 \mathrm{C}=0$ & $\mathrm{AE} T \mathrm{M}$ & 1307.48 & 877.48 & 215 & $<0.0001$ & 5 vs 4 \\
\hline & 1-6 Months ( $n=88$ Pairs) & & & & & & \\
\hline & 1. full & ACE TUV M & 1152.16 & 816.16 & 168 & & \\
\hline & 2. $U=0$ & ACE TV M & 1153.73 & 815.73 & 169 & 0.21 & 2 vs 1 \\
\hline & 3. $\mathrm{U}=0 \mathrm{~T}=0$ & ACE V M & 1154.04 & 814.04 & 170 & 0.58 & 3 vs 2 \\
\hline & 4. $U=0 T=0 V=0$ & ACE M & 1154.05 & 812.05 & 171 & 0.91 & 4 vs 3 \\
\hline & 5. $\mathrm{U}=0 \mathrm{~T}=0 \mathrm{~V}=0 \mathrm{C}=0$ & AE M & 1155.19 & 811.19 & 172 & 0.29 & 5 vs 4 \\
\hline & 6. $U=0 \mathrm{~T}=0 \mathrm{~V}=0 \mathrm{C}=0 \mathrm{~A}=0$ & E M & 1275.50 & 929.50 & 173 & $<0.0001$ & 6 vs 5 \\
\hline & 6-12 Months ( $n=140$ Pairs) & & & & & & \\
\hline & 1. full & ACE TUV M & 1557.07 & 1013.07 & 272 & & \\
\hline & 2. $U=0$ & ACE TV M & 1557.08 & 1011.08 & 273 & 0.91 & 2 vs 1 \\
\hline & 3. $U=0 \mathrm{~T}=0$ & ACE V M & 1558.04 & 1010.04 & 274 & 0.33 & 3 vs 2 \\
\hline & 4. $\mathrm{U}=0 \mathrm{~T}=0 \mathrm{~V}=0$ & ACE M & 1564.88 & 1014.88 & 275 & 0.009 & 4 vs 3 \\
\hline & 5. $\mathrm{U}=0 \mathrm{~T}=0 \mathrm{C}=0$ & AE V M & 1559.67 & 1009.67 & 275 & 0.20 & 5 vs 3 \\
\hline & 6. $U=0 \quad T=0 \quad C=0 A=0$ & E V M & 1712.04 & 1160.04 & 276 & $<0.0001$ & 6 vs 5 \\
\hline & 12-24 Months ( $n=65$ Pairs) & & & & & & \\
\hline & 1. full & ACE TUV M & 164.36 & -75.64 & 120 & & \\
\hline & 2. $U=0$ & ACE TV M & 165.85 & -76.15 & 121 & 0.22 & 2 vs 1 \\
\hline & 3. $\mathrm{U}=0 \mathrm{~T}=0$ & ACE V M & 165.90 & -78.10 & 122 & 0.81 & 3 vs 2 \\
\hline & 4. $\mathrm{U}=0 \mathrm{~T}=0 \mathrm{~V}=0$ & ACE M & 166.93 & -79.07 & 123 & 0.31 & 4 vs 3 \\
\hline & 5. $U=0 \mathrm{~T}=0 \mathrm{~V}=0 \mathrm{C}=0$ & AE M & 169.45 & -78.55 & 124 & 0.11 & 5 vs 4 \\
\hline & 6. $U=0 \mathrm{~T}=0 \mathrm{~V}=0 \mathrm{C}=0 \mathrm{~A}=0$ & E M & 241.20 & -8.80 & 125 & $<0.0001$ & 6 vs 5 \\
\hline \multirow{25}{*}{ 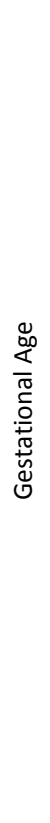 } & 0-1 Month (n=110 Pairs) & & & & & & \\
\hline & 1. full & ACE TUV M & 1276.49 & 852.49 & 212 & & \\
\hline & 2. $U=0$ & ACE TV M & 1286.27 & 860.27 & 213 & 0.002 & 2 vs 1 \\
\hline & 3. $T=0$ & ACE UV M & 1283.56 & 857.56 & 213 & 0.008 & 3 vs 1 \\
\hline & 4. $V=0$ & ACE TU M & 1281.87 & 855.87 & 213 & 0.020 & 4 vs 1 \\
\hline & 1-6 Months ( $n=88$ Pairs) & & & & & & \\
\hline & 1. full & ACE TUV M & 1144.76 & 808.76 & 168 & & \\
\hline & 2. $U=0$ & ACE TV M & 1161.85 & 823.85 & 169 & $<0.0001$ & 2 vs 1 \\
\hline & 3. $T=0$ & ACE UV M & 1147.12 & 809.12 & 169 & 0.13 & 3 vs 1 \\
\hline & 4. $T=0 \mathrm{~V}=0$ & ACE U M & 1147.13 & 807.13 & 170 & 0.90 & 4 vs 3 \\
\hline & 5. $T=0 \mathrm{~V}=0 \mathrm{~A}=0$ & CE U M & 1183.88 & 841.88 & 171 & $<0.0001$ & 5 vs 4 \\
\hline & 6-12 Months ( $n=140$ Pairs) & & & & & & \\
\hline & 1. full & ACE TUV M & 1562.20 & 1018.20 & 272 & & \\
\hline & 2. $U=0$ & ACE TV M & 1563.52 & 1017.52 & 273 & 0.25 & 2 vs 1 \\
\hline & 3. $\mathrm{U}=0 \mathrm{~T}=0$ & ACE V M & 1563.62 & 1015.62 & 274 & 0.75 & 3 vs 2 \\
\hline & 4. $\mathrm{U}=0 \mathrm{~T}=0 \mathrm{~V}=0$ & ACE M & 1566.78 & 1016.78 & 275 & 0.08 & 4 vs 3 \\
\hline & 5. $U=0 \mathrm{~T}=0 \mathrm{~V}=0 \mathrm{C}=0$ & AE M & 1568.75 & 1016.75 & 276 & 0.16 & 5 vs 4 \\
\hline & 5. $U=0 \quad T=0 \quad V=0 C=0 A=0$ & E M & 1712.15 & 1158.15 & 277 & $<0.0001$ & 6 vs 5 \\
\hline & 12-24 Months ( $n=65$ Pairs) & & & & & & \\
\hline & 1. full & ACE TUV M & 164.11 & -75.90 & 120 & & \\
\hline & 2. $U=0$ & ACE TV M & 164.11 & -77.89 & 121 & 0.96 & 2 vs 1 \\
\hline & 3. $\mathrm{U}=0 \mathrm{~T}=0$ & ACE V M & 164.31 & -79.69 & 122 & 0.65 & 3 vs 2 \\
\hline & 4. $\mathrm{U}=0 \mathrm{~T}=0 \mathrm{~V}=0$ & ACE M & 167.00 & -79.00 & 123 & 0.10 & 4 vs 3 \\
\hline & 5. $U=0 T=0 \mathrm{~V}=0 \mathrm{C}=0$ & AE M & 169.31 & -78.69 & 124 & 0.13 & 5 vs 4 \\
\hline & 6. $U=0 \mathrm{~T}=0 \mathrm{~V}=0 \mathrm{C}=0 \mathrm{~A}=0$ & E M & 245.10 & -4.90 & 125 & $<0.0001$ & 6 vs 5 \\
\hline
\end{tabular}


Results are given as model fits (AIC and -2LL) and were calculated by structural equation modeling (SEM). Pvalues were calculated by hierarchical $\chi^{2}$ tests. Best fitting models are shown in bold. Results are adjusted for birth weight and gestational age (0-1 month and 6-12 months); sex, birth weight and gestational age (1-6 months); and chorionicity, sex, gestational diabetes and paternal height (12-24 months). -2LL: Minus two log likelihood. AIC: Akaike's information criterion. M: Moderator; A: Additive genetic effect; C: Common environmental effect; $E$ : Unique environmental effect; $T: M * A$ interaction; $U$ : $M^{*} C$ interaction; $V: M * E$ interaction. 


\section{References}

1. Bergvall N, Iliadou A, Johansson S, de Faire U, Kramer MS, Pawitan Y, Pedersen NL, Lichtenstein P, Cnattingius S. Genetic and shared environmental factors do not confound the association between birth weight and hypertension: a study among Swedish twins. Circulation. 2007;115:2931-2938

2. Hales CN, Barker DJ, Clark PM, Cox LJ, Fall C, Osmond C, Winter PD. Fetal and infant growth and impaired glucose tolerance at age 64. BMJ. 1991;303:1019-1022

3. Leon DA, Lithell HO, Vagero D, Koupilova I, Mohsen R, Berglund L, Lithell UB, McKeigue PM. Reduced fetal growth rate and increased risk of death from ischaemic heart disease: cohort study of 15000 Swedish men and women born 1915-29. BMJ. 1998;317:241-245

4. Singhal A, Lucas A. Early origins of cardiovascular disease: is there a unifying hypothesis? Lancet. 2004;363:1642-1645

5. Hokken-Koelega AC, De Ridder MA, Lemmen RJ, Den Hartog H, De Muinck Keizer-Schrama SM, Drop SL. Children born small for gestational age: do they catch up? Pediatr Res. 1995;38:267-271

6. Ong KK. Size at birth, postnatal growth and risk of obesity. Horm Res. 006;65(suppl 3):65-69

7. Lanigan J, Singhal A. Early nutrition and long-term health: a practical approach. Proc Nutr Soc. 2009;68:422-429

8. Barker DJ, Osmond C, Forsen TJ, Kajantie E, Eriksson JG. Trajectories of growth among children who have coronary events as adults. N Engl J Med. 2005;353:1802-1809

9. Bhargava SK, Sachdev HS, Fall CH, Osmond C, Lakshmy R, Barker DJ, Biswas SK, Ramji S, Prabhakaran D, Reddy KS. Relation of serial changes in childhood body-mass index to impaired glucose tolerance in young adulthood. N Engl J Med. 2004;350:865-875.10. Ekelund U, Ong KK, Linne Y, Neovius M, Brage S, Dunger DB, Wareham NJ, Rossner S. Association of weight gain in infancy and early childhood with metabolic risk in young adults. J Clin Endocrinol Metab. 2007;92:98-103

11. van Houten VA, Steegers EA, Witteman JC, Moll HA, Hofman A, Jaddoe VW. Fetal and postnatal growth and blood pressure at the age of 2 years. The Generation R Study. J Hypertens. 2009;27:1152-1157

12. Hemachandra AH, Howards PP, Furth SL, Klebanoff MA. Birth weight, postnatal growth, and risk for high blood pressure at 7 years of age: results from the Collaborative Perinatal Project. Pediatrics. 2007;119:e1264-1270

13. Mericq V, Ong KK, Bazaes R, Pena V, Avila A, Salazar T, Soto N, Iniguez G, Dunger DB. Longitudinal changes in insulin sensitivity and secretion from birth to age three years in small- and appropriate -forgestational-age children. Diabetologia. 2005;48:2609-2614

14. Monteiro PO, Victora CG. Rapid growth in infancy and childhood and obesity in later life-a systematic review. Obes Rev. 2005;6:143-154

15. Singhal A, Fewtrell M, Cole TJ, Lucas A. Low nutrient intake and early growth for later insulin resistance in adolescents born preterm. Lancet. 2003;361:1089-1097

16. Stettler N, Stallings VA, Troxel AB, Zhao J, Schinnar R, Nelson SE, Ziegler EE, Strom BL. Weight gain in the first week of life and overweight in adulthood: a cohort study of European American subjects fed infant formula. Circulation. 2005;111:1897-1903

17. Singhal A, Cole TJ, Fewtrell M, Deanfield J, Lucas A. Is slower early growth beneficial for long-term cardiovascular health? Circulation. 2004;109:1108-1113

18. Levine RS, Hennekens $\mathrm{CH}$, Jesse MJ. Genetic variance of weight and length in infant twins. Am J Epidemiol. 1987;126:929-935

19. Dubois L, Girard M, Girard A, Tremblay R, Boivin M, Perusse D. Genetic and environmental influences on body size in early childhood: a twin birth-cohort study. Twin Res Hum Genet. 2007;10:479-485

20. Demerath EW, Choh AC, Czerwinski SA, Lee M, Sun SS, Chumlea WC, Duren D, Sherwood RJ, Blangero J, Towne B, et al. Genetic and environmental influences on infant weight and weight change: the Fels Longitudinal Study. Am J Hum Biol. 2007;19:692-702

21. van Dommelen P, de Gunst MC, van der Vaart AW, Boomsma DI. Genetic study of the height and weight process during infancy. Twin Res. 2004;7:607-616

22. Towne B, Guo S, Roche AF, Siervogel RM. Genetic analysis of patterns of growth in infant recumbent length. Hum Biol. 1993;65:977-989

23. Baker LA, Reynolds C, Phelps E. Biometrical analysis of individual growth curves. Behav Genet. 1992; 22:253-264 
24. Kahn B, Lumey LH, Zybert PA, Lorenz JM, Cleary-Goldman J, D'Alton ME, Robinson JN. Prospective risk of fetal death in singleton, twin, and triplet gestations: implications for practice. Obstet Gynecol. 2003; 102:685-692

25. Sairam S, Costeloe K, Thilaganathan B. Prospective risk of stillbirth in multiple-gestation pregnancies: a population-based analysis. Obstet Gynecol. 2002;100:638-641

26. Loos RJ, Beunen G, Fagard R, Derom C, Vlietinck R. The influence of zygosity and chorion type on fat distribution in young adult twins consequences for twin studies. Twin Res. 2001;4:356-364

27. Cammu H, Martens G, Landuyt J, de Koen K, Defoort P. Perinatale activiteiten in Vlaanderen 2006. [Perinatal activities in Flanders.] Brussels, Belgium, SPE: 2007 (in Dutch)

28. Roelants M, Hauspie R, Hoppenbrouwers K. References for growth and pubertal development from birth to 21 years in Flanders, Belgium. Ann Hum Biol. 2009;36:680-694

29. Touwslager RN, Gielen M, Derom C, Mulder AL, Gerver WJ, Zimmermann LJ, Houben AJ, Stehouwer $\mathrm{CD}$, Vlietinck R, Loos RJ, et al. Determinants of infant growth in four age windows: a twin study. $J$ Pediatr. 2011;158:566-572.e2

30. Neale MCCL. Methodology for genetic studies of twins and families. Dordrecht, Netherlands: Kluwer Academic, 1992

31. Purcell S. Variance components models for gene-environment interaction in twin analysis. Twin Res. 2002;5:554-571

32. Neale MC, Boker SM, Xie G, Maes HH. Mx: statistical modeling. $6^{\text {th }}$ ed. Richmond, VA: Department of Psychiatry, Virginia Commonwealth University, 2003. (VCU Box 900126, Richmond, VA 23298.)

33. GenomEUtwin Mx script library, GenomEUtwin project. Available from: http://www.psy.vu.nl/mxbib (cited 13 July 2010)

34. Patel AL, Engstrom JL, Meier PP, Jegier BJ, Kimura RE. Calculating postnatal growth velocity in very low birth weight (VLBW) premature infants. J Perinatol. 2009;29:618-622

35. Heijmans BT, Tobi EW, Stein AD, Putter H, Blauw GJ, Susser ES, Slagboom PE, Lumey LH. Persistent epigenetic differences associated with prenatal exposure to famine in humans. Proc Natl Acad Sci USA. 2008;105:17046-17049

36. Tosh DN, Fu Q, Callaway CW, McKnight RA, McMillen IC, Ross MG, Lane RH, Desai M. Epigenetics of programmed obesity: alteration in IUGR rat hepatic IGF1 mRNA expression and histone structure in rapid vs. delayed postnatal catch-up growth. Am J Physiol Gastrointest Liver Physiol. 2010;299: G1023-1029

37. Plagemann A. Perinatal programming and functional teratogenesis: impact on body weight regulation and obesity. Physiol Behav. 2005;86:661-668

38. Elks CE, Loos RJ, Sharp SJ, Langenberg C, Ring SM, Timpson NJ, Ness AR, Davey Smith G, Dunger DB, Wareham NJ, et al. Genetic markers of adult obesity risk are associated with greater early infancy weight gain and growth. PLoS Med. 2010;7:e1000284

39. Leunissen RW, Kerkhof GF, Stijnen T, Hokken-Koelega A. Timing and tempo of first-year rapid growth in relation to cardiovascular and metabolic risk profile in early adulthood. JAMA. 2009;301:2234-2242

40. Beardsall K, Ong KK, Murphy N, Ahmed ML, Zhao JH, Peeters MW, Dunger DB. Heritability of childhood weight gain from birth and risk markers for adult metabolic disease in prepubertal twins. J Clin Endocrinol Metab. 2009;94:3708-3713

41. Christensen K,Wienke A, Skytthe A, Holm NV, Vaupel JW, Yashin Al. Cardiovascular mortality in twins and the fetal origins hypothesis. Twin Res. 2001;4:344-349 


\section{Chapter 7}

Genetic and environmental factors in associations between infant growth and adult cardiometabolic risk profile in twins

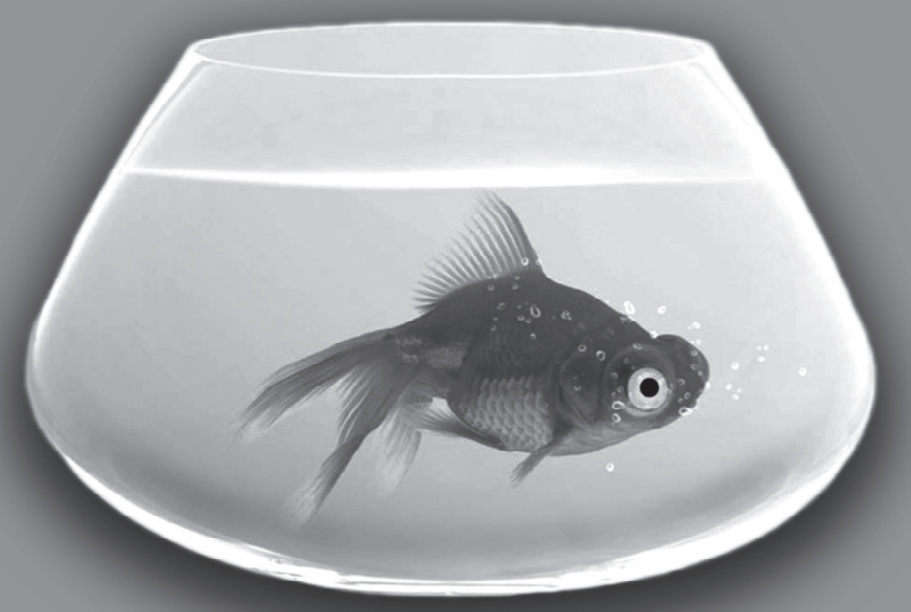

RNH Touwslager

M Gielen

ALM Mulder

WJM Gerver

LJ Zimmermann

PC Dagnelie

AJHM Houben

CDA Stehouwer

C Derom

R Vlietinck

RJF Loos

MP Zeegers

The American Journal of Clinical Nutrition 2013;98:994-1001 


\section{Abstract}

\section{Background}

Accelerated infant growth is associated with an altered, mostly adverse adult cardiometabolic risk profile. The importance of genetic and environmental factors to these associations is unclear.

\section{Objective}

The objective was to examine the importance of genetic and environmental factors in the associations between infant growth and adult cardiometabolic risk factors (anthropometrics, lipids, insulin sensitivity, leptin, blood pressure, and fibrinogen) in twins.

\section{Design}

Cardiometabolic risk factors were assessed in 240 twin pairs (aged 18-34 y) from the East Flanders Prospective Twin Survey. Infant growth was defined as change in weight $z$-score. We regressed intra-pair differences in growth during 4 growth windows (0-1, 1-6, 6-12, and 12-24 mo) against intra-pair differences in the risk factors in monozygotic and dizygotic twins separately.

\section{Results}

Within monozygotic twin pairs only, associations between infant growth and most adult lipids, glucose, leptin, and blood pressure (e.g. systolic blood pressure: $b=5.95$ $\mathrm{mm} \mathrm{Hg}$ per change in $\mathrm{z}$-score, $\mathrm{P}=0.01$ in monozygotic twins; $\mathrm{b}=21.64, \mathrm{P}=0.82$ in dizygotic twins from 12 to $24 \mathrm{mo}$ ) were found. Within dizygotic twin pairs only, associations between growth and triglycerides and fibrinogen (eg, fibrinogen: $b=0.07$ In $\mathrm{mg} / \mathrm{dl}$ per change in $\mathrm{z}$-score, $\mathrm{P}=0.31$ in monozygotic twins; $\mathrm{b}=0.79, \mathrm{P}=0.01$ in dizygotic twins from 0 to $1 \mathrm{mo}$ ) were identified. Most associations showed a detrimental effect of accelerated growth, but beneficial associations were also identified (eg, total-to-high-density-lipoprotein cholesterol ratio: $b=20.22$ per change in z-score from 1 to $6 \mathrm{mo}, \mathrm{P}=0.008$ in monozygotic twins).

\section{Conclusion}

Our data showed that environmental factors play a role in the associations between infant growth and most adult lipids, glucose, leptin, and blood pressure, whereas genetic factors are involved regarding triglycerides and fibrinogen. 


\section{Introduction}

Cardiovascular disease is a major cause of mortality worldwide ${ }^{1}$. The incidence of cardiovascular disease is increased in individuals with an adverse cardiometabolic risk profile, which includes obesity, an unfavorable lipid profile, insulin resistance, and high blood pressure. It has become clear that besides the importance of lifestyle, factors in early life are also involved in the development of this risk profile. Low birth weight is related to an adverse cardiometabolic risk profile and cardiovascular disease later in life $\mathrm{e}^{2-4}$. In addition, subsequent accelerated postnatal growth has been proposed as a mechanism that links low birth weight to an unfavorable cardiometabolic risk profile ${ }^{5,6}$. Growth during infancy (mostly defined as $0-2$ y) has been positively associated with obesity $^{7}$, hypertension ${ }^{8}$, an adverse cardiometabolic risk profile ${ }^{9}$, and metabolic syndrome ${ }^{10}$. On the contrary, there is also some evidence that slow infant growth is associated with certain harmful cardiometabolic outcomes in adulthood, e.g. regarding lipids $^{11,12}$, insulin resistance ${ }^{13,14}$, and stroke ${ }^{15}$.

Importantly, to regard "infancy" as one growth window from 0 to 2 y may be too broad a definition. For example, it was reported that the first 3 mo of life may be most important for the development of an adverse cardiometabolic risk profile ${ }^{16}$. In addition, accelerated growth in the first $2 \mathrm{wk}$ of life is related to adult endothelial dysfunction, a precursor of atherosclerosis ${ }^{17}$. However, only a minority of studies include growth windows, and the investigation of an early growth window ( $<3 \mathrm{mo})$ is especially uncommon ${ }^{13,16,18,19}$.

Twin or family data regarding genetic or environmental importance in the relation between early postnatal growth and adult cardiometabolic risk profile are scarce. Beardsall et al. ${ }^{20}$ showed that genetic factors associated with postnatal growth from birth are also likely to contribute to insulin resistance and obesity in prepubertal twins. In contrast, Skidmore et al. ${ }^{21,22}$ found no evidence of a genetic mediation of the relation between growth from birth and adult insulin resistance and lipids in female twins. Importantly, neither of these studies has specifically analyzed infant growth.

In the present study, we examine the importance of genetic and environmental factors in the associations between infant growth in different growth windows $(0-1,1-6$, 6-12, and 12-24 mo) and adult cardiometabolic risk factors (anthropometrics, blood pressure, insulin sensitivity, lipids, leptin, and fibrinogen).

\section{Subjects and methods}

\section{Participants}

Data were obtained from the East Flanders Prospective Twin Survey, which is a population-based study that has registered all twins born in the Belgian province of East Flanders since 1964 . We used a subsample that was collected during a prenatal 
programming study performed between February 1997 and April 2000. Details of the selection process were previously reported ${ }^{23}$. In short, 803 twin pairs aged 18-34 y were contacted and invited for measurements of cardiometabolic status; 424 (44 incomplete) twin pairs agreed to participate. A total of 522 participants ( 240 complete pairs) had data available on infant growth. We excluded participants with type 1 diabetes mellitus $(n=2)$, adrenogenital syndrome $(n=1)$, liver disease $(n=1)$, or thyroid disease $(n=5)$ and participants using vasoactive $(n=2)$, lipid-lowering $(n=1)$, or antihypertensive medication $(n=16)$. All participants gave informed consent, and ethical approval was given by the Ethics Committee of the Faculty of Medicine of the Katholieke Universiteit Leuven.

\section{Outcome variables}

\section{Anthropometric measures}

Standing height, weight, and hip and waist circumference were measured as described in detail before ${ }^{24}$. BMl was calculated as body mass (in $\mathrm{kg}$ ) divided by squared height (in $\mathrm{m}$ ). The waist-to-hip ratio was calculated by dividing waist circumference by hip circumference. Skinfold thicknesses were measured in duplicate, by use of a Harpenden skin fold caliper (British Indicators), to the nearest $0.1 \mathrm{~mm}$. Measurements were taken at the biceps, triceps, subscapular, and suprailiac, and these measurements were summed as a measure of overall subcutaneous fat. Lean body mass was estimated by use of bioelectrical impedance after an overnight fast in normally hydrated condition (BIA310; Biodynamics). Fat mass was calculated by subtracting lean body mass from total body mass and expressed as a percentage of total body mass.

\section{Blood pressure}

Ambulatory blood pressure was measured by using the SpaceLabs 90207 device (SpaceLabs), as previously described in detail ${ }^{23}$. In short, the twins applied the monitor at home on the non-dominant arm. They were instructed to perform normal activity, but not to engage in vigorous exercise or contact sports. The recordings were taken every 15 min during daytime and every 30 min during nighttime, for $24 \mathrm{~h}$ in total, and the obtained values for systolic and diastolic blood pressure were averaged to represent ambulatory blood pressure.

\section{Insulin sensitivity}

Fasting blood samples were drawn; plasma glucose was measured by using the hexokinase method on an auto-analyzer (AU600; Olympus). Plasma insulin was determined with a micro particle enzyme immunoassay (Axsym; Abbott Laboratories). Insulin sensitivity was calculated with the quantitative insulin sensitivity check index ${ }^{25}$. 
Insulin-like growth factor binding protein-1 was measured by radioimmunoassay ${ }^{26}$. Intact proinsulin was measured by ELISA (Mercodia).

\section{Lipids}

Total cholesterol, HDL cholesterol, and triglycerides were measured in fasting blood samples on an auto-analyzer (AU600). LDL cholesterol was calculated with the Friedewald formula ${ }^{27}$. Free fatty acids were measured by use of a colorimetric assay with the optical density measured at $550 \mathrm{~nm}$.

\section{Leptin and fibrinogen}

Leptin and fibrinogen were analyzed on fasting blood samples. Plasma leptin was measured with an immunoradiometric assay in a coated tube (Diagnostic Systems Laboratories). Fibrinogen was determined by measuring the clotting time with thrombin in a citrate tube (Electra $1600 \mathrm{C}$, Ortho Diagnostic Systems).

\section{Growth in infancy}

Growth (weight gain) was defined as change in body weight z-score and was calculated for 4 growth windows: from birth to $1 \mathrm{mo}$, from 1 to $6 \mathrm{mo}$, from 6 to $12 \mathrm{mo}$, and from 12 to 24 mo. The growth data were collected by means of growth charts from infant and child welfare centers ("Kind en Gezin": Child and Family). These centers offer medical examination throughout infancy, including weight recording. Parents and infants voluntarily visited after regular invitations. The availability of growth data differed for the 4 growth windows, which resulted in different subsamples in each growth window. Birth weight z-scores were constructed with Flemish sex-specific singleton reference data per week of gestation from the Study Center for Perinatal Epidemiology in Brussels (RNHT, personal written communication, 2011) ${ }^{28}$. Postnatal z-scores were based on postnatal ages corrected for gestational age and were calculated with the singleton Flemish weight references $2004^{29}$. Singleton reference data were used, because these represent normal growth in the Belgian population. Individuals were included in the analysis if they had 2 measurements available in the growth windows $0.04-0.12,0.4-0.6,0.75-1.25$, and 1.5-2.5 y. Linear interpolation was used to construct values at exactly $4 \mathrm{wk}$ and at 6,12 , and 24 mo of age (corrected for gestational age).

\section{Potential confounders}

At birth, weight, gestational age, sex, zygosity, and chorionicity were collected prospectively. Zygosity was determined with sequential analysis based on sex, fetal membranes, blood groups, placental alkaline phosphatase, and DNA marker analysis. When the twins were adults, the parents of the twins completed questionnaires retrospectively to collect information on parental education level (highest level was 
used in the analysis). Education level was operationalized according to the Belgian education system ${ }^{25}$ : no education or primary school, lower secondary education, higher secondary education, and tertiary education. The twins also completed questionnaires as adults to obtain family history of cardiovascular disease, smoking, alcohol use, and physical activity. A positive family history of cardiovascular disease was defined as the occurrence of cardiac disease, diabetes mellitus, peripheral vascular disease, or blood pressure abnormalities in a first-degree relative (parent, sibling, or child) and was expressed dichotomously. Current smoking was expressed as cigarettes per day and current alcohol use was analyzed as units per week. Regarding habitual physical activity, the twins rated themselves on a 10-point scale after brief instructions, where 1 represented very little and 10 very intensive physical activity. For example, a person with deskbound work, who goes to work by foot and works in the garden in his spare time, was instructed to award himself 4-5 points.

\section{Statistical analysis}

In the descriptive analysis, for continuous variables, differences between monozygotic and dizygotic twins within the growth windows were calculated by use of the test or the Wilcoxon's rank-sum test, when appropriate. The $x_{2}$ test was used to compare frequencies between monozygotic and dizygotic twins. First, the twins were regarded as individuals (instead of pairs). We used multivariable multilevel regression analysis to study the association between infant growth and the outcome variables. We used a random intercept model, taking into account the fact that the individuals are related. The variance-covariance structure of dizygotic (always dichorionic), monozygoticdichorionic, and monozygotic-monochorionic twins was allowed to differ, because chorionicity is known to affect birth weight and possibly postnatal growth from 12 to $24 \mathrm{mo}^{30,31}$. Two models were constructed: 1 ) basic model, only adjusting for sex and age, and 2) multivariable model, also including the potential confounders and other cardiometabolic risk factors that were not directly studied. The latter cardiometabolic risk factors were based on the National Cholesterol Education Program criteria for metabolic syndrome and included waist circumference, (ambulatory) systolic blood pressure, fasting glucose, HDL cholesterol, and triglycerides ${ }^{32}$. In the second model, the anthropometric variables were not adjusted for waist circumference, the blood pressure variables were not adjusted for ambulatory systolic blood pressure, the insulin sensitivity variables were not adjusted for fasting glucose, and the lipid variables were not adjusted for HDL cholesterol and triglycerides. The analyses were further adjusted for baseline weight z-score in the specific growth window to prevent estimates to be biased toward regression to the mean.

As a second step, the same-sex twins were studied as pairs with linear regression analysis. We analyzed the association between intra-pair difference in infant growth and intra-pair difference in the outcome variable for monozygotic and dizygotic twins separately. Because monozygotic twins share $\sim 100 \%$ of their genes, any association 
observed within monozygotic pairs indicates environmental influences on the association. Dizygotic twins share on average $50 \%$ of their genes, and therefore intrapair analysis in dizygotic twins is still partly confounded by genetic effects. The difference scores were calculated as first-born twin minus second-born twin (this yields the same results as subtracting the fastest from the slowest growing twin), and the regression line was restrained to pass through the origin ${ }^{33}$. In case of a significant association in monozygotic or dizygotic twins, we tested whether the difference between the monozygotic and dizygotic regression coefficient was significant by introducing an interaction term "zygosity*growth" to the model. Outcome variables were log transformed to ensure homoscedasticity and a normal distribution of the error terms, if necessary. All individuals used in the analysis had complete data for all variables. A P value $<0.05$ was considered statistically significant. The analyses were performed in SAS 9.2 with SAS Enterprise Guide 4 (SAS Institute).

\section{Results}

On average, the twins showed a decrease in weight z-score from 0 to $1 \mathrm{mo}$, a strong increase from 1 to $6 \mathrm{mo}$, and little change up to the age of $24 \mathrm{mo}$ (Table 7.1). The average age at which cardiometabolic measurements were taken ranged from 23.5 to 24.2 y in monozygotic twins and from 22.7 to 25.6 y in dizygotic twins in the 4 growth windows.

\section{Twins as "individuals"}

Results from the basic model and the multivariable model are shown in Table 7.2. Two significant associations were observed in the basic model: infant growth from 0 to 1 mo was inversely associated with the log-transformed (In) adult sum of 4 skinfolds [regression coefficient $(b)=20.09$ per $z$-score weight change, $\mathrm{P}=0.02$ ] (Table 7.2). This means that one $z$-score growth during the first month of life was associated with a decrease in adult sum of 4 skinfolds of 0.09 (log-transformed scale). Second, infant growth from 0 to 1 mo was inversely associated with In(total-to-HDL cholesterol ratio) $(b=-0.05, \mathrm{P}=0.04)$. In the multivariable model, growth from 0 to $1 \mathrm{mo}$ and growth from 1 to 6 mo were inversely associated with $\ln$ (total-to-HDL cholesterol ratio) in adulthood ( $b=-0.06, \mathrm{P}=0.01$, and $b=-0.07, \mathrm{P}=0.006$, respectively) (Table 7.2). Furthermore, growth from 0 to $1 \mathrm{mo}$ and from 1 to 6 mo showed a positive association with In(fibrinogen) ( $b=0.06, \mathrm{P}=0.04$, and $b=0.05, \mathrm{P}=0.04$, respectively). Infant growth from 1 to 6 mo was inversely associated with $\ln$ (leptin) $(b=-0.28, \mathrm{P}<0.0001)$. From 12 to $24 \mathrm{mo}$, a positive association between growth and ambulatory systolic blood pressure was identified $(b=2.82, \mathrm{P}=0.03)$. 


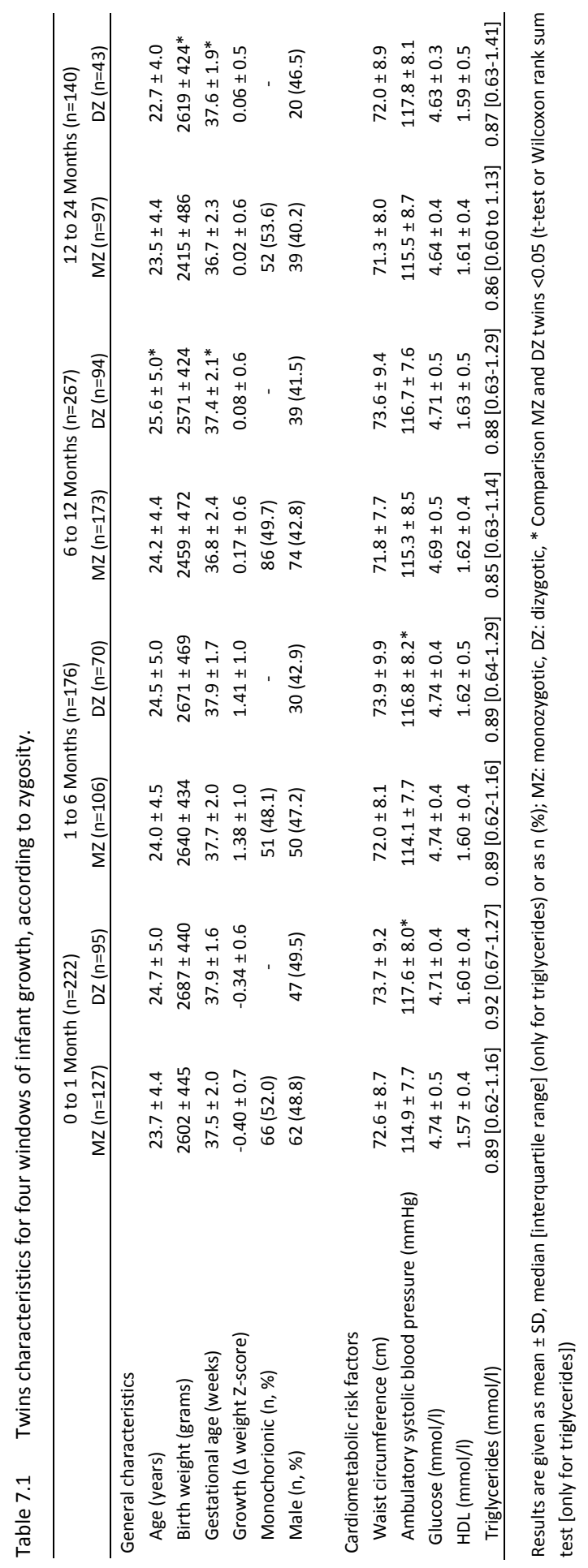




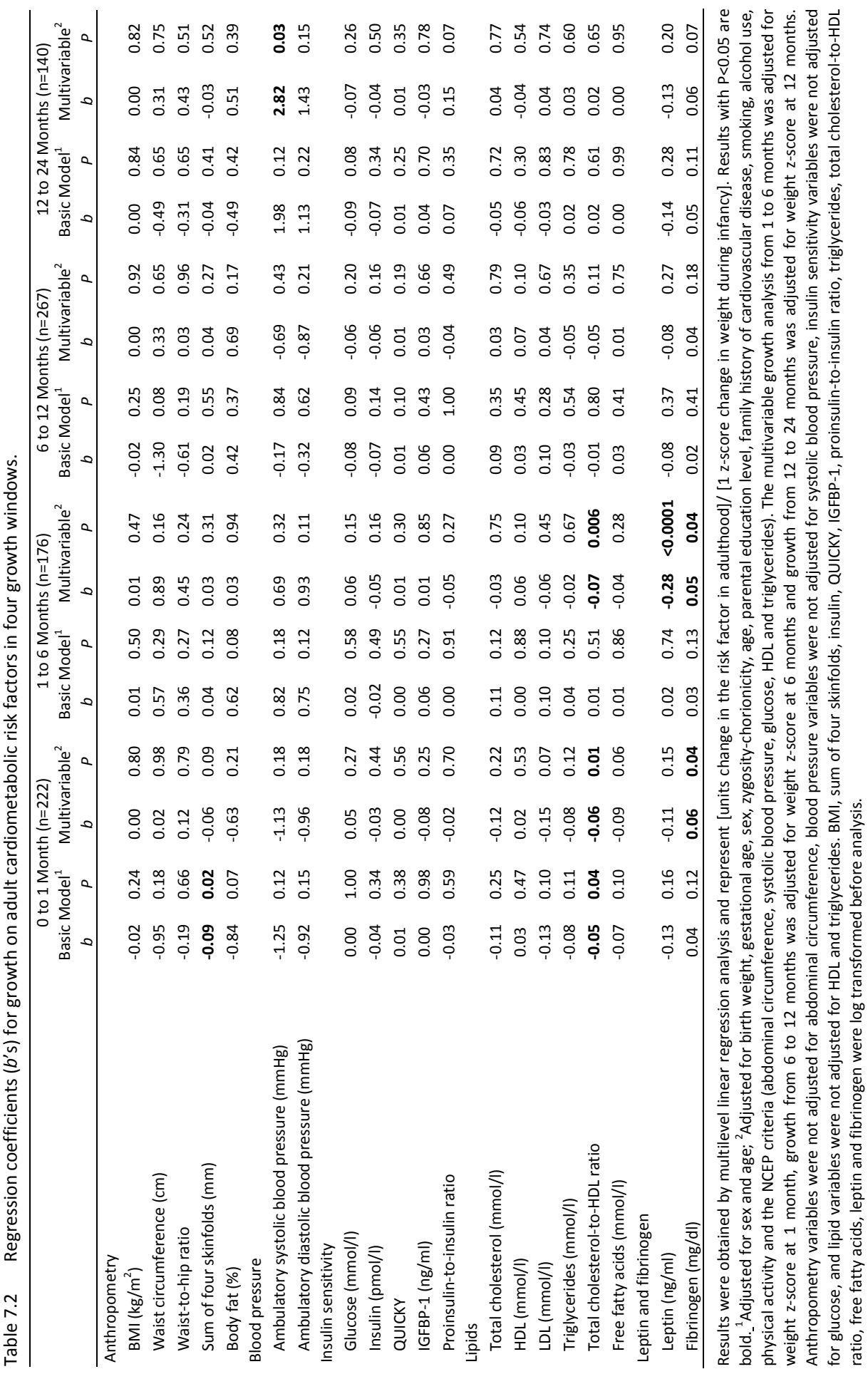




\section{Pairwise analysis}

When the twins were analyzed as pairs, intra-pair differences in growth from 0 to 1 mo were inversely associated with intra-pair differences in adult total cholesterol, but only in monozygotic twins ( $b=-0.46$ difference in $\mathrm{mmol} / /$ per intra-pair difference in z-score, $\mathrm{P}=0.04$ ) (Table 7.3), indicating a role for environmental factors in this association. The interpretation of this result is that, on average, when the first-born monozygotic twin had a 1-SD faster growth than the second-born twin from 0 to $1 \mathrm{mo}$, this first-born twin had a $0.46-\mathrm{mmol} / /$ lower total cholesterol concentration in adulthood. Growth from 0 to 1 mo was positively associated with In(triglycerides) in dizygotic twins $(b=0.68, \mathrm{P}=0.01)$ but not in monozygotic twins, suggesting a role for genetic factors in this association. Growth from 0 to 1 mo was positively associated with $\ln$ (fibrinogen) in dizygotic twins only $(b=0.79, \mathrm{P}=0.01)$.

For growth from 1 to $6 \mathrm{mo}$, a positive association with glucose was found in monozygotic twins $(b=0.43, \mathrm{P}=0.03)$. Furthermore, intra-pair differences in growth were again positively associated with intra-pair differences in $\ln$ (triglycerides) $(b=0.22$, $\mathrm{P}=0.04$ ) in dizygotic twins and negatively with intra-pair differences in $\ln$ (total -to-HDL cholesterol ratio) ( $b=-0.22, \mathrm{P}=0.008)$ in monozygotic twins. Growth from 1 to 6 mo was finally inversely associated with $\operatorname{In}($ leptin) $(b=-0.89, \mathrm{P}=0.02)$ but only in monozygotic twins.

Intra-pair difference in growth from 12 to 24 mo was positively associated with both intra-pair difference in ambulatory systolic and diastolic blood pressure within monozygotic twins ( $b=5.95, \mathrm{P}=0.01$ and $b=6.80, \mathrm{P}=0.01$, respectively) but not within dizygotic twins. Moreover, growth in this growth window was positively associated with adult $\ln$ (free fatty acids) $(b=0.67, \mathrm{P}=0.02)$ but only in monozygotic twins. Finally, in dizygotic twins only, growth was again positively associated with adult $\ln$ (fibrinogen) $(b=0.08, \mathrm{P}=0.04)$.

By including the interaction terms, we confirmed that the regression coefficients differed between monozygotic and dizygotic twins in the association between growth and triglycerides in the growth window from 0 to $1 \mathrm{mo}(P$-interaction=0.04) and in the association between growth and ambulatory diastolic blood pressure in the growth window from 12 to 24 mo (Pinteraction=0.02). With regard to fibrinogen, additional adjustment for chorionicity ${ }^{34}$ in the intra-pair analysis did not change the results (data not shown). 


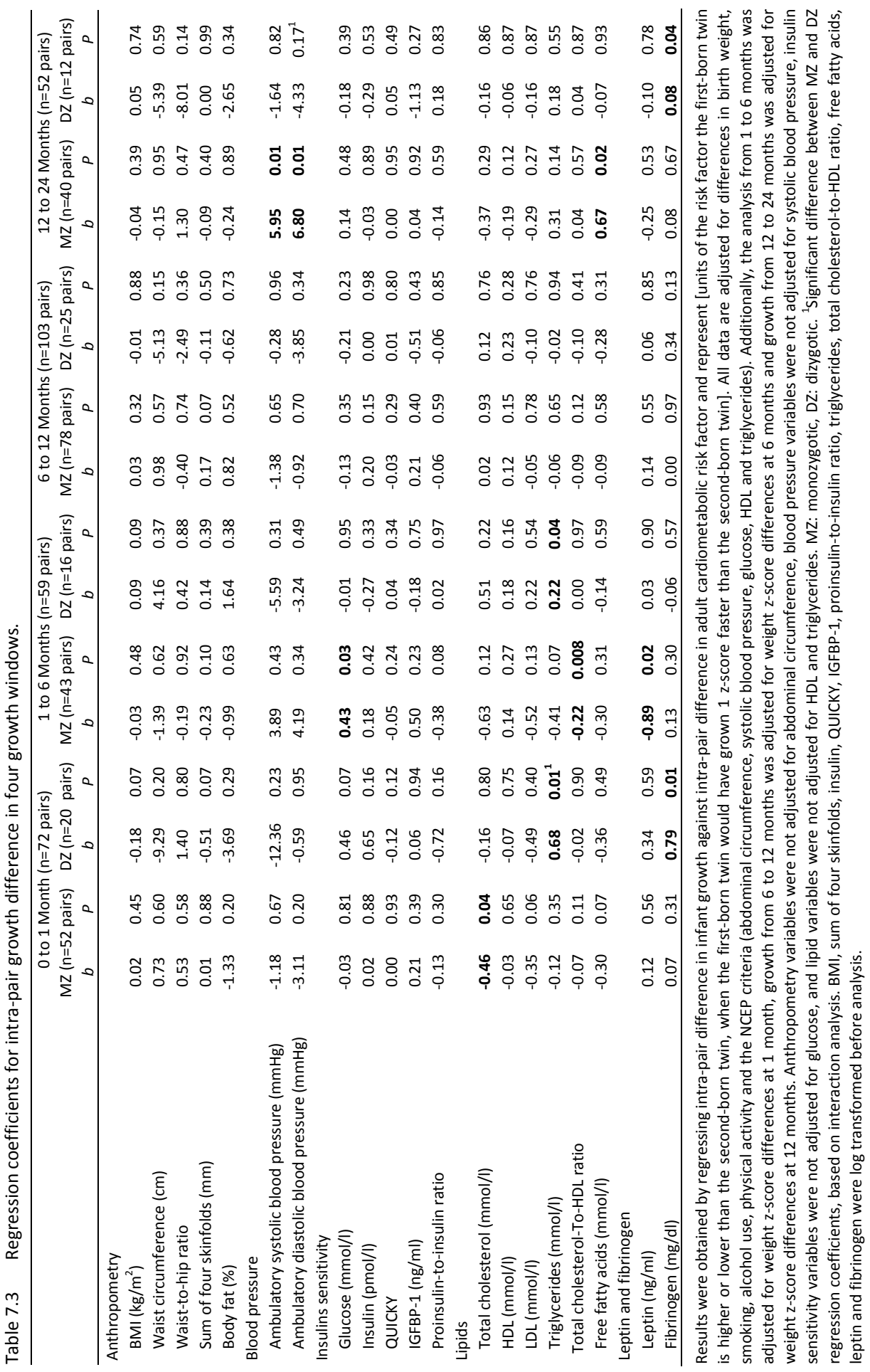




\section{Discussion}

In the present study, we investigated the importance of genetic and environmental factors in the associations between infant growth and adult cardiometabolic risk factors. From pairwise analysis, our data showed associations in monozygotic twins between infant growth and adult blood pressure, insulin sensitivity, most lipids, and leptin, pointing to environmental factors as potential explanations. In contrast, the associations between infant growth and adult triglycerides and fibrinogen were found only in dizygotic twins, which indicate that genetic factors were likely to be important. Before pair wise analysis, when the twins were regarded as individuals, we found a diverse pattern of associations among the different growth windows. We identified associations between infant growth before 6 mo and adult lipids, fibrinogen, and leptin, while the association between infant growth and adult blood pressure was only apparent in the second year of life. With regard to blood pressure, our data are consistent with previous studies, which have also shown that infant growth is positively related to adult blood pressure ${ }^{16,35}$. In addition, fibrinogen, of which high concentrations indicate a prothrombotic state and are related to cardiovascular disease, was positively associated with growth in the first 6 mo of life, unlike an earlier study $^{36}$. However, we also identified potentially advantageous associations with (accelerated) infant growth, as we found inverse associations between infant growth before the age of $6 \mathrm{mo}$ and adult total-to-HDL cholesterol ratio. Although several studies have identified a detrimental effect of (accelerated) infant growth on adult lipids ${ }^{16,19}$, there is also evidence for a beneficial effect of accelerated infant growth, to which we now add another study ${ }^{11,12}$.

Finally, with respect to the association between infant growth and adult leptin, we found the direction of effect we identified (faster infant growth being associated with lower adult leptin) surprising, because a high leptin concentration has been implicated in hypertension, endothelial dysfunction, and the development of atherosclerosis ${ }^{37}$. Adolescent leptin was not related to infant growth in a previous study ${ }^{18}$.

Although the body of evidence supporting a harmful effect of accelerated infant growth probably outweighs the evidence for a beneficial effect, the conflicting evidence in the literature was reflected in our data. We mainly found detrimental effects but also showed beneficial effects of growth on leptin and lipids, which further stresses that we need more data to come to a definite potential future public health advice. We therefore recommend large studies with multiple cardiometabolic outcomes in the same individuals that would use subsequent infant growth windows as predicting variables.

In our within-pair analysis, we predominantly found associations in which environmental factors are likely to be important, although there was a clear indication for a role for genetic factors in 2 associations. First, with regard to lipids, we identified relationships between intra-pair difference in infant growth and intra-pair difference in adult cholesterol, total-to-HDL cholesterol ratio, and free fatty acids. These 
associations were found only in monozygotic twins, indicating a role for environmental factors. In contrast, adult triglycerides were related to growth during the first 2 growth windows in dizygotic twins only, indicating genetic involvement in this association. Apparently, different factors underlie the associations between infant growth and the different components of the adult lipid profile. An earlier study on this subject did not show evidence for a genetic mediation of the association between change in size from birth and adult lipids ${ }^{22}$. Next, we found evidence for a role for environmental factors in the associations between infant growth and adult systolic and diastolic blood pressure, leptin, and glucose. Our finding regarding glucose is in line with a study by Skidmore et al. $^{21}$, who used weight gain from birth to adulthood as the growth variable, whereas Beardsall et al. ${ }^{20}$ concluded there were shared genetic factors between weight gain from birth and insulin in prepubertal twins. Finally, our data suggested a role for genetic factors in the association between infant growth and fibrinogen.

Although we realize that growth during childhood is also linked to later cardiovascular disease $\mathrm{e}^{38}$, one of the strengths of this study is that we distinctively combine studying the association between consecutive growth windows during the critical period of infancy and adult cardiometabolic risk factors with analyses on how genetic and environmental factors underlie such associations. Second, we adjusted the results for factors that are known to influence growth and cardiometabolic risk profile, the importance of which was clearly illustrated by the observed differences between our basic and multivariable models. By adjusting for the individual scores on the NCEP criteria for metabolic syndrome, we chose to regard each risk factor as a separate entity rather than part of a syndrome and were able to view the associations independently of adult characteristics. Finally, we had an extensive combination of cardiometabolic risk factors available for analysis within the same individuals.

As a limitation of our study, extrapolation of growth studies from twins to singletons should be done with caution. Twins do not have the same prenatal environment, average birth weight, gestational age, and growth patterns as singletons, and it is debated whether they show the same relationships between birth weight and cardiometabolic risk factors $^{20,39}$. Second, although we were able to reproduce several well-known associations, it is likely that some of our analyses were underpowered.

Finally, in reality many traits and associations will be subject to gene-environment interactions. Nevertheless, our twin data are very well suited to explore the general importance of genetic compared with environmental factors.

Future clinical research should test what is optimal infant growth in terms of beneficial effects on long-term cardiometabolic health. Moreover, if these studies would aim to slow down growth, they should ensure that the intervention in infant growth does not have a negative impact on other beneficial outcomes linked to accelerated growth, such as the associations we identified regarding lipids and leptin, as well as better resistance to infections, increased final height, and improved cognitive development ${ }^{40}$. In summary, our data suggest that environmental factors are involved in the associations between infant growth and adult blood pressure, insulin sensitivity, most 
Chapter 7

lipids, and leptin, whereas genetic factors possibly play a role with regard to triglycerides and fibrinogen. 


\section{References}

1. Yusuf S, Reddy S, Ounpuu S, Anand S. Global burden of cardiovascular diseases: part I: general considerations, the epidemiologic transition, risk factors, and impact of urbanization. Circulation. 2001;104:2746-2753

2. Barker DJ, Osmond C, Golding J, Kuh D, Wadsworth ME. Growth in utero, blood pressure in childhood and adult life, and mortality from cardiovascular disease. BMJ. 1989;298:564-567

3. Grunnet L, Vielwerth S, Vaag A, Poulsen P. Birth weight is nongenetically associated with glucose intolerance in elderly twins, independent of adult obesity. J Intern Med. 2007;262: 96-103

4. Poulter NR, Chang CL, MacGregor AJ, Snieder H, Spector TD. Association between birth weight and adult blood pressure in twins: historical cohort study. BMJ. 1999;319:1330-1333

5. Hokken-Koelega AC, De Ridder MA, Lemmen RJ, Den Hartog H, De Muinck Keizer-Schrama SM, Drop SL. Children born small for gestational age: do they catch up? Pediatr Res. 1995;38:267-271

6. Singhal A, Lucas A. Early origins of cardiovascular disease: is there a unifying hypothesis? Lancet. 2004;363:1642-1645

7. Ekelund U, Ong K, Linne Y, Neovius M, Brage S, Dunger DB, Wareham NJ, Rossner S. Upward weight percentile crossing in infancy and early childhood independently predicts fat mass in young adults: the Stockholm Weight Development Study (SWEDES). Am J Clin Nutr. 2006;83:324-330

8. Adair LS, Martorell R, Stein AD, Hallal PC, Sachdev HS, Prabhakaran D, Wills AK, Norris SA, Dahly DL, Lee NR, et al. Size at birth, weight gain in infancy and childhood, and adult blood pressure in 5 lowand middle-income-country cohorts: when does weight gain matter? Am J Clin Nutr. 2009;89: 1383-1392

9. Ekelund U, Ong KK, Linne Y, Neovius M, Brage S, Dunger DB, Wareham NJ, Rossner S. Association of weight gain in infancy and early childhood with metabolic risk in young adults. J Clin Endocrinol Metab. 2007;92:98-103

10. Fall CH, Sachdev HS, Osmond C, Lakshmy R, Biswas SD, Prabhakaran D, Tandon N, Ramji S, Reddy KS, Barker DJ, et al. Adult metabolic syndrome and impaired glucose tolerance are associated with different patterns of BMI gain during infancy: Data from the New Delhi Birth Cohort. Diabetes Care. 2008;31:2349-2356

11. Kajantie E, Barker DJ, Osmond C, Forsen T, Eriksson JG. Growth before 2 years of age and serum lipids 60 years later: the Helsinki Birth Cohort study. Int J Epidemiol. 2008;37:280-289

12. Tzoulaki I, Sovio U, Pillas D, Hartikainen AL, Pouta A, Laitinen J, Tammelin TH, Jarvelin MR, Elliott P. Relation of immediate postnatal growth with obesity and related metabolic risk factors in adulthood: the northern Finland birth cohort 1966 study. Am J Epidemiol. 2010;171:989-998

13. Eriksson JG, Osmond C, Kajantie E, Forsen TJ, Barker DJ. Patterns of growth among children who later develop type 2 diabetes or its risk factors. Diabetologia. 2006;49:2853-2858

14. Phillips DI, Goulden P, Syddall HE, Aihie Sayer A, Dennison EM, Martin H, Cooper C. Fetal and infant growth and glucose tolerance in the Hertfordshire Cohort Study: a study of men and women born between 1931 and 1939. Diabetes. 2005;54 Suppl 2:S145-150

15. Osmond C, Kajantie E, Forsen TJ, Eriksson JG, Barker DJ. Infant growth and stroke in adult life: the Helsinki birth cohort study. Stroke. 2007;38:264-270

16. Leunissen RW, Kerkhof GF, Stijnen T, Hokken-Koelega A. Timing and tempo of first-year rapid growth in relation to cardiovascular and metabolic risk profile in early adulthood. JAMA. 2009;301:2234-2242

17. Singhal A, Cole TJ, Fewtrell M, Deanfield J, Lucas A. Is slower early growth beneficial for long-term cardiovascular health? Circulation. 2004;109:1108-1113

18. Larnkjaer A, Schack-Nielsen L, Molgaard C, Ingstrup HK, Holst JJ, Michaelsen KF. Effect of growth in infancy on body composition, insulin resistance, and concentration of appetite hormones in adolescence. Am J Clin Nutr. 2010;91:1675-1683

19. Fabricius-Bjerre S, Jensen RB, Faerch K, Larsen T, Molgaard C, Michaelsen KF, Vaag A, Greisen G. Impact of birth weight and early infant weight gain on insulin resistance and associated cardiovascular risk factors in adolescence. PloS One. 2011;6:e20595

20. Beardsall K, Ong KK, Murphy N, Ahmed ML, Zhao JH, Peeters MW, Dunger DB. Heritability of childhood weight gain from birth and risk markers for adult metabolic disease in prepubertal twins. J Clin Endocrinol Metab. 2009;94:3708-3713 
21. Skidmore PM, Cassidy A, Swaminathan R, Richards JB, Spector TD, MacGregor AJ. Relation of birth weight, body mass index, and change in size from birth to adulthood to insulin resistance in a female twin cohort. J Clin Endocrinol Metab. 2008;93:516-520

22. Skidmore PM, Cassidy A, Swaminathan R, Falchi M, Spector TD, MacGregor AJ. Intrauterine, environmental, and genetic influences in the relationship between birth weight and lipids in a female twin cohort. Arterioscler Thromb Vasc Biol. 2006;26:2373-2379

23. Loos RJ, Fagard R, Beunen G, Derom C, Vlietinck R. Birth weight and blood pressure in young adults: a prospective twin study. Circulation. 2001;104:1633-1638

24. Loos RJ, Beunen G, Fagard R, Derom C, Vlietinck R. Birth weight and body composition in young women: a prospective twin study. Am J Clin Nutr. 2002;75:676-682

25. Katz A, Nambi SS, Mather K, Baron AD, Follmann DA, Sullivan G, Quon MJ. Quantitative insulin sensitivity check index: a simple, accurate method for assessing insulin sensitivity in humans. J Clin Endocrinol Metab. 2000;85:2402-2410

26. Verhaeghe J, Coopmans W, van Herck E, van Schoubroeck D, Deprest JA, Witters I. IGF-I, IGF-II, IGF binding protein 1, and C-peptide in second trimester amniotic fluid are dependent on gestational age but do not predict weight at birth. Pediatr Res. 1999;46:101-810

27. Friedewald WT, Levy RI, Fredrickson DS. Estimation of the concentration of low-density lipoprotein cholesterol in plasma, without use of the preparative ultracentrifuge. Clin Chem. 1972;18: 499-502

28. Cammu H, Martens G, Landuyt J, de Koen K, Defoort P. Perinatale Activiteiten in Vlaanderen 2006. SPE, Brussel 2007

29. Roelants M, Hauspie R, Hoppenbrouwers K. References for growth and pubertal development from birth to 21 years in Flanders, Belgium. Ann Hum Biol. 2009;36:680-694

30. Gielen M, Lindsey PJ, Derom C, Smeets HJ, Souren NY, Paulussen AD, Derom R, Nijhuis JG. Modeling genetic and environmental factors to increase heritability and ease the identification of candidate genes for birth weight: a twin study. Behav Genet. 2008;38:44-54

31. Touwslager RN, Gielen M, Derom C, Mulder AL, Gerver WJ, Zimmermann LJ, Houben AJ, Stehouwer $\mathrm{CD}$, Vlietinck R, Loos RJ, et al. Determinants of infant growth in four age windows: a twin study. $J$ Pediatr. 2011;158:566-572 e2

32. Executive Summary of The Third Report of The National Cholesterol Education Program (NCEP) Expert Panel on Detection, Evaluation, And Treatment of High Blood Cholesterol In Adults (Adult Treatment Panel III). JAMA. 2001;285:2486-2497

33. Carlin JB, Gurrin LC, Sterne JA, Morley R, Dwyer T. Regression models for twin studies: a critical review. Int J Epidemiol. 2005;34:1089-1099

34. Loos RJ, Beunen G, Fagard R, Derom C, Vlietinck R, Phillips DI. Twin studies and estimates of heritability. Lancet. 2001;357:1445

35. Law CM, Shiell AW, Newsome CA, Syddall HE, Shinebourne EA, Fayers PM, Martyn CN, de Swiet M. Fetal, infant, and childhood growth and adult blood pressure: a longitudinal study from birth to 22 years of age. Circulation. 2002;105:1088-1092

36. Fraser A, Hughes R, McCarthy A, Tilling K, Davies D, Rumley A, Lowe GD, Smith GD, Ben-Shlomo Y. Early life growth and hemostatic factors: the Barry Caerphilly Growth study. Am J Epidemiol. 2008;168: 179-187

37. Sweeney G. Cardiovascular effects of leptin. Nature Rev. 2010;7:22-29

38. Guilloteau P, Zabielski R, Hammon HM, Metges CC. Adverse effects of nutritional programming during prenatal and early postnatal life, some aspects of regulation and potential prevention and treatments. J Physiol Pharmacol. 2009;60 Suppl 3:17-35

39. Waterland RA, Lin JR, Smith CA, Jirtle RL. Post-weaning diet affects genomic imprinting at the insulinlike growth factor 2 (Igf2) locus. Human Mol Genet. 2006;15:705-716

40. Barker DJ, Osmond C, Forsen TJ, Kajantie E, Eriksson JG. Trajectories of growth among children who have coronary events as adults. N Engl J Med. 2005;353:1802-1809

41. Christensen K, Wienke A, Skytthe A, Holm NV, Vaupel JW, Yashin Al. Cardiovascular mortality in twins and the fetal origins hypothesis. Twin Res. 2001;4:344-349

42. Ong KK. Catch-up growth in small for gestational age babies: good or bad? Curr Opin Endocrinol Diab Obes. 2007; $14: 30-34$ 


\section{PART II}

A clinical study into birth weight, postnatal growth, body composition and their association with endothelial function

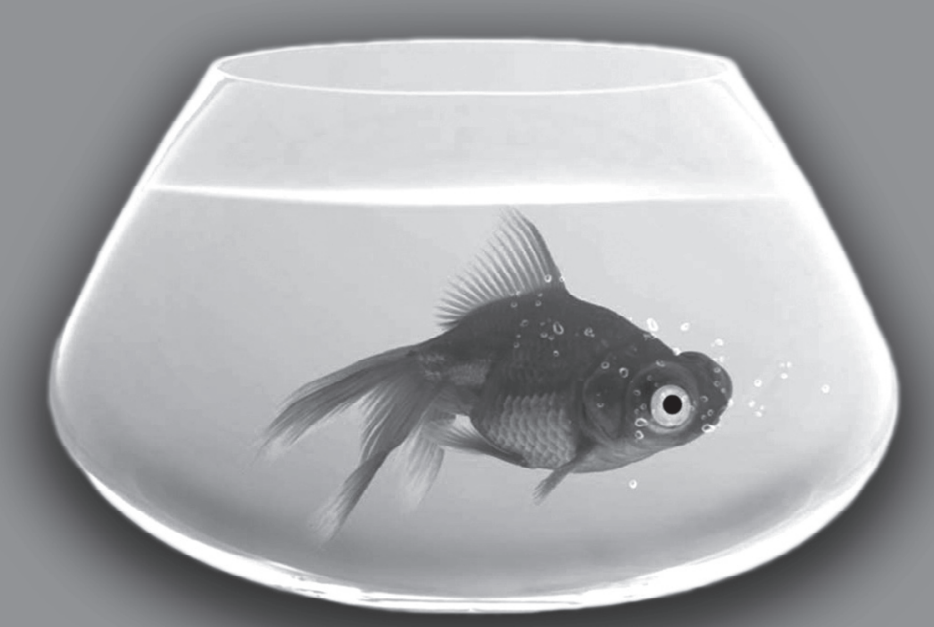




\section{Chapter 8}

Endothelial vasodilatation in newborns is related to body size and maternal hypertension

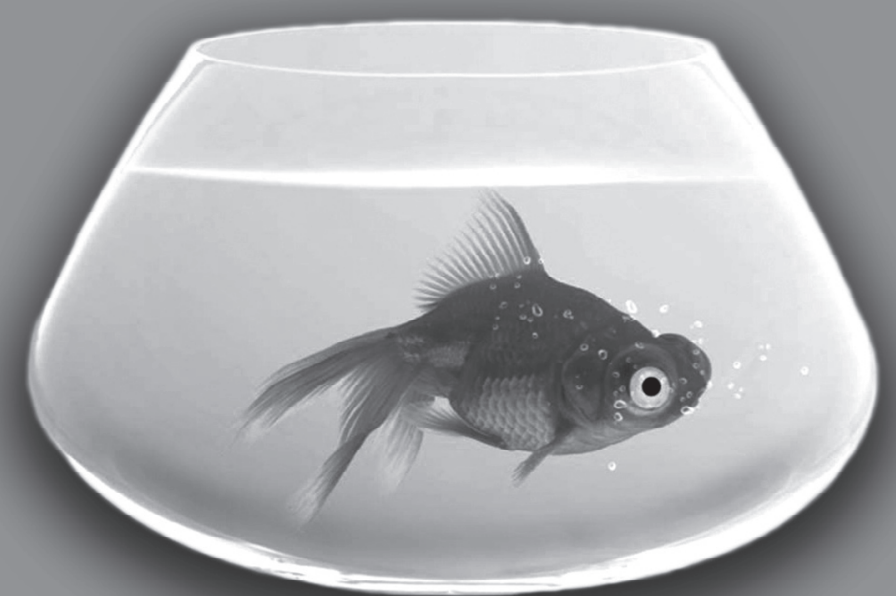

RNH Touwslager

AJHM Houben

M Gielen

MP Zeegers

CDA Stehouwer

L Zimmermann

AGH Kessels WJM Gerver CE Blanco ALM Mulder

The Journal of Hypertension 2012;30:124-131 


\section{Abstract}

\section{Objective}

The fetal response to an adverse intrauterine environment -reflected in low birth weight- is thought to cause an increased risk for adult hypertension. A possible mechanism by which fetal adaptive responses contribute to hypertension is an adverse effect on endothelial function. Identifying individuals with endothelial dysfunction as early as possible may assist in understanding the inverse association between birth weight and hypertension. The present study aimed to identify determinants of endothelial vasodilatation in the first week of life.

\section{Methods}

104 Term newborns were studied in the first week after birth with regard to maximum vasodilatation in response to acetylcholine (endothelium-dependent) and nitroprusside (endothelium-independent) in the vasculature of the forearm skin, by use of a laser-Doppler device and iontophoresis. Bivariable and multivariable linear regression with various familial, gestational and neonatal potential covariates were used for the analysis.

\section{Results}

In the bivariable analysis, maximum perfusion after administration of acetylcholine was positively associated with birth weight, length, head circumference and maternal education level, but negatively associated with maternal hypertension during pregnancy. In the multivariable analysis, head circumference ( $b=11.9$ perfusion units $(\mathrm{PU}) / \mathrm{z}$-score, $\mathrm{P}=0.02$ ) and hypertension during pregnancy $(b=-25.3 \mathrm{PU}$ from nonhypertensive to hypertensive, $P=0.02$ ) remained significantly associated. Maximum perfusion after administration of nitroprusside was not related to any of the anthropometric measures, it was however related to gestational age $(b=-11.1$ $\mathrm{PU} /$ week, $\mathrm{P}=0.009)$.

\section{Conclusions}

This study showed that body size, head circumference in particular, is positively associated with endothelial vasodilatation in newborns, whereas hypertension during pregnancy is inversely associated with endothelial vasodilatation. 


\section{Introduction}

Birth weight is inversely associated with hypertension, cardiovascular disease and other diseases later in life ${ }^{1,2}$. A low birth weight is considered to be a marker of the fetal adaptations to a suboptimal intrauterine environment. These fetal adaptive responses are thought to be the causal factor for the observed association between birth weight and adult disease ${ }^{3}$. A possible mechanism by which fetal adaptive responses contribute to hypertension is an adverse effect on endothelial function ${ }^{4}$. One of the important functions of the endothelium is the production of nitric oxide (NO), which has important vasodilatory properties and inhibits platelet function ${ }^{5,6}$. Endothelial dysfunction is considered a precursor of atherosclerosis, is an important feature of hypertension and may even precede the development of hypertension ${ }^{7}$. The presence of coronary endothelial dysfunction in adults predicts long-term atherosclerotic disease progression and cardiovascular events ${ }^{8,9}$. Endothelial dysfunction measured in the skin vasculature correlates well with cardiovascular disease risk in adults ${ }^{10}$.

Identifying individuals with endothelial dysfunction as early as possible may help to understand the inverse association between birth weight and hypertension, may guide future preventive strategies and may offer opportunities for early intervention. Since endothelial vasodilatory function can be measured non-invasively by use of laserDoppler flowmetry, this technique is suitable for research in the neonatal period. Previous studies using laser-Doppler flowmetry have shown that birth weight is positively associated with the vascular response to acetylcholine, an endotheliumdependent vasodilator, in term and near-term newborns ${ }^{11,12}$. This association was not found in infants born preterm at the age of three months, leading to the hypothesis that endothelial dysfunction develops late in pregnancy ${ }^{13}$.

Traditionally, studies use birth weight as an indicator of intrauterine growth retardation. However, birth weight is just one marker of retarded intrauterine growth and it has not been studied whether there are other, potentially valid anthropometric markers (such as birth length or head circumference) of fetal adaptive responses which are associated with endothelial vasodilatation. Furthermore, it may be important to adjust analyses for specific factors which can affect endothelial vasodilatation in newborns, such as gestational diabetes, maternal smoking and a low parental level of education.

In view of these considerations, the present study aimed to identify determinants of endothelial vasodilatation in the first week of life. 


\section{Methods}

\section{Subjects}

From January 2006 to May 2010, healthy term newborns (gestational age 37-42 weeks) who were born at Maastricht University Medical Center, The Netherlands, and remained at the hospital for at least 3 days were eligible to participate in the study. Exclusion criteria were perinatal hypoxia, acidosis, infection, abnormal genotype and abnormal phenotype (as evaluated by a neonatologist). Transient asymptomatic hypoglycemia, phototherapy and prophylactic treatment with antibiotics without signs of infection were not considered exclusion criteria. The study was approved by the Medical Ethics Committee of the Maastricht University Medical Center and all procedures followed were in accordance with local guidelines. All parents gave written informed consent.

\section{Measurements}

\section{Endothelial vasodilatation}

All measurements were performed in the first week of life. Measurements were taken shortly after feeding, when the children were asleep. Local microvascular skin blood flow of the dorsal side of the forearm was measured using single-point laser-Doppler flowmetry (Periflux system, Perimed A.B., Sweden) before and after pharmacologically induced vasodilatation. Blood perfusion was recorded in perfusion units (PU), which correlate with the number and velocity of passing blood cells in the microvasculature of the skin. Endothelium-dependent vasodilatation was induced by acetylcholine, which is known to release NO and prostanoids from the endothelium, with a possible accessory role for endothelium-derived hyperpolarization factor in adults ${ }^{14}$. Endothelium-independent vasodilatation was induced by nitroprusside, a direct NO donor $^{15}$. Administration of both drugs across the skin was realized by iontophoresis, a technique that uses a weak current to transport substances in ionic form across the skin. The drug delivery electrode was incorporated in the laser-Doppler probe. The study protocol prescribed multiple successive doses resulting in a cumulative dose response curve. For acetylcholine ( $1 \%$ solution, Miochol, Novartis Pharma) 7 successive doses were administered with a 60 second interval, and for nitroprusside $(0.1 \%$ solution, sodium nitroprusside) 9 doses with a 90 second interval were used. Administration required 20 seconds of iontophoresis using a $0.10 \mathrm{~mA}$ anodal current (acetylcholine) or a $0.20 \mathrm{~mA}$ cathodal current (nitroprusside) ${ }^{16}$. For statistical analysis, the average perfusion values in a steady period of at least 30 seconds without significant movement artifacts were taken at baseline and at maximum attained perfusion by use of specially designed software (Perisoft, Perimed A.B., Sweden). All analyses of the Laser-Doppler signal were conducted by one experienced researcher (RNT). 


\section{Anthropometry}

Birth weight was collected from the clinical records, after it was measured on an electronic scale (accurate to one gram) as part of the usual delivery protocol in our hospital. Further anthropometry was performed by two experienced researchers. Supine length was measured using a measuring table accurate to 1 millimeter. Head circumference was measured using a non-stretchable tape, accurate to 1 millimeter, around the most protruding points of occiput and forehead. Standard deviation scores (z-scores) were calculated using sex, parity and gestational age adjusted reference data from 'The Netherlands Perinatal Registry' for birth weight ${ }^{17}$. The Dutch data published in 'Paediatric Morphometrics' ${ }^{18}$ were used for the standardization of other measures of body size.

\section{Covariates}

Based on the literature, several potential covariates were considered, besides anthropometry. The following data were collected from hospital records: $\operatorname{sex}^{19,20}$, gestational age (based on the first day of the last menstrual period, recorded accurate to one day) ${ }^{13}$, maternal hypertension during pregnancy (includes preexistent hypertension, gestational hypertension, preeclampsia and HELLP syndrome $)^{20}$, gestational diabetes ${ }^{21}$ and mode of delivery ${ }^{22}$. Assisted pregnancy (including hormonal stimulation of ovulation, in vitro fertilization and intracytoplasmic sperm injection) and parity were also considered potentially important, as was blood pressure of the newborn. Blood pressure was measured on the arm using an automated blood pressure recorder (Philips M1008B module, Eindhoven, Netherlands) shortly before or after assessment of endothelial vasodilatation, when the newborn was quiet or asleep. Measurements were taken by an experienced researcher, with the newborn in the supine position, using an arm circumference-adjusted cuff. Systolic, diastolic and mean arterial blood pressure were recorded as mean of 2 measurements.

Parents were interviewed with regard to maternal smoking, feeding mode (breast feeding or not), parental ethnic background (Dutch descent or not), level of education and family history of cardiovascular disease. Level of education was defined as follows: $0=$ no education/ only primary school, $1=$ secondary school: lower level or lower secondary education, 2=secondary school: intermediate or high level and 3=tertiary education. Family history of cardiovascular disease was analyzed in four groups: $0=$ no cardiovascular diseases in the family, 1=hypertension, hypercholesterolemia or type 2 diabetes in a second-degree relative $<60$ years, $2=$ cardiovascular event (transient ischemic attack, stroke or myocardial infarction) in a second-degree relative $<60$ years and 3 =hypertension, hypercholesterolemia, type 2 diabetes or a cardiovascular event in a first-degree relative. Only one newborn had a cardiovascular event in a firstdegree relative. Since vascular function may change during the first week of life ${ }^{23}$, we finally examined the day of measurement as a covariate in our analyses. 


\section{Statistical analysis}

Inter-observer variability for the obtained signal was assessed in a random sub sample of 20 newborns and evaluated by the intra-class coefficient (ICC). To compare group means, the appropriate dependent or independent samples t-test was used. Linear regression was used to assess the associations between anthropometry, covariates and vasodilatation. First, a bivariable analysis with maximum perfusion as the outcome variable and all variables entered separately was performed. The corresponding baseline perfusion was always included in the model as a covariate to account for baseline perfusion differences. Second, the significant variables from the bivariable analysis were simultaneously entered into a multivariable model using the enter approach. Differences between regression models were analyzed using the F-change test. A two sided P-value of $<0.05$ was considered significant. All analyses were performed using SPSS version 16.0.

\section{Results}

\section{Baseline characteristics}

104 Newborns were included in the study, of whom two were excluded from the analysis due to technical problems. The baseline characteristics of the study sample are given in Table 8.1. The ICC for inter-observer variability of the obtained signal was $>0.98$ for all perfusion values. The mean baseline perfusion of the acetylcholine protocol was 17.3 PU, which was similar to the mean baseline perfusion of the nitroprusside protocol (18.7 PU), $\mathrm{P}=0.34$. The mean maximum perfusion in response to acetylcholine was 73.4 PU, which was significantly different from the mean maximum perfusion in response to nitroprusside (130.6 PU), $\mathrm{P}<0.0001$. Sex, ethnic background, postnatal day of measurement, assisted pregnancy, feeding mode, parity and delivery mode were not associated with acetylcholine-induced or nitroprusside-induced maximum perfusion in bivariable analysis (data not shown). The small for gestational age newborns had lower maximum perfusion in response to acetylcholine (21.0 PU lower, $P=0.03$ ) and similar maximum perfusion in response to nitroprusside $(P=0.86)$. 
Table 8.1 Characteristics of the study sample $(n=102)$.

\begin{tabular}{|c|c|c|}
\hline & Mean & SD \\
\hline Birth weight (g) & 3179 & 692 \\
\hline Length $(\mathrm{cm})$ & 49.1 & 2.9 \\
\hline Head circumference $(\mathrm{cm})$ & 34.3 & 1.8 \\
\hline Newborn systolic blood pressure (mmHg) & 70.0 & 9.6 \\
\hline Newborn diastolic blood pressure $(\mathrm{mmHg})$ & 43.5 & 8.4 \\
\hline Newborn mean blood pressure $(\mathrm{mmHg})$ & 52.7 & 8.1 \\
\hline Gestational age (weeks) & 39.2 & 1.3 \\
\hline \multirow[t]{2}{*}{ Postnatal day of measurement } & 2.1 & 1.3 \\
\hline & $\mathrm{N}$ & $\%$ \\
\hline Boys & 43 & 42.2 \\
\hline Birth weight $<\mathrm{p} 10$ & 27 & 26.5 \\
\hline Non-Dutch descent of parent(s) & 16 & 15.7 \\
\hline Hypertension During pregnancy & 19 & 18.6 \\
\hline Gestational diabetes & 2 & 2.0 \\
\hline Maternal smoking & 19 & 18.6 \\
\hline Assisted pregnancy & 15 & 14.7 \\
\hline Multiparous pregnancy & 39 & 38.2 \\
\hline \multicolumn{3}{|l|}{ Delivery mode } \\
\hline Vaginally & 24 & 23.5 \\
\hline Assisted delivery & 6 & 5.9 \\
\hline Caesarean section & 72 & 70.6 \\
\hline \multicolumn{3}{|l|}{ Education level mother } \\
\hline No education/ primary school & 5 & 4.9 \\
\hline Low level & 37 & 36.3 \\
\hline Intermediate level & 5 & 4.9 \\
\hline High level & 55 & 53.9 \\
\hline \multicolumn{3}{|l|}{ Education level father } \\
\hline No education/ primary school & 4 & 3.9 \\
\hline Low level & 32 & 31.4 \\
\hline Intermediate level & 5 & 4.9 \\
\hline High level & 61 & 59.8 \\
\hline \multicolumn{3}{|l|}{ Family history of cardiovascular disease } \\
\hline Negative & 25 & 24.5 \\
\hline Risk factors in second degree relative & 36 & 35.3 \\
\hline Event in second degree relative & 29 & 28.4 \\
\hline Risk factors or event in first degree relative & 12 & 11.8 \\
\hline
\end{tabular}

\section{Acetylcholine (endothelium-dependent vasodilatation)}

In bivariable analysis, all anthropometric measurements, except weight for height z-score, were found to be positively associated with maximum perfusion in response to the administration of acetylcholine (Table 8.2). The smallest effect size was found for weight and larger effect sizes were found for height and head circumference. In addition, a statistically significant inverse association was found with hypertension during pregnancy, as was a positive association with maternal, but not paternal, education level. Newborn systolic blood pressure attained an effect size of $0.95 \mathrm{PU}$ per $\mathrm{mm} \mathrm{Hg}$ increase $(P=0.051)$. 


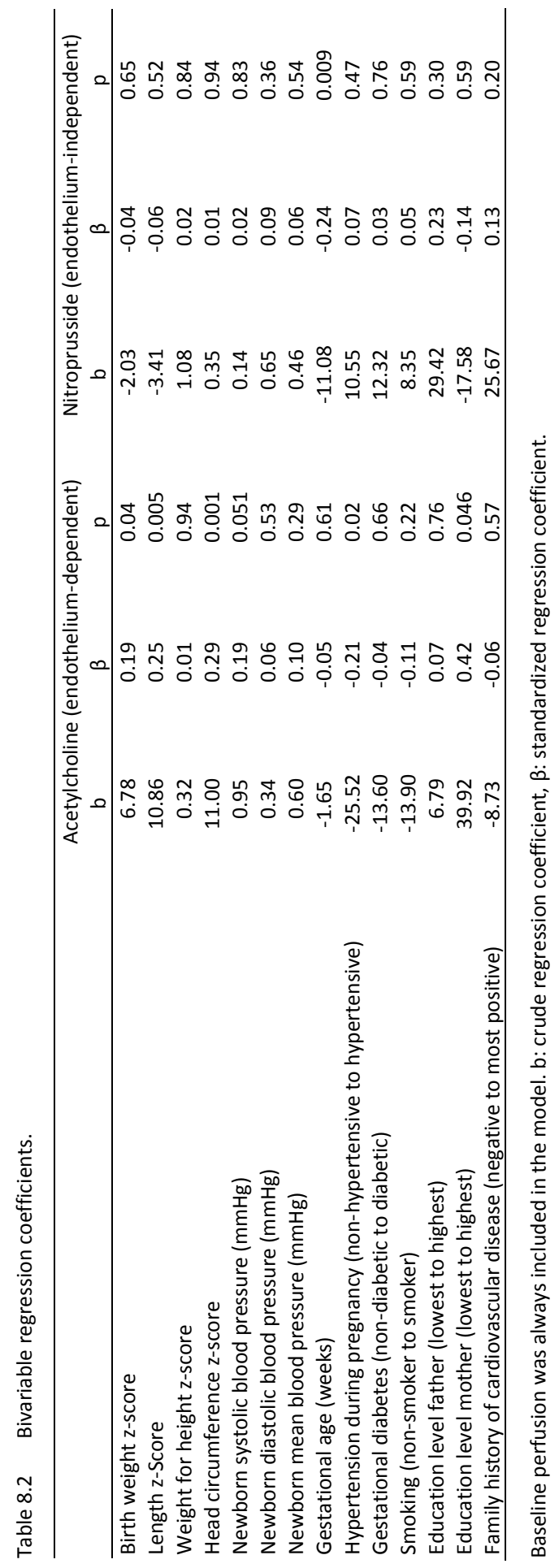


The significant variables of the bivariable analysis were simultaneously entered into a multivariable model. In this analysis, besides baseline perfusion ( $b=2.43 \mathrm{PU} / \mathrm{PU}$, $\mathrm{P}<0.0001)$, only head circumference $(\mathrm{b}=11.91 \mathrm{PU} / \mathrm{z}$-score, $\mathrm{P}=0.02)$ and hypertension during pregnancy $(b=-25.34 \mathrm{PU}$ from non-hypertensive to hypertensive, $P=0.02$ ) remained significantly associated. Since birth weight, length and head circumference were correlated at least with a correlation coefficient of 0.60 , an additional analysis was performed to study the independent importance of head circumference. Adding birth weight or length to a multivariable model containing head circumference and the significant covariates from the bivariable analysis did not improve the fit of the model (F-change test $\mathrm{P}=0.37$ and $\mathrm{P}=0.48$, respectively). Adding head circumference to $\mathrm{a}$ multivariable model containing either birth weight or length and the significant covariates from the bivariable analysis improved the fit of the birth weight model ( $F$-change test $P=0.01$ ), but did not significantly improve the fit of the length model $(P=0.07)$. Adding systolic blood pressure to any of the above models did not change the results. Excluding 27 newborns who had birth weight percentile $<$ p10 yielded similar results in the multivariable analysis. The association of head circumference with endothelium-dependent vasodilatation is visualized in Figure 8.1, by dividing the sample in quintiles for head circumference and by use of the uncorrected data. Figure 8.2 shows the association of hypertension during pregnancy with endotheliumdependent and endothelium-independent vasodilatation by use of the uncorrected data.

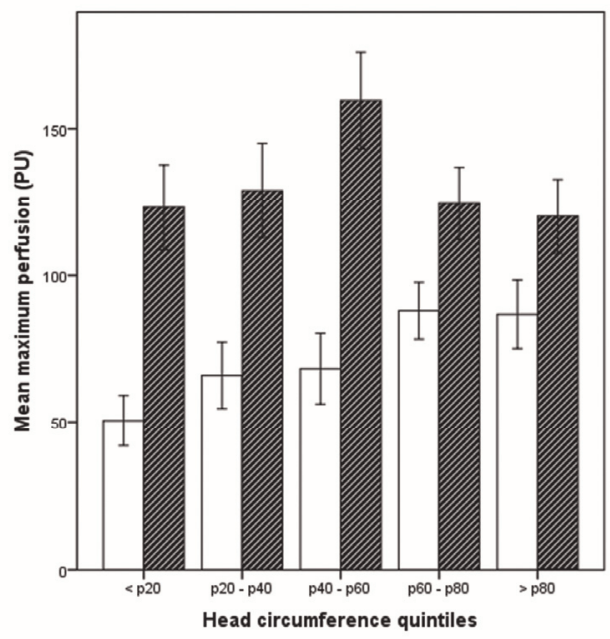

$\square$ acetylcholine

nitroprusside

Figure 8.1 Association of head circumference (Quintiles) with maximum perfusion in response to acetylcholine and nitroprusside. Results are shown as mean \pm standard error of the mean (SEM). Acetylcholine represents endothelium-dependent vasodilation, nitroprusside represents endothelium-independent vasodilation. PU: perfusion units. 


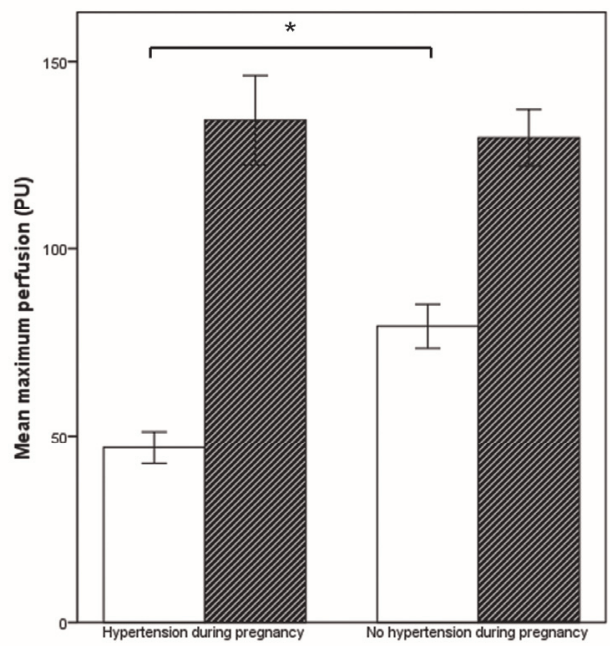

$\square$ acetylcholine

nitroprusside

Figure 8.2 Association of hypertension during pregnancy with maximum perfusion in response to acetylcholine and nitroprusside. Results are shown as mean \pm standard error of the mean (SEM). Acetylcholine represents endothelium-dependent vasodilation, nitroprusside represents endothelium-independent vasodilation. PU: perfusion units. * Significant association in regression analysis.

\section{Nitroprusside (endothelium-independent vasodilatation)}

In the bivariable analysis, no anthropometric measurement was associated with maximum perfusion after administration of nitroprusside. However, gestational age was negatively associated with maximum perfusion ( $b=-11.08 \mathrm{PU} /$ week, $\mathrm{P}=0.009$ ). There were no other associations found with maximum response to nitroprusside.

Similar results were obtained in all analyses when vasodilatation was expressed as absolute perfusion change from baseline.

\section{Discussion}

This study showed that both anthropometric measures and maternal hypertension during pregnancy are associated with endothelial vasodilatation in the first week of life in a large study sample, corrected for multiple covariates and by use of parallel endothelium-dependent and endothelium-independent measurements. We obtained similar values for maximum vasodilatation in response to acetylcholine (73 PU) as reported for normal birth weight children (76 PU) in a previous study ${ }^{12}$ and our data are consistent with previous work on the effect of birth weight on endothelial vasodilatation at birth ${ }^{11,12}$. 
It can be expected that the observed positive association between body size and endothelial vasodilatation indicates an effect of fetal adaptive responses to unfavorable intrauterine conditions. Several mechanisms may be involved in this association. First, endothelial dysfunction is linked to decreased endothelial NO synthase bioactivity and expression, leading to reduced NO synthesis, as shown in rat studies after intrauterine undernutrition ${ }^{24}$. Second, in the same animal model, it was shown that endothelial dysfunction was related to enhanced oxidative stress, which can also reduce the bioavailability of $\mathrm{NO}^{25}$. The other two main pathways -next to NOthat mediate vasodilatation after endothelial stimulation, endothelium-derived hyperpolarization factor and prostaglandins, do not seem to be importantly affected by intrauterine growth restriction ${ }^{26}$. Third, one can speculate that there is a role for angiotensin II receptor type 2 (AT2), which is mainly expressed intrauterinely, followed by a rapid decline after birth, and is involved in vasculogenesis and repair after vascular injury ${ }^{27}$. AT2 deficient mice show reduced flow-dependent (endotheliumdependent) dilatation ${ }^{28}$. Although there are alternative findings in other organs ${ }^{29}$, nutrient restricted (intrauterine growth retarded) ovine fetuses show a reduction of AT2 in the heart ${ }^{30}$. Finally, it has been suggested that low birth weight babies have a functional impairment of endothelial progenitor cells, which are important in vasculogenesis and repair of endothelial damage, in cord blood ${ }^{4}$.

Low birth weight is associated with endothelial dysfunction later in life $\mathrm{e}^{31,32}$. Our data imply that the excess risk for hypertension in low birth weight individuals is already apparent in newborns, and remains present throughout life. The results of this study represent a single measurement in the first week of life and therefore there is a need for longitudinal studies on the association between birth weight and endothelial function. It should also be addressed whether endothelial function is further influenced by other factors, such as growth ${ }^{33}$. Individuals with persistent (increased risk of) endothelial dysfunction, may be eligible for (early) prevention programs or future interventions. Interventions that have a favorable effect on endothelial function in adults are for example supplementation of folic acid $^{34}$, exercise ${ }^{35}$ or statin treatment ${ }^{36}$. Improvement of endothelial function is associated with an improvement in cardiovascular prognosis ${ }^{37}$.

The results of the multivariable analysis with endothelium-dependent vasodilatation as the dependent variable were similar after exclusion of 27 individuals who had birth weight percentile $<$ p10 (this number is probably high [26\%] because of recruitment of our study population in a tertiary center), which indicates that the observed associations are also present in 'normal' (>p10) newborns. This suggests that even in the normal range of birth weight there may be limitation of growth to some extent, which may trigger similar adaptive responses as seen in low birth weight newborns.

The focus of research in the field of developmental origins of adult health and disease has so far predominantly been on birth weight. This study however suggests that head circumference is more strongly associated with endothelial vasodilatation than birth weight and length. First, the associations with both birth weight and length were 
diminished in the presence of head circumference. Second, to test whether this finding was not based on a small statistical difference (because of correlation between the anthropometric variables), it was shown that adding birth weight or length did not improve the fit of the model which only contained head circumference. The other way around, adding head circumference to a model with birth weight did improve the fit, while we could not statistically show the same improvement for length, $\mathrm{P}=0.07$. Nevertheless, we feel confident to conclude that head circumference 'summarizes' the other anthropometric associations. Head circumference may represent a different intrauterine growth pattern than the other growth parameters. It has been suggested that small head circumference represents slow growth during the entire course of gestation $^{38}$. Alternatively, small head circumference may indicate more severe intrauterine growth retardation. In accordance with the above, the well-known associations between birth weight and hypertension and cardiovascular disease later in life have also been found for head circumference ${ }^{38-40}$. The relevance of head circumference may have implications for research, counseling and possibly for guidance of interventions.

Another important finding in our study is the inverse association of hypertension during pregnancy with endothelium-dependent vasodilatation, but not with endothelium-independent vasodilatation. Preeclampsia may be complicated by a lower newborn body size ${ }^{41}$. However, the association of hypertension during pregnancy with endothelium-dependent vasodilatation was consistently shown in the bivariable and multivariable analyses, indicating that its effect is independent of infant body size or the other variables we measured in this study. One study has investigated the impact of preeclampsia on baseline microvascular function in newborns and found sex-specific alterations over the first three days of life ${ }^{20}$. However, this study did not include induction of vasodilatation by acetylcholine or nitroprusside and an effect of hypertension during pregnancy was not found earlier in other studies in infants ${ }^{12,13}$. Our results are in accordance with a recent study in prematurely born offspring of hypertensive pregnancies, which concluded that endothelial function (measured in young adulthood, as flow-mediated dilatation in the brachial artery) plays a key role in the development of hypertension ${ }^{42}$. Our study adds that this is also apparent in the microvasculature of term offspring and it can already be found shortly after birth. Mothers suffering from preeclampsia or gestational hypertension are subject to endothelial dysfunction ${ }^{43}$, and the development of endothelial dysfunction in their offspring may therefore be caused by a heritable predisposition to endothelial dysfunction. Alternatively, endothelial dysfunction in the offspring may be a reflection of intrauterine endothelial dysfunction, caused by the same maternal and/ or placental factors that cause endothelial dysfunction in the preeclamptic mothers ${ }^{42}$. It should be noted that the present study was not specifically designed to investigate preeclampsia or gestational hypertension. Unfortunately, therefore we did not measure any prepregnancy blood pressures in the mothers. Furthermore, the definition of hypertension during pregnancy was quite broad. It included gestational hypertension, 
preeclampsia and the HELLP syndrome, but also preexistent hypertension and the diagnoses were all collected from hospital records. The observed association was however consistent and of large effect size, despite the broad case definition used.

Importantly, our findings regarding the associations of anthropometric measures with endothelium-dependent vasodilatation were not replicated for endotheliumindependent vasodilatation. This suggests that small size at birth and possibly intrauterine growth retardation are selectively affecting endothelial vasodilatation. However, we did find an inverse association of gestational age with the response to nitroprusside. This is in accordance with earlier work, in which a negative correlation between gestational age and vascular response to heat (which is another method to measure endothelium-independent vasodilatation) was found in preterm newborns ${ }^{19}$. This association was however not found in other studies ${ }^{44-46}$.

In conclusion, this study showed that body size, head circumference in particular, is positively associated with endothelial vasodilatation in newborns, whereas hypertension during pregnancy is inversely associated with endothelial vasodilatation. As endothelial dysfunction is an important feature of hypertension and may even precede its development, our results can be useful in future research regarding the inverse association between birth weight and hypertension. Furthermore, early identification of individuals at risk for persistent endothelial dysfunction may offer possibilities for prevention and intervention programs in the future. 


\section{References}

1. Barker DJ, Osmond C, Golding J, Kuh D, Wadsworth ME. Growth in utero, blood pressure in childhood and adult life, and mortality from cardiovascular disease. BMJ. 1989;298:564-567

2. Bergvall N, Iliadou A, Johansson S, de Faire U, Kramer MS, Pawitan $Y$, et al. Genetic and shared environmental factors do not confound the association between birth weight and hypertension: a study among Swedish twins. Circulation. 2007;115:2931-2938

3. Gluckman PD, Hanson MA, Cooper C, Thornburg KL. Effect of in utero and early-life conditions on adult health and disease. N Engl J Med. 2008;359:61-73

4. Ligi I, Grandvuillemin I, Andres V, Dignat-George F, Simeoni U. Low birth weight infants and the developmental programming of hypertension: a focus on vascular factors. Semin Perinatol. 2010;34:188-192

5. Furchgott RF, Zawadzki JV. The obligatory role of endothelial cells in the relaxation of arterial smooth muscle by acetylcholine. Nature. 1980;288:373-376

6. Loscalzo J. Nitric oxide insufficiency, platelet activation, and arterial thrombosis. Circulation research. 2001;88:756-762

7. Rossi R, Chiurlia E, Nuzzo A, Cioni E, Origliani G, Modena MG. Flow-mediated vasodilation and the risk of developing hypertension in healthy postmenopausal women. J Am Coll Cardiol. 2004;44:1636-1640

8. Suwaidi JA, Hamasaki S, Higano ST, Nishimura RA, Holmes DR, Jr., Lerman A. Long-term follow-up of patients with mild coronary artery disease and endothelial dysfunction. Circulation. 2000;101:948-954

9. Schachinger V, Britten MB, Zeiher AM. Prognostic impact of coronary vasodilator dysfunction on adverse long-term outcome of coronary heart disease. Circulation. 2000;101:1899-1906

10. IJzerman RG, de Jongh RT, Beijk MA, van Weissenbruch MM, Delemarre-van de Waal HA, Serne EH, et al. Individuals at increased coronary heart disease risk are characterized by an impaired microvascular function in skin. Eur J Clin Invest. 2003;33:536-542

11. Martin H, Gazelius B, Norman M. Impaired acetylcholine-induced vascular relaxation in low birth weight infants: implications for adult hypertension? Pediatr Res. 2000;47:457-462

12. Martin H, Lindblad B, Norman M. Endothelial function in newborn infants is related to folate levels and birth weight. Pediatrics. 2007;119:1152-1158

13. Norman M, Martin H. Preterm birth attenuates association between low birth weight and endothelial dysfunction. Circulation. 2003;108:996-1001

14. Turner J, Belch JJ, Khan F. Current concepts in assessment of microvascular endothelial function using laser Doppler imaging and iontophoresis. Trends Cardiovasc Med. 2008;18:109-116

15. Feelisch M. The use of nitric oxide donors in pharmacological studies. Naunyn Schmiedebergs Arch Pharmacol.. 1998;358:113-122

16. Serne EH, Gans RO, ter Maaten JC, ter Wee PM, Donker AJ, Stehouwer CD. Capillary recruitment is impaired in essential hypertension and relates to insulin's metabolic and vascular actions. Cardiovasc Res. 2001;49:161-168

17. Visser GH, Eilers PH, Elferink-Stinkens PM, Merkus HM, Wit JM. New Dutch reference curves for birthweight by gestational age. Early Hum Dev. 2009;85:737-744

18. Gerver WJM, de Bruin R. Paediatric Morphometrics, a reference manual: University Press Maastricht; 2001

19. Stark MJ, Clifton VL, Wright IM. Sex-specific differences in peripheral microvascular blood flow in preterm infants. Pediatr Res. 2008;63:415-419

20. Stark MJ, Clifton VL, Wright IM. Neonates born to mothers with preeclampsia exhibit sex-specific alterations in microvascular function. Pediatr Res. 2009;65:292-295

21. Segar EM, Norris AW, Yao JR, Hu S, Koppenhafer SL, Roghair RD, et al. Programming of growth, insulin resistance and vascular dysfunction in offspring of late gestation diabetic rats. Clin Sci (Lond). 2009;117:129-138

22. Martin H, Norman M. Skin microcirculation before and after local warming in infants delivered vaginally or by caesarean section. Acta Paediatr. 1997;86:261-267

23. Suichies HE, Brouwer C, Aarnoudse JG, Jentink HW, de Mul FF, Greve J. Skin blood flow changes, measured by laser Doppler flowmetry, in the first week after birth. Early Hum Dev. 1990;23:1-8 
24. Franco Mdo C, Arruda RM, Dantas AP, Kawamoto EM, Fortes ZB, Scavone C, et al. Intrauterine undernutrition: expression and activity of the endothelial nitric oxide synthase in male and female adult offspring. Cardiovasc Res. 2002;56:145-153

25. Franco Mdo C, Dantas AP, Akamine EH, Kawamoto EM, Fortes ZB, Scavone C, et al. Enhanced oxidative stress as a potential mechanism underlying the programming of hypertension in utero. $J$ Cardiovascr Pharmacol. 2002;40:501-509

26. Morton JS, Rueda-Clausen CF, Davidge ST. Mechanisms of endothelium-dependent vasodilation in male and female, young and aged offspring born growth restricted. Am J Physiol. 2010;298:R930-938

27. Yamada H, Akishita M, Ito M, Tamura K, Daviet L, Lehtonen JY, et al. AT2 receptor and vascular smooth muscle cell differentiation in vascular development. Hypertension. 1999;33:1414-1419

28. Bergaya $\mathrm{S}$, Hilgers $\mathrm{RH}$, Meneton $\mathrm{P}$, Dong $\mathrm{Y}$, Bloch-Faure $\mathrm{M}$, Inagami $\mathrm{T}$, et al. Flow-dependent dilation mediated by endogenous kinins requires angiotensin AT2 receptors. Circ Res. 2004;94:1623-1629

29. Ruster M, Sommer M, Stein G, Bauer K, Walter B, Wolf G, et al. Renal Angiotensin receptor type 1 and 2 upregulation in intrauterine growth restriction of newborn piglets. Cells Tissues Organs. 2006;182: 106-114

30. Gilbert JS, Lang AL, Nijland MJ. Maternal nutrient restriction and the fetal left ventricle: decreased angiotensin receptor expression. Reprod Biol Endocrinol. 2005;3:27

31. Martin H, Hu J, Gennser G, Norman M. Impaired endothelial function and increased carotid stiffness in 9-year-old children with low birthweight. Circulation. 2000;102:2739-2744

32. Leeson CP, Kattenhorn M, Morley R, Lucas A, Deanfield JE. Impact of low birth weight and cardiovascular risk factors on endothelial function in early adult life. Circulation. 2001;103:1264-1268

33. Singhal A, Cole TJ, Fewtrell M, Deanfield J, Lucas A. Is slower early growth beneficial for long-term cardiovascular health? Circulation. 2004;109:1108-1113

34. de Bree A, van Mierlo LA, Draijer R. Folic acid improves vascular reactivity in humans: a meta-analysis of randomized controlled trials. Am J Clin Nutr. 2007;86:610-617

35. Hambrecht R, Wolf A, Gielen S, Linke A, Hofer J, Erbs S, et al. Effect of exercise on coronary endothelial function in patients with coronary artery disease. N Engl J Med. 2000;342: 454-460

36. Balk EM, Karas RH, Jordan HS, Kupelnick B, Chew P, Lau J. Effects of statins on vascular structure and function: a systematic review. Am J Med. 2004;117:775-790

37. Modena MG, Bonetti L, Coppi F, Bursi F, Rossi R. Prognostic role of reversible endothelial dysfunction in hypertensive postmenopausal women. J Am Coll Cardiol. 2002;40: 505-510

38. Huxley RR, Shiell AW, Law CM. The role of size at birth and postnatal catch-up growth in determining systolic blood pressure: a systematic review of the literature. J Hypertens. 2000;18:815-831

39. Barker DJ, Osmond C, Simmonds SJ, Wield GA. The relation of small head circumference and thinness at birth to death from cardiovascular disease in adult life. BMJ. 1993;306:422-426

40. Risnes KR, Nilsen TI, Romundstad PR, Vatten L. Head size at birth and long-term mortality from coronary heart disease. Int J Epidemiol. 2009;38:955-962

41. Odegard RA, Vatten LJ, Nilsen ST, Salvesen KA, Austgulen R. Preeclampsia and fetal growth. Obstet Gynecol. 2000;96:950-955

42. Lazdam M, de la Horra A, Pitcher A, Mannie Z, Diesch J, Trevitt C, et al. Elevated blood pressure in offspring born premature to hypertensive pregnancy: is endothelial dysfunction the underlying vascular mechanism? Hypertension. 2010;56:159-165

43. Savvidou MD, Hingorani AD, Tsikas D, Frolich JC, Vallance P, Nicolaides KH. Endothelial dysfunction and raised plasma concentrations of asymmetric dimethylarginine in pregnant women who subsequently develop pre-eclampsia. Lancet. 2003;361:1511-1517

44. Jahnukainen $\mathrm{T}$, Lindqvist $\mathrm{A}$, Jalonen J, Kero $\mathrm{P}$, Valimaki I. Reactivity of skin blood flow and heart rate to thermal stimulation in infants during the first postnatal days and after a two-month follow-up. Acta Paediatr. 1996;85:733-738

45. Beinder E, Trojan A, Bucher HU, Huch A, Huch R. Control of skin blood flow in pre- and full-term infants. Biol Neonate. 1994;65:7-15

46. Goh KL, Shore AC, Quinn M, Tooke JE. Impaired microvascular vasodilatory function in 3-month-old infants of low birth weight. Diabetes Care. 2001;24:1102-1107 


\section{Chapter 9}

Influence of growth during infancy on endotheliumdependent vasodilatation at the age of 6 months

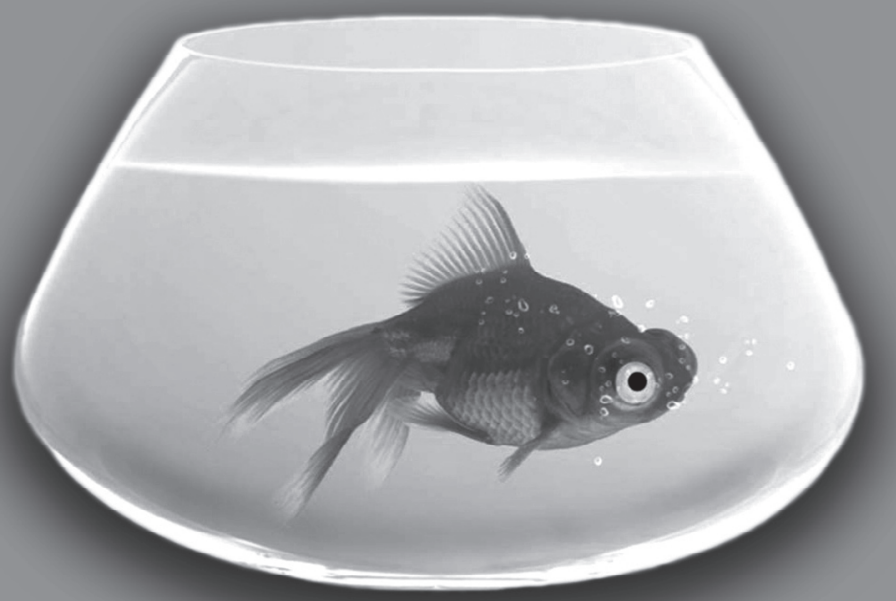

RNH Touwslager WJM Gerver

FES Tan

M Gielen

MP Zeegers

L Zimmermann

AJHM Houben

CE Blanco

CDA Stehouwer

ALM Mulder

Hypertension 2012;60:1294-1300 


\begin{abstract}
Low birth weight and accelerated infant growth are associated with cardiovascular disease in adulthood. Endothelial dysfunction is regarded as a precursor of atherosclerosis and is also related to infant growth. We aimed to examine whether an association between infant growth and endothelial function is already present during discrete periods of growth during the first 6 months of life in healthy term infants. A cohort of 104 newborns was studied in the first week after birth and reexamined at the age of 6 months. Maximum vasodilatation in response to acetylcholine (endothelium dependent) and nitroprusside (endothelium independent) was measured in the vasculature of the forearm skin, using laser Doppler flowmetry and iontophoresis. Growth was calculated as difference in z-scores for weight, length, weight-for-length, and head circumference. Multivariable multilevel linear regression was used for the analysis. Growth from 0 to 1 month (calculated as difference in weight) was the only window in the first 6 months of life that was significantly and inversely associated with endothelium-dependent vasodilatation at 6 months ( $b=-11.72$ perfusion units per $\mathrm{z}$-score, $\mathrm{P}=0.01$ in multivariable analysis). Birth size was not important when considered simultaneously with infant growth. Maximum endothelium-independent vasodilatation was not associated with birth size or growth parameters. We conclude that growth in the first month of life is inversely associated with endothelium-dependent vasodilatation at the age of 6 months in healthy term infants, regardless of birth size.
\end{abstract}




\section{Introduction}

Birth weight is inversely associated with adult hypertension, cardiovascular disease, and other diseases ${ }^{1,2}$. Accelerated postnatal growth (catch-up growth) is one of the proposed mechanisms to explain this relationship ${ }^{3}$. More specifically, growth during infancy (mostly defined as 0-2 years) has been proven to be an important critical age window. Accelerated infant growth has been associated with adult cardiovascular risk factors, including reduced insulin sensitivity, an adverse lipid profile, and hypertension $^{4,5}$.

Along with conventional risk factors for cardiovascular disease, preclinical, functional vascular impairment has also been linked to accelerated infant growth, including endothelial dysfunction ${ }^{6}$. Endothelial dysfunction, considered a precursor of atherosclerosis in adults ${ }^{7}$, is an important feature of hypertension and may even precede the development of hypertension ${ }^{8}$. Furthermore, adolescent endothelial dysfunction is a sensitive early marker of an adverse cardiovascular phenotype ${ }^{9}$.

Although the associations between infant growth and adult adverse cardiovascular outcomes have been studied extensively in retrospect, studies prospectively investigating the early effects of infant growth are less common. In one study, smallfor-gestational-age (SGA) infants with weight catch-up growth in the first year of life had higher levels of fasting insulin at the age of 1 year than SGA infants without catchup growth or appropriate-for-gestational-age infants ${ }^{10}$. In another study, a positive association was found between growth during the first 6 months of life and blood pressure at as early as the age of 3 years ${ }^{11}$. With regard to endothelial function, however, there is a need for prospective studies with measurements early in life, because retrospective studies are more likely to be subject to bias (e.g. recall bias).

In the present study, we collected follow-up data from a cohort of 104 newborns, in whom we have previously shown inverse associations between body size and endothelium-dependent vasodilatation. We performed these measurements in the forearm skin in the first week of life using laser Doppler flowmetry and iontophoresis of acetylcholine, an endothelium-dependent vasodilator ${ }^{12}$. Data obtained by this technique are associated with markers of systemic endothelial function ${ }^{13}$, are strongly correlated with flow-mediated dilatation of the brachial artery ${ }^{14}$, and are linked to coronary microvascular function ${ }^{15}$ in adults.

The primary aim of the present study was to examine whether there is an association between (critical windows of) infant growth and endothelium-dependent vasodilatation already in the first 6 months of life in healthy term infants. Second, we examined whether body size at birth or early postnatal growth is more important in the development of endothelium-dependent vasodilatation in the first 6 months of life. 


\section{Methods}

An extended Methods section is available in the online-only Data Supplement.

\section{Subjects}

As described previously in detail ${ }^{12}$, from January 2006 to May 2010, healthy term newborns (gestational age 37-42 weeks) born at Maastricht University Medical Center who remained at the hospital for $\geq 3$ days, could participate in the study.

\section{Measurements}

\section{Endothelium-dependent vasodilatation}

Measurements were performed in the first week of life and at the age of 6 months. Local microvascular skin blood flow was measured in perfusion units (PU) on the dorsal side of the forearm. These data were obtained by use of single-point laser Doppler flowmetry (Periflux System, Perimed AB, Sweden), before and after pharmacologically induced vasodilatation. Endothelium-dependent vasodilatation was induced by acetylcholine, and endothelium-independent vasodilatation was induced by nitroprusside. Administration of both drugs across the skin was realized by iontophoresis. The study protocol prescribed multiple successive doses resulting in a cumulative dose-response curve. For statistical analysis, the average perfusion values in a steady period of $\geq 30$ seconds without significant movement artifacts were taken at baseline and at maximum attained perfusion.

\section{Anthropometry}

Birth weight was collected from the clinical records after it was measured on an electronic scale (accurate to $1 \mathrm{~g}$ ) as part of the usual delivery protocol in our hospital. All other anthropometry was performed by 2 experienced researchers. All data points were converted into SD scores (z-scores), using reference data accurate to 1 day. Furthermore, we collected growth data (weight, length, and head circumference) from the infant and child welfare centers and extracted the measurements closest to 30 days ( 1 month) and 90 days ( 3 months).

\section{Covariates}

The following variables were collected from hospital records: $\operatorname{sex}^{16,17}$, gestational age ${ }^{18}$, maternal hypertension during pregnancy, 17 gestational diabetes ${ }^{19}$, and mode of delivery $^{20}$. Assisted pregnancy and parity were also considered potentially important, as was blood pressure of the infant. Blood pressure was measured on the arm using an automated blood pressure recorder shortly before or after assessment of vasodilatation, when the infant was quiet or asleep. Measurements were taken by an 
experienced researcher, with the newborn in the supine position or when held by one of the parents, using an arm circumference-adjusted cuff. Systolic, diastolic, and mean arterial blood pressures were recorded as mean of 2 measurements.

Parents were interviewed with regard to maternal smoking during pregnancy ${ }^{21}$, breast feeding ${ }^{22}$, parental ethnic background, level of education, and family history of cardiovascular disease. Level of education was expressed dichotomously, and family history of cardiovascular disease was analyzed in 4 groups. We always included the time point (either birth or 6 months) as a covariate in our analyses.

\section{Statistical analysis}

To compare group means, the dependent $t$ test was used. Multilevel linear regression with an unstructured covariance matrix describing the covariance between the 2 time points was used to assess the associations among growth, covariates, and vasodilatation. First, all variables were tested separately in a basic analysis with maximum perfusion as the outcome variable and sex, time point, and baseline perfusion as covariates. Because we showed their importance previously, hypertension during pregnancy was included in the acetylcholine basic model, and gestational age was added to the nitroprusside basic model ${ }^{12}$. Second, the variables with $P<0.10$ from the basic model were added to the basic birth size and growth models to create multivariable models. Third, the growth parameters that showed a P value $<0.10$ in the multivariable model when considered over the 0 to 6 months period were studied in more detail by decomposing growth into 3 age windows: 0 to 1,1 to 3 , and 3 to 6 months. These subwindows were tested separately and finally simultaneously to assess their relative importance. A 2 sided $P$ value of $<0.05$ was considered significant, and $a \mathrm{P}$ value of $<0.10$ was considered a trend.

\section{Results}

\section{Baseline characteristics}

From all 104 newborns included in the study, 90 attended the follow-up visit at the age of 6 months. We experienced technical problems during 3 of these 90 measurements, and 1 nitroprusside protocol could not be performed successfully.

This yielded a total of 87 and 86 successful protocols of acetylcholine and nitroprusside, respectively. At birth, there were 102 and 94 successful measurements of acetylcholine and nitroprusside, respectively. The reason for the lower number of successful nitroprusside protocols at birth was that acquiring an acetylcholine measurement (always performed first) had sometimes taken too long for the newborn or the parents. The 90 infants who returned for a second visit did not differ from the 14 infants who were not measured for all birth, pregnancy, and general covariates, 
except for maternal educational level and maternal weight (both lower in the missing group).

Maternal education level and weight were not related $(P>0.90)$. To account for these differences, we additionally added maternal education level and maternal weight as a covariate to all multivariable models, when these variables were not included already. In Table S9.1 in the online-only Data Supplement, the characteristics of all infants of whom vascular measurements were available from the second time point of our study (6 months) are shown. When the data from Table S9.1 were statistically tested, there was no difference in baseline perfusion between the acetylcholine and the nitroprusside protocols at birth and the age of 6 months $(P=0.3412$ and $P=0.55$, respectively). At birth, maximum perfusion in response to acetylcholine was significantly lower than maximum perfusion in response to nitroprusside (69.8 PU versus $127.6 \mathrm{PU} ; \mathrm{P}<0.0001)^{12}$; at the age of 6 months, this difference was no longer significant (117.5 versus 127.3 PU; $\mathrm{P}=0.06$ ). Maximum perfusion in response to acetylcholine (endothelium-dependent vasodilatation) was higher at the age of 6 months than at birth $(P<0.0001)$, whereas maximum perfusion in response to nitroprusside (endothelium-independent vasodilatation) was similar at both ages $(P=0.89)$. The exact age of measurement at birth did not influence vascular measurements in our sample ${ }^{12}$, and exact age of measurement (in days) was not associated with maximum response to acetylcholine or nitroprusside in linear regression analysis ( $\mathrm{P}=0.83$ and $\mathrm{P}=0.35$, respectively). Therefore, all measurements were regarded as measurements at either 0 or 6 months. In a total of 95 infants (91\%), growth data from the infant and child welfare centers were retrieved. Within these 95 infants, the availability of growth data varied from $100 \%$ (weight at 3 months) to $83 \%$ (head circumference at 1 month).

\section{Acetylcholine (Endothelium-dependent vasodilatation)}

Maximum skin perfusion in response to acetylcholine at the age of 6 months was positively associated with all measures of size at birth, except weight-for-length z-score, in both the basic and the multivariable analyses (Table 9.1). However, none of these birth sizes, when included in the appropriate multivariable models for growth, remained significantly associated with maximum skin perfusion in response to acetylcholine at the age of 6 months: birth weight $b=0.62, \mathrm{P}=0.85$; birth length $b=1.81$, $\mathrm{P}=0.60$; birth weight-for-length $b=-0.64, \mathrm{P}=0.87$; and head circumference at birth $b=5.96, P=0.08$. With regard to the growth parameters, growth expressed as change in weight $z$-score was significantly negatively associated with maximum perfusion ( $b=-8.15$ PU per $z$-score; $\mathrm{P}=0.02$ in the multivariable analysis). There was a trend for an inverse association between growth in weight-for-length and maximum perfusion $(b=-6.95 ; \mathrm{P}=0.06)$. 


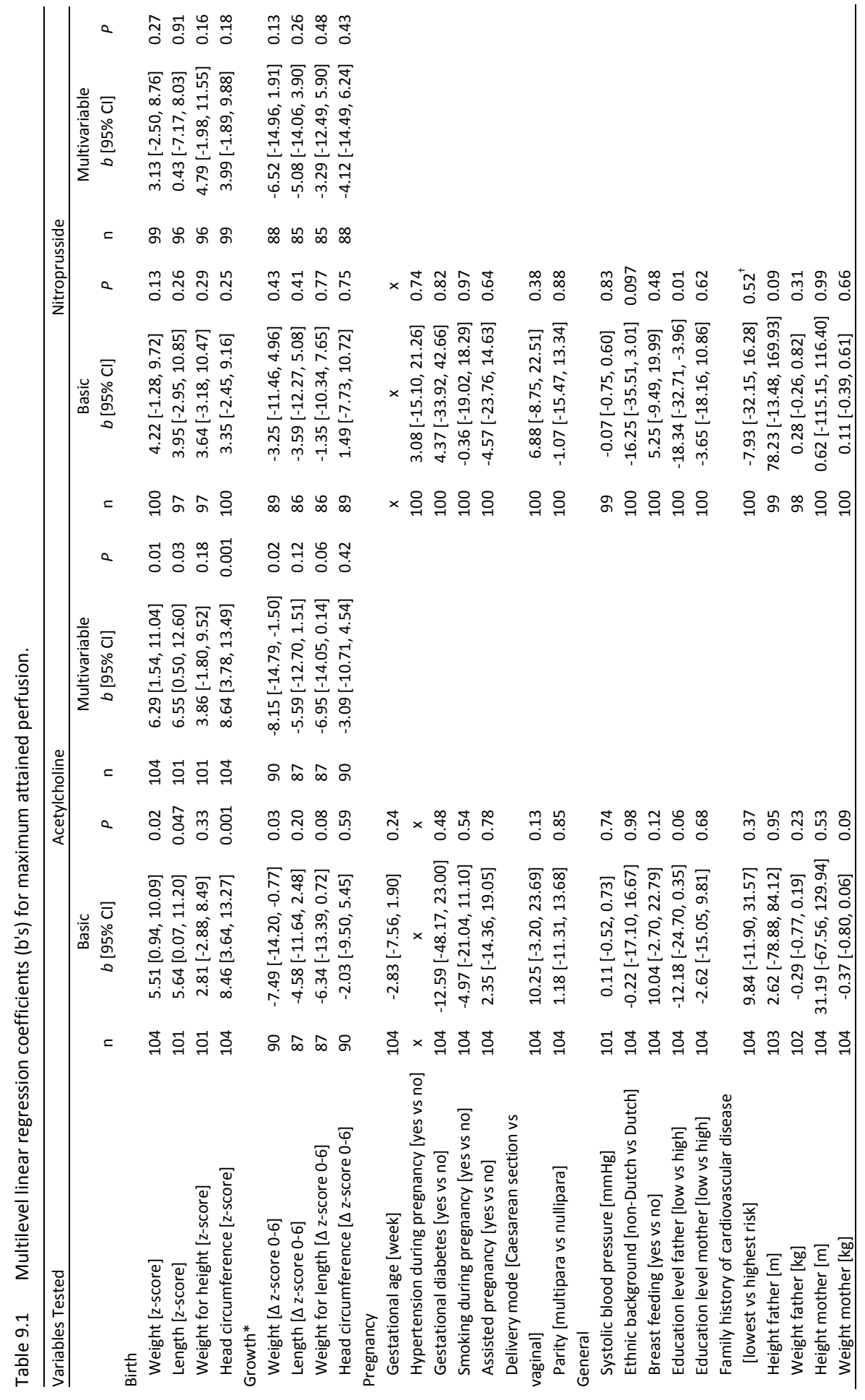


Basic model acetylcholine: Adjusted for baseline perfusion, time point, sex and hypertension during pregnancy. Multivariable model acetylcholine: Basic model also adjusted for maternal education level, paternal education level and maternal weight. Basic model nitroprusside: Adjusted for baseline perfusion, time point, sex and gestational age. Multivariable model nitroprusside: Basic model also adjusted for maternal education level, paternal education level, ethnic background, family history of cardiovascular disease, maternal weight and paternal height. *Growth parameters were always additionally adjusted for baseline value; so 'Weight [ $\Delta$ z-score $0-6]$ ' was adjusted for weight z-score at birth. †There was a trend for a difference between the second lowest group (group 1) and the highest group: group 1 versus highest $b=-20.23, P=0.09$.

When growth in weight and in weight relative to length was investigated in detail, we found that weight growth from 0 to 1 and from 1 to 3 months was associated with maximum perfusion after stimulation with acetylcholine, whereas weight growth from 3 to 6 months was not (Table 9.2). With regard to weight-for-length, only growth from 0 to 1 month showed a relationship with maximum perfusion. To determine which of the 3 subwindows of growth in weight and weight-for-length $(0-1,1-3$, or 3-6 months) was most important, they were also tested simultaneously (Table 9.2). Weight growth from 0 to 1 month was the only subwindow significantly associated with maximum perfusion in response to acetylcholine $(b=-11.72 ; \mathrm{P}=0.01)$, and analogously weight-for-length growth from 0 to 1 month was solely associated with maximum perfusion $(b=-9.45 ; \mathrm{P}=0.03$ ). Next, in a separate analysis, all SGA infants (birth weight $<p 10 ; n=27$ ) were excluded from these final models. The results were similar, although non-significant for weight-for-length, despite a drop in number of participants in the model $(b=-14.72 ; \mathrm{P}=0.009$ and $b=-10.40 ; \mathrm{P}=0.052$ for weight and weight-for-length, respectively).

\section{Nitroprusside (Endothelium-independent vasodilatation)}

Maximum skin perfusion in response to nitroprusside was not associated with any of the birth or growth parameters in the basic or the multivariable analysis (Table 9.1), it was, however, positively related to paternal education level (low versus high level; $b=-18.34 ; \mathrm{P}=0.01$ ). 


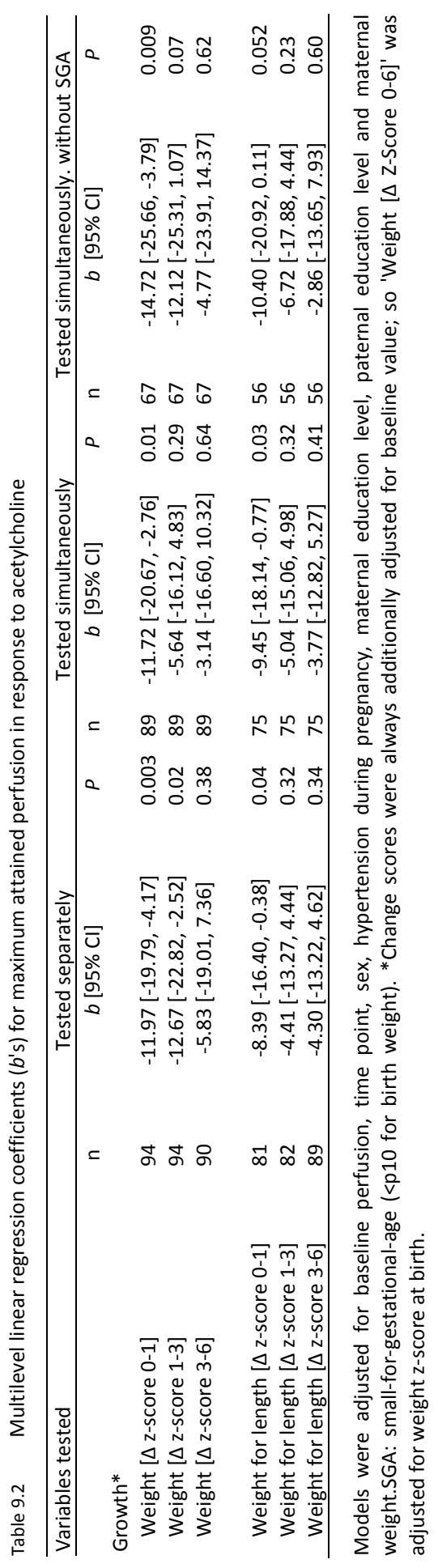




\section{Discussion}

This prospective study showed that infant growth in weight was negatively associated with endothelium-dependent vasodilatation, already at the age of 6 months, independent of birth weight. More specifically, growth in weight (and weight-for length) during the first month of life seemed to be of pivotal importance for the early development of endothelium-dependent vasodilatation.

The results from the present study are consistent with the finding that early postnatal growth (during the first 2 weeks of life) was associated with adolescent endothelial function in individuals born preterm ${ }^{6}$. Moreover, we have shown a similar association at a much younger age and, notably, that the association is also present in healthy infants, born at term. In addition, we confirmed that the association between infant growth and endothelium-dependent vasodilatation is not confined to SGA infants but extends to appropriate-for-gestational-age infants ${ }^{6}$. The latter emphasizes that even growth in the spectrum of a normal population may have negative effects on endothelium-dependent vasodilatation. It should also be noted that, in separate models, growth consistently showed a negative influence, in both an age period in which the infants showed slow growth (0-1 month) and in a period in which they showed faster growth (1-3 months). A beneficial effect of breast feeding (which is associated with slower postnatal growth than formula feeding during the first months of life $)^{23}$, as suggested by earlier work, 22 could not be demonstrated in our study. This might be a consequence of our moderate sample size. Finally, our data underline the importance of an early critical growth window by a direct statistical comparison of the importance of the early age window (0-1 month) with that of later age windows (1-3 and 3-6 months).

The finding of such an early effect of growth on endothelium dependent vasodilatation further stresses that fast infant growth is not necessarily optimal growth in the long term ${ }^{24}$. Our study therefore emphasizes the potential of early parental counseling and of interventions regarding infant growth. In addition, the fact that an effect of growth on endothelium-dependent vasodilatation is now shown so early in life also implies that there may be a large age window (6 months to adolescence) in which individuals with accelerated growth in the first month of life may benefit from (lifestyle) advice regarding their possibly increased risk for endothelial dysfunction. This advice may be composed of many different aspects. For example, in adults, exercise ${ }^{25}$ has a favorable effect on endothelial function. In turn, improvement of endothelial function is associated with an improvement in cardiovascular prognosis ${ }^{26}$.

Although there is no concrete evidence for a mechanism behind the observed association between accelerated growth and endothelial function specifically, there are several hypotheses. Accelerated infant growth, at least postnatal overfeeding, may exert its effect by impacting on the hypothalamus-pituitary-adrenal axis, the growth hormone-insulin-like growth factor axis, or on appetite hormones like leptin, as reviewed by Guilloteau et al. ${ }^{27}$. There is also a possible role for epigenetic 
modifications, which have been shown to occur after post-weaning diet changes in mice ${ }^{28}$. Alternatively, and focusing on endothelial function, one could speculate that endothelial dysfunction acts as a defense mechanism to protect the infant from the adverse effects of even faster growth, because endothelial dysfunction may lead to decreased nutrient and oxygen supply to the growing tissues. Another possibility is that the endothelium is not able to adapt to the sudden rise in circulating blood volume accompanying fast growth and experiences permanent alterations in function. Finally, accelerated growth promotes adipocyte size in mice ${ }^{29}$, which may increase the production of adipokines, which are detrimental to endothelial function, such as leptin and resistin, although adiponectin may have beneficial effects ${ }^{30,31}$.

The present study describes the natural development of vascular function, namely a significant increase in endothelium dependent vasodilatation from birth to 6 months and a steady endothelium-independent vasodilatation. With regard to the development of endothelial function, our data support a role for postnatal growth, rather than birth size, because the effects of birth size were diminished in the statistical models incorporating postnatal growth. The strong tendency of SGA infants to show accelerated postnatal growth ${ }^{32}$ has been proposed as an explanation ${ }^{3}$ for the identification of associations between birth weight and endothelial function in 9-year olds, adolescents, and adults ${ }^{6,33,34}$. However, this poses a problem because SGA newborns already show signs of endothelial dysfunction at birth ${ }^{12,35,36}$. Apparently, slow intrauterine growth and fast postnatal growth may both be linked to impaired endothelial function later in life. It is possible that accelerated postnatal growth is a second hit, which adds to an already existing excess risk in SGA infants. We suggest that this second hit is more powerful than the effect of being SGA. This view is supported by our finding that birth weight was negatively associated with endothelium-dependent vasodilatation at 6 months when its effect was tested separately from growth but not in simultaneous analysis with growth. Because growth and birth weight are closely related, growth may override the effect of birth weight in statistical testing when its effect is more powerful. In line with our observations, the study by Singhal et al. ${ }^{6}$ also showed a significant influence of birth weight on endothelial function at the age of 16 years, when growth was not included in the model. A multihit hypothesis for the development of cardiovascular and renal diseases has been proposed earlier, the first hit being low birth weight and the second hit being, for example, rapid weight gain ${ }^{37}$.

Our study has several distinctive features in the field, the first being a prospective study that has taken many potential confounding factors into account. Second, our results can be extrapolated to the general population to a high degree because of the healthy, term study population. However, our sample was recruited in an academic hospital and, for example, had a higher rate of cesarean sections than the general population. Third, we showed that the observed associations regarding infant growth were absent when an endothelium independent vasodilator was used. This suggests that we found an exclusive association with endothelium-dependent vasodilatation 
and that this association was not influenced by the technique used. As an exception, we did observe an association between paternal educational level and endothelium independent vasodilatation; however, because we do not have a plausible biological explanation for this, we expect it to reflect a type 1 error. Our study also has several limitations. As in any observational study, no conclusions can be drawn with regard to causality. Second, because of the modest study size, we were not able to explore potentially important interactions between growth and other variables. Third, we used laser Doppler flowmetry of the forearm skin to assess endothelial function because this is the most feasible technique for use in newborns and infants. Although endothelial dysfunction measured in the skin vasculature correlates well with cardiovascular disease risk in adults ${ }^{38}$ and endothelial dysfunction is thought to be a sensitive early marker in adolescence associated with an adverse later cardiovascular phenotype 9 , we cannot be sure what the exact meaning of endothelium-dependent vasodilatation at this young age is and whether the observed associations will track into adulthood.

Also, although peripheral vascular endothelial dysfunction is thought to play a role in hypertension and diabetes mellitus, at least in adult obesity ${ }^{39}$, the association between our peripheral vascular measure and endothelial dysfunction in the conduit arteries (the main site of atherosclerosis) in infants is unknown. Finally, we have only studied infant growth, whereas it is clear that childhood growth may also have important effects on later cardiovascular health ${ }^{40}$.

\section{Perspectives}

We have shown in a prospective study that growth in the first month of life is inversely associated with endothelium dependent vasodilatation at the age of 6 months in healthy infants born at term, regardless of SGA or appropriate-for-gestational-age condition at birth. Birth size was not important when considered simultaneously with infant growth. These data underline the potential of counseling and intervening in early infant growth to prevent later cardiovascular disease and these data open up a new window ( 6 months to adolescence) in which a health benefit may be achieved with regard to endothelial function. 


\section{References}

1. Barker DJ, Osmond C, Golding J, Kuh D, Wadsworth ME. Growth in utero, blood pressure in childhood and adult life, and mortality from cardiovascular disease. BMJ. 1989;298:564-567

2. Bergvall N, Iliadou A, Johansson S, de Faire U, Kramer MS, Pawitan Y, Pedersen NL, Lichtenstein P, Cnattingius S. Genetic and shared environmental factors do not confound the association between birth weight and hypertension: a study among Swedish twins. Circulation. 2007;115:2931-2938

3. Singhal A, Lucas A. Early origins of cardiovascular disease: is there a unifying hypothesis? Lancet. 2004;363:1642-1645

4. Leunissen RW, Kerkhof GF, Stijnen T, Hokken-Koelega A. Timing and tempo of first-year rapid growth in relation to cardiovascular and metabolic risk profile in early adulthood. JAMA. 2009;301:2234-2242

5. Adair LS, Martorell R, Stein AD, Hallal PC, Sachdev HS, Prabhakaran D, Wills AK, Norris SA, Dahly DL, Lee NR, Victora CG. Size at birth, weight gain in infancy and childhood, and adult blood pressure in 5 lowand middle-income-country cohorts: when does weight gain matter? Am J Clin Nutr. 2009;89: 1383-1392

6. Singhal A, Cole TJ, Fewtrell M, Deanfield J, Lucas A. Is slower early growth beneficial for long-term cardiovascular health? Circulation. 2004;109:1108-1113

7. Singhal A. Endothelial dysfunction: role in obesity-related disorders and the early origins of CVD. Proc Nutr Soc. 2005;64:15-22

8. Rossi R, Chiurlia E, Nuzzo A, Cioni E, Origliani G, Modena MG. Flowmediated vasodilation and the risk of developing hypertension in healthy postmenopausal women. J Am Coll Cardiol. 2004;44:1636-1664

9. Lazdam M, Lewandowski AJ, Kylintireas I, Cunnington C, Diesch J, Francis J, Trevitt C, Neubauer S, Singhal A, Leeson P. Impaired endothelial responses in apparently healthy young people associated with subclinical variation in blood pressure and cardiovascular phenotype. Am J Hypertens. 2012;25:46-53

10. Soto N, Bazaes RA, Peña V, Salazar T, Avila A, Iñiguez G, Ong KK, Dunger DB, Mericq MV. Insulin sensitivity and secretion are related to catch-up growth in small-for-gestational-age infants at age 1 year: results from a prospective cohort. J Clin Endocrinol Metab. 2003;88:3645-3650

11. Hindmarsh PC, Bryan S, Geary MP, Cole TJ. Effects of current size, postnatal growth, and birth size on blood pressure in early childhood. Pediatrics. 2010;126:e1507-e1513

12. Touwslager RN, Houben AJ, Gielen M, Zeegers MP, Stehouwer CD, Zimmermann LJ, Kessels AG, Gerver WJ, Blanco CE, Mulder AL. Endothelial vasodilatation in newborns is related to body size and maternal hypertension. J Hypertens. 2012;30:124-131

13. Elherik K, Khan F, McLaren M, Kennedy G, Belch JJ. Circadian variation in vascular tone and endothelial cell function in normal males. Clin Sci. 2002;102:547-552

14. Debbabi H, Bonnin P, Ducluzeau PH, Lefthériotis G, Levy BI. Noninvasive assessment of endothelial function in the skin microcirculation. Am J Hypertens. 2010;23:541-546

15. Khan F, Patterson D, Belch JJ, Hirata K, Lang CC. Relationship between peripheral and coronary function using laser Doppler imaging and transthoracic echocardiography. Clin Sci. 2008;115:295-300

16. Stark MJ, Clifton VL, Wright IM. Sex-specific differences in peripheral microvascular blood flow in preterm infants. Pediatr Res. 2008;63:415-419

17. Stark MJ, Clifton VL, Wright IM. Neonates born to mothers with preeclampsia exhibit sex-specific alterations in microvascular function. Pediatr Res. 2009;65:292-295

18. Norman M, Martin H. Preterm birth attenuates association between low birth weight and endothelial dysfunction. Circulation. 2003;108:996-1001

19. Segar EM, Norris AW, Yao JR, Hu S, Koppenhafer SL, Roghair RD, Segar JL, Scholz TD. Programming of growth, insulin resistance and vascular dysfunction in offspring of late gestation diabetic rats. Clin Sci. 2009;117:129-138

20. Martin H, Norman M. Skin microcirculation before and after local warming in infants delivered vaginally or by caesarean section. Acta Paediatr. 1997;86:261-267

21. Hutchison SJ, Glantz SA, Zhu BQ, Sun YP, Chou TM, Chatterjee K, Deedwania PC, Parmley WW, Sudhir $\mathrm{K}$. In-utero and neonatal exposure to secondhand smoke causes vascular dysfunction in newborn rats. J Am Coll Cardiol. 1998;32:1463-1467 
22. Khan F, Green FC, Forsyth JS, Greene SA, Newton DJ, Belch JJ. The beneficial effects of breastfeeding on microvascular function in 11- to 14-year-old children. Vasc Med. 2009;14:137-142

23. Kramer MS, Guo T, Platt RW, Vanilovich I, Sevkovskaya Z, Dzikovich I, Michaelsen KF, Dewey K; Promotion of Breastfeeding Intervention Trials Study Group. Feeding effects on growth during infancy. J Pediatr. 2004;145:600-605

24. Ong KK. Catch-up growth in small for gestational age babies: good or bad? Curr Opin Endocrinol Diabetes Obes. 2007;14:30-34

25. Hambrecht R, Wolf A, Gielen S, Linke A, Hofer J, Erbs S, Schoene N, Schuler G. Effect of exercise on coronary endothelial function in patients with coronary artery disease. N Engl J Med. 2000;342: 454-460

26. Modena MG, Bonetti L, Coppi F, Bursi F, Rossi R. Prognostic role of reversible endothelial dysfunction in hypertensive postmenopausal women. J Am Coll Cardiol. 2002;40:505-510

27. Guilloteau P, Zabielski R, Hammon HM, Metges CC. Adverse effects of nutritional programming during prenatal and early postnatal life, some aspects of regulation and potential prevention and treatments. J Physiol Pharmacol. 2009;60(suppl 3):17-35

28. Waterland RA, Lin JR, Smith CA, Jirtle RL. Post-weaning diet affects genomic imprinting at the insulinlike growth factor 2 (Igf2) locus. Hum Mol Genet. 2006;15:705-716

29. Isganaitis E, Jimenez-Chillaron J, Woo M, Chow A, DeCoste J, Vokes M, Liu M, Kasif S, Zavacki AM, Leshan RL, Myers MG, Patti ME. Accelerated postnatal growth increases lipogenic gene expression and adipocyte size in low-birth weight mice. Diabetes. 2009;58:1192-1200

30. Couillard C, Mauriège P, Imbeault P, Prud'homme D, Nadeau A, Tremblay A, Bouchard C, Després JP. Hyperleptinemia is more closely associated with adipose cell hypertrophy than with adipose tissue hyperplasia. Int J Obes Relat Metab Disord. 2000;24:782-788

31. Goldstein BJ, Scalia R. Adipokines and vascular disease in diabetes. Curr Diab Rep. 2007;7:25-33

32. Hokken-Koelega AC, De Ridder MA, Lemmen RJ, Den Hartog H, De Muinck Keizer-Schrama SM, Drop SL. Children born small for gestational age: do they catch up? Pediatr Res. 1995;38:267-271

33. Martin H, Hu J, Gennser G, Norman M. Impaired endothelial function and increased carotid stiffness in 9-year-old children with low birthweight. Circulation. 2000;102:2739-2744

34. Leeson CP, Kattenhorn M, Morley R, Lucas A, Deanfield JE. Impact of low birth weight and cardiovascular risk factors on endothelial function in early adult life. Circulation. 2001;103:1264-1268

35. Martin H, Gazelius B, Norman M. Impaired acetylcholine-induced vascular relaxation in low birth weight infants: implications for adult hypertension? Pediatr Res. 2000;47:457-462

36. Martin H, Lindblad B, Norman M. Endothelial function in newborn infants is related to folate levels and birth weight. Pediatrics. 2007;119:1152-1158

37. Simeoni U, Ligi I, Buffat C, Boubred F. Adverse consequences of accelerated neonatal growth: cardiovascular and renal issues. Pediatr Nephrol. 2011;26:493-508

38. IJzerman RG, de Jongh RT, Beijk MA, van Weissenbruch MM, Delemarrevan de Waal HA, Serné EH, Stehouwer $\mathrm{CD}$. Individuals at increased coronary heart disease risk are characterized by an impaired microvascular function in skin. Eur J Clin Invest. 2003;33:536-542

39. De Boer MP, Meijer RI, Wijnstok NJ, Jonk AM, Houben AJ, Stehouwer CD, Smulders YM, Eringa EC, Serné $\mathrm{EH}$. Microvascular dysfunction: a potential mechanism in the pathogenesis of obesity-associated insulin resistance and hypertension. Microcirculation. 2012;19:5-18

40. Barker DJ, Osmond C, Forsén TJ, Kajantie E, Eriksson JG. Trajectories of growth among children who have coronary events as adults. N Engl J Med. 2005;353:1802-1809 


\section{Chapter 10}

Growth and endothelial function in the first 2 years of

life: a longitudinal study

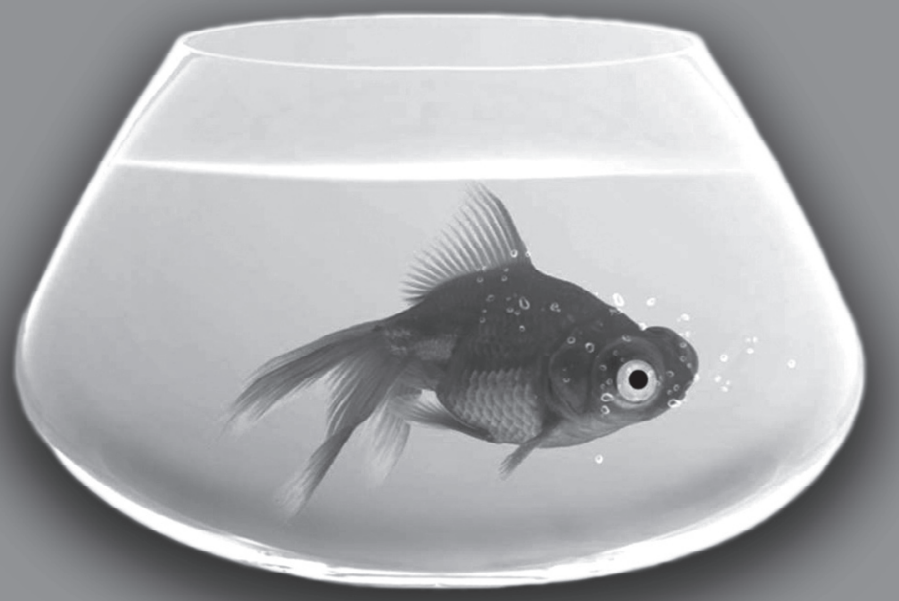

RNH Touwslager

AJHM Houben

FES Tan

M Gielen

MP Zeegers

CDA Stehouwer

WJM Gerver

KR Westerterp

L Wouters

CE Blanco

L Zimmermann

ALM Mulder

Submitted 


\section{Abstract}

\section{Background}

Accelerated infant growth is related to later cardiovascular disease risk. We hypothesized that the harmful association between infant growth and endothelial function at 6 months we identified earlier would persist to the age of 24 months and, second, that accelerated growth would lead to an increased fat percentage and that this would in turn impact negatively on endothelial function.

\section{Methods}

In a prospective study 104 healthy term newborns underwent anthropometry and measurements of vascular vasodilatation at $0,6,12$ and 24 months. We recorded maximum vasodilatation in response to acetylcholine (endothelium-dependent) and nitroprusside (endothelium-independent) by use of laser-Doppler vascular perfusion monitoring of the forearm skin vasculature. Additional anthropometry at 1 and 3 months was collected from child welfare centers. The data were analyzed by multilevel linear regression.

\section{Results}

Weight gain from 0-1 month was associated inversely with maximum perfusion in response to acetylcholine ( $b=-8.28 \mathrm{PU}$ per $\Delta z$-score, $\mathrm{P}=0.03$ ). Weight gain from 0-1 month was related positively to maximum perfusion in response to nitroprusside $(b=10.12$ PU per $\Delta z$-score, $P=0.04)$, as was birth weight $(b=8.02$ PU per $z$-score, $P=0.02$ ). Fat percentage did not have a significant effect in any of the perfusion models and was not related to maximum perfusion at 2 years.

\section{Conclusions}

Infant weight gain from 0-1 month is inversely related to endothelial function in healthy term infants, at least up till the age of 2 years. This relationship was not likely to be explained by an increased fat percentage. 


\section{Introduction}

Cardiovascular disease is one of the leading causes of morbidity and mortality worldwide ${ }^{1}$. Low birth weight is related to mortality from cardiovascular disease, which has been termed the 'Barker hypothesis' ${ }^{2}$. Evidence is thereby accumulating that accelerated infant growth is related to later cardiovascular disease risk ${ }^{3-6}$. As infant growth is largely nutrition-driven and accelerated growth may thereby be avoided, infant growth is a potential target for primary prevention to target long-term cardiovascular health ${ }^{7}$. It should however be kept in mind that there is a complicated trade-off with the beneficial effects of accelerated early growth, such as improved neurodevelopmental outcome ${ }^{8}$.

Endothelial function is considered a precursor of atherosclerosis and has been shown to precede an adverse cardiovascular phenotype in adolescents ${ }^{9}$. By use of a prospective longitudinal design, we have shown earlier that infant growth is inversely associated with endothelial function during the first 6 months of life ${ }^{10}$. When we compared growth from 0-1, 1-3 and 3-6 months, growth during the first month seemed to be of particular importance. There is increasing evidence that this very early growth period is of major significance for long-term risk ${ }^{4,11}$. During the first few months, growth velocities are high and, moreover, especially small for gestational age infants are more likely to cross percentile lines upwardly. The period of high growth velocity continues until about the age of 1 year. Therefore, it is of importance to know whether our observed association persists into older age, when growth is more stable and the potentiating fast growth period longer ago. We now present follow-up data from our earlier study, with additional measurements of endothelial function at the ages of 12 and 24 months.

Accelerated infant growth leads to (central) obesity in young adulthood, but also as early as childhood (6-7 years) $)^{6,12,13}$. In children obesity is related to endothelial dysfunction, both measured as flow mediated dilatation and by use of laser-Doppler flowmetry ${ }^{14-17}$. Hence, we studied whether fat percentage is of importance in the development of endothelial function.

In the present study we hypothesized that the harmful association between infant growth and endothelial function would persist to the age of 24 months and, second, that accelerated growth would lead to an increased fat percentage and that this would in turn impact negatively on endothelial function.

\section{Methods}

\section{Subjects}

The selection of the study population was described previously in detail ${ }^{18}$. In short, at Maastricht University Medical Center, The Netherlands, we recruited healthy term 
newborns (gestational age 37-42 weeks) from January 2006 to May 2010. For logistical reasons, they had to remain admitted to the hospital for at least 3 days. Ethical approval was given by the Medical Ethics Committee of the Maastricht University Medical Center. All parents gave written informed consent.

\section{Measurements}

\section{Endothelium-(in)dependent vasodilatation}

A detailed description of the vascular measurements was provided earlier ${ }^{18}$. In short, we performed the measurements in the first week ( 0 months) and at the ages of 6,12 and 24 months. At 0 months, measurements were taken when the newborns were asleep, mostly after feeding. At 6 months, the infants were mostly measured awake, lying in their own baby seat. At 12 and 24 months, the infants and children were measured on their parent's lap or in their stroller while they were watching a video, a picture book or while sleeping. We gently fixated the forearm to minimize movement artifacts. We recorded microvascular skin blood flow of the dorsal side of the forearm by use of single-point laser-Doppler flowmetry (Periflux system 5000, Perimed A.B., Sweden) before and after pharmacologically induced vasodilatation. We fixed the temperature of the probe to $32^{\circ}$ Celsius. Blood perfusion was recorded in perfusion units (PU), which correlate with the number and velocity of passing blood cells in the skin microvasculature. We induced endothelium-dependent vasodilatation by iontophoresis of acetylcholine, which releases nitric oxide (NO) and prostanoids from the endothelium (with a possible accessory role for endothelium-derived hyperpolarization factor $)^{19}$. Multiple successive doses were given resulting in a cumulative dose response curve. Endothelium-independent vasodilatation was induced by iontophoresis of nitroprusside, a direct $\mathrm{NO}$ donor ${ }^{20}$. One experienced researcher (RNT) extracted the average perfusion values in a steady period of at least 30 seconds without significant movement artifacts at baseline (covariates) and at maximum attained perfusion (primary outcome variables) by use of specially designed software (Perisoft, Perimed A.B., Sweden).

\section{Percentage body fat}

We measured body fat using the deuterium dilution method, because of its acceptability in all age groups ${ }^{21}$. As the percentage of FFM that consists of water is known (this 'hydration constant' is for example 73\% in adults, but higher in children ${ }^{22}$ ), FFM can be estimated if the total amount of water in the body (TBW) is known. We used an adapted version of the Maastricht protocol ${ }^{23}$. The children ingested $25 \mathrm{ml}$ of a $5 \%$ deuterium oxide solution under supervision of the researchers, after a baseline urine sample was collected at home first. Absorbent cotton wool rolls were placed in the children's diapers by their parents to collect the urine samples. At least six hours after ingestion of the deuterium, to allow for full equilibration with the body water, a 
second urine sample was collected at home by the parents and the exact time between ingestion of the deuterium oxide and collection of the sample was recorded. The parents sent these samples back to the hospital in glass containers (to prevent evaporation) by mail and the samples were stored at $-20^{\circ}$ Celsius until analysis.

The obtained samples (baseline and enriched) were analyzed using isotope ratio mass spectrometry (Optima, Micromass, United Kingdom). TBW was calculated as deuterium dilution space divided by 1.04 to adjust for the $4 \%$ exchange of the deuterium oxide with the non-water compartment in the body.

Subsequently, FFM was calculated as follows:

$$
\text { FFM }_{\text {boys }}(\mathrm{kg})=\frac{T B W}{0.77} \text { and } \mathrm{FFM}_{\text {girls }}(\mathrm{kg})=\frac{T B W}{0.78}
$$

The percentage of body fat was calculated by the following formula:

$$
\% \text { fat }=\frac{\text { weight }-F F M}{\text { weight }} * 100
$$

\section{Anthropometry}

Birth weight was measured on an electronic scale (accurate to 1 gram) as part of the usual delivery protocol in our hospital. Supine length was measured using a measuring table (0, 6 and 12 months) or, if possible, standing ( 24 months). The measurements were accurate to 1 millimeter. Head circumference was measured using a nonstretchable tape, accurate to 1 millimeter, around the most protruding points of occiput and forehead. Standard deviation scores (z-scores) were calculated accurate to 1 day, as described earlier (data at 12 and 24 months were standardized similar to data at 6 months) ${ }^{10}$. We furthermore collected weight, length and head circumference data from the infant and child welfare centers and extracted the measurements closest to 30 days ( 1 month) and 90 days ( 3 months).

\section{Covariates}

Detailed collection and scaling methods of covariates were described before ${ }^{18}$. We collected the following variables from hospital records: $\operatorname{sex}^{24,25}$, gestational age (based on the first day of the last menstrual period, recorded accurate to one day) ${ }^{26}$, maternal hypertension during pregnancy (includes preexistent hypertension, gestational hypertension, preeclampsia and HELLP syndrome) $)^{25}$, gestational diabetes ${ }^{27}$ and mode of delivery ${ }^{28}$. Furthermore, whether the child was born after an assisted pregnancy (including hormonal stimulation of ovulation, in vitro fertilization and intracytoplasmic sperm injection) was recorded, as was parity and blood pressure of the infant/ child. Blood pressure was measured by use of an arm circumference-adjusted cuff and an 
automated blood pressure recorder (at 0 months: Philips M1008B module, Eindhoven, The Netherlands; at 6, 12 and 24 months: Dinamap Pro 300, GE Healthcare, Chalfont St. Giles, United Kingdom) when the infant was quiet or asleep.

We interviewed the parents and collected data on maternal smoking during pregnancy ${ }^{29}$, breast feeding ${ }^{30}$, parental ethnic background (Dutch descent or not), level of education and family history of cardiovascular disease. Level of education was expressed dichotomously: $0=$ from no education to lower secondary education, $1=$ from intermediate level secondary school to tertiary education. Family history of cardiovascular disease had 4 categories: $0=$ no known cardiovascular diseases in the family, 1=hypertension, hypercholesterolemia or type 2 diabetes in a second-degree relative $<60$ years, $2=$ cardiovascular event (transient ischemic attack, stroke or myocardial infarction) in a second-degree relative $<60$ years and $3=$ hypertension, hypercholesterolemia, type 2 diabetes or a cardiovascular event in a first-degree relative. Only one infant had a cardiovascular event in a first-degree relative. We always included the time point $(0,6,12$ or 24$)$ as a covariate in our analyses.

\section{Statistical analysis}

Inter-observer variability for baseline and maximum perfusion in a random subsample of 20 newborns was assessed before and reached an intra-class coefficient of $>0.98^{18}$. To compare group means between the children with and without a (successful) visit at the age of 24 months, the independent t-test was used for continuous variables, the chi-square test was used for dichotomous variables and the Mann-Whitney test was used to compare the family history of cardiovascular disease. If a variable predicted completion of the final visit it was included in the subsequent (multilevel) models.

We applied multilevel linear regression to take our 4 subsequent measurements into account. Since multilevel analysis requires complete data for all covariates, we imputed missing values in the covariates by use of multiple imputation and used this data file for the multilevel analyses only. We assumed a missing at random pattern for our missing data, which means that our missing observations would only be related to variables we measured. First, we performed an initial analysis for both response to acetylcholine and nitroprusside including all covariates and all growth intervals simultaneously for the 4 different growth parameters (weight, length, weight-forlength and head circumference). Second, we constructed a final model in which we excluded all variables from the initial model with $\mathrm{P}>0.10$ (in the pooled results of the 5 imputed data sets). As exceptions, we always kept time point, gender and baseline perfusion in the models. For response to acetylcholine we kept hypertension during pregnancy in the model because we identified its effect earlier ${ }^{18}$. For response to nitroprusside, we always kept familial history of cardiovascular disease and gestational age in the model, since they proved significant in our previous final models ${ }^{10}$. We reported the data obtained by the imputed data file. 
Bivariate Pearson correlation coefficients were calculated between fat percentage, the other anthropometric variables and maximum perfusion values at the age of 2 years. Associations between fat percentage at the age of 2 years and growth were tested by linear regression. Analogously to our multilevel approach, first a multivariable model was constructed containing all available covariates, except the perfusion variables. Second, only the covariates with $\mathrm{P}<0.10$ were kept in the model. Since we aimed to test all growth windows simultaneously, only children with complete data could be included in these models. All analyses were performed using IBM SPSS Statistics version 20 .

\section{Results}

Figure 10.1 shows the exact number of measurements at each time point. The total loss-to-follow-up at 24 months was 16 children (15\%), with an additional 2 unsuccessful measurements at 24 months. The characteristics of the children with a (successful) visit at the age of 24 months are given in Table 10.1. There were no differences between children with and without a measurement for the variables shown in Table 10.1, except for a higher prevalence of low educated mothers in the children without a visit compared to the children with a visit, $67 \%$ vs. $36 \%, P=0.02$. Two children had negative calculated fat percentages, which indicated the occurrence of technical errors (for example unrecorded spilling). These were excluded from the analysis.

Weight gain from 0-1 month was associated inversely with maximum perfusion in response to acetylcholine ( $\mathrm{b}=-8.28 \mathrm{PU}$ per $\Delta \mathrm{z}$-score, $\mathrm{P}=0.03$ ) (Table 10.2). Weight gain from 0-1 month was related positively to maximum perfusion in response to nitroprusside ( $\mathrm{b}=10.12 \mathrm{PU}$ per $\Delta \mathrm{z}$-score, $P=0.04)$, as was birth weight ( $\mathrm{b}=8.02 \mathrm{PU}$ per $\mathrm{Z}$-score, $\mathrm{P}=0.02$ ). Length, weight-for-length and head circumference birth or growth variables were not associated with maximum perfusion. Fat percentage did not have a significant effect in any of the models, for example in the weight model: $b=0.06$, $\mathrm{P}=0.94$.

Fat percentage was bivariately correlated to weight-for-length z-score at 2 years $(r=0.30, P=0.01)$, but not to weight, length or head circumference $z$-scores and not to maximum perfusion in response to acetylcholine $(r=0.09, P=0.48)$ or nitroprusside ( $r=-0.08, P=0.50$ ) (data not shown).

Faster weight gain between 6 and 12 months was associated with a higher fat percentage at the age of 2 years ( $b=3.28 \%$ per $\Delta z$-score, $P=0.02$ ) (Table 10.3). This was also the case for a faster increase in weight-for-length in nearly all growth periods, most strikingly between 6 and 12 months ( $b=3.68 \%$ per $\Delta z$-score, $P<0.0001)$. Finally, head growth from 3-6 months was positively associated with fat percentage at the age of 2 years ( $b=4.57 \%$ per $\Delta z$-score, $P=0.003$ ). 


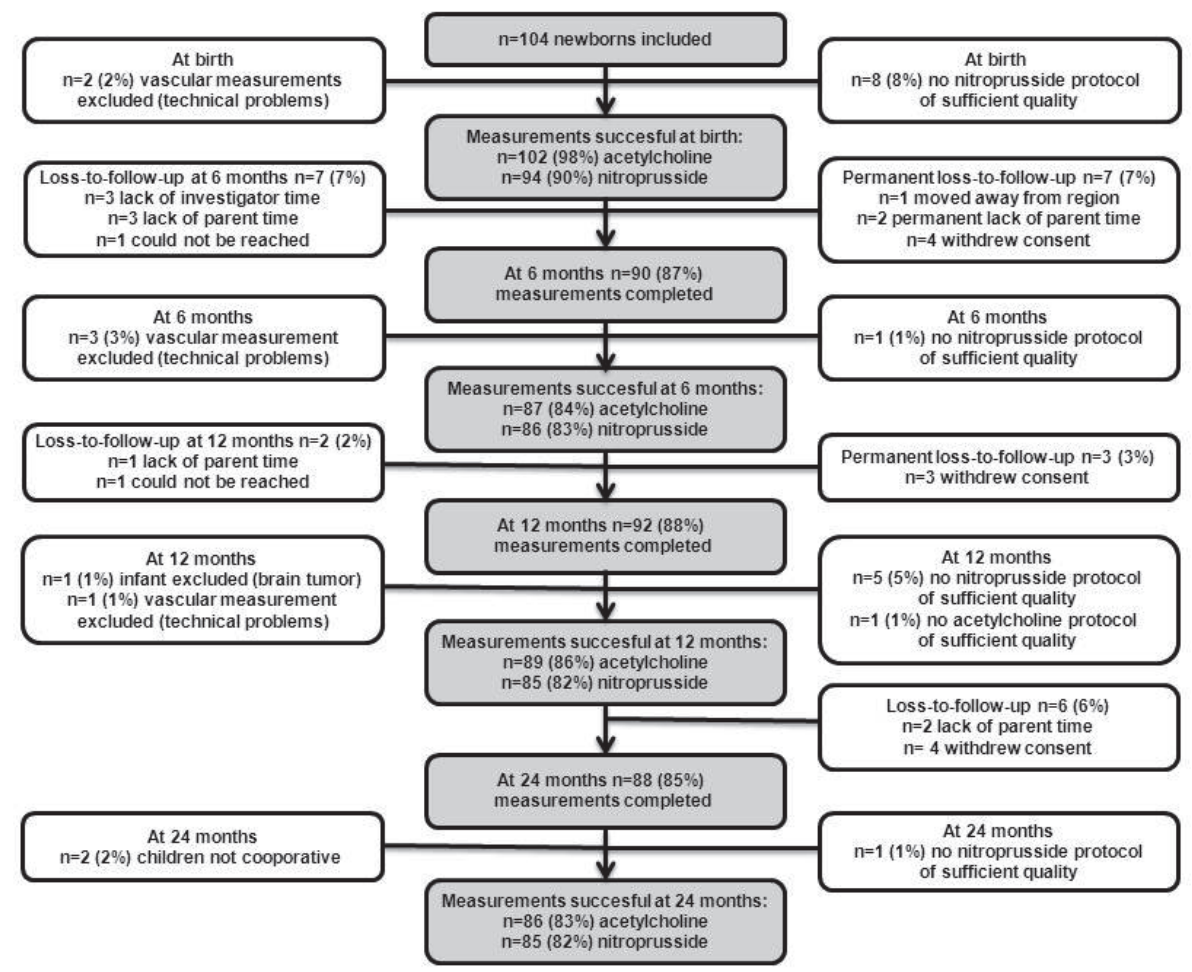

Figure 10.1 Participant flow. 
Table 10.1 Characteristics of the children with a measurement at 24 months ( $n=86$ ).

\begin{tabular}{|c|c|c|c|}
\hline Variable & Mean/n & $\mathrm{SD} / \%$ & $\mathrm{n}(\%)$ missing \\
\hline \multicolumn{4}{|l|}{ Birth } \\
\hline Age at day of measurement [days; mean, SD] & 2,1 & 1,4 & $0(0)$ \\
\hline Weight [Z-score; mean, SD] & $-0,4$ & 1,3 & $0(0)$ \\
\hline Born small for gestational Age $(<p 10)[n, \%]$ & 21 & 24,4 & $0(0)$ \\
\hline \multicolumn{4}{|l|}{24 Months } \\
\hline Age at follow-up visit [days; mean, SD] & 738 & 15 & $0(0)$ \\
\hline Weight [Z-Score; mean, SD] & $-0,3$ & 1,0 & $0(0)$ \\
\hline \multicolumn{4}{|l|}{ Growth } \\
\hline Weight [ $\Delta$ Z-Score 0-1; mean, SD] & $-0,3$ & 0,8 & $3(3.5)$ \\
\hline Weight [ $\Delta$ Z-Score 1-3; mean, SD] & 0,5 & 0,7 & $3(3.5)$ \\
\hline Weight [ $\Delta$ Z-Score 3-6; mean, SD] & 0,0 & 0,6 & $5(5.8)$ \\
\hline Weight [ $\Delta$ Z-Score 0-6; mean, SD] & 0,2 & 1,2 & $5(5.8)$ \\
\hline Weight $[\Delta$ Z-Score 6-12; mean, SD] & $-0,1$ & 0,5 & $6(7.0)$ \\
\hline Weight [ $\Delta$ Z-Score 12-24; mean, SD] & 0,0 & 0,4 & $2(2.3)$ \\
\hline \multicolumn{4}{|l|}{ Pregnancy } \\
\hline Gestational age [weeks; mean, SD] & 39,3 & 1,4 & $0(0)$ \\
\hline Hypertension during pregnancy [n, \%] & 16 & 18,6 & $0(0)$ \\
\hline Gestational diabetes $[\mathrm{n}, \%]$ & 3 & 3,5 & $0(0)$ \\
\hline Smoking during pregnancy [n, \%] & 13 & 15,1 & $0(0)$ \\
\hline Assisted pregnancy $[n, \%]$ & 15 & 17,4 & $0(0)$ \\
\hline Caesarean section $[\mathrm{n}, \%]$ & 59 & 68,6 & $0(0)$ \\
\hline Multipara [n, \%] & 33 & 38,4 & $0(0)$ \\
\hline \multicolumn{4}{|l|}{ General } \\
\hline Male $[n, \%]$ & 36 & 41,9 & $0(0)$ \\
\hline Systolic blood pressure at 24 months [mmHg; mean, SD] & 93,1 & 8,3 & $13(15.1)$ \\
\hline Non-dutch ethnic background $[n, \%]$ & 13 & 15,1 & $0(0)$ \\
\hline Breast feeding $[\mathrm{n}, \%]$ & 61 & 70,9 & $0(0)$ \\
\hline Low education level father [n, \%] & 27 & 31,4 & $0(0)$ \\
\hline Low education level mother $[n, \%]$ & 31 & 36,0 & $0(0)$ \\
\hline Family history of cardiovascular disease [n, \%] & & & $0(0)$ \\
\hline No known cardiovascular disease & 24 & 27,9 & \\
\hline Risk factors in second degree relative & 27 & 31,4 & \\
\hline Event in second degree relative & 23 & 26,7 & \\
\hline Risk factors or event in first degree relative & 12 & 14,0 & \\
\hline Height father [m; mean, SD] & 1,81 & 0,08 & $1(1.2)$ \\
\hline Weight father [kg; mean, SD] & 81,1 & 12,9 & $2(2.3)$ \\
\hline Height mother [m; mean, SD] & 1,69 & 0,06 & $0(0)$ \\
\hline Weight mother [kg; mean, SD] & 67,5 & 14,1 & $0(0)$ \\
\hline
\end{tabular}


Table 10.2 Associations between anthropometry at birth, growth and maximum perfusion in response to acetylcholine and nitroprusside.

\begin{tabular}{|c|c|c|c|c|c|c|c|c|}
\hline \multirow[t]{3}{*}{ Variable } & \multicolumn{4}{|c|}{ Acetylcholine $(n=104)$} & \multicolumn{4}{|c|}{ Nitroprusside $(n=102)$} \\
\hline & \multicolumn{2}{|c|}{ All covariates } & \multicolumn{2}{|c|}{ Final model } & \multicolumn{2}{|c|}{ All covariates } & \multicolumn{2}{|c|}{ Final model } \\
\hline & $\mathrm{b}$ & $\mathrm{P}$ & $\mathrm{b}$ & $\mathrm{P}$ & $\mathrm{b}$ & $\mathrm{P}$ & $\mathrm{b}$ & $\mathrm{P}$ \\
\hline \multicolumn{9}{|l|}{ Weight } \\
\hline Birth weight Z-score & $-1,20$ & 0,74 & 0,68 & 0,79 & 6,70 & 0,13 & 8,02 & $0,02 *$ \\
\hline Growth 0-1 month ( $\Delta$ Z-score) & $-8,85$ & 0,15 & $-8,28$ & $0,03^{*}$ & 14,96 & $0,02 *$ & 10,12 & $0,04^{*}$ \\
\hline Growth 1-3 months ( $\Delta$ Z-score) & $-8,25$ & 0,13 & $-4,85$ & 0,25 & $-5,26$ & 0,46 & $-2,09$ & 0,73 \\
\hline Growth 3-6 months ( $\Delta$ Z-score) & $-2,87$ & 0,63 & 0,82 & 0,87 & 3,88 & 0,56 & 2,92 & 0,60 \\
\hline Growth 6-12 months ( $\Delta$ Z-score) & 0,96 & 0,87 & 3,44 & 0,50 & $-0,23$ & 0,98 & $-0,38$ & 0,96 \\
\hline Growth $12-24$ months ( $\Delta$ Z-score) & 1,85 & 0,76 & 2,02 & 0,72 & $-4,18$ & 0,55 & $-1,72$ & 0,78 \\
\hline \multicolumn{9}{|l|}{ Length } \\
\hline Birth Length Z-score & 4,21 & 0,24 & 4,76 & 0,07 & 4,53 & 0,28 & 6,22 & 0,054 \\
\hline Growth 0-1 month ( $\Delta$ Z-score) & $-4,26$ & 0,30 & $-3,53$ & 0,25 & $-0,14$ & 0,98 & 1,51 & 0,81 \\
\hline Growth 1-3 months ( $\Delta$ Z-score) & $-9,62$ & 0,08 & $-4,74$ & 0,29 & $-3,03$ & 0,75 & $-2,98$ & 0,71 \\
\hline Growth 3-6 months ( $\Delta$ Z-score) & $-1,69$ & 0,71 & 1,17 & 0,77 & $-2,80$ & 0,61 & $-2,68$ & 0,59 \\
\hline Growth 6-12 months ( $\Delta$ Z-score) & $-1,79$ & 0,68 & 0,00 & 1,00 & $-3,98$ & 0,46 & $-3,20$ & 0,46 \\
\hline Growth $12-24$ months ( $\Delta$ Z-score) & $-1,47$ & 0,78 & $-0,08$ & 0,99 & $-2,87$ & 0,65 & $-3,25$ & 0,57 \\
\hline \multicolumn{9}{|l|}{ Weight-for-length } \\
\hline Weight-for-length Z-score & $-1,56$ & 0,72 & $-2,38$ & 0,54 & 5,13 & 0,23 & 7,09 & 0,06 \\
\hline Growth 0-1 month ( $\Delta$ Z-score) & $-2,73$ & 0,58 & $-3,31$ & 0,43 & 5,36 & 0,20 & 4,95 & 0,18 \\
\hline Growth 1-3 months ( $\Delta$ Z-score) & $-3,85$ & 0,49 & $-3,85$ & 0,44 & 2,70 & 0,67 & 3,94 & 0,45 \\
\hline Growth 3-6 months ( $\Delta$ Z-score) & $-3,89$ & 0,41 & $-2,43$ & 0,55 & 3,88 & 0,46 & 5,79 & 0,19 \\
\hline Growth 6-12 months ( $\Delta$ Z-score) & 5,59 & 0,34 & 6,73 & 0,17 & 6,55 & 0,26 & 6,70 & 0,18 \\
\hline Growth 12 -24 months ( $\Delta$ Z-score) & 6,25 & 0,31 & 6,91 & 0,21 & $-0,83$ & 0,89 & 0,49 & 0,92 \\
\hline \multicolumn{9}{|l|}{ Head circumference } \\
\hline Head circumference Z-score & 3,03 & 0,40 & 3,64 & 0,16 & 4,24 & 0,34 & 4,53 & 0,21 \\
\hline Growth 0-1 month ( $\Delta$ Z-score) & $-2,44$ & 0,69 & $-2,01$ & 0,62 & 2,41 & 0,70 & 2,18 & 0,67 \\
\hline Growth 1-3 months ( $\Delta$ Z-score) & $-0,61$ & 0,94 & $-0,56$ & 0,94 & 3,49 & 0,62 & 1,90 & 0,78 \\
\hline Growth 3-6 months ( $\Delta$ Z-score) & $-5,11$ & 0,41 & $-3,57$ & 0,47 & $-4,89$ & 0,49 & $-4,85$ & 0,43 \\
\hline Growth 6-12 months ( $\Delta$ Z-score) & $-7,56$ & 0,37 & $-3,46$ & 0,52 & $-6,54$ & 0,46 & $-4,09$ & 0,61 \\
\hline Growth $12-24$ months ( $\Delta$ Z-score) & $-5,52$ & 0,48 & $-2,70$ & 0,71 & $-3,88$ & 0,66 & $-3,23$ & 0,65 \\
\hline
\end{tabular}

The outcome variable is maximum perfusion (PU) in response to acetylcholine or nitroprusside. The data were analyzed by multilevel linear regression with compound symmetric covariance, all 6 parameters were tested simultaneously in 1 model. 'All covariates' constitutes time point, baseline perfusion, fat percentage, gender, gestational age, parental weight, parental height, parental socio-economic status, race, familial history of cardiovascular disease, assisted pregnancy, parity, hypertension during pregnancy, gestational diabetes, maternal smoking, delivery mode, breast feeding, and systolic blood pressure of the child. The final acetylcholine models were adjusted for time point, gender, baseline perfusion, hypertension during pregnancy, maternal socio-economic status and gestational diabetes. The final model for weight was additionally adjusted for paternal socio-economic status. The final nitroprusside models were adjusted for time point, gender, baseline perfusion, maternal socio-economic status, gestational age, familial history of cardiovascular disease and race. The final models for weight and length were additionally adjusted for maternal smoking. * Indicates a significant association $(P<0.05)$ 
Table 10.3 Association between anthropometry at birth, growth and fat percentage at the age of 2 years.

\begin{tabular}{|c|c|c|c|c|}
\hline \multirow[t]{2}{*}{ Variable } & \multicolumn{2}{|c|}{ All covariates } & \multicolumn{2}{|c|}{ Final model } \\
\hline & $\mathrm{B}$ & $\mathrm{P}$ & $\mathrm{b}$ & $\mathrm{P}$ \\
\hline \multicolumn{5}{|l|}{ Weight $(n=56, n=66)$} \\
\hline Birth weight Z-score & 0,69 & 0,52 & 0,42 & 0,50 \\
\hline Growth 0-1 month ( $\Delta$ Z-score) & 0,80 & 0,68 & 1,13 & 0,20 \\
\hline Growth 1-3 months ( $\Delta$ Z-score) & 2,36 & 0,14 & 0,38 & 0,72 \\
\hline Growth 3-6 months ( $\Delta$ Z-score) & 0,004 & 1,00 & 0,35 & 0,81 \\
\hline Growth 6-12 months ( $\Delta$ Z-score) & 4,80 & $0,04 *$ & 3,28 & $0,02 *$ \\
\hline Growth $12-24$ months ( $\Delta$ Z-score) & 1,01 & 0,57 & 1,33 & 0,36 \\
\hline \multicolumn{5}{|l|}{ Length $(n=48, n=56)$} \\
\hline Birth Length Z-score & 1,24 & 0,32 & 1,05 & 0,18 \\
\hline Growth 0-1 month ( $\Delta$ Z-score) & 0,31 & 0,84 & 0,08 & 0,92 \\
\hline Growth 1-3 months ( $\Delta$ Z-score) & 1,38 & 0,36 & 0,94 & 0,35 \\
\hline Growth 3-6 months ( $\Delta$ Z-score) & 1,97 & 0,25 & 1,39 & 0,23 \\
\hline Growth 6-12 months ( $\Delta$ Z-score) & 0,64 & 0,70 & 0,61 & 0,55 \\
\hline Growth $12-24$ months ( $\Delta$ Z-score) & 1,04 & 0,58 & $-0,36$ & 0,78 \\
\hline \multicolumn{5}{|l|}{ Weight-for-length $(n=48, n=56)$} \\
\hline Weight-for-length Z-score & 1,45 & 0,14 & 1,08 & 0,13 \\
\hline Growth 0-1 month ( $\Delta$ Z-score) & 2,53 & $0,04 *$ & 1,87 & $0,02 *$ \\
\hline Growth 1-3 months ( $\Delta$ Z-score) & 2,24 & 0,09 & 2,00 & $0,02 *$ \\
\hline Growth 3-6 months ( $\Delta$ Z-score) & 1,43 & 0,21 & 1,44 & 0,08 \\
\hline Growth 6-12 months ( $\Delta$ Z-score) & 4,66 & $0,004 *$ & 3,68 & $<0.0001^{*}$ \\
\hline Growth $12-24$ months ( $\Delta$ Z-score) & 1,28 & 0,28 & 1,95 & $0,03 *$ \\
\hline \multicolumn{5}{|l|}{ Head circumference $(n=44, n=49)$} \\
\hline Head circumference Z-score & 1,05 & 0,34 & 0,54 & 0,39 \\
\hline Growth 0-1 month ( $\Delta$ Z-score) & 2,26 & 0,22 & 1,25 & 0,12 \\
\hline Growth 1-3 months ( $\Delta$ Z-score) & $-0,88$ & 0,66 & $-1,52$ & 0,28 \\
\hline Growth 3-6 months ( $\Delta$ Z-score) & 2,81 & 0,18 & 4,57 & $0,003^{*}$ \\
\hline Growth 6-12 months ( $\Delta$ Z-score) & 1,85 & 0,50 & 1,71 & 0,28 \\
\hline Growth $12-24$ months ( $\Delta$ Z-score) & 0,45 & 0,87 & 0,19 & 0,91 \\
\hline
\end{tabular}

The outcome variable is fat percentage, as determined by the deuterium dilution method. The data were analyzed by linear regression, all 6 parameters were tested simultaneously in 1 model. 'All covariates' constitutes gender, gestational age, parental weight, parental height, parental socio-economic status, race, familial history of cardiovascular disease, assisted pregnancy, parity, hypertension during pregnancy, gestational diabetes, maternal smoking, delivery mode, breast feeding, and systolic blood pressure of the child. The covariates in the final models were: race (for weight); gender, maternal height and hypertension during pregnancy (for length); gender, maternal height and weight, hypertension during pregnancy and race (for weight-for-length); and gender, paternal height and parity (for head circumference). * Indicates a significant association $(\mathrm{P}<0.05)$.

\section{Discussion}

The present prospective study shows that weight gain very early in life, more specifically in the first month of life, is associated with endothelial function at the age of 2 years. Body fat percentage at the age of 2 years was positively related to growth, but not associated with endothelial function. Hence, growth seems to have an effect 
on endothelial function at the age of 2 years, independently of its influence on fat percentage.

In contrast to what we hypothesized and to previous studies in older children, we did not find a correlation between fat percentage and vascular function at the age of 2 years ${ }^{14-17}$. In our growth models fat percentage did not have any effect. We hypothesize our study population might have been too young: in the referenced literature, the children were all $>9$ years of age. The degree of fat accumulation during childhood - following fast infant weight gain - that is associated with complications such as increased blood pressure and impaired insulin sensitivity, may not have been attained yet at the age of 2 years ${ }^{31}$. Alternatively, an observed harmful effect of fat percentage may be a proxy for accelerated infant growth, since growth was not measured in these studies. We recommend future studies to take both infant and childhood growth data into account, as well as obesity and fat percentage when assessing the association between growth and vascular function.

Earlier we found that infant growth, particularly during the first 3 months, is related inversely to endothelial function at the age of 6 months ${ }^{10}$. It is important to assure this association is still relevant later in life, when growth rates are slower. We can now confirm that this association persists at least up till the age of 2 years, 1 year after the fast growth period of 0-1 year ended. The association was significant after adjustment for birth weight and other important covariates, such as socioeconomic status and gestational hypertension. We suggest a harmful effect of accelerated weight gain during the first month on the development of the endothelium, which might eventually contribute to the increased risk fast growing infants have for metabolic syndrome later in life $\mathrm{e}^{3,5}$. Our results are consistent with a recent study, which also linked accelerated weight gain in small for gestational age individuals (measured as change from birth to adulthood) to later, adult, endothelial function ${ }^{32}$.

As we suggested earlier, we think that accelerated growth results in a second, stronger, hit onto the already existing increased risk for endothelial dysfunction and cardiovascular disease in small for gestational age individuals ${ }^{2,10,18}$. In the present study, the models containing both birth weight and postnatal growth indeed did not show an association between birth weight and endothelial function, while growth did show an inverse association. Small for gestational age babies are more likely to show accelerated growth and therefore we think that future studies should test the effects of birth weight and growth simultaneously ${ }^{33}$. Mechanistically speaking, there are data describing modifying effects of (accelerated) growth on the hypothalamus-pituitaryadrenal axis, growth hormone, leptin, adipocytes and epigenetic profiles ${ }^{34-36}$. Furthermore, we suggested earlier that the endothelium may be injured by the rapid increase in circulating blood volume accompanying accelerated growth. Alternatively, the association may reflect a protective mechanism in which endothelial dysfunction prevents even faster tissue growth by decreasing nutrient and oxygen uptake.

Contrary to our expectations, we identified positive associations between birth weight and response to nitroprusside (endothelium-independent vasodilatation) and between 
weight growth from 0-1 month and response to nitroprusside. However, in the literature, acetylcholine and nitroprusside responses are mostly affected in the same direction of effect, or nitroprusside responses remain unaffected. For example, both are negatively related to fat percentage in children ${ }^{17}$. Should our results be confirmed in other studies, one may speculate that the smooth muscle cells increase their sensitivity to nitric oxide when the infant grows fast, to compensate suboptimal endothelial release of nitric oxide, prostanoids and other vasodilatory mediators. This may also imply that the responses to acetylcholine are even more impaired after accelerated growth than we have measured, since these children are more likely to have above-average responsive smooth muscle cells.

To our knowledge, we present the first study in the field to feature a prospective design with multiple vascular measurements in the same children. The data on endothelial function were collected by use of laser-Doppler flowmetry and iontophoresis of acetylcholine, because this is the most feasible technique in newborns and infants. Data generated by this method are associated with markers of systemic endothelial function ${ }^{37}$, flow-mediated dilatation of the brachial artery ${ }^{38}$ and coronary microvascular function ${ }^{39}$ in adults. Although there is reason to assume that the laserDoppler technique is able to measure endothelial function appropriately, we cannot be sure what the predictive value of the measurements we performed is at these early ages.

Data from a healthy term study population can easily be extrapolated to the general population. Furthermore, we tested many confounders, birth weight and 5 growth windows simultaneously, hereby adjusting the effects for each other and avoiding multiple testing issues. On the contrary, although the deuterium dilution method is considered a valid measure for body composition, we relied on the expertise of the parents at home for sample collection and this may have affected the reliability of our measurements. In addition, our study is limited to the first 2 years of life. Later growth windows have also been linked to later cardiovascular disease and were not studied here $^{40}$.

\section{Conclusion}

In a prospective longitudinal study in healthy term infants we found evidence for an inverse association between growth from 0-1 month and endothelial function at the age of 2 years. In the near future, the currently expanding body of evidence on the harmful effects of accelerated growth on later (cardiovascular) disease may lead to clinical guidelines on prevention of accelerated growth in early infancy. First, further research is needed into optimal early infant growth, which must yield adequate primary prevention without compromising neurological development. 


\section{References}

1. Yusuf S, Reddy S, Ounpuu S, Anand S. Global burden of cardiovascular diseases: part I: general considerations, the epidemiologic transition, risk factors, and impact of urbanization. Circulation. 2001;104:2746-2753

2. Barker DJ, Osmond C, Golding J, Kuh D, Wadsworth ME. Growth in utero, blood pressure in childhood and adult life, and mortality from cardiovascular disease. BMJ. 1989;298:564-567

3. Kerkhof GF, Leunissen RW, Hokken-Koelega AC. Early origins of the metabolic syndrome: role of small size at birth, early postnatal weight gain, and adult IGF-I. J Clin Endocrinol Metab. 2012;97:2637-2643

4. Singhal A, Cole TJ, Fewtrell M, Deanfield J, Lucas A. Is slower early growth beneficial for long-term cardiovascular health? Circulation. 2004;109:1108-1113

5. Khuc K, Blanco E, Burrows R, Reyes M, Castillo M, Lozoff B, et al. Adolescent metabolic syndrome risk is increased with higher infancy weight gain and decreased with longer breast feeding. Int J Pediatr. 2012;2012:478610

6. Ekelund U, Ong KK, Linne Y, Neovius M, Brage S, Dunger DB, et al. Association of weight gain in infancy and early childhood with metabolic risk in young adults. J Clin Endocrinol Metab. 2007;92:98-103

7. Koletzko B, von Kries R, Closa R, Escribano J, Scaglioni S, Giovannini M, et al. Lower protein in infant formula is associated with lower weight up to age $2 \mathrm{y}$ : a randomized clinical trial. Am J Clin Nutr. 2009;89:1836-1845.

8. Ong KK. Catch-up growth in small for gestational age babies: good or bad? Curr Opin Endocrinol Diabetes Obes. 2007;14:30-34

9. Lazdam M, Lewandowski AJ, Kylintireas I, Cunnington C, Diesch J, Francis J, et al. Impaired endothelial responses in apparently healthy young people associated with subclinical variation in blood pressure and cardiovascular phenotype. Am J Hypertens. 2012;25:46-53

10. Touwslager RN, Gerver WJ, Tan FE, Gielen M, Zeegers MP, Zimmermann L, et al. Influence of growth during infancy on endothelium-dependent vasodilatation at the age of 6 months. Hypertension. 2012;60:1294-1300

11. Leunissen RW, Kerkhof GF, Stijnen T, Hokken-Koelega A. Timing and tempo of first-year rapid growth in relation to cardiovascular and metabolic risk profile in early adulthood. JAMA. 2009;301:2234-2242

12. Druet C, Stettler N, Sharp S, Simmons RK, Cooper C, Smith GD, et al. Prediction of childhood obesity by infancy weight gain: an individual-level meta-analysis. Paediatr Perinat Epidemiol. 2012;26:19-26

13. Victora CG, Sibbritt D, Horta BL, Lima RC, Cole T, Wells J. Weight gain in childhood and body composition at 18 years of age in Brazilian males. Acta Paediatr. 2007;96:296-300

14. Meyer AA, Kundt G, Steiner M, Schuff-Werner $P$, Kienast W. Impaired flow-mediated vasodilation, carotid artery intima-media thickening, and elevated endothelial plasma markers in obese children: the impact of cardiovascular risk factors. Pediatrics. 2006;117:1560-1567

15. Woo KS, Chook P, Yu CW, Sung RY, Qiao M, Leung SS, et al. Overweight in children is associated with arterial endothelial dysfunction and intima-media thickening. Int J Obes Relat Metab Disord. 2004; 28:852-857

16. Zhu W, Huang X, He J, Li M, Neubauer H. Arterial intima-media thickening and endothelial dysfunction in obese Chinese children. Eur J Pediatr. 2005;164:337-344

17. Khan F, Green FC, Forsyth JS, Greene SA, Morris AD, Belch JJ. Impaired microvascular function in normal children: effects of adiposity and poor glucose handling. J Physiol. 2003;551:705-711

18. Touwslager RN, Houben AJ, Gielen M, Zeegers MP, Stehouwer CD, Zimmermann L, et al. Endothelial vasodilatation in newborns is related to body size and maternal hypertension. J Hypertens. 2012;30:124-131

19. Turner J, Belch JJ, Khan F. Current concepts in assessment of microvascular endothelial function using laser Doppler imaging and iontophoresis. Trends Cardiovasc Med. 2008;18:109-116

20. Feelisch M. The use of nitric oxide donors in pharmacological studies. Naunyn Schmiedebergs Arch Pharmacol. 1998;358:113-122

21. Wells JC, Fewtrell MS. Measuring body composition. Arch Dis Child. 2006;91: 612-617

22. Butte NF, Hopkinson JM, Wong WW, Smith EO, Ellis KJ. Body composition during the first 2 years of life: an updated reference. Pediatr Res. 2000;47:578-585 
23. Westerterp KR, Wouters L, van Marken Lichtenbelt WD. The Maastricht protocol for the measurement of body composition and energy expenditure with labeled water. Obes Res. 1995;3 Suppl 1:49-57

24. Stark MJ, Clifton VL, Wright IM. Sex-specific differences in peripheral microvascular blood flow in preterm infants. Pediatr Res. 2008;63:415-419

25. Stark MJ, Clifton VL, Wright IM. Neonates born to mothers with preeclampsia exhibit sex-specific alterations in microvascular function. Pediatr Res. 2009;65:292-295

26. Norman M, Martin H. Preterm birth attenuates association between low birth weight and endothelial dysfunction. Circulation. 2003;108:996-1001

27. Segar EM, Norris AW, Yao JR, Hu S, Koppenhafer SL, Roghair RD, et al. Programming of growth, insulin resistance and vascular dysfunction in offspring of late gestation diabetic rats. Clin Sci (Lond). 2009; 117:129-138

28. Martin H, Norman M. Skin microcirculation before and after local warming in infants delivered vaginally or by caesarean section. Acta Paediatr. 1997;86:261-267

29. Hutchison SJ, Glantz SA, Zhu BQ, Sun YP, Chou TM, Chatterjee K, et al. In-utero and neonatal exposure to secondhand smoke causes vascular dysfunction in newborn rats. J Am Coll Cardiol. 1998;32: 1463-1467

30. Khan F, Green FC, Forsyth JS, Greene SA, Newton DJ, Belch JJ. The beneficial effects of breastfeeding on microvascular function in 11- to 14-year-old children. Vasc Med. 2009;14:137-142

31. Kerkhof GF, Hokken-Koelega AC. Rate of neonatal weight gain and effects on adult metabolic health. Nat Rev Endocrinol. 2012;8:689-692

32. Leunissen RW, Kerkhof GF, Stijnen T, Hokken-Koelega AC. Effect of birth size and catch-up growth on adult blood pressure and carotid intima-media thickness. Horm Res Paediatr. 2012;77:394-401

33. Hokken-Koelega AC, De Ridder MA, Lemmen RJ, Den Hartog H, De Muinck Keizer-Schrama SM, Drop SL. Children born small for gestational age: do they catch up? Pediatr Res. 1995;38:267-271

34. Guilloteau P, Zabielski R, Hammon HM, Metges CC. Adverse effects of nutritional programming during prenatal and early postnatal life, some aspects of regulation and potential prevention and treatments. J Physiol Pharmacol. 2009;60 Suppl 3:17-35

35. Isganaitis E, Jimenez-Chillaron J, Woo M, Chow A, DeCoste J, Vokes M, et al. Accelerated postnatal growth increases lipogenic gene expression and adipocyte size in low-birth weight mice. Diabetes. 2009;58:1192-1200

36. Waterland RA, Lin JR, Smith CA, Jirtle RL. Post-weaning diet affects genomic imprinting at the insulinlike growth factor 2 (Igf2) locus. Hum Mol Genet. 2006;15:705-716

37. Elherik K, Khan F, McLaren M, Kennedy G, Belch JJ. Circadian variation in vascular tone and endothelial cell function in normal males. Clin Sci (Lond). 2002;102:547-552

38. Debbabi H, Bonnin P, Ducluzeau PH, Leftheriotis G, Levy BI. Noninvasive assessment of endothelial function in the skin microcirculation. Am J Hypertens. 2010;23:541-546

39. Khan F, Patterson D, Belch JJ, Hirata K, Lang CC. Relationship between peripheral and coronary function using laser Doppler imaging and transthoracic echocardiography. Clin Sci (Lond). 2008;115:295-300

40. Eriksson JG. Early growth, and coronary heart disease and type 2 diabetes: experiences from the Helsinki Birth Cohort Studies. Int J Obes. 2006;30 Suppl 4:S18-22 


\section{Chapter 11}

General discussion

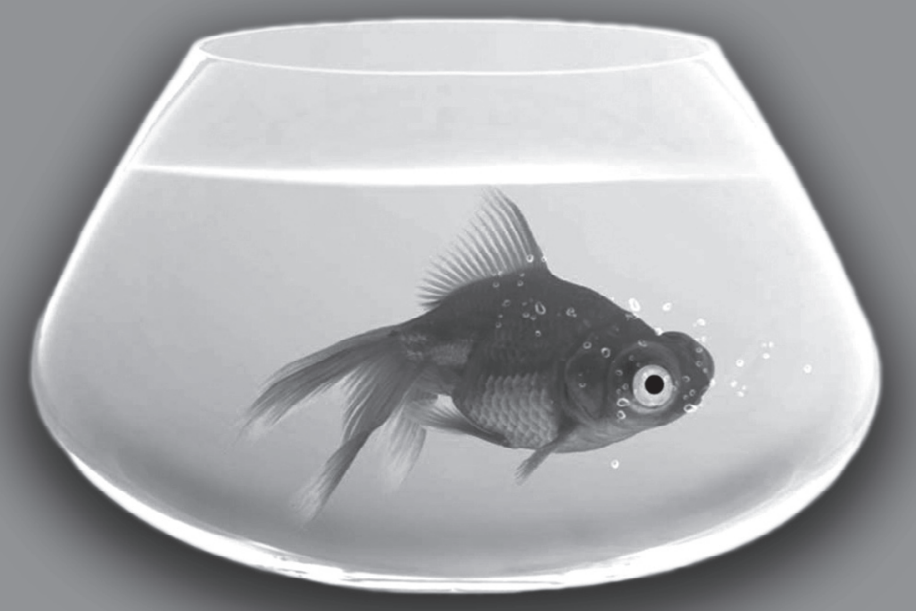


Chapter 11 


\section{General discussion}

\section{Environmental and genetic factors in the developmental origins of health and disease (DOHaD)}

The $\mathrm{DOHaD}$ are a conceptual framework which holds the existence of associations between early life factors, such as birth weight and postnatal growth, and many diseases in later life. The first aim of the present thesis was to assess the relative importance of genetic and environmental factors in the associations between early life factors and later health. In a twin analysis it was shown that the positive association between birth weight and later muscle strength was most likely based on individual placental factors, hence highlighting environmental importance (chapter 3 ). When the independent (predictor) variable was infant growth a more diverse picture was drawn. In its associations with adult cardiometabolic measures, again environmental factors were important in certain associations (for example with glucose and blood pressure), but others were under the main influence of genetic factors (triglycerides and fibrinogen) (chapter 7). While this type of data appears to be of rather theoretical nature, there are potential clinical implications.

If a certain association exists due to environmental factors influencing or creating it, this means that targeting these environmental factors may modify the association. So, if the factors linking low birth weight to adult muscle strength can be altered, muscle strength in adulthood may be targeted by modification of early environmental factors, such as maternal diet. An impact of maternal diet on birth weight has been made clear in the Dutch hunger winter studies. During the Dutch hunger winter in 1944-1945, the German occupiers banned food transports in response to a railway strike. As a result the Dutch population including pregnant women had to live from 400-800 daily calories $^{1}$. It was shown that birth weights declined in response ${ }^{2}$. Furthermore, (especially first trimester) gestational exposure to famine leads to an increased risk for many cardiometabolic diseases in the offspring, including glucose intolerance and coronary heart disease ${ }^{1}$. In contrast to the option of environmental intervention, in current medical practice genetic material cannot be influenced to a great extent and therefore attempting to influence a genetically determined association does not seem to be a good strategy. Although it is thinkable that this may be an option in the future, for now it may be best to focus attempts for early prevention of later disease on those associations that are subject to environmental influence.

From this thesis it can be learned that one should not have a simplistic view on associations between early life factors and later health. For example, while both blood pressure and fibrinogen showed a harmful association with accelerated growth, they were under environmental and genetic influence, respectively. Second, both cholesterol and blood pressure were under environmental control, but they exhibited beneficial and harmful associations with accelerated growth, respectively. Third, decomposing infant growth in separate growth windows showed that infant growth 
may have different effects, depending on the exact period. In the literature, most studies point towards a harmful effect of accelerated infant growth ${ }^{3-5}$, although studies can be found which highlight the potential harmful effects of slow infant growth ${ }^{6}$. Due to the current dogma of accelerated growth being harmful, there may however be a publication bias to be kept in mind. Studies showing a harmful effect of slow growth may be less likely to be submitted for publication or published. The previous highlights the need for open-minded studies and analyses.

Some specific points of concern have been raised in the analysis of twins regarding the $\mathrm{DOHaD}$ and these should be taken into account when the results of the twin studies in chapters 3, 5, 6 and 7 are interpreted $^{7-9}$. First, a small size at birth in twins may not have the same background and meaning as in singletons (in which it is a gross indicator of intrauterine undernourishment), as maternal constraint may play a relatively more important role in twins, compared to singletons. Also, postnatal growth patterns differ from those found in singletons ${ }^{10}$, although they resemble growth patterns in singletons born small for gestational age. Second, circulating (endocrine) factors in one twin may also program the co-twin, because the factors may reach the co-twins by diffusion through the fetal membranes or via the maternal circulation. A male or female co-twin may thereby lead to differences in for example testosterone exposure. Finally, chorionicity should be taken into account, since monochorionicity may lead to birth weight discordance and later vascular changes ${ }^{11}$ and the vascular connections between the twins may facilitate the exchange of potentially important programming factors. However, chorionicity was not important in the association between birth weight and adult blood pressure according to an earlier study ${ }^{12}$. Additionally, in chapter 7 it was shown that chorionicity was not of importance with regard to the association between infant growth and adult fibrinogen. Despite all differences between twins and singletons mentioned above, it is likely that cardiovascular findings in twins can be extrapolated to the general population ${ }^{13}$. Importantly, within the group of twins, the same associations between birth weight and adult (risk factors for) cardiovascular disease have been found as in singletons ${ }^{14-17}$. In chapter 3 the association between birth weight and adult fitness was shown and in chapter 7 several well-known associations between early growth and adult cardiometabolic risk profile were reproduced. Therefore, twins seem a proper study population for investigations into the $\mathrm{DOHaD}^{18}$.

\section{Infant growth, a detailed update}

Given the potentially harmful role of accelerated growth in the $\mathrm{DOHaD}^{4}$ the second aim of the present thesis was to obtain more detailed knowledge on normal infant growth, the factors affecting it, and the degree to which infant growth is influenced by genetic factors. It became clear in a study in children from the Dutch province of Limburg that 'normal' is a very broad definition with respect to early growth, even for small-for-gestational-age newborns (chapter 4). It should be noted, however, that the 
prospective clinical study showed that even growth in the spectrum of a normal term population may give rise to vascular changes, at least at the level of the endothelium (chapters 9 and 10). It was furthermore shown in chapter 4 that expected growth depends on starting position and regression to the mean. The effect of the latter becomes small after 1 year of age, which means the child follows 'its own percentile line'. It seems useful to judge growth of infants individually, when one is interested in detecting abnormal growth.

Because of a similar rationale as described above, growth may be most easily influenced when it is under environmental control. By a detailed comparison of $\mathrm{MZ}$ and DZ twins it was shown that this is only the case in the first month of life, after which age genetic factors are of predominant importance (chapter 6). This coincides strikingly with the importance of early growth that was identified in the clinical study (chapters 9 and 10). Moreover, when gene-environment interaction was studied, it was shown that especially the infants of average birth weight (which is by definition also the largest group) showed a minimum impact of genetic factors on their growth. Therefore this average group is theoretically an especially suitable group for environmental interventions to optimize their postnatal growth. As noted above, also growth in the spectrum of a normal population may have long-term effects.

Next, if one wants to initiate early preventive strategies by influencing growth, it is of importance what determines infant growth. From the twin study in chapter 5 , it can be concluded that there are multiple factors, but birth weight and gestational age are the main players in the early growth windows ( $<1$ year), pointing to the prenatal period as a potential target. After 1 year of age, other factors became important, such as paternal height. In addition, an important environmental factor that can easily be influenced is prenatal and postnatal nutrition, on which this thesis will elaborate in the final paragraph. The described growth studies point towards the early postnatal growth period as a period which is characterized by large anthropometric changes, is important for later disease and which is likely to be influenced externally, both prenatally and postnatally. It therefore qualifies as a true window of opportunity.

\section{Growth and endothelial function}

The final aim of this thesis was to study the association between infant growth, body composition and endothelial function, a precursor of atherosclerosis, in the first 2 years of life.

The clinical study conducted at the Maastricht University Medical Center and described in chapters 8-10 indicates that both birth weight and postnatal growth are of importance in endothelial function. However, after simultaneous analysis growth seemed to be the most powerful factor. In accordance with the literature, the clearest effects were found when weight gain or gain in weight-for-height z-score was analyzed $^{3}$. In the following 'growth' will therefore refer to weight gain or increase in weigh-for-height z-score. Importantly, the first month of life seemed to be of particular 
importance for endothelial function. This finding is in accordance with the literature, which had already narrowed the importance of growth for later cardiovascular disease down to the early postnatal period. In a direct comparison between infant (0-6 months) and childhood (3-6 years) growth, it was shown before that infant growth was more important for later metabolic disease risk ${ }^{19}$. In a direct comparison between growth periods within infancy, the first few months were most important ${ }^{4}$. Growth in the first 2 weeks of life has even been linked to decreased endothelial function in adolescence, with an effect size comparable to diabetes or smoking ${ }^{20}$.

The clinical study described in chapters 8-10 signals a new step in the field of DOHaD research, in which prospective studies are being conducted. Prospective studies have the advantage of being less vulnerable to certain types of bias, such as recall bias. Our prospective study therefore further supports what was expected based on the preceding retrospective studies ${ }^{4,5,21}$, namely an inverse association between early growth and vascular health, in this case endothelial function. A main feature of the study is the healthy term study population. This means that the vast majority of all newborns could theoretically have been included in our study and therefore our results can be easily extrapolated to the general population. Furthermore, by use of multivariable models both birth weight, early growth and growth later in infancy could be analyzed simultaneously and hence be evaluated adjusted for each other's effects. Given the strong influence of birth weight on postnatal growth (see chapter 5), this was of vital importance for a 'fair' analysis, which used as many growth data as possible.

To define accelerated growth a cut-off value of $0,50-0,67$ standard deviations or z-scores is sometimes used ${ }^{22}$. This is a rather artificial way to express accelerated growth, since 0.67 standard deviations change represents the difference between adjacent lines on the growth curve (for example from the $2^{\text {nd }}$ to the $10^{\text {th }}$ percentile). While a cut-off value may be of importance for standardization of studies and for possible clinical application, it should be emphasized that there is no evidence for a clinically important cut-off value for later disease risk. Regression coefficients thereby give more precise information than comparison of groups by a cut-off value.

The clinical study in chapters 8-10 was set up to analyze early postnatal and infant growth, because of its potential of being a critical growth window. It has lived up to this expectation, but there may also be important growth windows after the age of 2 years. Therefore it would be best to follow these children into adulthood, so other growth windows can be included for-simultaneous- analysis. One can think of growth in childhood, which has also been linked to adult health ${ }^{23}$.

\section{Directions for future research}

The DOHaD have opened up a whole new era for preventive medicine. While classical clinical practice aimed for a change in lifestyle factors, such as diet, physical activity and smoking, to target cardiovascular disease, the upcoming decades may be 
dedicated to maternal nutrition, prenatal care, breast feeding and appropriate postnatal growth. While this new approach is in no way able to replace targeting life style factors, it may be a powerful addition to the diagnostic and therapeutic options available. On the level of pathophysiology, there also seems to be a need for further research, since no fully explanatory mechanism or combination of mechanisms for the DOHaD has been identified so far.

In the future twin data are likely to be used in novel approaches in the explanatory mechanisms for the DOHaD. At the moment there is great interest in the role of epigenetics. Epigenetic changes are changes in genome expression that do not involve changes in the nucleotide sequence (genotype). These changes can be initiated by methylation and histone modifications and may be a coping mechanism to deal with changing environmental circumstances, in which case it may be beneficial to switch certain genes 'on' or 'off'. In this type of research particularly MZ twins are of interest, since they have an identical genotype. Therefore, developing epigenetic differences between the members of the pair can be analyzed against the background of the same genotype. Fetal undernourishment, fetal hypoxia and/or accelerated postnatal growth may initiate epigenetic changes, which in turn may impact on later health. In humans, it has been shown that prenatal exposure to famine can induce permanent epigenetic modifications ${ }^{24}$. Epigenetic differences have also been shown to occur after postweaning diet changes in mice ${ }^{25}$. At birth, $M Z$ twins already differ in epigenetic profile ${ }^{26}$, and this difference became ever larger over time (in a study with a cross-sectional design $)^{27}$. The fact that these profiles already differ at birth highlights that developmental changes due to (maternal or intrauterine) environment also operate on the level of the epigenome. Moreover, genome-wide epigenetic profiles have been shown to be subject to both environmental and genetic influence ${ }^{28}$. It seems that discordance for a disease in a MZ twin pair is a powerful study design in the search for (epi)genetic localization of disease: in discordant $M Z$ twins (a $M Z$ twin pair with one healthy member and one member with a disease) a comparison of their epigenome possibly indicates the location of the involved genes ${ }^{28}$. Second, these types of analyses may give insight into the mechanisms linking early life events to later disease. For example, $M Z$ twins with discordant postnatal growth may be compared for epigenetic changes in genes involved in cardiovascular disease. A large prospective twin study (the Peri/postnatal Epigenetic Twins Study, PETS) is being conducted in Australia with sequential measurements of epigenetic profiles and assessment of several healthrelated characteristics as well as neurodevelopmental outcomes ${ }^{29}$. So far, this study was able to show that about one third of the epigenome changes in the first 18 months of life ${ }^{30}$. Additionally, birth weight discordance was associated with methylation discordance of genes involved in lipid metabolism, supporting the existence of epigenetic mechanisms behind the $\mathrm{DOHaD}^{29}$.

Although not the focus of this thesis and with respect to influencing postnatal growth in an attempt to target later health, nutrition also plays a major role. It may be the easiest way to modify growth as part of future public policy changes, of which it seems 
reasonable to expect effectuation in the upcoming decades. In fact, opinion articles already argue to start primary prevention in pregnant women and in infants ${ }^{31}$. To influence growth, maternal dietary interventions can impact on birth weight ${ }^{32}$ and postnatal nutritional interventions in infancy can impact on postnatal growth ${ }^{33}$.

Actively slowing down growth does not appear to be a strategy that is to be applied to all infants ${ }^{34}$. In prematurely born children, there is a trade-off between the beneficial impact of accelerated growth on neurodevelopmental outcome on the one hand and the suspected increased risk for later disease on the other hand. The latter types of associations have also been proven in prematurely born children ${ }^{35}$. In these prematurely born infants, particularly growth on the neonatal intensive care unit is of importance for neurodevelopmental outcome. In term infants, whether appropriate or small for gestational age, in developed countries there is no clear neurodevelopmental benefit of fast growth and therefore an attempt for primary prevention of adult disease by slowing down infant growth seems closer in these groups ${ }^{34}$. Because of the healthy term study population, the clinical study described in chapters 8-10 therefore even seems more relevant.

Before public policy changes can be initiated, there is a need for studies into an actual causal relationship between accelerated growth and later disease. One of these studies is currently being performed (the European Childhood Obesity Project) and has childhood obesity as primary outcome variable. Healthy term infants are divided into 3 groups: breast feeding, low-protein formula and high-protein formula. It was already shown that growth is highest in the high-protein group ${ }^{36}$. Furthermore, it was shown that there are emerging differences between the groups in IGF-1 and insulin concentrations ${ }^{37}$. These results seem to be supportive of their 'early protein' hypothesis, which states that high early protein exposure leads to alterations in the IGF-1 axis and leads to accelerated growth. However, it may not just be the amount of nutrition or protein that is exerting an effect on growth (and thereby possibly on later health), as also specific nutritional components may be involved. For example, maternal fish oil supplementation during lactation impacts on the growth of their children $^{38}$. Next to assessment of causality, the cost-effectiveness of a possible intervention should also be subject of study in the future. It should also be noted that there is still a need for large-scale prospective observational studies, such as the National Children's Study, which is a proposed study in 100,000 American children from birth to 21 years of age and aims to collect extensive information, including epigenetic data ${ }^{39}$. As long as growth interventions are not implemented, at least early and repeated measurement of both height and weight should become common practice in order to identify persons at increased risk for cardiovascular disease. In this way, adequate preventive measures can be applied to these individuals. Moreover, it is recommended that risk-stratifying approaches used in adults incorporate early life factors (such as postnatal growth) as soon as more details are known on the effect sizes of these early life factors. 
The study design of the European Childhood Obesity project could also be used to analyze functional and anatomical changes in the vasculature and in that case should, ideally, also monitor (very) long-term neurodevelopmental outcome and a wide variety of potential confounders. In this way evidence could be found for a causal relationship between early life factors and later cardiovascular disease to support policy changes and to gain stronger mechanistic insight in these associations. It should be noted, namely, that the current body of observational evidence for a relationship between early growth and later health could still be based on non-causal pathways, such as the existence of factors of influence on both accelerated infant growth and the adverse health outcome.

Many questions remain to be elucidated in the $\mathrm{DOHaD}$. Some of these questions could also be answered, at least initially, by observational research. One can think of a more detailed analysis of a critical growth window. It is therefore recommended to integrate these types of research questions into already existing studies on, for example, cardiovascular disease. It should be relatively easy to include additional birth weight data, because birth weight is a well-recorded characteristic. This would open up a new scope of research questions to be answered in a financially attractive way. Moreover, contemporary studies can easily ask their participants to look for early growth data, for example in their booklet from the child welfare center. Hopefully, life course research will benefit from future digitalization of these early life measurements. Not only studies into cardiovascular disease could use the concept of adding early life data, as the $\mathrm{DOHaD}$ do not confine to cardiovascular disease, but extend to asthma (linked to reduced early fetal growth and rapid postnatal growth ${ }^{40,41}$ ), breast cancer and childhood leukemia (both linked to high birth weight ${ }^{42,43}$ ) and, most likely, many other diseases. The broadening of the $\mathrm{DOHaD}$ concept in this sense (more outcome variables should be studied) is still in a very early phase. On the other side of the association stand the predictor variables. This thesis is focused on (low) birth weight and early growth, but also many other early life factors can be studied, such as maternal smoking (linked to increased diastolic blood pressure ${ }^{44}$ ) and preeclampsia (linked to increased incidence of stroke and to vascular dysfunction ${ }^{45,46}$ ). As an example from this thesis, the potential importance of preeclampsia for endothelial function was shown at birth (chapter 8), although in our study population and by use of our outcome measure no long-term effect was identified (chapters 9 and 10). Second, the potential importance of high birth weight for later physical fitness was highlighted (chapter 3 ). In conclusion, the $\mathrm{DOHaD}$ are a highly promising field of research. Both the unclear mechanistic concepts and the potentially vast possibilities for primary prevention make this an exciting focus for research in the remainder of the $21^{\text {st }}$ century. 


\section{References}

1. Roseboom T, de Rooij S, Painter R. The dutch famine and its long-term consequences for adult health. Early Hum Dev. 2006;82:485-491

2. Smith CA. The effect of wartime starvation in holland upon pregnancy and its product. Am J Obstetr Gynecol. 1947;53:599-608

3. Kerkhof GF, Leunissen RW, Hokken-Koelega AC. Early origins of the metabolic syndrome: Role of small size at birth, early postnatal weight gain, and adult igf-i. J Clinl Endocrinol Metab. 2012;97:2637-2643

4. Leunissen RW, Kerkhof GF, Stijnen T, Hokken-Koelega A. Timing and tempo of first-year rapid growth in relation to cardiovascular and metabolic risk profile in early adulthood. JAMA. 2009;301:2234-2242

5. Ong KK, Loos RJ. Rapid infancy weight gain and subsequent obesity: Systematic reviews and hopeful suggestions. Acta Paediatr. 2006;95:904-908

6. Kajantie E, Barker DJ, Osmond C, Forsen T, Eriksson JG. Growth before 2 years of age and serum lipids 60 years later: The helsinki birth cohort study. Int J Epidemiol. 2008;37:280-289

7. Leon DA. The foetal origins of adult disease: Interpreting the evidence from twin studies. Twin Res. 2001;4:321-326

8. Morley R, Dwyer T, Carlin JB. Studies of twins: Can they shed light on the fetal origins of adult disease hypothesis? Twin Res. 2003;6:520-525

9. Phillips DI, Davies MJ, Robinson JS. Fetal growth and the fetal origins hypothesis in twins--problems and perspectives. Twin Res. 2001;4:327-331

10. Wilson RS. Twin growth: Initial deficit, recovery, and trends in concordance from birth to nine years. Ann Hum Biol. 1979;6:205-220

11. Cheung YF, Taylor MJ, Fisk NM, Redington AN, Gardiner HM. Fetal origins of reduced arterial distensibility in the donor twin in twin-twin transfusion syndrome. Lancet. 2000;355:1157-1158

12. Loos RJ, Fagard R, Beunen G, Derom C, Vlietinck R. Birth weight and blood pressure in young adults: A prospective twin study. Circulation. 2001;104:1633-1638

13. Christensen K, Wienke A, Skytthe A, Holm NV, Vaupel JW, Yashin Al. Cardiovascular mortality in twins and the fetal origins hypothesis. Twin Res. 2001;4:344-349

14. Bergvall N, Iliadou A, Johansson S, de Faire U, Kramer MS, Pawitan Y, Pedersen NL, Lichtenstein P, Cnattingius S. Genetic and shared environmental factors do not confound the association between birth weight and hypertension: A study among swedish twins. Circulation. 2007;115:2931-2938

15. Grunnet L, Vielwerth S, Vaag A, Poulsen P. Birth weight is nongenetically associated with glucose intolerance in elderly twins, independent of adult obesity. J Intern Med. 2007;262: 96-103

16. Skidmore PM, Cassidy A, Swaminathan R, Falchi M, Spector TD, MacGregor AJ. Intrauterine, environmental, and genetic influences in the relationship between birth weight and lipids in a female twin cohort. Arterioscler Thromb Vasc Biol. 2006;26:2373-2379

17. Vagero D, Leon D. Ischaemic heart disease and low birth weight: A test of the fetal-origins hypothesis from the swedish twin registry. Lancet. 1994;343:260-263

18. Ijzerman RG, Boomsma DI, Stehouwer CD. Intrauterine environmental and genetic influences on the association between birthweight and cardiovascular risk factors: Studies in twins as a means of testing the fetal origins hypothesis. Paediatr Perinat Epidemiol. 2005;19 Suppl 1:10-14

19. Ekelund U, Ong KK, Linne Y, Neovius M, Brage S, Dunger DB, Wareham NJ, Rossner S. Association of weight gain in infancy and early childhood with metabolic risk in young adults. $J$ Clin Endocr Metab. 2007;92:98-103

20. Singhal A, Cole TJ, Fewtrell M, Deanfield J, Lucas A. Is slower early growth beneficial for long-term cardiovascular health? Circulation. 2004;109:1108-1113

21. Kerkhof GF, Willemsen RH, Leunissen RWJ, Breukhoven PE, Hokken-Koelega ACS. Health profile of young adults born preterm: Negative effects of rapid weight gain in early life. J Clin Endocr Metab. 2012;97:4498-4506

22. Kerkhof GF, Hokken-Koelega AC. Rate of neonatal weight gain and effects on adult metabolic health. Nature reviews. Endocrinology. 2012;8:689-692

23. Barker DJ, Osmond C, Forsen TJ, Kajantie E, Eriksson JG. Trajectories of growth among children who have coronary events as adults. N Engl J Med. 2005;353:1802-1809 
24. Heijmans BT, Tobi EW, Stein AD, Putter H, Blauw GJ, Susser ES, Slagboom PE, Lumey LH. Persistent epigenetic differences associated with prenatal exposure to famine in humans. Proc Nat Acad Sci USA. 2008;105:17046-17049

25. Waterland RA, Lin JR, Smith CA, Jirtle RL. Post-weaning diet affects genomic imprinting at the insulinlike growth factor 2 (igf2) locus. Hum Mol Genet. 2006;15:705-716

26. Ollikainen M, Smith KR, Joo EJ, Ng HK, Andronikos R, Novakovic B, Abdul Aziz NK, Carlin JB, Morley R, Saffery R, Craig JM. DNA methylation analysis of multiple tissues from newborn twins reveals both genetic and intrauterine components to variation in the human neonatal epigenome. Hum Mol Genet. 2010;19:4176-4188

27. Fraga MF, Ballestar E, Paz MF, Ropero S, Setien F, Ballestar ML, Heine-Suner D, Cigudosa JC, Urioste M, Benitez J, Boix-Chornet M, Sanchez-Aguilera A, Ling C, Carlsson E, Poulsen P, Vaag A, Stephan Z, Spector TD, Wu YZ, Plass C, Esteller M. Epigenetic differences arise during the lifetime of monozygotic twins. Proc Nat Acad Sci USA. 2005;102:10604-10609

28. van Dongen J, Slagboom PE, Draisma HH, Martin NG, Boomsma DI. The continuing value of twin studies in the omics era. Nat Rev Genet. 2012;13:640-653

29. Loke YJ, Novakovic B, Ollikainen M, Wallace EM, Umstad MP, Permezel M, Morley R, Ponsonby AL, Gordon L, Galati JC, Saffery R, Craig JM. The peri/postnatal epigenetic twins study (pets). Twin Res Hum Genet. 2013;16:13-20

30. Martino D, Loke YJ, Gordon L, Ollikainen M, Cruickshank MN, Saffery R, Craig JM. Longitudinal, genome-scale analysis of DNA methylation in twins from birth to 18 months of age reveals rapid epigenetic change in early life and pair-specific effects of discordance. Genome Biol. 2013;14:R42

31. Gillman MW, Ludwig DS. How early should obesity prevention start? N Engl J Med. 2013;369: 2173-2175

32. Makrides M, Anderson A, Gibson RA. Early influences of nutrition on fetal growth. Nestle Nutr Inst Workshop Ser. 2013;71:1-9

33. Koletzko B, Beyer J, Brands B, Demmelmair H, Grote V, Haile G, Gruszfeld D, Rzehak P, Socha P, Weber $\mathrm{M}$, European Childhood Obesity Trial Study G. Early influences of nutrition on postnatal growth. Nestle Nutr Inst Workshop Ser. 2013;71:11-27

34. Belfort MB, Gillman MW. Healthy infant growth: What are the trade-offs in the developed world? Nestle Nutr Inst Workshop Ser. 2013;71:171-184

35. Kerkhof GF, Willemsen RH, Leunissen RW, Breukhoven PE, Hokken-Koelega AC. Health profile of young adults born preterm: Negative effects of rapid weight gain in early life. J Clin Endocrinol Metab. 2012;97:4498-4506

36. Koletzko B, von Kries R, Closa R, Escribano J, Scaglioni S, Giovannini M, Beyer J, Demmelmair H, Gruszfeld D, Dobrzanska A, Sengier A, Langhendries JP, Rolland Cachera MF, Grote V, European Childhood Obesity Trial Study G. Lower protein in infant formula is associated with lower weight up to age 2 y: A randomized clinical trial. Am J Clin Nutr. 2009;89:1836-1845

37. Socha P, Grote V, Gruszfeld D, Janas R, Demmelmair H, Closa-Monasterolo R, Subias JE, Scaglioni S, Verduci E, Dain E, Langhendries JP, Perrin E, Koletzko B, European Childhood Obesity Trial Study G. Milk protein intake, the metabolic-endocrine response, and growth in infancy: Data from a randomized clinical trial. Am J Clin Nutr. 2011;94:1776S-1784S

38. Lauritzen L, Hoppe C, Straarup EM, Michaelsen KF. Maternal fish oil supplementation in lactation and growth during the first 2.5 years of life. Pediatr Res. 2005;58:235-242

39. Guttmacher AE, Hirschfeld S, Collins FS. The national children's study--a proposed plan. N Engl J Med. 2013;369:1873-1875

40. Turner S. Perinatal programming of childhood asthma: Early fetal size, growth trajectory during infancy, and childhood asthma outcomes. Clin Dev Immunol. 2012;2012:962923

41. Sonnenschein-van der Voort AM, Jaddoe VW, Raat H, Moll HA, Hofman A, de Jongste JC, Duijts L. Fetal and infant growth and asthma symptoms in preschool children: The generation $r$ study. Am J Respir Crit CareMed. 2012;185:731-737

42. Xue F, Michels KB. Intrauterine factors and risk of breast cancer: A systematic review and metaanalysis of current evidence. Lancet Oncol. 2007;8:1088-1100

43. Caughey RW, Michels KB. Birth weight and childhood leukemia: A meta-analysis and review of the current evidence. Int J Cancer.. 2009;124: 2658-2670 
44. Taal HR, de Jonge LL, van Osch-Gevers L, Steegers EA, Hofman A, Helbing WA, van der Heijden AJ, Jaddoe VW. Parental smoking during pregnancy and cardiovascular structures and function in childhood: The generation r study. Int J Epidemiol. 2013;42:1371-1380

45. Kajantie E, Eriksson JG, Osmond C, Thornburg K, Barker DJ. Pre-eclampsia is associated with increased risk of stroke in the adult offspring: The helsinki birth cohort study. Stroke. 2009;40:1176-1180

46. Jayet PY, Rimoldi SF, Stuber T, Salmon CS, Hutter D, Rexhaj E, Thalmann S, Schwab M, Turini P, SartoriCucchia C, Nicod P, Villena M, Allemann Y, Scherrer U, Sartori C. Pulmonary and systemic vascular dysfunction in young offspring of mothers with preeclampsia. Circulation. 2010;122:488-494 


\section{Samenvatting}

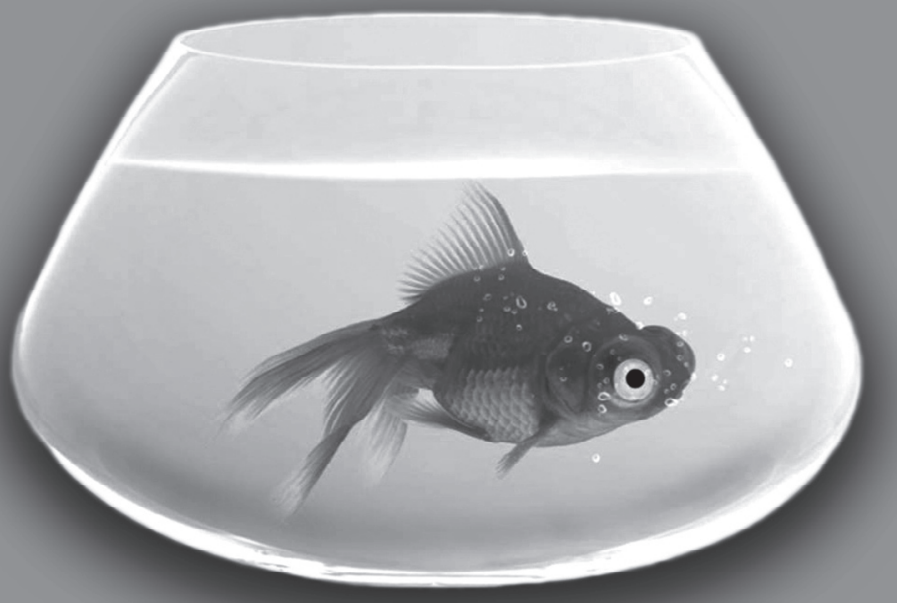




\section{Samenvatting}

In de inleiding van dit proefschrift (hoofdstuk 1) wordt de 'developmental origins of health and disease' theorie geïntroduceerd. Deze theorie houdt in dat vele ziekten die we in ons leven kunnen krijgen, een (gedeeltelijke) oorzaak in de vroege ontwikkeling hebben. Deze vroege ontwikkeling kan bijvoorbeeld bestaan uit de omstandigheden in de baarmoeder, welke deels zijn af te lezen in het geboortegewicht. Tevens kan bijvoorbeeld het opleidingsniveau van moeder of de groei na de geboorte invloed hebben op latere ziekten. De foetus of het kind past zich waarschijnlijk aan de omgeving aan in een bepaalde periode, waarna deze veranderingen niet meer kunnen worden teruggedraaid. Deze veranderingen zijn soms gunstig op de korte termijn, maar kunnen later in het leven voor problemen gaan zorgen. Zo zouden baby's met een slechte voedselvoorziening in de baarmoeder meer geneigd kunnen zijn om dit schaarse voedsel zo efficiënt mogelijk op te slaan als vet. Dit kan voor de periode in de baarmoeder gunstig zijn, maar als het lichaam dit blijft doen, is het op de lange termijn schadelijk. Het is inmiddels duidelijk aangetoond dat er een verband bestaat tussen zowel een laag geboortegewicht als versnelde groei na de geboorte enerzijds en een verhoogd risico op hart- en vaatziekten als volwassene anderzijds. Het lijkt er op dat er een zeer korte periode na de geboorte (binnen drie maanden) is waarin de belangrijkste invloed van groei op dit latere risico plaatsvindt, maar dit is nog niet goed aangetoond. Om in de toekomst wellicht primaire preventie in het vroege leven voor latere hart- en vaatziekten te kunnen implementeren, bijvoorbeeld door het aanpassen van babyvoeding, is het nodig meer te weten over die vroege groei. Staan vroege groei en het verband tussen vroege groei en latere hart- en vaatziekten bijvoorbeeld onder invloed van genetische (momenteel niet te beïnvloeden) of omgevingsfactoren (wellicht wél te beïnvloeden)? En wat beïnvloedt die vroege groei zelf eigenlijk?

In dit proefschrift is gebruik gemaakt van drie verschillende studies. De eerste is de East Flanders Prospective Twin Survey (EFPTS), een grote tweelingstudie uitgevoerd in Vlaanderen. Van deze tweelingen was het geboortegewicht bekend en bij een deel is hun fitheid gemeten gedurende de puberteit. Van een ander deel was het geboortegewicht én de vroege groei bekend en zijn op de leeftijd van ongeveer 25 jaar metingen verricht op het gebied van hart- en vaatziekten, zoals bloeddruk en insulinegevoeligheid. Omdat eeneiige tweelingen wat betreft genetische informatie gelijk zijn en twee-eiige tweelingen slechts voor 50\% gelijk zijn, kunnen conclusies worden getrokken wat betreft de rol van genetische en omgevingsfactoren, door deze twee soorten tweelingen met elkaar te vergelijken. De tweede studie heeft 104 kinderen in Maastricht gevolgd vanaf de geboorte tot de leeftijd van twee jaar. In deze studie werd de groei, de vet-spier verhouding in het lichaam (lichaamssamenstelling) en het functioneren van de bloedvatwand (endotheel) vier maal beoordeeld. In de derde studie werd de groei in de eerste vier jaar van meer dan 1000 Zuid-Limburgse kinderen gedetailleerd in kaart gebracht. 
In hoofdstuk 2 wordt tot in detail uitgelegd hoe de statische analyse van de tweelingdata, de meting van de lichaamssamenstelling met de deuterium verdunningsmethode en het meten van de reactiviteit van de bloedvatwand met iontoforese en Laser-Doppler in zijn werk zijn gegaan.

In hoofdstuk 3 is in een tweelingstudie uitgezocht of er een verband tussen geboortegewicht en fysieke fitheid in de puberteit is, en of dit verband onder invloed staat van individuele factoren (bijvoorbeeld de aanvoer van zuurstof en voedingsstoffen via de moederkoek) of gedeelde factoren (zoals het opleidingsniveau van moeder). Fysieke fitheid werd gebruikt omdat die meting sterk verband houdt met het risico op hart- en vaatziekten. Het bleek dat kinderen met een laag geboortegewicht minder goed presteerden op fysieke testen, zoals maximale spierkracht in de armen en benen, maar ook in het houden van balans. Het leek erop dat de maximale zuurstofopname, onze primaire uitkomstmaat, bij zowel kinderen met een laag als een hoog geboortegewicht slechter was dan bij de meer gemiddelde kinderen. Als er echter rekening gehouden werd met de body mass index (BMI) van de ouders verdween dit patroon. Mogelijk komt dit doordat de BMI van de ouders een suboptimale levensstijl of sociale omgeving, dan wel een genetische aanleg voor overgewicht reflecteert. Het verband tussen geboortegewicht en kracht in de benen en armen leek te berusten op individuele (dit kunnen nog steeds zowel genetische als omgevingsfactoren zijn) in plaats van gedeelde factoren. Bij de beenkracht kon worden aangetoond dat de eigenschappen van de moederkoek waarschijnlijk een belangrijke rol spelen en genetische factoren niet belangrijk zullen zijn. Deze studie is een steun om in de toekomst de moederkoekfunctie te optimaliseren om latere fitheid positief te beïnvloeden.

In hoofdstuk $\mathbf{4}$ is nauwkeurig gekeken naar de groei in de eerste vier levensjaren van meer dan 1000 Limburgse kinderen. Er werden formules opgesteld die, aan de hand van de afmetingen van het kind aan het begin van een groeiperiode, kunnen voorspellen hoe hard het kind waarschijnlijk zal gaan groeien in die komende groeiperiode. Er werd een duidelijke regressie naar het gemiddelde gezien. Dit betekent dat grote kinderen naar het gemiddelde toe groeiden en dus relatief minder hard groeiden in vergelijking met de hele groep. Aan de andere kant groeiden kleine kinderen ook naar het gemiddelde toe en zij groeiden dus relatief harder dan de groep. Deze regressie naar het gemiddelde is groot in het eerste levensjaar, maar wordt steeds kleiner over de jaren. De voorspellende formules hadden een breed betrouwbaarheidsinterval in het eerste levensjaar. Dit houdt in dat de verwachte groei die uit de formules kwam nog een grote spreiding in mogelijke resultaten had. Na het eerste levensjaar werden de formules preciezer. Het brede betrouwbaarheidsinterval betekent wel dat kinderen wiens daadwerkelijke groei zelfs nog buiten die brede betrouwbaarheidsgrenzen van de voorspelde waarde van de formule ligt, duidelijk afwijken en in de gaten zouden moeten worden gehouden. De klein geboren kinderen pasten overigens in het normale regressie naar het gemiddelde patroon van de gehele groep en ze groeiden dus niet anders dan de rest. 
Hoofdstuk 5 beschrijft een studie waarin is gekeken naar de groei van meer dan 400 Belgische tweelingen in de eerste twee levensjaren. Er werd onderzocht welke factoren deze groei beïnvloeden. Het bleek dat geboortegewicht en zwangerschapsduur in het eerste jaar belangrijk waren, terwijl er in het tweede levensjaar meer effect te zien was van andere factoren, zoals de lengte van vader. Er waren in deze studie al aanwijzingen dat de groei in de eerste levensmaand meer afhankelijk was van omgevingsfactoren dan van genetische factoren doordat de groei binnen de eeneiige tweelingen evenveel op elkaar leek als de groei binnen de twee-eiige tweelingen. Na de eerste maand gingen de eeneiige tweelingen wat groei betreft méér op elkaar lijken dan dat de twee-eiige tweelingen op elkaar leken, wat het waarschijnlijk maakt dat genetische factoren van invloed zijn.

In hoofdstuk 6 is nog beter geanalyseerd hoe het met die genetische of omgevingsinvloeden op groei zit. Opnieuw werden er tweelingen bekeken en werd de erfelijkheid van groei bepaald. Met deze erfelijkheidsanalyse werd bekeken hoeveel van de variatie in de groei die gemeten was, kon worden verklaard door genetische factoren. Het bleek dat groei in de eerste levensmaand niet onder invloed stond van erfelijke factoren, ofwel dat de erfelijkheid $0 \%$ was in het beste statistische model. Ter vergelijking, van de variatie in groei van de leeftijd van één tot twee jaar was $86 \%$ te verklaren door genetische factoren. Het feit dat genetische factoren waarschijnlijk minder belangrijk zijn in de eerste levensmaand biedt mogelijkheden voor groeiinterventies (zoals verandering van babyvoeding, wat een omgevingsinterventie is) in deze periode. Er werd ook nog dieper gekeken of de schattingen van de erfelijkheid van groei voor alle kinderen hetzelfde waren. Ten eerste bleek dat met name de groep kinderen met een gemiddeld geboortegewicht een lage mate van erfelijkheid van groei had in de eerste levensmaand; de extremer kleine of grote kinderen hadden een hogere mate van erfelijkheid van groei. Daarnaast bereiken tweelingen meestal niet de volle zwangerschapsduur van 40 weken, maar hoe verder ze in die richting kwamen (beginnend bij 36 weken), hoe belangrijker de erfelijke factoren werden in de groei in de eerste levensmaand.

Diezelfde groep tweelingen waarin de voorgaande twee studies waren gedaan, is ook uitgenodigd voor onderzoeken op volwassen leeftijd, rond 25 jaar. In hoofdstuk 7 wordt beschreven wat het verband was tussen hun groei als kind en latere metingen van onder andere bloeddruk, cholesterol en overgewicht. Er werd een divers palet aan verbanden gevonden tussen de vroege groei en latere risicofactoren. Zo hield snelle groei verband met een hogere bloeddruk en slechtere bloedstollingswaarde (fibrinogeen). Echter, er waren ook positieve invloeden van snelle groei, zoals een betere verhouding tussen totaal en HDL ('goed') cholesterol. Ook had snelle groei verschillende effecten in verschillende tijdsperiodes: het effect van groei in de eerste maand was bijvoorbeeld anders dan van groei tussen één en twee jaar. Er werd, ten eerste, geconcludeerd dat niet gezegd kan worden dat snelle groei voor álle risicofactoren voor hart- en vaatziekten slecht is. Ten tweede is het effect niet toe te wijzen aan één bepaalde groeiperiode. $\mathrm{Er}$ is in deze studie nog verder gekeken naar de 
mate waarin omgevingsfactoren en genetische factoren de verbanden beïnvloeden. Het bleek dat ook in dit licht niet alle verbanden door dezelfde factoren beïnvloed worden. Verbanden tussen groei als kind en latere bloeddruk en bloedsuikerspiegels waren bijvoorbeeld beïnvloed door omgevingsfactoren, terwijl de verbanden tussen groei en bepaalde vetten (triglyceriden) en fibrinogeen meer onder invloed stonden van genetische factoren. Als primaire preventie wordt overwogen door in te grijpen op de groei op de kinderleeftijd, kan wellicht het beste worden gemikt op verbanden waarin omgevingsfactoren een rol spelen. Als omgevingsfactoren géén rol spelen, heeft het namelijk meest waarschijnlijk ook geen zin om omgevingsfactoren zoals babyvoeding aan te pakken.

In hoofdstuk 8 wordt het eerste meetpunt van een studie in 104 kinderen uit het academisch ziekenhuis in Maastricht beschreven. De belangrijkste uitkomstmaat was het functioneren van de bloedvatwand, omdat op latere leeftijd slecht functioneren hiervan een sterke voorspeller van hart- en vaatziekten is. Eén van de functies van de bloedvatwand is het versmallen en verwijden van de bloedvaten om de bloeddruk te reguleren. Het doel van de studie was om te kijken of de bloedvatwand al op jonge leeftijd te lijden heeft onder snelle groei of onder een laag geboortegewicht. Dit kon worden getest door de bloedvatwand van buitenaf te prikkelen (met acetylcholine) om stoffen af te geven die de bloedvaten verwijden. Deze verwijding kon worden gemeten in de huid. Bij het eerste meetpunt werd duidelijk dat kinderen die klein geboren zijn een minder goede bloedvatwandfunctie hadden. Dit was het geval voor klein zijn in gewicht, lengte en hoofdomtrek, waarvan de laatste het sterkste effect liet zien. Ten tweede scoorden kinderen wiens moeder een hoge bloeddruk in de zwangerschap of zwangerschapsvergiftiging had ook minder. Bij zwangerschapsvergiftiging is sprake van slecht functioneren van de bloedvatwand bij de moeder. Mogelijk wordt dit doorgegeven aan het kind via de bloedsomloop in de moederkoek. Er werden met precies dezelfde onderzoekstechniek ook metingen uitgevoerd die weliswaar de bloedvaten lieten verwijden, maar die hiervoor de bloedvatwand niet nodig hadden (prikkeling met nitroprusside). Deze metingen werden onder andere uitgevoerd om te testen hoe exclusief de test effecten op de bloedvatwand weergeeft, in plaats van een meer algemeen effect op de capaciteit van het lichaam om de bloedvaten te laten verwijden. Deze metingen bleken alleen verband te houden met de zwangerschapsduur en niet met de afmetingen van de baby's.

Omdat de primaire interesse bij groei lag, zijn de baby's nogmaals gemeten op de leeftijd van zes maanden. Deze meting wordt beschreven in hoofdstuk 9. Groei werd opgeknipt in drie delen, om nauwkeurig te kunnen kijken welk stukje van de vroege groei van het grootste belang is in de ontwikkeling van de bloedvatwandfunctie. Het bleek dat baby's die snel groeiden in de eerste maand een achteruitgang in bloedvatwandfunctie vertoonden. Dit sluit aan bij het feit dat snelle groei als baby het risico op hart- en vaatziekten in het latere leven vergroot. Deze studie was de eerste om aan te tonen dat bloedvatwanddisfunctie al zeer vroeg in het leven te meten is, en dat het effect heel vroeg na de geboorte al op trad. Ook geboortegewicht had nog een 
negatief effect op de leeftijd van zes maanden, maar dit effect viel weg als geboortegewicht en groei gezamenlijk werden getoetst. Dit geeft ten eerste aan dat groei belangrijker is dan geboortegewicht in het kader van hun invloed op de bloedvatwandfunctie. Ten tweede geeft het aan dat snelle groei op zich een negatief effect heeft en dat dit effect zich niet beperkt tot groei bij kleine baby's.

In hoofdstuk 10 werden de lange termijn effecten besproken van de studie naar bloedvatwandfunctie. Lange termijn is in dit kader op de leeftijd twee jaar, wanneer de groei al ongeveer een jaar in rustiger vaarwater zit. Zelf na de periode van snelle groei (in het eerste levensjaar) bleef de groei in de eerste maand een voorspeller van de bloedvatwandfunctie. Dit geeft aan dat er ook een zeker lange termijn effect van de groei in de eerste maand is. Of deze associatie zich doorzet tot in de volwassen leeftijd zal in de toekomst moeten blijken. De groei in de eerste maand had een positief effect op de hierboven genoemde meting met nitroprusside (vaatverwijding onafhankelijk van de bloedvatwand). Dit kan een compensatiemechanisme zijn, maar hier is nog meer onderzoek naar nodig. In dit hoofdstuk werd tevens gekeken of het ophopen van vet bij snelle groei wellicht een bijdrage leverde aan de achteruitgang van de bloedvatwandfunctie, maar dit bleek niet het geval.

In de discussie, hoofdstuk 11, wordt stil gestaan bij de plaats die dit proefschrift inneemt binnen de al bestaande kennis. Uitgangspunt hierbij blijft het verband tussen vroege levensfactoren zoals (snelle, maar wellicht ook langzame) groei als baby, en latere hart- en vaatziekten. Allereerst werden in dit proefschrift dergelijke verbanden aangetoond in tweelingen en werd een divers beeld geschetst wat betreft het belang van omgevingsfactoren en genetische factoren hierbij. Dit type data was tot nu toe weinig voorhanden. Omdat we (nog) niet kunnen ingrijpen in genetische informatie, lijken met name de verbanden die onder invloed staan van omgevingsfactoren interessant voor toekomstige primaire preventie van latere hart- en vaatziekten. Als we in de toekomst willen werken aan primaire preventie door bijvoorbeeld de voeding van baby's aan te passen, is er kennis nodig over groei. In de groeistudies werd essentiële kennis op gedaan over normale groei, welke factoren groei beïnvloeden, en de rol van omgevingsfactoren en genetische factoren bij vroege groei. Met name van belang was het feit dat genetische factoren niet belangrijk leken in de eerste levensmaand. Hierdoor lijken er in die maand kansen te liggen voor voedingsaanpassingen. Juist in die eerste maand lijkt daarbij het grootste negatieve effect van snelle groei op te treden, in ieder geval op het gebied van bloedvatwandfunctie en in ieder geval tot de leeftijd van twee jaar. Groei in de eerste maand lijkt dus grote kansen te bieden in het kader van primaire preventie van hart- en vaatziekten op volwassen leeftijd. Een unieke eigenschap van de studie naar bloedvatwandfunctie in dit proefschrift is de vooruit kijkende opzet, die de bewijskracht groot maakt, maar desondanks geen oorzakelijk verband kan aantonen. De resultaten zijn daarbij verkregen in gezonde kinderen, wat de maatschappelijke toepasbaarheid van de resultaten groot maakt. Er wordt voorspeld dat de komende jaren veel onderzoek gaan brengen naar gezondheid van aanstaande moeders, (borst)voeding en groei als baby. 
Wellicht zullen de eerste onderzoeken naar het optimaliseren van vroege groei, bijvoorbeeld met voedingsaanpassingen, binnenkort gaan starten. Hierbij moet gekeken worden naar het ontwikkelen van risicofactoren voor hart- en vaatziekten, maar ook naar de ontwikkeling en verdere gezondheid van de kinderen, alsmede de kosteneffectiviteit van deze interventies. 


\section{Dankwoord}

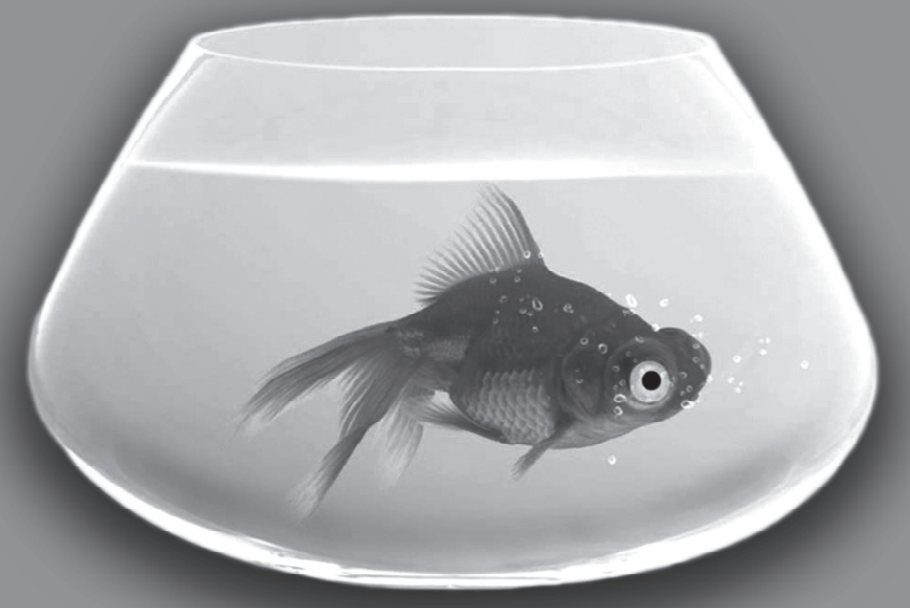




\section{Dankwoord}

Mijn dank gaat uit naar dr. Willem-Jan Gerver, die mij in 2004 onder zijn hoede nam om als student nog een jaar aan de co-schappen te ontsnappen. Op zijn iMac in het printerhok op de dr. Tanslaan zijn mijn eerste onderzoeksstappen gezet. Gedurende dit jaar kwam ik in contact met dr. Twan Mulder. Beste Twan, bedankt voor alle uren begeleiding en planning, puzzelen met potjes geld, artikelopbouw en gecompliceerde zinnen, en het leerzame fysiologische redeneren. Daarnaast dank voor de gezelligheid bij onze vele congressen. Ik zie ernaar uit om ook onder jouw leiding de opleiding te gaan volgen. Professor Luc Zimmermann heeft ons project vanuit het begin ondersteund en ik prijs me dan ook gelukkig met zijn benaderbaarheid, volharding en kritische denken wat betreft de studie en het promotietraject. Onze Laser-Doppler meetmethode was al in gebruik op de afdeling interne geneeskunde en deze metingen zijn mij aangeleerd door dr. Boy Houben, bij wie ik ook terecht kon voor technische vragen en de vroege fine tuning. Als hoofd van de afdeling interne geneeskunde heeft professor Coen Stehouwer me aangeraden te gaan praten met professor Maurice Zeegers van complexe genetica om de scope van een eventuele promotie uit te breiden met tweelingonderzoek. Beste Coen, dank je voor je indrukwekkende analytische blik en feitenkennis, pijlsnelle revisies en je vertrouwen in, en ondersteuning van mijn project. Beste Maurice, dank voor jouw inspirerende visie, het delen en inzetten van je netwerk en data en je inhoudelijke aanwijzingen. De dagelijkse begeleiding vanuit de complexe genetica is gedaan door dr. Marij Gielen. Beste Marij, achter jouw schaterlach zat een scherpe begeleider die veel tijd voor me heeft genomen. Jouw geduld en deskundigheid bij de eindeloze analyses, je pragmatische instelling, bescheiden opstelling en humor hebben me veel geleerd en erg geholpen. Aan het gehele promotieteam nog eens extra mijn dank om me niet één keer aan te spreken op de planning, ook niet toen ik tijdens mijn ANIOS periode overal meer tijd voor nodig had. Dit heeft ertoe geleid dat ik met weinig druk vanuit jullie optimaal de tijd heb kunnen nemen om dit manuscript naar mijn tevredenheid af te schrijven. Mijn promotieteam verzorgde uiteraard niet de enige inhoudelijke begeleiding. Mijn lange lijst co-auteurs is hiervan getuige en ook hen dank ik voor hun specifieke expertise en aanscherpen van de manuscripten. Voor de spoedige beoordeling van mijn proefschrift ben ik de leden van mijn beoordelingscommissie, professor Spaanderman, professor Van Goudoever, professor De Leeuw, professor Prins en professor Thiery, erkentelijk.

Tevens spreek ik veel dank uit aan alle deelnemers aan de studies die ik heb geanalyseerd. De kinderen van de Zuid-Limburgse groeistudie, gemeten door Angèle Gerver, en de deelnemers aan de Oost-Vlaamse tweelingstudie heb ik helaas niet zelf kunnen ontmoeten. Wat daarom extra indruk op me maakte, is de manier waarop de 104 kinderen en ouders uit de studie die ik zelf uitvoerde, twee jaar lang belangeloos en zonder enige vergoeding voor mijn studie naar het ziekenhuis zijn gekomen, 
ondanks hun soms moeilijke financiële of logistieke situatie, of verhuizing naar ver buiten de regio. Het was me een genoegen om al deze prachtige kinderen te mogen zien opgroeien. Wat betreft het meten van deze kinderen wil ik ook Marian, Irene, Rick, Gwen, Gertrude, Stephanie en Oenone (semi-artsen), alsmede Marieke en Cecile (research nurses) hartelijk danken voor het uitvoeren van en helpen bij de metingen. Jullie hulp, tussentijdse analyses en kritische vragen waren hard nodig en het was erg leuk om jullie te leren kennen. Tevens wil ik de polidames (kindergeneeskunde en klinische genetica), de dames van de kraamafdeling, de dames en heren van E2 en het secretariaat (met name Tamara, Lea en Natascha) bedanken voor het vele plannen en de wijzigingen in mijn toelatingen, aanstelling en de talrijke andere administratieve 'uitdagingen'.

Dankzij mijn dispuutsgenoten en vrienden Aron, Margit, Martijn, Jonas, Tim, Tom, Emiel en Sanne is de onderzoekstijd er met ' 4 uur niveau 4', en andere feesten en partijen, erg prettig op geworden. Het was fijn en nodig om bij jullie stoom af te kunnen blazen in Maastricht, net als bij de mannen van het Urste van de Maastrichtse Hockey Club. Buiten Maastricht hebben de weekenden met buurman Matthijs, de dagen en etentjes met Maarten, Stan en Nick, en de Den Haag avonturen met de party weekend gang (Jelmer, Astrid, Anouk en wederom oude middelbare school vriend Aron) me de broodnodige ontspanning geboden. Ik wil ook mijn collega's artsassistenten en de kinderartsen uit het Catharina ziekenhuis niet vergeten: jullie hebben me in mijn klinische opstarttijd altijd erg gesteund (zowel met interesse als met tijd) in het werken aan mijn promotieonderzoek.

Beste collega's! Ik heb het erg getroffen met jullie, des te meer omdat we met een grote groep aan de start stonden en het hele traject gezamenlijk hebben doorlopen. Cynthia, Inge, Marieke, Marlou, Sasha, Maartje, Dillys, Ester en Kim, ik heb het heel leuk gevonden om met jullie deze onderzoeksreis aan te gaan. Al was ik onderzoekstechnisch wel een eenling in de groep; ik heb me altijd deel van de klinische-kinder-AIO's gevoeld. Het was ook mooi om te zien dat we elkaar ook persoonlijker leerden kennen met lunchen, etentjes, films en Carnaval. Kim, jij lag een handig stuk voor en ik kon je dan ook alle promotie-inhoudelijke vragen stellen vanaf het begin. We hebben heel wat af gelachen, konden alles bespreken en dat hebben we ook na mijn vertrek goed voort kunnen zetten. Ester, jouw niet aflatende interesse en rust waren erg prettig om dagelijks te kunnen ervaren. Ik heb jullie door 4 jaar een kamer te delen leren kennen als gezellige, goedlachse en intelligente dames, dank voor jullie kameraadschap. Wat ook niet onbelangrijk is, is dat ik door jullie strak georganiseerde ADEM studie op tijd merkte dat ik misschien ook een fatsoenlijke administratie moest hebben. 
Lieve ouders, dank uitspreken naar jullie is vanzelfsprekend. Jullie onvoorwaardelijke steun voor alles wat ik ooit verzonnen heb te gaan doen voelt als een oersterke fundering. Met jullie als stabiel thuisfront is er altijd een plek om op adem te komen. Ook denk ik dat de onderzoekende biologische geest me met de paplepel is ingegoten door mijn vader's interesse voor de natuur (vogels, bomen, you name it) en biologie, al was het maar als rustige en uitstekende docent op de Nassau. De volharding en wil om te 'winnen' heb ik zeker vanuit mijn lieve moeder mee gekregen.

Beste Maarten, onze levens lopen al een jaar of 18 parallel: van Breda naar Maastricht, van geneeskundestudent naar AIO en van AIO naar arts-assistent. Met jou was het dan ook het gemakkelijkst levelen en ik vind jouw combinatie van theoretische, sociale en ethische intelligentie in onze vele gesprekken indrukwekkend. Beste Wouter, vooral in leeftijd ben je nog mijn broerTJE, maar dus ben je nog steeds mijn broertje. Er zitten enkele jaren tussen ons, maar nu de levensfases synchroon gaan lopen, merk ik dat we meer en nu ook veel van elkaar mee krijgen en het uitstekend kunnen vinden. Mannen, bedankt dat jullie vandaag aan mijn zijde staan (want er wordt niet gezeten).

Lieve lieve Margot, één van de fijnste dingen aan het afronden van mijn promotie is het vooruitzicht dat ik meer tijd heb om met jou door te brengen, zowel hier als op onze reizen. Dank je voor het doorlezen van mijn stukken en voor het vormen van mijn liefdevolle thuisbasis. Ik vind je geweldig en kan me de toekomst niet zonder jou voorstellen. 
Curriculum Vitae

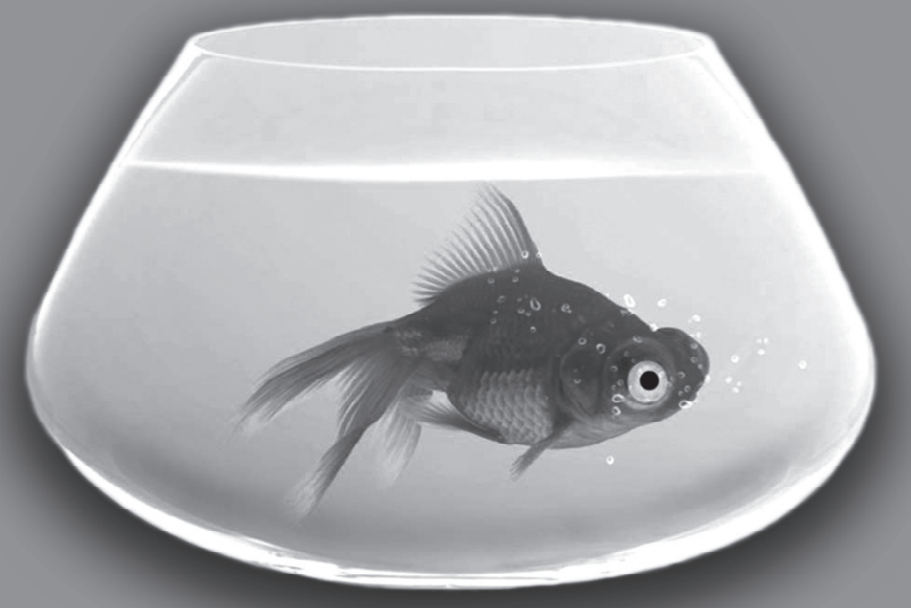




\section{Curriculum Vitae}

Bob Touwslager was born in Breda, The Netherlands on October $7^{\text {th }}$ 1983. He attended the Nassau Scholengemeenschap and graduated with distinction from the gymnasium in 2001. That same year, he started studying medicine at Maastricht University, The Netherlands, completed his 'doctoraal' (first 4 years) with distinction in 2005 and finished as a master of science in 2008. His elective rotations were spent in Vancouver, Canada, at the BC Cancer Agency and at the NICU at Maastricht University Medical Center. After receiving a Kootstra Talent Fellowship grant in 2008 he started working as a PhD

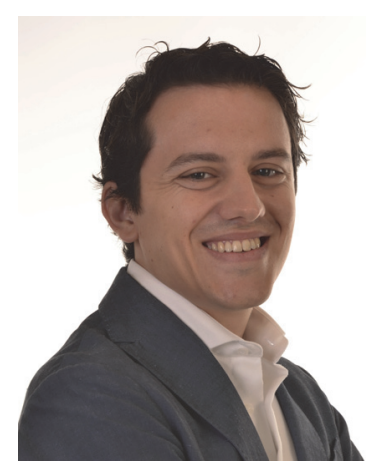
student at Maastricht University Medical Center at the department of Pediatrics under supervision of professor Zimmermann, professor Stehouwer, dr. Gielen and dr. Mulder until 2012. His projects focused on early growth, twin research and endothelial function. He supervised several last-year medical students during their scientific rotation. During his PhD trajectory he completed the master 'Epidemiology' with distinction at Maastricht University in 2011 and became a registered epidemiologist in 2013. From 2012 to 2013 he worked as a physician at the department of Pediatrics at the Catharina hospital in Eindhoven, The Netherlands, under supervision of dr. Brackel, dr. Bunt and dr. Dors. In 2014 he started his training as a resident in pediatrics at Maastricht University Medical Center under supervision of dr. Mulder. He has been together with Margot for over 8 years and they live together in Maastricht. 


\section{List of publications}

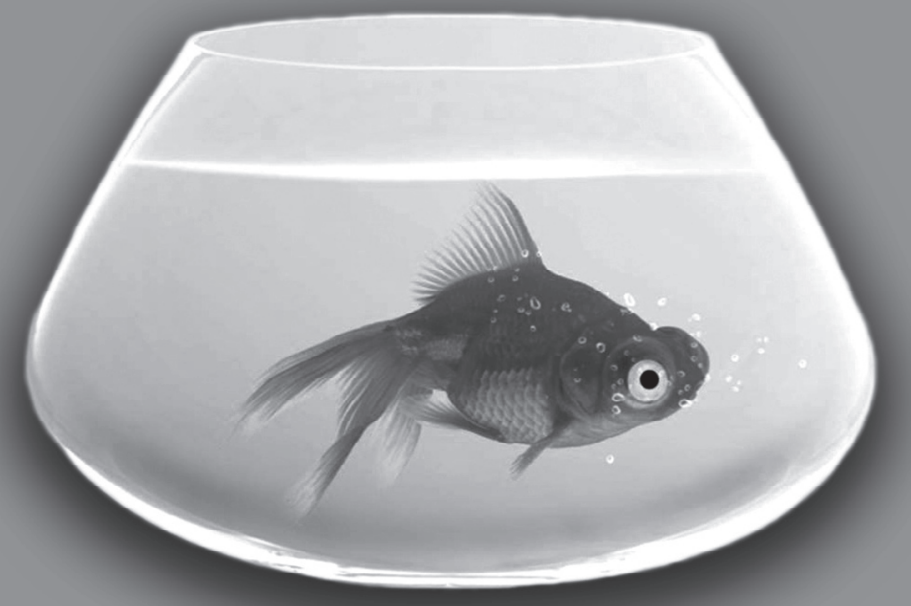




\section{List of publications}

Touwslager RN, Gielen M, Mulder AL, Gerver WJ, Zimmermann LJ, Dagnelie PC, Houben AJ, Stehouwer CD, Derom C, Vlietinck R, Loos RJ, Zeegers MP. Genetic and environmental factors in associations between infant growth and adult cardiometabolic risk profile in twins. Am J Clin Nutr. 2013;98:994-1001

Touwslager RN, Gielen M, Tan FE, Mulder AL, Gerver WJ, Zimmermann L, Houben AJ, Zeegers MP, Derom C, Vlietinck R, Maes HH, Stehouwer CD, Thomis M. Genetic, maternal and placental factors in the association between birth weight and physical fitness: a longitudinal twin study. PLoS One. 2013;8:e76423

Touwslager RN, Gerver WJ, Tan FE, Gielen M, Zeegers MP, Zimmermann LJ, Houben AJ, Blanco CE, Stehouwer CD, Mulder AL. Influence of growth during infancy on endothelium-dependent vasodilatation at the age of six months. Hypertension. 2012;60:1294-1300

Touwslager RN, Houben AJ, Gielen M, Zeegers MP, Stehouwer CD, Zimmermann LJ, Kessels AG, Gerver WJ, Blanco CE, Mulder AL. Endothelial vasodilatation in newborns is related to body size and maternal hypertension. J Hypertens. 2012;30: 124-131

Touwslager RN, Gielen M, Mulder AL, Gerver WJ, Zimmermann LJ, Fowler T, Houben AJ, Stehouwer CD, Derom C, Vlietinck R, Loos RJ, Zeegers MP. Changes in genetic and environmental effects on growth during infancy. Am J Clin Nutr. 2011;94:1568-74

Touwslager RN, Gielen M, Derom C, Mulder AL, Gerver WJ, Zimmermann LJ, Houben AJ, Stehouwer CD, Vlietinck R, Loos RJ, Zeegers MP. Determinants of infant growth in four age windows: a twin study. J Pediatr. 2011;158:566-572.e2

Touwslager RN, Gerver WJ, Mulder AL, Gerver Jansen AJ, de Bruin R. Longitudinal growth during the first years of life: what is normal? Horm Res. 2008;70: 273-277 
